\title{
Insurance Risks as Fictitious Commodities: The Institutional Constitution of Insurance Markets
}

by

Mathieu Charbonneau

\author{
A thesis submitted to \\ the Faculty of Graduate and Postdoctoral Affairs \\ And \\ École Doctorale V - Concepts et Langages \\ in partial fulfillment of the requirements for the degree of \\ Doctor of Philosophy \\ in \\ Sociology
}

Carleton University

Ottawa, Canada

And

Université Paris-Sorbonne (Paris IV)

Paris, France

(C) 2016, Mathieu Charbonneau 


\begin{abstract}
Résumé
This dissertation aims at shifting the focus in the emerging sociology of insurance literature from the epistemic and cultural construction of private insurability towards the political-legal constitution of insurance markets. It investigates why the availability of actuarial data and/or extra-actuarial knowledge of risks are insufficient conditions for the functioning of the private insurance business. Drawing on Karl Polanyi's institutional analysis, I develop a theory of the institutional constitution of markets and the concept of insurance risks as fictitious commodities, in order to analyse insurance markets as politically and legally constituted institutions. Following evidence that the private insurance governance cannot self-sufficiently ensure its profitability through contractual incentives and private controls of the insured, I claim that the institutional organization of substantive uncertainties as fictitiously commoditized insurance risks accounts for the basic determinant of private insurability. From the Polanyian perspective, the uncertainties experienced by individuals and threatening social provisioning, nature, and the market economy represent the raw materials which insurers capitalize. While the incentives insurers deal with prevent them from seeking the removal of these uncertainties, private insurers cannot autonomously ensure the profitable reduction, control and configuration of the covered uncertainties. To support these arguments, this dissertation first presents an historical analysis of the construction of insurance law in England from 1664 to 1774 , demonstrating that the private insurance market proved unstable and generated uncertainty from its inception. This dissertation then presents a central, contemporary case study of the institutional constitution of the Canadian prescription drug insurance market in the context of the arrival of new high cost specialty medicines. I reach two key findings. First, insurance capitalization itself generates instabilities and hence depends on the fictitious commoditization of substantive uncertainties into insurance risks by virtue of political-legal and non-competitive reduction and control of the underlying uncertainties covered as capital. Second, the fictitious commoditization process can involve the decommoditization of "bad" insurance risks by their distribution across the diversity of the institutional modes of economic integration. The Polanyian framework thus empirically examines how insurance capitalization of substantive uncertainties can impact individuals, institutions, and the citizenry.
\end{abstract}

$* * *$

Cette thèse contribue au champ émergeant de la sociologie de l'assurance en déplaçant l'analyse de la construction épistémique et culturelle de l'assurabilité privée vers la constitution politico-juridique des marchés d'assurance. Elle vise à comprendre pourquoi les données actuarielles et les connaissances extra-actuarielles ne représentent pas des conditions suffisantes au fonctionnement des marchés d'assurance. À partir de l'analyse institutionnelle de Karl Polanyi, je formule une théorie de la constitution institutionnelle des marchés et le concept de risques assurantiels comme marchandises fictives. Considérant que la gouvernance assurantielle privée ne peut garantir sa rentabilité de manière autonome grâce aux incitations contractuelles et au contrôle de l'assurée, je soutiens que l'organisation institutionnelle des incertitudes empiriques en tant que risques 
assurantiels fictivement marchandisés constitue le déterminant fondamental de l'assurabilité privée. Suivant l'approche polanyienne, les incertitudes de la vie individuelle et touchant les modes de prestations sociales, la nature et les marchés représentent la matière première dont les assureurs tirent profit. Alors que différentes incitations organisationnelles découragent les assureurs de contribuer à la suppression des incertitudes, ils se révèlent incapables d'opérer eux-mêmes le contrôle et la réduction profitables des incertitudes couvertes en tant que risques assurantiels. Afin d'étayer ces arguments, cette thèse expose d'abord une analyse historique de la construction du droit des assurances en Angleterre (1664-1774). Cette analyse démontre l'instabilité du marché des assurances et sa tendance à générer de l'incertitude, et ce, depuis ses origines. Elle offre ensuite, à titre d'étude de cas centrale, une analyse de la constitution institutionnelle du marché canadien de l'assurance médicaments dans le contexte actuel de l'arrivée des médicaments de spécialité onéreux. Cette thèse présente deux conclusions principales. Premièrement, la gouvernance assurantielle génère des instabilités et dépend donc de la marchandisation fictive des risques assurantiels grâce à la réduction et au contrôle politiques, juridiques et non-concurrentiels des incertitudes sous-jacentes. Deuxièmement, le processus de marchandisation fictive peut exiger la démarchandisation des «mauvais » risques assurantiels par leur répartition à travers la diversité des modes d'intégration économique. Le cadre théorique polanyien permet ainsi d'étudier en quoi la capitalisation assurantielle des incertitudes affecte les individus, les institutions et les communautés politiques. 


\section{Acknowledgements}

I would first like to thank my co-supervisor at Carleton University, Aaron Doyle, for his pioneering, insightful and open approach to the study of private insurance and, above all, for helping me better understand the nature of research as labour and academia's inner workings. He has also been a highly rigorous and generous reader along the different stages of this doctoral research and during the writing of this dissertation. Moreover, his patience and support have been invaluable during difficult times.

I would also like to thank my co-supervisor at Université Paris-Sorbonne, Philippe Steiner, for helping me keep an open mind to socio-economic theories and empirical evidence. His passion and rigour make him a role model for any intellectual, and especially for the reader of sociological and economic thoughts. I am grateful for the fascinating theoretical discussions we have had over the past years.

I am especially indebted to Marc-André Gagnon for his powerful empirical analysis of the pharmaceutical industry and for his inspirational theoretical understanding of the sectoral analysis of capitalism. I am thankful for his help in getting access to various Canadian drug insurance market stakeholders and for his financial support through research assistantships at the School of Public Policy and Administration (Carleton).

Many people provided essential technical, administrative and "diplomatic" support and contributions during the long and complex process leading to the establishment of this cotutelle agreement. Langis Roy, formerly at the Faculty of Graduate and Postdoctoral Affairs (Carleton), played a decisive role, from start to finish, in this cotutelle agreement. I am thankful for his enthusiastic and friendly handling of this project. I wish to thank Wallace Clement, also formerly at Carleton's FGPA, for overseeing and facilitating this cotutelle process, but also for his precious teaching of sociology and especially for his inspiring ability at making methods and methodologies clear and meaningful. I must also give thanks to Igor Bratusek and Claudia Villa Gutierrez (Sorbonne), as well as to Claire Samson and Xiaobei Chen (Carleton), for making this cotutelle agreement a reality. Finally, I wish to thank the French Embassy in Canada for its cotutelle financial support.

This dissertation would not have been possible without the constant technical and administrative support of Paula Whissell (Carleton) and Claire Ryckmans (Sorbonne) who have always been available, thorough and fast in responding to my questions and helping me moving ahead with my doctoral studies.

Bruce Curtis, Alan Hunt, Laura MacDonald and Hugh Armstrong all deserve special mentions for their excellent teaching at Carleton University. I also wish to thank Carleton University librarians Janet Hempstead (Social sciences) and Trish O'Flaherty (Business) for always showing interest in my sociology of insurance and insurance history book requests.

A friendly thank you to Joel Z. Garrod (Carleton) who has been acting, for more than five years now, as a brilliant interlocutor through fascinating and challenging discussions of sociological and political economic theories, and also concerning the possible futures of capitalism. I am grateful to have shared my years of doctoral studies with many other stimulating colleagues at Carleton University and Université ParisSorbonne. I also wish to thank Magnus P. Hansen for the great theoretical and friendly discussions we had in Montreal, Paris and Copenhagen. A special thought in memory of 
Blake MacMillan: we all miss you.

Most importantly, I wish to thank my parents for encouraging me and helping me to pursue my passions. Without their constant support this thesis would not have been possible. Finally, Marie-Christine, you made things much easier and pleasant when, at some points, the dissertation writing process was hard and even painful. I am grateful to you for your patience, understanding, friendship, and love.

I wish to thank the Fonds de Recherche du Québec - Société et Culture and the Social Sciences and Humanities Research Council of Canada for financially supporting my doctoral studies. 


\section{Table of Contents}

ABSTRACT - RÉSUMÉ ...................................................................................................................

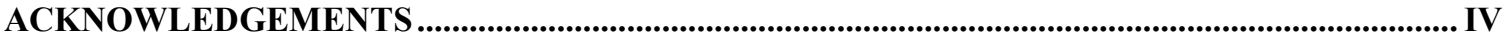

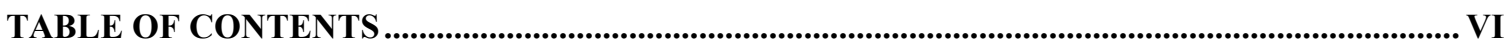

LIST OF TABLES ...................................................................................................................................... IX

LIST OF FIGURES .............................................................................................................................................X

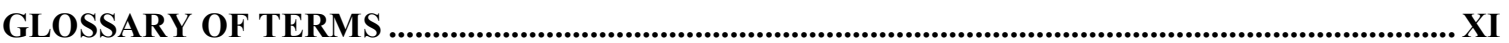

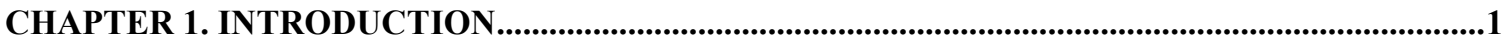

1.1. PRIVATE INSURANCE BEYOND THE MORAL HAZARD PARADIGM .....................................................

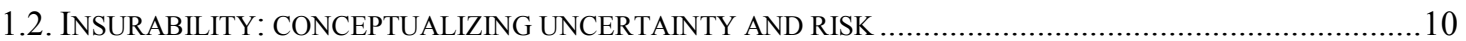

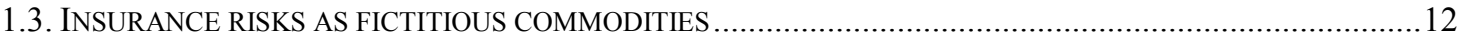

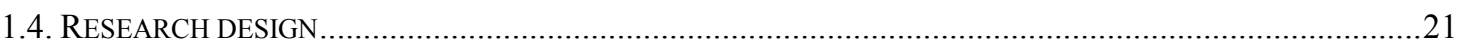

CHAPTER 2. LITERATURE REVIEWS: THE EMERGING SOCIOLOGY OF INSURANCE AND THE OVERSIGHT OF THE INSTITUTIONALIST TRADITION IN CONTEMPORARY

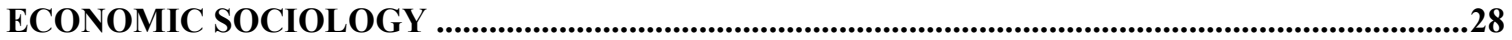

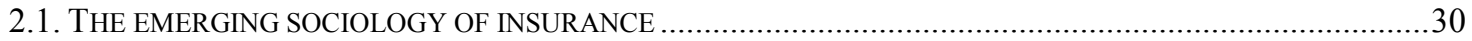

2.1.1. From socio-legal studies to the insurance-as-governance approach …....................................... 32

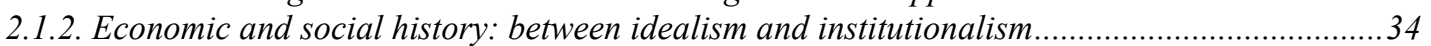

2.1.3. The theory of risk society: the private uninsurability of catastrophic risks? ..............................35

2.1.4. The institutional ethnographic sociology of the insurance industry ..........................................36

2.1.5. Partial conclusions: the insurance-as-governance approach ................................................... 38

2.2. CONTEMPORARY ECONOMIC SOCIOLOGY: OVERLOOKING THE INSTITUTIONALIST TRADITION .............41

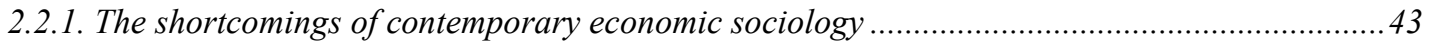

a) Foucault and anglo-neo governmentality: the primacy of the economic? ................................43

b) Callon and the theory of performativity: the network paradigm .............................................49

c) Granovetter and new economic sociology: overlooking the institutionalist tradition .................50

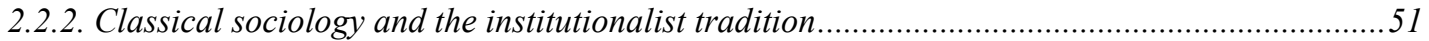

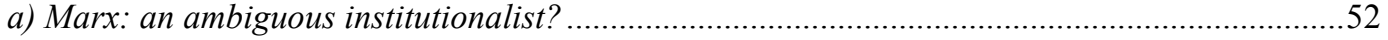

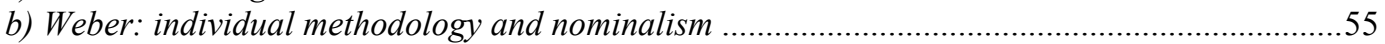

c) Durkheim and Veblen: classical sociology and the institutionalist tradition .............................59

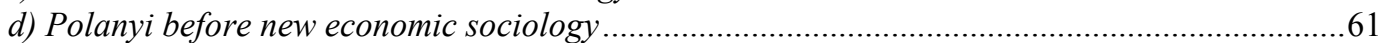

2.2.3. Partial conclusions: classical sociology and the institutionalist tradition ................................67

2.3. CONCLUSIONS: TOWARDS THE POLANYIAN SOCIOLOGY OF PRIVATE INSURANCE .............................72

\section{CHAPTER 3. THEORETICAL FRAMEWORK AND RESEARCH DESIGN: THE}

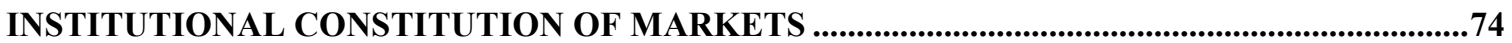

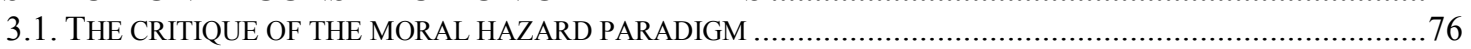

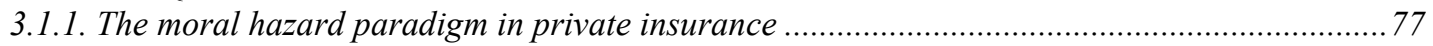

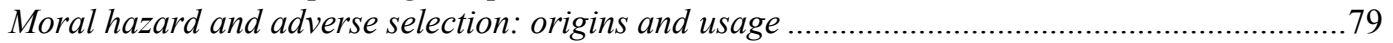

From character and temptation to incentives: the economics of moral hazard ..............................8

Partial conclusions: the moral hazard paradigm and beyond ....................................................... 87

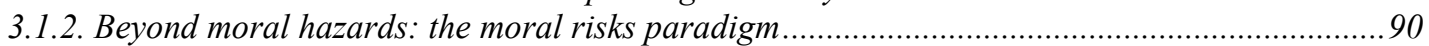

Market misconducts, the construction of fraud and the ironies of insurance .................................91

Outside closed doors: the ideal form of the private insurance governance ……............................96

Partial conclusions: private insurance and public institutions .....................................................97

3.1.3. Summary and conclusions: theorizing uncertainty and risk ................................................99

3.2. THEORETICAL FRAMEWORK: THE INSTITUTIONAL CONSTITUTION OF MARKETS ..............................106 


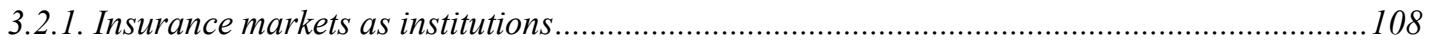

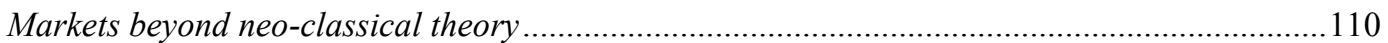

Insurance markets as politically and legally constituted institutions..............................................112

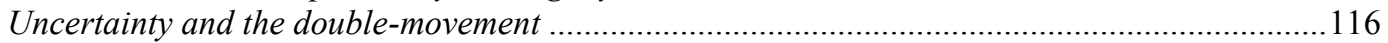

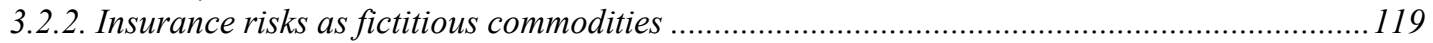

The fictitious commodities in The Great Transformation: an update .........................................120

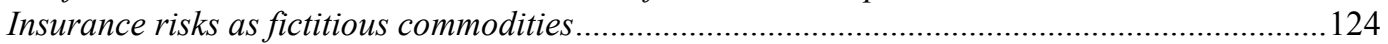

3.2.3. Partial conclusions: the institutional constitution of insurance markets ................................ 133

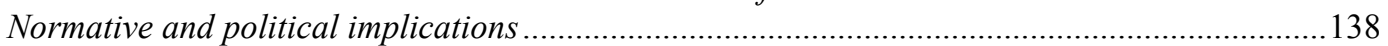

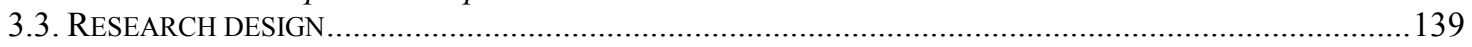

3.3.1. General question, working hypotheses and secondary questions .......................................139

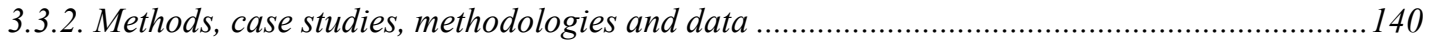

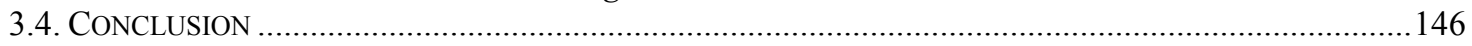

CHAPTER 4. THE MODERN ORIGINS OF PRIVATE INSURANCE: INSTITUTIONALIZING THE INSURABLE INTEREST PRINCIPLE IN ENGLAND, 1664-1774 ....................................148

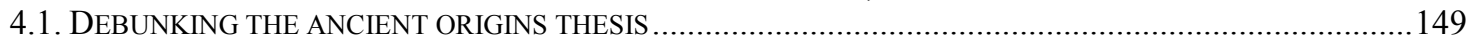

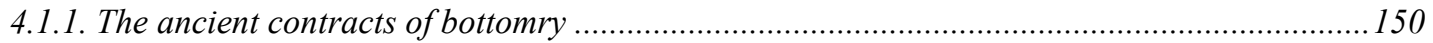

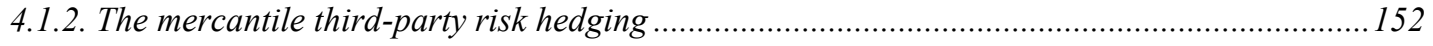

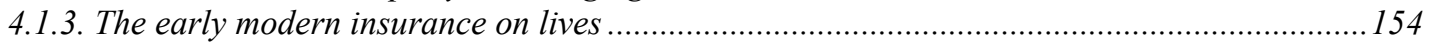

4.2. THE CONSTRUCTION OF INSURANCE LAW IN $18^{\mathrm{TH}}$ CENTURY ENGLAND .........................................155

4.2.1. Mutuality: financial capitalism and insurance mutual societies........................................157

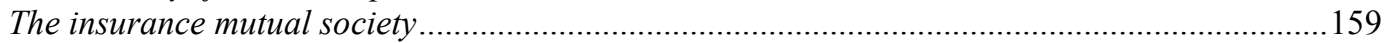

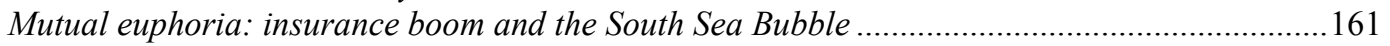

4.2.2. Uncertainty: insurance, gambling, speculation and the mid-century shift ............................163

4.2.3. Recognition: the institutionalization of the insurable interest principle ................................... 166

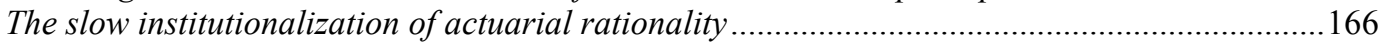

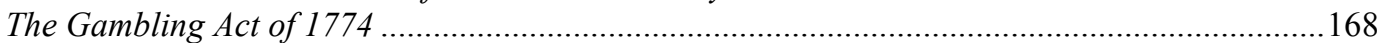

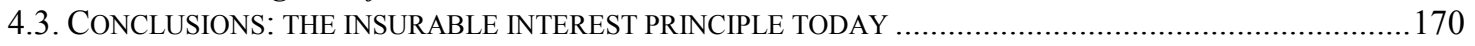

\section{CHAPTER 5. THE INSTITUTIONAL CONSTITUTION OF THE CANADIAN PRESCRIPTION DRUG INSURANCE MARKET: WHEN PRIVATE PLANS FACE HIGH PRICE SPECIALTY DRUGS.}

5.1. PRESCRIPTION DRUG INSURANCE IN CANADA: THE PATCHWORK SYSTEM AND THE ARRIVAL OF

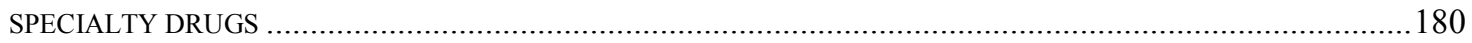

5.1.1. A brief history of healthcare in Canada: the exclusion of PD coverage .................................181

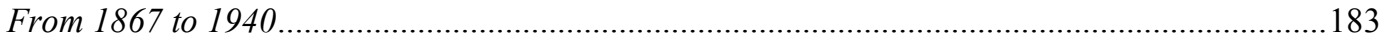

Post-WWII and the 1950s: the therapeutic revolution and the public funding of hospital care ...185

The 1960s: resisting physicians, the Hall Commission and the Medical Care Act .......................188

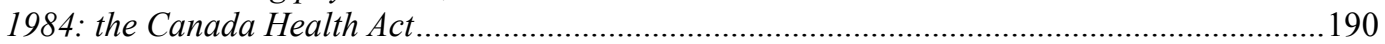

Partial conclusions: the exclusion of PD coverage from Medicare .............................................192

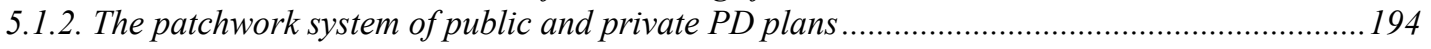

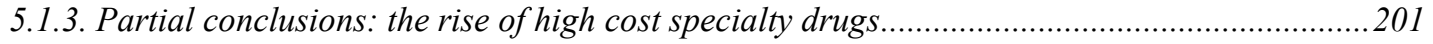

Drug prices in Canada and the patchwork system: an overview .............................................202

From Blockbusters to Nichebusters: the rise of specialty medicines ............................................206

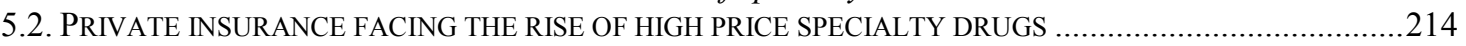

5.2.1. The Canadian PD insurance market: structure and organization .........................................216

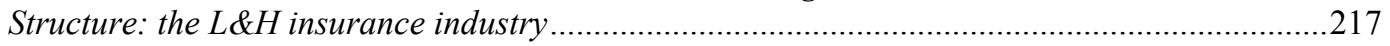

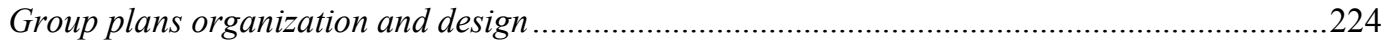

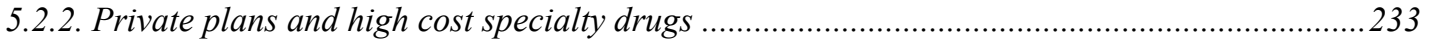

Evidence on the past outcomes of private health insurance and PD coverage ............................234

Plan design facing the rise of high cost specialty drugs ........................................................227

Private insurers facing specialty drugs: from isolated to industry-wide initiatives .......................244

5.2.3. Partial conclusions: private insurance and specialty drugs in Canada ..................................256

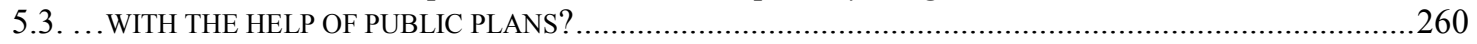

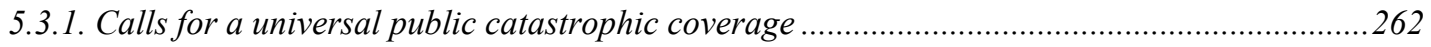


5.3.2. Public catastrophic coverage in Canada: an overview ..................................................265

5.3.3. Partial conclusions: the expansion of provincial catastrophic coverage ...............................268

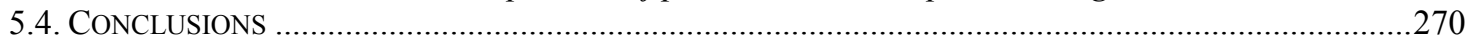

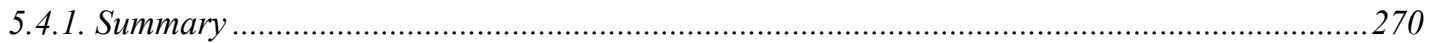

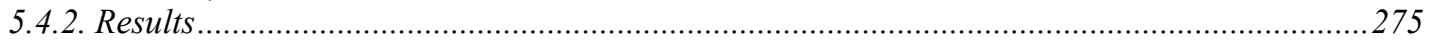

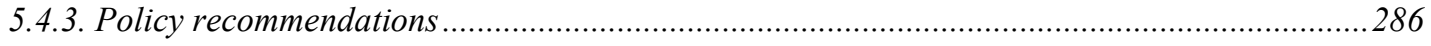

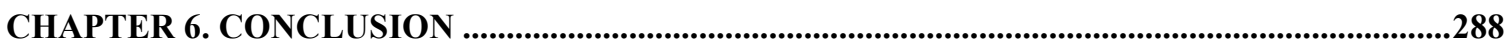

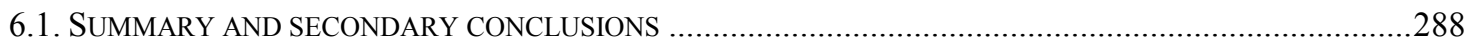

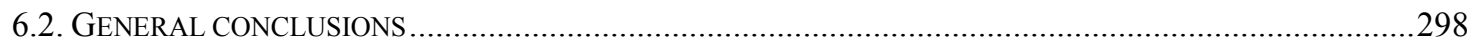

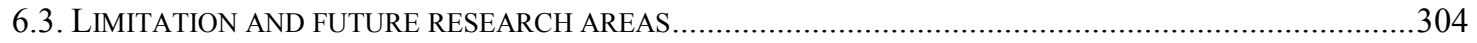

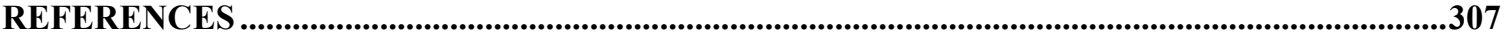




\section{List of Tables}

TABLE 3.1. ThE UPDATED PoLANYIAN FiCTITIOUS COMMODITIES ......................................................... 122

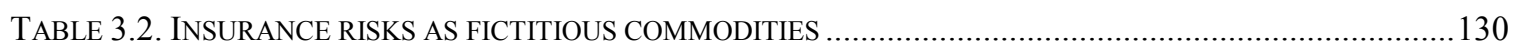

TABLE 5.1. IMPORTANT DATES IN THE DEVELOPMENT OF HEALTH CARE IN CANADA...............................182

TABLE 5.2. FEDERALLY PROVIDED PUBLIC AND PRIVATE PRESCRIPTION DRUG COVERAGE IN 2016 ............199

TABLE 5.3. TOP 10 L\&H INSURERS IN CANADA BY NET PREMIUMS WRITTEN, 2013 (THOUSAND CAD) ......218

TABLE 5.4. RISK/SURPLUS IN REFUND/NON-REFUND PRODUCTS OFFERED BY A TOP THREE CANADIAN L\&H

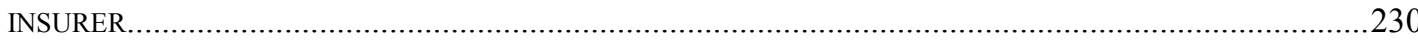

TABLE 5.5. MAXIMUM OUT-OF-POCKET EXPENDITURES IN PROVINCIAL CATASTROPHIC PROGRAMS ...........268 


\section{List of Figures}

FIGURE 3.1. INSURANCE MARKETS AND THE MODES OF ECONOMIC INTEGRATION ..................................133

FIGURE 5.1. PRESCRIPTION DRUG EXPENDITURE BY TYPE OF COVERAGE IN CANADA, 2014 (FORECAST) .....195

FIGURE 5.2. EVOLUTION/FORECAST OF SPECIALTY DRUGS SPENDING AS PERCENTAGE OF TOTAL PD EXPENDITURE IN CANADA

FIGURE 5.3. EVOLUTION OF SPECIALTY DRUGS SHARE OF TOTAL COSTS AND CLAIMS AT TELUS HEALTH, $2008-15$

FIGURE 5.4. NUMBER AND COSTS OF HIGH-COST ACTIVE BENEFICIARIES IN PRIVATE DRUG PLANS, 2005-2015

FIGURE 5.5. TOP 10 CANADIAN GROUP L\&H INSURERS' MARKET SHARE BY TOTAL REVENUE, 2015 .........221

FIGURE 5.6. TOP 10 GROUP L\&H INSURERS’ MARKET SHARE BY TOTAL REVENUE IN QUEBEC, 2015 .........223

FIGURE 5.7. THE CDIPC POOLING MECHANISM ............................................................................25

FIGURE 5.8. THE CANADIAN PD INSURANCE MARKET FACING THE RISE OF SPECIALTY DRUGS.................281 


\section{Glossary of Terms}

$\begin{array}{lll}\text { ANG } & - & \text { Anglo-neo governmentality } \\ \text { ANT } & - & \text { Actor-network theory } \\ \text { AODP } & - & \text { Asset Owners Disclosure Project } \\ \text { AS } & - & \text { Adverse selection } \\ \text { ASO } & - & \text { Administrative services only } \\ \text { CACC } & - & \text { Cancer Advocacy Coalition of Canada } \\ \text { CADTH } & - & \text { Canadian Agency for Drugs and Technology in Health } \\ \text { CDR } & - & \text { Common Drug Review } \\ \text { CDIPC } & - & \text { Canadian Drug Insurance Pooling Corporation } \\ \text { CES } & - & \text { Contemporary economic sociology } \\ \text { CHA } & - & \text { Canada Health Act } \\ \text { CHIA } & - & \text { Canadian Health Insurance Association } \\ \text { CIA } & - & \text { Canadian Institute of Actuaries } \\ \text { CIHI } & - & \text { Canadian Institute for Health Information } \\ \text { CLHIA } & - & \text { Canadian Life and Health Insurance Association } \\ \text { CLIA } & - & \text { Canadian Life Insurance Association } \\ \text { CLIOA } & - & \text { Canadian Life Insurance Officers Association } \\ \text { CMA } & - & \text { Canadian Medical Association } \\ \text { CPhA } & - & \text { Canadian Pharmacists Association } \\ \text { CPI } & - & \text { Consumer price index } \\ \text { CSIS } & - & \text { Canadian Security Intelligence Service } \\ \text { D\&O } & - & \text { Directors and Officers } \\ \text { DIN } & - & \text { Drug identification number } \\ \text { EHC } & - & \text { Extended health care } \\ \text { EP3 } & - & \text { Extended Care Policy Protection Plan } \\ \text { HIDSA } & - & \text { Hospital Insurance and Diagnosis Services Act } \\ \text { HTA } & - & \text { Health technology assessment } \\ \text { IasG } & - & \text { Insurance as governance } \\ \text { IC } & - & \text { Institutional constitution } \\ \text { IIP } & - & \text { Insurable interest principle } \\ \text { IPE } & - & \text { International political economy } \\ \text { IR } & - & \text { International relations } \\ \text { L\&H } & - & \text { Life and health } \\ \text { LAP } & - & \text { Large Amount Pooling } \\ \text { MCA } & - & \text { Medical Care Act } \\ \text { MH } & - & \text { Moral hazard } \\ \text { NBP } & - & \text { Naissance de la biopolitique } \\ \text { NES } & - & \text { New economic sociology } \\ \text { NPDUIS } & - & \text { National Prescription Drug Utilization Information System } \\ \text { OECD } & - & \text { Organisation for Economic Co-operation and Development } \\ \text { P\&C } & - & \text { Property and casualty } \\ \text { pCPA } & - & \text { Pan-Canadian Pharmaceutical Alliance } \\ \text { PD } & - & \text { Prescription drug } \\ \text { PLA } & - & \text { Product listing agreement } \\ & & \end{array}$




$\begin{array}{lll}\text { PMPRB } & - & \text { Patented Medicine Prices Review Board } \\ \text { PSHCP } & - & \text { Public Service Health Care Plan } \\ \text { QDIPC } & - & \text { Quebec Drug Insurance Pooling Corporation } \\ \text { R\&D } & - & \text { Research and development } \\ \text { RGAM } & - & \text { Régime général d'assurance médicaments } \\ \text { SL } & - & \text { Socio-legal } \\ \text { SRM } & - & \text { Self-regulating market } \\ \text { STP } & - & \text { Sécurité, territoire et population } \\ \text { TCMP } & - & \text { Trans-Canada Medical Plans } \\ \text { TGT } & - & \text { The Great Transformation } \\ \text { TPA } & - & \text { Third party administrator } \\ \text { UK } & - & \text { United Kingdom } \\ \text { US } & - & \text { United States of America } \\ \text { WWI } & - & \text { World War I } \\ \text { WWII } & - & \text { World War II }\end{array}$




\section{Chapter 1. Introduction}

One can hardly understand why the insurance industry has remained off the radar of classical political economists and sociologists. During most of the $20^{\text {th }}$ century, only a few isolated social scientists then endeavoured to produce knowledge on private insurance from perspectives different from the insurance industry's own selfrepresentation based on actuarialism and the moral hazard paradigm. Up until fairly recently, no systematical research agenda on private insurance had been developed outside of the actuarial discipline, mainstream economics, and finance and management studies. However, beyond these orthodox approaches, starting with Hugh L. Ross's (1970) pioneering ethnography of automobile insurance adjusters, the first heterodox studies $^{1}$ of the insurance industry were offered by socio-legal scholars who began to analyze private insurance as a form of "governance beyond the state" (see Baker, 2010).

Since the 1980s, and especially since the 1990s, socio-legal studies of private insurance have shed light on various gaps between the socio-economic reality of private insurance and standard economic theory. More or less loosely inspired by Michel Foucault's (1991, 2004a, 2004b) concept of governmentality, these socio-legal studies stressed that insurantial risk management generates "power as governance" outside the public institutions. Even more recently, this insurance-as-governance approach was combined with other post-structuralist frameworks - such as the actor-network and performativity theories - and revealed that the underwriting and risk classification

\footnotetext{
1 Borrowing a distinction from the field of economics between heterodox economics as the "nonneoclassical" economics and the mainstream or orthodox neo-classical economics (see Lee, 2009: 4), the term "heterodox" herein refers to studies and analyses of the insurance industry refusing to approach private insurance from the perspective of the orthodox actuarial discipline, mainstream economics, and finance and management studies in general, and from the moral hazard paradigm in particular (see below and Chapter 3).
} 
processes require the objectification of a wide range of knowledge and calculating devices provided by the fields of economics, management, accounting and medicine, to name only a few. Thanks to the emphasis on the interplays between power and knowledge and to a theory of power as governance beyond the state, Foucauldian governmentality can be considered as the foundational framework for the emerging sociology of insurance.

Nine years after Ross' foundational contribution, the famous contemporary economic sociologist Viviana Zelizer (1979) offered Morals and Markets, now seen as a classic study of the cultural and moral legitimization of life insurance in the US during the $19^{\text {th }}$ century. Again, up until recently, Zelizer's Weberian approach has failed to translate into a systematised heterodox research agenda on the insurance industry. Since the first decades of the $21^{\text {st }}$ century, however, some economic sociologists followed Zelizer's insights and have begun analyzing the emergence and construction of insurance markets in historically non-capitalist societies by focusing on the cultural and moral resistance to and legitimization of economic and financial innovations. For instance, the comparative interplays between cultural resistance and political negotiations in the emergence of life insurance in Taiwan and China has been the object of socio-economic investigation (see Chan, 2012a, 2012b).

Since the 1990s, the social and economic history of insurance produced another major body of literature laying grounds for the emerging sociology of private insurance. While historians of statistics and probabilities had either merely touched on insurance or focused on the development of statistical probabilities as a determinant factor in the emergence of actuarial insurance in late $18^{\text {th }}$ century England, social and economic 
historians began to supersede the analytical emphasis on the role of knowledge and culture in the analysis of the emergence of insurance and the construction of insurance markets; they instead began major investigations into the legal and organizational development of the insurance industry in early modern English history. Despite these major contributions from social and economic historians, the recent wave of economic sociologists and political economists stepping into the emerging field of the sociology of insurance and investigating new empirical sites features a tendency to put the epistemic and cultural aspects of the construction of private insurability and insurance markets into the analytical foreground.

Along with Weberian economic sociology, governmentality studies and its hybrid versions are characterized by an inability to closely articulate the economic and the political realms in addressing the fundamental relations between private insurers and public institutions. For example, the following diagnosis from leading socio-legal scholars of private insurance surprisingly still holds true today, twenty years later: "[w]hile the contours of [the] relationship [between private and public insurance] are not well understood, it is nevertheless clear that the availability of market insurance strongly influences state or state-sponsored insurance and that the reverse is true as well." (Baker and McElrath, 1996: 231). The neglect of the constitutive function of public institutions for the insurance industry became increasingly apparent, even through a major, although rather unnoticed sociological debate over the private uninsurability principle formulated by risk society theorist Ulrich Beck, representing the moment when the sociology of insurance took off. 
According to Beck's private uninsurability principle, the insurance industry refuses to insure new types of global, irreversible and un-quantifiable catastrophic risks characterized by low frequency and high severity (Beck, 1992a, 2009). Somewhat paralleling a wide-spread thesis in the fields of international political economy and critical sociology suggesting that the globalized economy within which transnational firms operate and in which new risks emerge signals the "retreat of the state" (see Strange, 1996), Beck claims that the new industrial, technological, financial, ecological and sanitary dangers can neither be controlled by private and public institutions nor quantified through probabilistic calculus. ${ }^{2}$ One aspect that caught additional academic attention is the fact that Beck (2002: 44) included terrorism as a supposedly uninsurable threat:

[...] the principle of private insurance is partly being replaced by the principle of state insurance. In other words, in the terrorist risk society the world of individual risk is being challenged by a world of systemic risk, which contradicts the logic of economic risk calculation. Simultaneously, this opens up new questions and potential conflicts, namely how to negotiate and distribute the costs of terrorist threats and catastrophes between businesses, insurance companies and states.

In part against Beck's private uninsurability principle, Ericson et al. (2004a, 2004c) developed the first ethnographic sociology of private insurance as an institution in North America and examined how insurers operate under conditions of extreme uncertainty and cover terrorism-related uncertainties by turning to non-actuarial forms of knowledge, surveillance technologies, financial securitization and public-private collaborations in order to construct and ensure insurability. Through the formulation of this principle, Beck must hence be considered as a forerunner of the sociology of insurance. Perhaps

\footnotetext{
2 According to Beck (2002: 41), “[the] '[u]ncontrollable risks' must be understood as not being linked to place, that is they are difficult to impute to a particular agent and can hardly be controlled on the level of the nation state. This then also means that the boundaries of private insurability dissolve, since such insurance is based on the fundamental potential for compensation of damages and on the possibility of estimating their probability by means of quantitative risk calculation."
} 
unintentionally, he raised a simple, but central question for the sociology of insurance: what is insurable? In doing so, however, Beck assumed that public institutions intervened in insurance markets only under exceptional circumstances, more specifically when risks cannot be actuarially quantified.

The pioneering sociology of insurance developed by Ericson and his collaborators in reaction to Beck's thesis actually focused on two central components of the functioning of the insurance industry. On the one hand, they revealed how private insurers are able to profitably cover highly "uncertain risks" concerning which there is limited, shaky, or even no actuarial data (Ericson and Doyle, 2004c). ${ }^{3}$ The ethnographic sociology of the insurance industry has thus addressed the relationships between power and knowledge by analyzing the institutional production of the various forms of knowledge private insurers seek in constructing the insurability of unquantifiable uncertainties and turning them into known, or rather knowable and hence insurable risks. On the other hand, Ericson et al. (2003: 13) suggest that private insurers should be considered as the locus of governance beyond the state in neoliberal societies and that a "great deal of what is attributed to the welfare state regarding moral risk creation, debt financing, and bureaucratic red tape can also be attributed to the insurance industry." Although investigating typical Foucauldian research areas such as the power/knowledge interplay and power as governance beyond the state, the ethnographic sociology of

\footnotetext{
${ }^{3}$ According to these authors, "a high degree of scientific and technical uncertainty permeates the insurance industry, the very business that is charged with transforming uncertainty into risk. Insurers do not necessarily back off from a high degree of uncertainty. Rather, they respond with a range of creative and sometimes ingenious solutions. However, they also regularly confront the limitations of their own science, technology, and institution for addressing risk. [...]. Insurance is a key institution in which to understand knowledge of risk and uncertainty." (Ericson and Doyle, 2004c, p. 5).
} 
private insurance nonetheless acknowledged the symbiotic relationships between the insurance industry and state institutions (see ibid.: 7). But Ericson et al. have not systematically investigated the interplays between insurers and the state, nor have they investigated the ways in which public institutions could actually contribute to the constitution of the power of private insurance as governance.

Simply put, what the insurance-as-governance approach and Weberian economic sociology of private insurance have not investigated is the fact that insurance markets require institutional constitution. In this context, the following dissertation aims at shifting the focus from the epistemic and cultural construction of private insurability in the emerging sociology of insurance literature towards the political-legal construction and maintenance of insurance markets. It argues that, and investigates why the availability of actuarial data and extra-actuarial knowledge of risks are insufficient conditions for the functioning of the private insurance business. Drawing on reinterpretations of Karl Polanyi's (1944) institutional analysis, it develops a theory of the institutional constitution of markets and the concept of insurance risks as fictitious commodities in order to analyse insurance markets as politically and legally constituted institutions. Following evidence that private insurers cannot self-sufficiently ensure their profitability through contractual incentives and private controls of the insured, it claims that the institutional mediation and organization of substantive uncertainties as fictitiously commoditized insurance risks accounts for the basic determinant of private insurability.

From the perspective of the Polanyian institutional analysis, the uncertainties experienced by individuals and threatening the modes of social provisioning, nature, the political institutionalization of society and the market economy itself represent the raw 
materials which insurers capitalize. While the financial and organizational incentives the insurance industry deals with prevent insurers from seeking the complete removal of these uncertainties, the private insurance governance cannot autonomously ensure the required levels of uncertainty reduction and control nor the profitable configurations of the underlying uncertainties covered as insurance risks. Private insurance capitalization actually generates instabilities and hence depends on the fictitious commoditization of substantive uncertainties into insurance risks by virtue of the political-legal and noncompetitive reduction and control of the underlying uncertainties covered as capital. The fictitious commoditization process can also involve the decommoditization and individualization of "bad" or "high" insurance risks by their distribution across the diversity of the institutional modes of economic integration. Through the Polanyian framework, this dissertation thus empirically examines how private insurance capitalization of substantive uncertainties impacts individuals, institutions, and the citizenry.

\subsection{Private insurance beyond the moral hazard paradigm}

The critique of the moral hazard paradigm represents one of most basic moments in the emergence of what I am referring to as the heterodox analysis of the insurance industry. Moreover, it also reveals the fundamental role of public institutions in the construction and maintenance of private insurability. First formulated in the insurance industry during the second half of the $19^{\text {th }}$ century before being formalized and universalized by the neoclassical economics of information in the 1960s and 1970s, the moral hazard paradigm portrays the instability inherent to the insurance contract as being primarily 
generated by the behavior of the insured, pictured as highly aware, knowledgeable, calculative and self-interested. As such, the idea of moral hazard constitutes the insurance industry's own self-representation portraying private insurance as one-sided and atomistic or "institutions-less." The moral hazard paradigm actually represents a sophisticated version of the theory of the self-regulating market since it allows insurers to epistemologically legitimize private risk classification and contractual incentive-based controls of the insured while, at the same time, alleviating most, if not all responsibility for the destabilization of private insurance from the insurer's back. In a nutshell, according to the moral hazard paradigm, the private insurance governance would be able to autonomously ensure its own stability and profitability thanks to risk classification, contractual incentives and other private controls of the insured.

Against this orthodox representation, the ethnographic sociology of private insurance suggests that the concept of moral risks better renders the nature of private insurance as a social relationship, that is "the paradoxical tendency of the structure and culture of the insurance institution to facilitate and encourage risky behavior on behalf of the various players in the insurance relationship." (Ericson and Doyle, 2006: 993). Even before the late $19^{\text {th }}$ century formulation of the moral hazard paradigm, some actors from the financial sector, government authorities and even the English public were already aware that private insurers were themselves a central source of destabilization of the insurantial relationship (see Chapter 4). The moral risks paradigm thus points to the instabilities and uncertainties intrinsically generated by the insurantial relationship and broadens the analysis of the private insurance governance beyond private risk classification and contractual incentives-based controls by reconstructing the ideal form 
of private insurance governance. On the one hand, despite claiming to be based on mutualization as a basic organizational principle, private insurers' struggle for profitmaking ironically leads to risk unpooling, to risk creation, to financial risk-taking, to covering highly "uncertain risks" and to the creation of fraud (Doyle and Ericson, 2010). On the other hand, institutional ethnographic sociology's ideal form of private insurance governance (Ericson and Doyle, 2004c; see Ericson et al., 2003: 5-6) reveals that the integrity of the insurantial relationship requires non-actuarial types of knowledge and non-competitive institutional interventions and arrangements.

Relying on non-actuarial data and knowledge in constructing insurability when risks cannot be purely actuarially computed, insurers must turn to other sciences and other forms of knowledge - including subjective and speculative knowledge - in order to mediate uncertainty as insurable risk. But most importantly, the insurantial relationship is objectified as a contract - the insurance policy - that requires laws and regulations within legal, judicial and political systems. The relationship between insurer and insured rests on a contract involving various rights, obligations, and responsibilities. Private insurance is indeed a law-intensive business (Baker, 2010). State and public institutions thus appear as central actors in the functioning of the insurance industry, for instance through publicprivate collaborations in risk control and reduction, through the public construction of insurance markets by the partial underwriting of risks, and with the state as the insurer in last resort (Ericson and Doyle, 2004c; Ericson et al., 2003). To put it simply, private insurance governance of various uncertainties as insurance risks cannot be considered to be a self-sustaining process. From the perspective of economic sociology, the moral risks paradigm raises the theoretical issue of the capacity of various institutions - and 
especially of private insurers and insurance markets - to mediate and organize diverse uncertainties as profitably covered, commodified, and hence transferrable insurance risks.

\subsection{Insurability: conceptualizing uncertainty and risk}

The ethnographic sociology of private insurance's finding that private insurability can be ensured despite a lack of archival-historical and probabilistic data represents a major step forward, away from the canonical, neoclassical dichotomy between uncertainty and risk. While Ericson and Doyle (2004c) revealed that private insurers cover a wide range of uncertainties as insurance risks by turning to various types of non-actuarial knowledge, neo-classical economics has long reduced the concept of risk to actuarially quantified uncertainty.

Building on a version of the marginalist theory according to which corporate and insurance organizations manage risks as per the subjective actuarial value of capital in a world devoided of uncertainty (see Clark, 1892), Frank H. Knight (1921) provided what can be considered as the canonical, neoclassical concept of risk as opposed to uncertainty. Knight defined risk as an actuarially calculable occurrence, in contrast to uncertainty understood as a condition under which decisions are made without available archival-historical statistics. From the epistemology of probability, Knight then translated

the analysis of uncertainty towards business decision-making and suggested that profitability relies both on planned risk-taking by the entrepreneur and on the mitigation of unpredictable events and uncertainty through the organizational form of the firm. This Knightian defense of the theory of the self-regulating market clearly appears in contradiction with evidence from the emerging sociology of insurance signalling that 
private insurance governance cannot self-sufficiently stabilize the insurantial relationship and hence cannot autonomously ensure the profitability of the private insurance business.

Against the neoclassical dichotomy between uncertainty and risk, John M. Keynes proposed that the actuarial calculus of risk is actually built on the rationalization of Benthamian utilitarianism, hence concealing radical epistemic uncertainty. ${ }^{4}$ In his 1921 Treatise on Probability, Keynes developed the concept of logical probability as a critique of the neoclassical concept of risk and of the standard numerical approach to probability. Since the large of large numbers is empirically restricted in the real world, and considering the epistemic importance of ignorance, Keynes (1921) suggested that probability first and foremost rests on various degrees of beliefs concerning specific statements previously judged as reasonable. The Keynesian theory of uncertainty thus placed ethical concerns and historical contingency at the core of the concept of probability; the future is by definition uncertain and contingent upon human decisions and actions. The central position of temporality in Keynes' theory of probability thus points to the fundamental function of normative judgments in conditions of anticipation and fear (Dostaler, 2005). ${ }^{5}$ As a result, the critique of standard probabilism led Keynes to formulate the idea of "epistemic uncertainty," referring not to the improbable but to the unknown (Keynes, 1937). Most importantly, by rejecting the neoclassical dichotomy between uncertainty and risk, the Keynesian theory of epistemic uncertainty signals that

\footnotetext{
${ }^{4}$ See Section 3.1.3.

${ }^{5}$ For example, this perspective inspired Keynes' idea of "animal spirits" for the analysis of money and the liquidity preference in The General Theory (see Keynes, 1936).
} 
social conventions and power better explain decision-making under conditions of uncertainty than the utilitarian calculus and the actuarial rationality (Lavoie, 1985). ${ }^{6}$

This invaluable Keynesian insight points to the analytical shift in the emerging sociology of private insurance from the focus on data, ideas, knowledge and culture as the determinants of the construction of uncertainties into insurable risks towards power and institutions as keys to private insurability and the construction and maintenance of insurance markets. Building on Keynes, it seems that analysing why the availability of actuarial data and extra-actuarial knowledge are insufficient conditions for the functioning of the private insurance business would provide a better understanding of the ways in which the insurance industry operates. But how could the institutional analysis actually illuminate the private capitalization of uncertainties as insurance risks?

\subsection{Insurance risks as fictitious commodities}

Despite diverging on various levels, classical sociologists such as Émile Durkheim and founders of American institutionalism like Thorstein Veblen shared a refusal to treat "the economic" as an autonomous category. While Durkheim $(1893,1894)$ suggested studying "economic facts" as "social facts" and pointed to the non-contractual bases of the contract, Veblen $(1899,1904)$ also recognized the institutional constitution of the economy by providing a non-productivist and socio-legal understanding of economy, capital and the firm. Following classical sociology and the institutionalist tradition, Karl Polanyi $(1944,1957)$ later challenged the idea of the autonomy of the economy by

\footnotetext{
${ }^{6}$ Institutionalist frameworks such as the French economics of conventions (Orléan, 2004) and Regulation school (Boyer, 2004) have theorized and analyzed the fundamental role of social conventions in contexts of uncertainty generated by the dynamics of the capitalist economy (Chavance, 2009). See Section 3.1.2.
} 
rejecting the "economistic fallacy" and shedding light on "the always and everywhere embedded economy" (Block and Somers, 2014).

Drawing on economic history and anthropology, the Polanyian approach builds on the diagnosis and denunciation of the economistic fallacy, defined as the conflation of the economic activity as a whole with the market form and the retrospective application of this fallacy across time and space (Polanyi, 1977). Polanyi suggests that the reduction of the economic to its market form constitutes the formal conception of the economic, in contrast to the substantive definition. While the formal concept is the product of rationalism, rests on a logical relation between means and ends, and conflates subsistence with scarcity, Polanyi states that the substantive meaning is a matter of empirical evidence, relates to the human dependence on nature and society and points to the connection between subsistence and recognition. ${ }^{7}$ The substantive conception thus allowed Polanyi to analyze the economic as necessarily contributing to what he refers to as human beings' "livelihood," not only as the space of material production and circulation (Polanyi, 1957: 243).

Against the economistic fallacy, the substantive concept of the economic thus led Polanyi to define the economy as an "instituted process." This means that

[t]he human economy, [...], is embedded and enmeshed in institutions, economic and noneconomic. The inclusion of the noneconomic is vital. For religion or government may be as important for the structure and functioning of the economy as monetary institutions or the availability of tools and machines themselves that lighten the toil of labor. (Polanyi, 1957: 250)

\footnotetext{
7 The distinction between the formal and substantive meanings of the economic implies a dichotomy between, on the one side, the abstract and ahistorical Market seen as an impersonal force and its metaphoric Hand - representing its "natural" and formal laws constructed by liberal theorists of natural law and neoclassical economists - and, on the other, the empirical and historically-situated markets as institutions within which diverse hands (i.e. individuals and groups) and their converging and conflicting material and ideal interests interact.
} 
Accordingly, at its most basic level, the Polanyian framework considers the economic as a constituent of the reality of society, both in historical societies and under the modern capitalist market system. ${ }^{8}$ Through historical and anthropological comparative studies (see Polanyi et al., 1957b), Polanyi (1977: 35) thus distinguished four institutional modes of economic integration (reciprocity, redistribution, exchange and autarchy) defined as "the institutionalized movements through which the elements of the economic process from material resources and labour to the transportation, storage and distribution of goods - are connected." Simply put, from the Polanyian perspective, there is no such thing as a "free market"; the economic realm has never been autonomous, not even under the capitalist market system.

As Polanyi (1944) showed in The Great Transformation, the long historical construction of the first market economy in England from late $16^{\text {th }}$ to mid- $19^{\text {th }}$ centuries required the constitution of a market society through constant political and legal interventions. Often misinterpreted, the Polanyian analysis of the "Great Transformation" actually posited that the self-regulating market is an utopian representation (Block and Somers, 2014; Plociniczak, 2007). As Polanyi stated (1944: 3), a self-adjusting market "could not exist for any length of time without annihilating the human and natural substance of society." From the Polanyian perspective, the history of the attempted institutionalization of the self-regulating market utopia is the history of the active, forced, destabilizing, potentially destructive and necessarily incomplete commoditization of land,

\footnotetext{
${ }^{8}$ Through the substantive conception, the Polanyian institutional analysis considers the economic as a constituent of the "reality of society" understood as the interdependence between individuals and societies or "persons and institutions," the co-constitutive nature of the material and the symbolic - their connections and interactions - and the political-legal construction and maintenance of economic and market practices and institutions (Block, 2001; Block \& Somers, 2014; Plociniczak, 2007). For more details on Polanyi and the idea of reality of society, see Block and Somers (2014: 218-240).
} 
labor and money - the three basic fictitious commodities - through policies and legislation. This history is also the history of the counter-movement of society's selfprotection against this destabilizing and potentially destructive utopian project (Block and Somers, 2014; Plociniczak, 2007). Through the historical analysis of the constitution and regulation of the fictitious commodities, Polanyi hence debunks the myth of the "liberal creed" by shedding light on what he calls the double movement.

On the one hand, the laissez-faire movement and its will to institutionalize the self-regulating market utopia by fictitiously constituting the empirical forms of nature, human life, and the political institutionalization of society as commodities requires constant and growing state and legislative interventions - not mere administrative processes - as capitalists themselves seek the certainty and stability of profit-making. ${ }^{9}$ On the other hand, the utopia of the self-regulating market and its disruptive consequences for nature, human life, money and society as a whole (social dislocations, growing inequality, speculation, wars, ecological destructions, etc.) triggers protective countermovements: working class, women and social movements, labor laws, social insurance and the welfare state, anti-trust laws, etc. Polanyi moreover warns against the dangerous counter-movements - first and foremost authoritarian regimes and ultimately totalitarianism - representing reactions to the self-regulating market utopia threatening democratic institutions and individual freedoms. Hence, as Polanyi (1944: 147) concluded, "[w]hile laissez-faire economy was the product of deliberate state action,

9 As Polanyi (1944: 147) explained, "[j]ust as, contrary to expectation, the invention of labor-saving machinery had not diminished but actually increased the uses of human labor, the introduction of free markets, far from doing away with the need for control, regulation, and intervention, enormously increased their range." 
subsequent restrictions on laissez-faire started in a spontaneous way. Laissez-faire was planned; planning was not."

Against the standard embeddedness-centered interpretation of Polanyi's approach due to the major influence of new economic sociology (see Granovetter, 1985), ${ }^{10}$ a recent renewal of the Polanyian institutional analysis has begun focusing on the political and legal constitution of the economy in general and markets in particular (see Block and Somers, 2014; Frerichs, 2009; Plociniczak, 2007; Veitch, 2013). For example, it has recently been suggested that "regulation is constitutive for insurance markets." (Mabbett, 2015: 25). Building on these new interpretations of the Polanyian institutional analysis, the following dissertation moves one step further as it conceptualizes one of the theoretical pillars of The Great Transformation in order to develop a novel framework for the sociology of insurance at the intersection of economic sociology, sociology of law and historical institutionalism. Through the core concept of insurance risks as fictitious commodities, the Polanyian institutional economic sociology herein developed provides a framework for the sectoral analysis of capitalism in general and of the insurance industry in particular. Defining markets as politically and legally constituted institutions, this Polanyian framework investigates the three components of the theory of the institutional constitution of insurance markets: (1) the necessarily incomplete and destabilizing institutionalization of the self-regulating market utopia; (2) insurance risks as fictitious commodities; and (3) the diversity of the institutional modes of economic integration.

First, Polanyian commentators have so far failed to notice that Polanyi's diagnosis of the necessarily incomplete and destabilizing institutionalization of the self-regulating

\footnotetext{
${ }^{10}$ For more details, see Subsection 2.2.1.C.
} 
market utopia can be understood as providing the implicit bases of a theory of the institutional production of uncertainty. Instead of shedding light on uncertainty through either production (Marx) or innovation (Schumpeter), the Polanyian framework builds upon Keynesian insights and considers that power and institutions must be the independent variables in the study of uncertainty. Through the analysis of this first process of the institutional constitution of insurance markets, light is shed on the epistemic forms of the self-regulating market utopia, their incomplete and destabilizing institutionalization, and the gaps between these forms as abstract representations of the functioning of markets and the reality of the political-legal constitution of markets as institutions. As a result, the institutional interventions and arrangements seeking to eliminate, control, reduce, and capitalize various uncertainties are brought into the analytical foreground.

Second, as Polanyi (1944) pointed out, the fictitious commodities' underlying empirical forms - nature, human life and the political institutionalization of society - are not and cannot be produced for sale on the market. In other words, the production, distribution and regulation of these underlying empirical forms cannot be totally privatized and commodified. Privately capitalizing a fictitious commodity intrinsically generates instability at best, and destruction, at worst. Interestingly, uncertainty represents the insurer's "raw material." The classification, pricing and underwriting of insurance risks presume that insurers objectify the underlying uncertainties as a given level of capital against which a promise of future indemnification or reimbursement is offered, notwithstanding the specific nature of the covered uncertainty (see Ericson and Doyle, 2003; Ewald, 1986). As François Ewald (1991: 199) famously pointed out, 
"[n]othing is a risk in itself; there is no risk in reality. But on the other hand, anything can be a risk [...] insurance is first and foremost a schema of rationality, a way of breaking down, rearranging, ordering certain elements of reality." The gap between the potential pains, losses and damages experienced as empirical uncertainties and the actual injuries and illnesses, thefts, accidents or any other covered occurrences, and their indemnification or reimbursement as capital is indeed a source of both symbolic and material conflicts between the insurer and the insured.

But this basic conflict between the insurer and the insured stems from the fact that the uncertainties underlying insurance risks are initially generated and mediated in wider institutional and societal settings, out of the scope of private insurance governance. Before being institutionally mediated as insurance risks, these uncertainties are substantive since they are empirically experienced in the non-insurance world through various extra-insurantial modes of perception, organization and provisioning. From the Polanyian perspective, the uncertainties experienced by individuals and threatening social provisioning, nature, the political institutionalization of society and the market economy - both at the firm and macro-economic levels - provide a quasi-infinite array of uncertainties which private insurers can capitalize. As a matter of fact, business and technological innovations, as well as the growth of third-party markets requiring insurance coverage, lead to the expansion of insurance profit opportunities (see Strange, 1996: 130-1). While different non-private insurance institutions and arrangements can perform the removal, reduction and control of substantive uncertainties, the financial and organizational incentives the insurance industry deals with nonetheless prevent insurers from seeking the complete removal of the uncertainties they cover as insurance risks. 
Moreover, the insurer's private governance cannot autonomously ensure the specific levels of uncertainty reduction and control it requires in order ensuring the relatively stable and profitable capitalization of the underlying uncertainties.

Under these conditions, the private capitalization of substantive uncertainties through their necessarily destabilizing and incomplete or fictitious commoditization as insurance risks - depends on the political-legal and non-competitive control and reduction of uncertainty. Through its core concept of insurance risks as fictitious commodities, the theory of the institutional constitution of markets allows us to study a second process, vital to the insurance industry: the institutional mediation of substantive uncertainties into insurance risks. The concept of insurance risks as fictitious commodities highlights the gap between "insurance risk" as the organizing principle of private insurance governance and its destabilizing and uncertainty generating attempt at autonomously covering and commoditizing empirical uncertainties, on the one side, and the necessary political and legal constitution of insurance markets as institutions, on the other. With or without available and robust actuarial data and extra-actuarial knowledge, it is not sufficient for the insurance industry to privately organize and commoditize uncertainties through risk classification and contractual incentive-based controls, and to financially hedge and spread these uncertainties as insurance risks onto reinsurance and financial markets. Private insurers have to collaborate with legislators, policy-makers, regulators, and with each other in order to ensure the relative stabilization of their capitalization over substantive uncertainties they cover as fictitiously commoditized insurance risks. 
In this sense, the concept of insurance risks as fictitious commodities points to the third process in the institutional constitution of insurance markets: the decommoditization and individualization of insurance risks. The constitution of insurance markets can require the unloading of insurance risks as empirical uncertainties on individuals, institutions and throughout the citizenry. The status of private insurance risks as fictitious commodities leads to the analysis of the constitution of insurance markets as relying on the diversity of the institutional modes of economic integration (private exchange, reciprocity-mutuality, redistribution-intervention and relative autarchy) necessary for the decommoditization of insurance risks. The fictitious commoditization of insurance risks thus also means that the integrity of private insurers' capitalization of the underlying substantive uncertainties can entail the decommoditization of insurance risks - generally those insurance risks deemed as "bad," "high" or even "uninsurable" by insurers through redistributive and reciprocal-mutual institutional interventions and arrangements.

Furthermore, the status of insurance risks as fictitious commodities can lead insurers to unload risk directly on individuals, hence compelling the insured to resort to out-of-pocket expenses in place of insurance indemnity or reimbursement. Forcing the insured to resort to relative autarchy, the individualization of insurance risks can occur ex ante - through decisions of uninsurability, contractual exclusions and incentive-based controls (i.e. deductibles, co-payments co-insurance and maximums) - or ex post, in situations in which the insurer determines that specific conditions and circumstances authorize denying a claim. The individualization of insurance risks can ultimately 
represents one of the signals that the state as the insurer of last resort must or will jump in and intervene as a market maker.

\subsection{Research design}

To sum up, the concept of insurance risks as fictitious commodities points to politicallegal interventions and other non-competitive institutional arrangements the insurance industry depends on in order to profitably cover substantive uncertainties as insurance risks within institutionally constituted markets. In accordance with the theory of the institutional constitution of markets, this dissertation raises the following general question: which political-legal interventions and other non-competitive institutional arrangements contribute to ensuring the constitution of insurance markets?

On the theoretical level, Polanyian institutional economic sociology seeks to contribute to socio-economic discussions of uncertainty and risk by clarifying the nature of and the relationships between these concepts through a better understanding of the functioning of the insurance industry. On the empirical level, the role of public institutions in insurance markets and the interplays between the various institutional modes of economic integration and their constitutive function for insurance markets are brought into the analytical foreground.

By throwing light on insurance risks as fictitious commodities, the theory of the institutional constitution of insurance markets is equipped with an analytical apparatus enabling the empirical evaluation of the impacts that the institutional arrangements required by the private insurers' capitalization of specific uncertainties have on individuals, institutions and citizenries. On the one hand, it reveals that insurance markets 
generate instabilities, and investigates how public institutions, social movements, and individuals bear, manage or resist these uncertainties. On the other hand, the study of the institutional constitution of insurance markets through the diversity of institutional modes of economic integration enables the comparative assessment of the extent to and the ways in which each modes of integration either promote or prevent the removal, reduction or control of the covered uncertainties.

Chapter 2 first presents an assessment of the current state of the emerging field of sociology of insurance. It argues that this literature - and especially the insurance-asgovernance approach and Weberian economic sociology - has neglected to focus on the complex relationships between private insurers and public institutions. Chapter 2 then goes back to classical sociology and to the institutionalist tradition in order to the lay the basis of a novel theoretical framework for the sociological study of private insurance. After having discussed the shortcomings of the dominant frameworks in contemporary economic sociology, it points to the limits of both Marx and Weber in the analysis of institutions before presenting Durkheim's and Veblen's foundational contributions to institutional economic sociology. Chapter 2 concludes with a discussion of the recent reinterpretations of Polanyi's institutional analysis as the theoretical basis of an institutional economic sociology of private insurance.

Chapter 3 aims at developing a theoretical framework in order to overcome the main neglect in the emerging sociology of insurance literature: the study of the institutional constitution of insurance markets. Building on socio-legal studies of private insurance, Chapter 3 starts by formulating a critique of the orthodox moral hazards paradigm and rather defends the alternative moral risks paradigm provided by the 
ethnographic sociology of private insurance as the adequate representation of the insurantial relationship. Following the recent wave of post-embeddedness Polanyian literature, Chapter 3 then undertakes a reconstruction of the core conceptual apparatus of The Great Transformation (Polanyi, 1944) in order to develop a theoretical framework for the sectoral analysis of capitalism in general and insurance markets in particular. A Polanyian theory of the institutional constitution of insurance markets is formulated through the Polanyian concepts of the necessarily incomplete and destabilizing institutionalization of the self-regulating market utopia, insurance risks as fictitious commodities and the diversity of the institutional modes of economic integration. Chapter 3 ends with a presentation of specific research questions, hypotheses, the methods and methodologies employed, and a brief discussion of the nature of the data analysed in the historical analysis (Chapter 4) and the central case study (Chapter 5) through which this dissertation operationalizes the theory of the institutional constitution of markets and the concept of insurance risks as fictitious commodities.

The analytical relevance of the theory of the institutional constitution of markets can be demonstrated both by its capacity to shed light on the historical development of private insurance and to investigate current issues and dynamics in the insurance industry. By reconstructing the historical construction of insurance law through the institutionalization of the insurable interest principle in England between the late $17^{\text {th }}$ and the late $18^{\text {th }}$ centuries, Chapter 4 reveals the modern origins of the insurance industry and shows that more than three quarters of a century before the first explicit formulation of the moral hazard paradigm as the insurance version of the self-regulating market utopia, private insurance governance already proved unstable and uncertainty generating. In the 
current context of the growing public debates over the sustainability of prescription drug coverage in Canada, Chapter 5 presents the central case study of this dissertation and analyses how the Canadian prescription drug insurance market responds to the new nichebuster pharmaceutical business model featuring the rise of high costs specialty drugs. In doing so, the theory of the institutional constitution of markets provides a better understanding of the interactions between private and public insurance coverage and of the interplays between the diversity of the institutional modes of economic integration in the context of the emergence of uncertainty in the Canadian prescription drug insurance market.

As a historical primer for the theory of the institutional constitution of insurance markets, Chapter 4 brings into focus the legal aspect of the constitution of private insurance through the lens of the historical institutional method. In doing so, it first offers a concrete illustration of the Polanyian critique of the economistic fallacy and aims at debunking the ancient origins of insurance thesis defined as the assumption that private insurance originated as marine insurance in ancient history. Second, building on the social and economic history of insurance literature, Chapter 4 reconstructs the process through which the insurance industry originated between the late $17^{\text {th }}$ and late $18^{\text {th }}$ centuries within the novel English commercial and financial system. Against the ancient origins thesis, a Polanyian institutional analysis of the historical construction of insurance law in England from 1664 to 1774 reveals the modern origins of the insurance industry. It is only in late $17^{\text {th }}$ century emerging English financial capitalism that insurance emerged by gaining its autonomy under novel institutional arrangements: the primacy of private property and the first modern financial system. 
The theory of the institutional constitution of markets allows a reconstruction of the 110-year-long process through which private insurance emerged as a relatively autonomous business in England by virtue of the legislative institutionalization of the insurable interest principle. By requiring that the beneficiary of the insurance coverage can demonstrate an objective financial or emotional interest in the insured property or life, the insurable interest principle allowed for the political-legal recognition of insurance against widespread insurantial speculation and especially against gambling over human lives. Chapter 4 highlights that the insurance industry emerged as a politically and legally constituted institution before slowly incorporating actuarialism and getting increasingly corporatized by the mid- $19^{\text {th }}$ century. It moreover claims that more than a century before the first formulation of the moral hazard paradigm by the insurance industry as the insurance version of the self-regulating market utopia, financial sector insiders, political and legal actors, and even members of the English public were already implicitly aware that the moral risks conception better describes the nature of the insurantial relationship and that private insurers were themselves a major source of destabilization of the insurance industry. From its origins, private insurance governance proved unstable and uncertainty generating, and hence required political-legal interventions and non-competitive institutional arrangements in order to ensure its own integrity.

I chose the case of prescription drug insurance coverage in Canada as the central study to examine my research questions. This contemporary case study provides an opportunity to observe a changing insurance market. Despite the fact that health and prescription drug insurers can easily compute actuarial data based on populational health 
statistics and probabilistic models, the Canadian prescription drug insurance market has recently been fundamentally destabilized due to the emergence of "bad" insurance risks generated by new, highly priced drugs for rare conditions. Over the past few years, various stakeholders have raised concerns over the sustainability of the Canadian fragmented public-private prescription drug coverage system (Gagnon, 2014; Morgan al., 2015), and especially of the private employer-sponsored health and prescription drug benefits group plans (CLHIA, 2013a; Coughlin \& Associates Ltd., 2013). These concerns, formulated by health policy academics, health sector unions, healthcare professional associations, and even by the Canadian life and health insurance industry have fuelled growing public debates as to how to reform prescription drug coverage in Canada in the context of the shift from the old "blockbuster" pharmaceutical business model to the new "nichebuster" model. The new nichebuster pharmaceutical business model entails the rise of high costs specialty drugs, now representing the new structural driver of the overall growth in drug expenditures. Generating the emergence of new "bad" insurance risks from the point of view of the private insurance governance, these new specialty drugs constitute a major challenge for the Canadian patchwork system of hybrid public/private prescription drug coverage in general and for the Canadian life and health insurance industry in particular. In fact, the arrival of specialty medicines generates a crisis among the employer-sponsored private health benefits group plans offered and managed by the Canadian life and health insurers.

Presenting the central, present-day case study of this dissertation, Chapter 5 thus brings the political aspect of the institutional constitution of private insurance and the analysis of insurance markets as politically and legally constituted institutions into the 
analytical foreground through the lens of the political-legal institutional method. Its aims at finding how the Canadian prescription drug insurance market responds to the rise of the nichebuster pharmaceutical business model and the high cost of new specialty medicines. Through the lens of the theory of the institutional constitution of markets and the concept of insurance risks as fictitious commodities, it raises the following specific research question: which political-legal interventions and non-competitive institutional arrangements contribute to ensuring the constitution of the Canadian prescription drug insurance market in the context of the rise of high price specialty drugs? By answering this specific question, this central case study moreover attempts to provide answers to the secondary research questions formulated in Chapter 3 (Section 3.3.1).

Finally, Chapter 6 presents a summary of previous chapters, provides answers to research questions, discusses research results, and concludes on limitations and future research areas for the Polanyian institutional economic sociology of private insurance. 


\section{Chapter 2. Literature reviews: the emerging sociology of insurance and the oversight of the institutionalist tradition in contemporary economic sociology}

[The insurance industry] is hardly mentioned in texts on world politics; and in economics, the study of insurance is dominated by a few informed specialists, most of whom are ideologically committed to the value judgments of economic liberalism, putting the pursuit of free trade and untrammeled competition above all other possible policy objectives. [...]. Yet it is still generally true that the most widely read academic journals in social science, whether in economics or politics, pay little or no attention to the political economy of the insurance business as it is conducted in the real world. (Strange, 1996: 122-3)

Considering its pervasiveness in everyday life, economy and society, it appears surprising that social scientists have only recently begun to systematically study the insurance industry (Ericson et al., 2000; Strange, 1996). While Max Weber (1978: 569) mentioned the Lutheran resistance to insurance contracts and listed private insurance as a central institution in the development of limited liability and the secular corporation (ibid.: 347, 715, 720 and 725), classical sociologists have overlooked the insurance industry. John R. Commons (1921: 83-4), the father of American institutional economics, for its part regarded compulsory health insurance as a "sickness-tax on industry" and asserted the ability of private insurers to contribute to sickness prevention. Then, The Sociology of Life Insurance by Edward A. Woods (1928) was posthumously published, a book described as an "unusually clever bit of propaganda for life insurance" by American sociologist Everett C. Hughes (1930: 656). ${ }^{11}$ Fifty one years later, Rosemary Crompton (1979) presented in Sociology a Marxian analysis of the surge in insurance clerks union membership in the UK during the 1960s. The same year, Viviana Zelizer (1979) offered

\footnotetext{
${ }^{11}$ Edward A. Woods (1865-1927) dropped out of school at age 15 and joined his father at the Equitable Life Assurance Co. of the United States, now AXA Equitable (see Webb, 2011). In 1916, he joined the Carnegie Bureau of Salesmanship Research and, in 1919, he contributed to the first official insurance educative program with the creation of the Carnegie School of Life Insurance Salesmanship (now the University of Pittsburgh). Having created his own insurance agency by 1927, he became this same year the first president of The American College of Life Underwriters in Bryn Mawr (now the American College of Financial Services), founded along with economist and author of the first life insurance textbook Solomon S. Huebner (1882-1964). See also Zelizer (1979: 142).
} 
Morals and Markets, now a classic study of the cultural and moral legitimization of life insurance in the US during the $19^{\text {th }}$ century. Unfortunately, these contributions have remained isolated efforts as, for almost a century, no heterodox research agenda on the insurance industry has been developed.

On the one hand, this chapter aims at assessing the current state of the emerging field of the sociology of insurance. Part 2.1 does so by presenting the four main bodies of literature comprising this emerging field: socio-legal studies, economic and social history, risk society theory, and institutional ethnographic sociology. It argues that this literature has neglected to focus on the complex relationships between the insurance industry and public institutions. On the other hand, Chapter 2 seeks to lay the bases of a novel theoretical framework for the sociology of risk and insurance. Part 2.2 starts by presenting the shortcomings of the dominant frameworks in contemporary economic sociology: new economic sociology, the theory of performativity, and anglo-neo governmentality. It then quickly discusses the weaknesses of both Marx and Weber in the analysis of institutions before presenting Durkheim's and Veblen's foundational contributions to economic sociology and the institutionalist tradition. Finally, Part 2.2 concludes by building upon Polanyi’s (1944, 1977; Polanyi et al., 1957a) "institutional analysis" and on recent reinterpretations of the Polanyian approach (Block \& Somers, 2014; Plociniczak, 2007) as the theoretical bases of an institutional economic sociology of private insurance. 


\subsection{The emerging sociology of insurance}

Interestingly, the first systematic research agenda on private insurance outside of the orthodox economics and the actuarial discipline was produced by socio-legal (SL) scholars focusing on the gap between "law in the books and law in action." Starting with Hugh L. Ross' (1970) pioneering ethnography of automobile insurance adjusters, SL studies have shed light on various gaps between the socio-economic reality of private insurance and standard economic theory. By stressing that insurantial risk management produces power from the outside of public institutions, SL studies contributed to the development of the "insurance as governance beyond the state" approach (Baker, 2010), inspired more or less loosely by Michel Foucault's (1991) governmentality framework. Since the early 1990s, the economic and social history of insurance produced a second major body of literature laying the grounds for future sociological studies of private insurance (see below and Chapter 4).

In the past two decades, the sociology of insurance started to emerge through the debate over Ulrich Beck's private uninsurability principle. Against Beck’s (1992a, 2009) thesis suggesting that the private uninsurability of new catastrophic risks illustrates the advent of risk society, Ericson et al. (2004a, 2004c; 2003) developed the first ethnographic sociology of private insurance as an institution in North America and examined how insurers operate under extreme uncertainty and covers terrorism-related risks by turning to non-actuarial forms of knowledge, surveillance technologies, financial securitization and public-private collaborations. While Zelizer's Weberian approach has been recently pushed further (Chan, 2012b; Sarah Quinn, 2008), a new wave of insurance studies has built on the insurance as governance (IasG) framework and innovated by 
combining governmentality with critical international relation studies (Lobo-Guerrero, 2011, 2012) and performativity and actor-network theories (see Lehtonen, 2014; McFall, 2009, 2015a, 2015b, Van Hoyweghen, 2007, 2014; Van Hoyweghen \& Horstman, 2010). In contrast, Ericson et al. (2003) acknowledged that public institutions contribute in various ways to the construction and maintenance of the power of private insurance as governance.

Part 2.1 aims at both presenting these four bodies of literature - SL studies (or law \& society), economic and social history, risk society theory, and institutional ethnographic sociology - and discussing their contributions to the development of the sociology of insurance. This chapter's central thesis suggests that this literature has neglected to focus on the complex relationships between the insurance industry and public institutions. More specifically, this literature has mostly been influenced, in some cases implicitly, by Foucauldian and anglo-neo governmentality (ANG) frameworks and has tended to analyse "insurance as governance beyond the state." 12 This focus on IasG has led some authors to analyze the power of the insurance industry as a form of "entrepreneurial sovereignty" (Lobo-Guerrero, 2011) and even as "insurantial sovereignty" (Lobo-Guerrero, 2012) disconnected or at least relatively autonomous from state institutions, policy-making and legislation. It hence appears that the IasG approach has taken international political economist Susan Strange (1996) quite seriously; the diffusion of power in the global economy would entail the "retreat of the state" and the reduction of the authority of national and local public institutions. What follows suggests

\footnotetext{
12 Anglo-neo governmentality (ANG) studies (Burchell, Gordon, \& Miller, 1991; Dean, 1999; Miller \& Rose, 2008; Rose \& Miller, 1992) rests mainly on a radical constructivist interpretation of Foucauldian governmentality (Foucault, 1991, 2004a, 2004b). On Foucault and ANG, see Section 2.2.1.
} 
that IasG approach has overlook that economic activities in general and insurance markets in particular require institutional construction and maintenance.

\subsubsection{From socio-legal studies to the insurance-as-governance approach}

The foundational contributions of SL studies to the heterodox analysis of private insurance have first and foremost consisted in focusing on the "gap between law in the books and law in action" (Baker, 2010). Starting with Ross's (1970) pioneering ethnographic study of automobile insurance adjusters, SL scholars have provided evidence of the role of private insurers in the rise of out-of-court settlements and on the ways in which tort law is both shaping and shaped by liability insurance (Abraham, 2008; Abraham and Liebman, 1993). Other SL scholars have pointed to the "ideological effects of actuarial practices" (Simon, 1988). Simon (1987) and others have stressed that the actuarial and insurantial risk management produces power outside of the state's sphere of influence. O'Malley's (1991) study of Australian home insurance detailed the ways in which a network of domestic security has been constructed through the interplay between public policing bodies and private insurance adjusters. According to Baker (2010: 442), "O'Malley's research on the role of property insurers in governing security in the home represents what may well be the first field research self-consciously within what came to be known as the insurance-as-governance theoretical framework." Heimer's (1982) inquiry into the issue of access to the insurance market has observed discriminatory redlining based on racialized data used in insurance underwriting. ${ }^{13}$ Moreover, Glenn

\footnotetext{
13 "Prompted in part by the insurance market's retreat from the central city in the wake of civil unrest in the 1960s, this research has examined access to insurance largely through the lens of civil rights discourse" (Baker and McElrath, 1996: 232). This finding is noteworthy since it demonstrates that private insurance
} 
(2000: 780) pushed the critical analysis of insurance underwriting - also known as "risk classification" and "insurance exclusion" (see Chapter 3) - further by shedding light on the "myth of the actuary" defined as "a powerful rhetorical situation in which decisions appear to be based on objectively determined criteria when they are also largely based on subjective ones." 14

Finally, Tom Baker has been one of the most active scholars in the SL studies of private insurance. In the aftermath of the 1992 Hurricane Andrew, Baker and McElrath (1996) investigated how home insurance, as a "private safety net," contributes to the reproduction of inequalities through the process of disaster recovery. ${ }^{15}$ For Baker, private insurance risk management transfers responsibility in addition to risk by redistributing responsibility from individuals to insurance funds through risk-transfer choices (Baker, 2002: 33). ${ }^{16}$ Baker and Griffith (2007) also observed structural inequality within Directors' and Officers' (D\&O) insurance. "D\&O insurers do not provide corporate governance monitoring or other loss prevention services ex ante or defense cost management services ex post" (ibid.: 1800-1). D\&O insurance actually insulates

structures the lives of those who are excluded from the market, and not only of those already insured. The study of insurance redlining, in the case of homeowner insurance, has been furthered during the 1990s by SL scholars now taking into account the impact of public regulations and policies in correcting such discriminations (Squires, 1997a, 1997b). See Baker and McElrath (1997) and Squires (1997a).

14 Studying "the narratives that members of the insurance industry construct to depict certain groups as uninsurable", Glenn (2000: 779) warns regulators and citizens in concluding that "[t]he difference between the old era of underwriting and the current one is that the appearance of subjectivity has been hidden behind a process that appears objective, mitigating the denied applicants the opportunity to develop an awareness that they have been excluded on the basis of subjective opinions about their lifestyles." (ibid.: 793).

15 The authors found that "[p]rivate home insurance disproportionately benefits the relatively advantaged, who are more likely to be insured and who fare better in the insurance claims process. This means that disaster, whether individual or collective, increases the economic inequality existing in our society" (Baker and McElrath, 1996: 260).

16 See also Abraham (1986). 
managers "from shareholder[s'] challenge by the business judgment rule" (ibid.: 1842). ${ }^{17}$ Hence, in the end, one of Baker's most important contributions to the emerging sociology of insurance has been to shed light on different gaps between the socio-economic reality of private insurance and standard economic theory. He has moreover suggested to consider the SL studies of private insurance as the "Insurance-as-governance" framework (Baker, 2010).

\subsubsection{Economic and social history: between idealism and institutionalism}

Especially since the turn of the 1990s, economic and social historians have provided a second major body of research upon which sociologists of insurance could later build from. While an important, albeit almost unnoticed, debate over the origins of insurance took place during the early $20^{\text {th }}$ century, ${ }^{18}$ the economic and social history of insurance took off much later, for instance with Zelizer's (1979) seminal historical economic sociology of the emergence of private insurance in the US during the first half of the $19^{\text {th }}$ century. In Morals and Markets, Zelizer traces the process of ideological and cultural legitimization of the life insurance contract, slowly emerging as a "contemporary death ritual." While historians of statistics and probabilities have merely touched on insurance (see Desrosières, 1993; Hacking, 1975, 1990), others have focused on the development of statistical probabilities as a determinant factor in the emergence of actuarial insurance (Daston, 1987, 1988, Lobo-Guerrero, 2011, 2012). At the turn of the 1990s, this analytical emphasis on the role of rationality, science and probabilities in the emergence

\footnotetext{
${ }^{17}$ See also Baker and Griffith (2011).

18 See Boîteux (1968), De Roover (1945), Holdsworth (1917), Hoover (1926), Trenerry (1926) and Vance (1908). See de Roover (1945, p. 172) for a quick presentation of late $19^{\text {th }}$ century Italian, German and French historiography on the origins of insurance. See Chapter 4.
} 
of insurance has been superseded by major investigations into the institutional, organizational and legal development of insurance in the early modern English history. Historians have thus shed light on the birth of life insurance and the development of insurance law in Britain during the $18^{\text {th }}$ and $19^{\text {th }}$ centuries, ${ }^{19}$ on private insurers' role in the rise of British imperialism (Goeffrey Clark, 2010; Pearson, 2010b, 2012), on the centrality of fire insurance during the English industrialization, ${ }^{20}$ on Victorian British life insurers as the first fund managers and on Victorian actuaries (Alborn, 1994, 2002), as well as on the internationalization of British insurers and the development of reinsurance markets. ${ }^{21}$ This literature will be discussed and problematized in Chapter 4 in order to historically analyse the constitutive role of lawmaking in the modern origins of the private insurance business.

\subsubsection{The theory of risk society: the private uninsurability of catastrophic risks?}

Third, compared with the major contributions from SL scholars and historians to the heterodox study of private insurance, Ulrich Beck's theory of risk society should not be downplayed. Beck is a forerunner of the sociology of insurance by virtue of having addressed the fundamental issue of insurability (see Charbonneau, 2011). According to the risk society theory, the second half of the $20^{\text {th }}$ century is characterized by a shift from the "old" social risks of the first industrial and national modernity - quantified by modern institutions and mitigated by the welfare state - to the "new" global risks of the second

\footnotetext{
19 See Alborn (2009, 2010), Alborn and Murphy (2013a, 2013b, 2013c), Clark (1999, 2002), Kreitner (2000), O’Malley (2003), Pearson (1990, 1997, 2002b, 2010d).

${ }^{20}$ See Pearson (1993, 2002c, 2004, 2010a) and Pearson and Richardson (2001).

${ }^{21}$ See Borscheid and Haueter (2012), Pearson (1995, 2001, 2002a, 2010b, 2010c, 2012) and Pearson and Lonnborg (2008).
} 
modernity (i.e. industrial, technological, ecological, sanitary, and terrorism-related risks) (Beck, 1992b, 2009). For Beck (2006), and also for Strange (1996), the globalized political economy within which transnational firms operate and in which new risks emerge entails the "retreat of the state." In this new socio-historical context, a crisis of modern institutions would have occurred since these same institutions would now be unable to control the low frequency and high severity risks that they are themselves producing. In 1992, Beck has hence formulated a "private uninsurability principle" considered as the institutional indicator of the shift from the first to the second modernity. According to this principle, the insurance industry would actually refuse to insure the new type of global, irreversible and un-quantifiable catastrophic risks (Beck, 1992a). In other words, the private uninsurability principle claims that the technological risk calculated by techno-scientists, engineers and industries contradicts the potentially unlimited financial risk constructed and managed by private insurers. This thesis has however been in part debunked thanks to the institutional ethnographic sociology of private insurance (Ericson \& Doyle, 2004a, 2004c), hence triggering what must be considered as the "debate over the private uninsurability principle."

\subsubsection{The institutional ethnographic sociology of the insurance industry}

Building on a critical reading of the risk society theory, on SL studies, on the critical criminology of white collar crimes and on the institutional production of knowledge, Ericson et al. can be considered as the first sociologists of private insurance since Zelizer (1979), Crompton (1979) and Heimer (1982). Their pioneering research on the AngloAmerican insurance industry methodologically consists in an ethnography of institutions 
and is theoretically informed by an implicitly "institutionalist" version of the governmentality approach. In line with Glenn (2000), they have shed a first systematic light on the contradictions or "ironies" of private insurance: despite claiming to be based on mutualization as an organizational principle, private insurers' struggle for profitmaking can actually lead to the actuarial un-pooling or "deselection" of risks, to risk creation, to risk-taking, to "insuring the uninsurable" and to the creation of fraud (Doyle \& Ericson, 2010). Ericson et al. thus pointed out that the insurance industry should be considered as the locus of governance beyond the state in neoliberal societies and that a "great deal of what is attributed to the welfare state regarding moral risk creation, debt financing, and bureaucratic red tape can also be attributed to the insurance industry." (Ericson et al., 2003: 13). More than simply selecting risks and security technologies, the insurance industry moreover constructs risks while organizing the distribution of responsibility throughout citizenry and society as a whole. As a result of the insurantial risk management, the insurers' private practices reveal the morality of economic practices (Ericson et al., 2000).

Pushing further their institutional ethnographic sociology of the ironies of private insurance, Ericson and Doyle have then addressed the relationships between power and knowledge by focusing on the institutional production of knowledge. ${ }^{22}$ Against Beck's use of the private uninsurability principle in the case of terrorism (Beck, 2002), ${ }^{23}$ they have revealed the extent to which private insurance requires both actuarial and

\footnotetext{
${ }^{22}$ On the institutional production of knowledge, see for instance Haggerty et al. (2011).

23 According to Beck (2002: 41), terrorism-related risks are "uncontrollable risks" which "must be understood as not being linked to place, that is they are difficult to impute to a particular agent and can hardly be controlled on the level of the nation state. This then also means that the boundaries of private insurability dissolve, since such insurance is based on the fundamental potential for compensation of damages and on the possibility of estimating their probability by means of quantitative risk calculation."
} 
probabilistic ("scientific") as well as lay and speculative ("extra-scientific") forms of knowledge in order to construct insurability, since it is in the market of mediating uncertainty into measurable and known risks (Ericson \& Doyle, 2004a, 2004c). ${ }^{24}$ Moreover, Ericson and Doyle observed the privatization of justice and policing through the ways in which insurers privately construct and manage fraud. They showed how fraud “crackdown mostly deploys the notion that fraud is a 'crime' as a way to deny claims, particularly from less desirable customers, and to cut costs." (Ericson \& Doyle, 2004b, p. 122). More recently, Ericson and Doyle (2006) have observed that market misconduct and fraudulent practices such as deceptive selling and over-selling are actually institutionalized within the insurance industry.

\subsubsection{Partial conclusions: the insurance-as-governance approach}

Over the past few years, more economic sociologists and political economists have been stepping into the emerging field of the sociology of insurance. Quinn (2008) has traced the cultural and moral legitimization of secondary markets for life insurance settlements mainly through the transformation of the meaning of death. Horan's (2011) critical cultural study of the "actuarial age" in the postwar US addressed how actuarial practices and private insurers have contributed to the spread of neoliberal governance rationalities within the American culture. Combining International relations and critical security studies with the governmentality framework, Lobo-Guerrero $(2011,2012)$ has theorized

\footnotetext{
${ }^{24}$ More specifically, against Beck, Ericson and Doyle (2004a, 2004c) observed how an insurance market for terrorism-related risks is being constructed and maintained by taking into account precaution within uncertainty and risk knowledge, by preventively imposing private security and surveillance technologies within contracts, by relying on the state as an "insurer-of-last-resort," and by financially spreading risks within reinsurance and derivative markets (through financial securitization and the use of "catbonds").
} 
insurance as a biopolitical technology ensuring the security of "ways of life" based on political arithmetic and probabilistic rationality, and constituting a type of "entrepreneurial power" or "insurantial sovereignty" autonomous from sovereign power and external to public institutions. ${ }^{25}$ Another research axis has recently been developed both from the perspective of the governmentality approach and the actor-network theory $(\mathrm{ANT})^{26}$ focusing on the use of genetic data in life insurance risk classification and on the political aspect of the "calculating devices" within the underwriting process which requires the performativity of economic, managerial, accountancy, actuarial and medical knowledge (Van Hoyweghen, 2007, 2014; Van Hoyweghen and Horstman, 2010). ANT has also led to the analysis of insurance advertising materials through which both insurers and consumers construct the heterogeneous ontology of private insurance by picturing its value as both material and relational (Lehtonen, 2014). Finally, building on the politicalcultural (Fligstein, 2001) and varieties of capitalism (Hall \& Soskice, 2001) approaches, Chan (2012a, 2012b) investigated the comparative interplays between cultural resistance and political negotiations in the emergence of life insurance in historically non-capitalist countries such as Taiwan and China.

All in all, despite investigating new empirical sites, this recent wave of economic sociology and political economy of private insurance seems to have followed two main research paths. First, some have basically reproduced Zelizer's (1979) Weberian emphasis on the moral resistance to and the cultural legitimization of economic innovations, as if market construction mainly implied the removal or transformation of

\footnotetext{
${ }^{25}$ Lobo-Guerrero's Foucauldian approach to private insurance is generally complex and sometimes even difficult to interpret. It has nonetheless provided important insights into the history and political economy of the insurance industry. See Chapter 4.

${ }^{26}$ On ANT, see Callon and Latour (1991) and Latour (1991).
} 
cultural obstacles and impediments in order to succeed. Second, the Foucauldian governmentality and especially its radical anglo-neo version still appear as the dominant theoretical strands within the emerging sociology of insurance literature. Thanks to the emphasis on the power/knowledge interplay and to a theory of power as governance beyond the state, Foucauldian governmentality can be considered as the foundational framework for the sociology of insurance. But along with Weberian economic sociology and Beck's theory of risk society, governmentality studies and its hybrid versions are characterized by the inability to closely articulate the economic and the political in addressing the fundamental relations between private insurers and public institutions, including Law ("Droit"), legislation ("lois"), ${ }^{27}$ regulations and policy-making.

However, while Baker (2010) rightly describes SL studies as the "insurance-asgovernance" approach, he does not fully recognize the contributions of institutional ethnographic sociology. Despite being titled Insurance as Governance, Ericson et al.'s (2003) pioneering book contains numerous considerations for the role of the state in relation to the insurance industry. By implicitly bridging a moderate version of the governmentality framework with an ethnography of institutions, Ericson et al. did analyze private insurance as "the institution of governance beyond the state" (ibid.: 14), but also acknowledged the symbiotic relations between the insurance industry and public institutions:

The state is $[\ldots]$ entwined with the private insurance industry, helping to form the economic, social, legal, cultural, and political aspects of insurance as governance [...]. The insurance industry is a significant contributor of investment capital in the political economy, and its investment practices are regulated by the state. The state also regulates the fairness of risk pooling practices,

\footnotetext{
${ }^{27}$ On the distinction between "Law" as a legal system and specific "laws" as pieces of legislation, its absence in Anglo-saxon common law and its presence in continental European traditions, see Supiot (2007). Similarly, there is no English equivalent for "impôt" as a general category for "income tax," as distinct from specific "taxes."
} 
and the manner in which insurance policies are sold and claims are compensated, in order to shape how insurance functions as a social technology of justice. The state frequently collaborates with the insurance industry in joint ventures, for example, to form entire insurance markets or to partially underwrite specific risks. (ibid.: 7)

Unfortunately, Ericson et al. have not systematically investigated the insurers/state interplay; they have not shed light on the ways in which the state actually contributes to the constitution of the power of private insurance as governance. In order to better illuminate the empirical blind spots of the Weberian and Foucauldian approaches, Part 2.2 now examines the theoretical contributions of classical sociology and the institutionalist tradition to the analysis of the role of state and public institutions in the functioning of economies and markets.

\subsection{Contemporary economic sociology: overlooking the institutionalist tradition}

As shown above, Weberian and post-structuralist approaches (including governmentality, risk society, performativity and actor-network theories) to private insurance have neglected to articulate the economic and the political as analytical categories in the study of the fundamental relations between private insurers and public institutions. Surprisingly, Baker and McElrath's (1996: 231) diagnosis still holds true today, two years later: "[w]hile the contours of [the] relationship [between private and public insurance] are not well understood, it is nevertheless clear that the availability of market insurance strongly influences state or state-sponsored insurance and that the reverse is true as well." ${ }^{28}$ The previous review of the emerging sociology of insurance literature indeed revealed a need to study how state and public institutions contribute to the constitution of the insurance industry. Part 2.2 now seeks to lay the bases of a novel

\footnotetext{
${ }^{28}$ Furthermore, Baker and McElrath (1996: 231) add that insurance and liability are "two side of the same coin," private and public insurance are "two halves of one side of that coin."
} 
theoretical framework for the sociology of risk and insurance at the intersection of economic sociology, sociology of law and historical institutionalism. Of course, a similar project had already been undertaken more than a century ago as classical sociology - also considered as the "first economic sociology" (Gislain \& Steiner, 1995) - and the institutionalist tradition have long recognized the theoretical impossibility of disconnecting the political, the juridical and the institutional from the economic. ${ }^{29}$

In what follows, I first present the shortcomings of the dominant frameworks in contemporary economic sociology (CES): new economic sociology (NES), the theory of performativity, and anglo-neo governmentality (ANG). On the one side, I shed light on the hegemony of the Weberian and post-structuralist frameworks within CES. On the other, I propose to move beyond the revival of economic sociology since the early 1980s through NES (Granovetter, 1985), its over-emphasis on the Polanyian embeddedness metaphor and its failed attempt to transform it into a sociological concept. Second, going back to classical sociology and old institutionalism, I suggest to define sociology as such as "the science of institutions" (Mauss \& Fauconnet, 1901). I quickly discuss the weaknesses of both Marx and Weber in the analysis of institutions before presenting Durkheim's and Veblen's foundational contributions to economic sociology and the institutionalist tradition. Part 2.2 concludes by discussing Polanyi's (1944, 1977; Polanyi et al., 1957a) "institutional analysis" and the recent post-embeddedness reinterpretations of the Polanyian approach (Block \& Somers, 2014; Plociniczak, 2007) as the theoretical bases of an institutional economic sociology of private insurance.

\footnotetext{
${ }^{29}$ For a similar understanding of the "institutionalist tradition," see Steiner (2005a), and especially Chavance (2009) and Nau and Steiner (2002).
} 


\subsubsection{The shortcomings of contemporary economic sociology}

\section{a) Foucault and anglo-neo governmentality: the primacy of the economic?}

Among the three frameworks that have dominated economic sociology since its revival in the 1980s, anglo-neo governmentality (ANG) is basically never acknowledged as such in the sociological literature. Having laid the ground for novel studies of accounting, audit, management and insurance, ${ }^{30}$ ANG borrows mainly from Foucault's (2004a, 2004b) idea of governmentality and has been formulated and systematized under a strong poststructuralist version by Rose and Miller (1992). ${ }^{31}$ While Foucauldian governmentality has proved highly useful in analyzing the micro-physics of power, the power/knowledge interplay and subjectivation processes, it falls short in studying institutional constructions and arrangements. Foucault actually developed a post-structuralist approach focusing on what Marxian historian Bryan B. Palmer (1990: 112) describes as a discursive, centerless and pervasive concept of power. ${ }^{32}$ This can be partially explained by the general aim of Foucault's posthumous publications on governmentality, and perhaps of his whole philosophical enterprise: the critique of the model of sovereignty (see Grenier and

\footnotetext{
${ }^{30}$ See for instance Miller et al. (1986, 1990, 1991; 1991; 1987, 1993; 1992), Power (1999, 2007), Hatchuel et al. (2005) and O’Malley (1991).

31 See also Miller and Rose (1990).

32 On post-structuralism, see Dews (2007). On the one hand, Foucault's post-structuralism may actually be understood as a radical form of structuralism. Commenting L'archéologie du savoir and Les mots et les choses (Foucault, 1966, 1969), Lafontaine (2004, p. 108) suggests that Foucault radicalizes structuralism through his rejection of the subject and the emphasis on the idea of system. Observing similarities between the Foucauldian approach and cybernetics, Lafontaine (ibid.: 110; my trans.) notes that the "depoliticized, decentralized and totalizing conception of power elaborated by Foucault strangely resembles the cybernetic concept of control." She goes on to add: "In asserting that power 'is the way to describe a complex strategic situation in a given society,' [Foucault, 1976: 123] Foucault meets the cybernetics' model of relational logic. Not only is power depolitized, but the political becomes another way to wage war. [...]. In this sense, one can say that Foucault theoretically participates in the logic he is himself denouncing by enclosing the subject in networks of discursive relations." (ibid.: 110-11; my trans.). On the other hand, Foucault's poststructuralism can also be described as a radical form of constructivism (see Keucheyan, 2007).
} 
Orléan, 2007: 1167). ${ }^{33}$ This overarching theoretical concern led both Foucault and ANG to separate the economic from the political, on the one hand, and even to assert the primacy of the former over the latter. ${ }^{34}$

In Sécurité, territoire et population (STP) and Naissance de la biopolitique (NBP) (Foucault, 2004a, 2004b), "[w]hile Foucault claims to be mainly analyzing the history of governmentality, he is actually more interested in the issue of population, that is to say in the autonomy of society." (Grenier and Orléan, 2007: 1162; my trans.). Early in STP, facing classical liberalism's emphasis of the natural character of social phenomena, Foucault pursues his previous research concerns and insists on bio-power as the control of individual behaviors and bodies. At some point, the figure of Machiavelli's Prince thus constitutes Foucault's basis for understanding the emergence of governmentality. Later on, turning to economic liberalism and mainly to French Physiocrats, he begins to picture governmentality as a mode of power based on the instrumentalization of the knowledge of political economy and on the search for governmental self-limitation. Following Foucault's genealogy of governmentality understood as the "self-limited liberal government" (ibid.: 1179; my trans.),

far from constituting a destructive oppression, the primacy of the economy over the political represents the best possible guarantee for protecting the subject's independence. [...]. The argument essentially relies on the fact that economics, as a discipline, has no totality. Foucault finds the main elements of his analysis in F. von Hayek [sic] but also in the XVIIIe century thought and in political economy's 'denunciation [...] of the paralogism featuring the political

\footnotetext{
33 As will be seen, this is clearly the case in Sécurité, territoire et population and Naissance de la biopolitique (Foucault, 2004a, 2004b). For example, in Il faut défendre la société (Foucault, 1997), the juridical is fundamentally addressed as "a question of rights: on the one side, rights which have been ceded by the subject, which have been given up and, on the other, rights acquired by the sovereign, in the name of which the later exerts its authority." (Grenier \& Orléan, 2007: 1168; my trans.).

${ }^{34}$ In Grenier and Orléan's (ibid.: 1169) view, "[t]his renewed critique of the juridical does not lead to the total disappearance of sovereignty but to an analysis in which it now plays a peripheral role, as a background of no interest to the thinker. [...]. Sovereignty hence appears as a secondary dispositif, entirely conceived in order to serve government $[\ldots]$."
} 
totalization of the economic process.' Hence, the state appears remarkably blind [...]. (ibid.: 1180 ; my trans., emphasis added)

Numerous and major implications stem from this theoretical choice - that is to oppose the economic to the political, the juridical and the sovereign - which greatly diminishes the theoretical power of governmentality as a framework in economic sociology: namely, the exclusion of property rights, the contract and money (see ibid.). ${ }^{35}$

Refusing both universals and abstract objects since cognitive categorizations would supposedly be disconnected from empirical practices, Foucault's nominalist ontology - at least in STP and NBP - can be seen as being partly grounded in a theoretical credit implicitly given to the Hayekian theory of radical uncertainty. In Hayek's $(1944,1960)$ neoliberal theory, the market economy is considered as a complex system and its knowledge is struck by an insurmountable uncertainty: "it is by nature untotalizable" (Foucault, 2004a: 285; my trans.). ${ }^{36}$ As a result, for both Hayek and Foucault, "the state does not possess the cognitive means required for an effective intervention in the market economy." (Grenier \& Orléan, 2007: 1169; my trans.). ${ }^{37}$ In other words, by considering the competitive mechanism as essentially opposed to any type of intervention outside of the realm of private interests, Foucault refers to the

\footnotetext{
${ }^{35}$ First, the separation of the political from the economic allows Foucault to picture law as the antinomy of political economy; and this exclusion of legislation can be observed, for instance, in the absence of the question of property rights from Foucault's works (ibid.: 1159). Second, in refusing to articulate political economy and law, Foucault's analysis of liberal governmentality ends up opposing the market to the legal logic of the contract (see ibid.: 1169). Third, "[a]s a careful reader of the neoliberal thought, Foucault implicitly complies with [the] analysis [of money as a neutral veil]. Neither money nor currency can be found in the indexes. The close and proven links between money and sovereignty do not even catch Foucault's attention." (ibid.: 1171; my trans.).

${ }^{36}$ See Section 3.1.3.

${ }^{37}$ For Foucault, following Hayek, "[state intervention] stumbles over the market economy's complexity. As a result, the sovereign's aptitude in administering economic processes is radically disqualified, not because it does not possess the right to do so, but because it is out of its capacities: 'one cannot act since one does not know and one does not know since one cannot know' (NBP, p. 286)." (ibid.: 1169; my trans.). Foucault's Nietzschean influence is reveal here by the extent to which the French philosopher tends to corroborate a type of cognitive nihilism, at least in the case of the economic analysis.
} 
Hayekian model of the spontaneous or "cattalactic" order in approaching economic knowledge and political economy. In the Foucauldian perspective, "[n]ot only is state intervention unnecessary to the functioning of competitive regulation, but this intervention is inherently disruptive in nature. Foucault concludes this analysis with very strong statements concerning the worthlessness of economic sovereign [...]. $\mathrm{He}$ concludes that there is not such thing as an economic sovereign (NBP, p. 287)." (ibid.: 1170; my trans.). ${ }^{38}$ Furthermore, the Foucauldian nominalism and the analytical credit it confers to the Hayekian theory of uncertainty have provided the foundations of ANG's "problematics of government" approach to "political power beyond the state" (see Rose \& Miller, 1992).

ANG follows Foucault's nominalism and accepts the Hayekian distrust of the power, capabilities and resources of state, government and public institutions. Offering a quasi-apologetic appreciation of the neoliberal critique of Keynesianism and welfarism, ${ }^{39}$ Rose and Miller assert that "[g]overnment is a congenitally failing operation" (ibid.: 190). ${ }^{40}$ Claiming to innovate in approaching "political power beyond the state," ANG

38 According to Grenier and Orléan (ibid.: 1170; my trans.), "[t] $]$ his condemnation of exteriority and transcendence is not only limited to state action. It also targets any actor who would loose sight of its personal interest in order to seek a collective goal. [...]. If some actors would abandon this orientation and focus on the collective good, it could only be a source of abuses."

${ }^{39}$ Rose and Miller (1992: 198; emphasis added) actually refer to Hayek $(1944,1960)$ - as well as to Milton Friedman (1962) - and suggest that "[f]rom the mid-seventies onwards, [...], neo-liberal analyses began to underpin the appeal of conservative political programmes and pronouncements. [...]. Against the assumption that the ills of social and economic life are to be addressed by the activities of government, it warns against the arrogance of government overreach and overload. It counter-poses the inefficiencies of planned economies to the strength of the market in picking winners. [...]. Because 'the welfare state' depends on bureaucracy, it is subject to constant pressure from bureaucrats to expand their own empires, again fuelling an expensive and inefficient extension of the governmental machine." It thus appears that ANG also supports the Weberian theory of bureaucracy as a self-sustaining system.

${ }^{40}$ As they explain, "the sublime image of a perfect regulatory machine is internal to the mind of the programmers. [...]. Technologies [of government] produce unexpected problems, are utilised for their own ends by those who are supposed to merely operate them, are hampered by under-funding, professional rivalries, and the impossibility of producing the technical conditions that would make them work - reliable 
radicalizes and even naturalizes the Foucauldian notion of "liberal governmentality" defined as the self-limitation of government. The analytical focus is hence restricted to "governing at a distance": "Political forces have sought to utilise, instrumentalize and mobilize techniques and agents other than those of 'the State' in order to govern 'at a distance'; other authorities have sought to govern economic, familial and social arrangements according to their own programmes to mobilize political resources for their own ends." (ibid.: 180-1; emphasis added). ANG's nominalist ontology reduces reality to discursive constructions and hence defines government as "a problematizing activity: it poses the obligation of rulers in terms of the problems they seek to address." (ibid.: 181). Again following Foucault's depoliticized concept of power (see Lafontaine, 2004), Rose and Miller put forth an operational notion of the political, therefore reducing governing to problem solving.

This post-structuralist approach to power moreover opens the theoretical space for a neo-functionalist theory (see e.g. Luhmann, 1991). One need not over-interpret ANG and see in Rose and Miller's framework a complex world made out of systems each crossed by networks within which self-referential or autonomous entities pursue their own programmatic ends. ${ }^{41}$ For example, ANG suggests that the "[1]iberal government

statistics, efficient communications systems, clear lines of command, properly designed buildings, well framed regulations or whatever. Unplanned outcomes emerge from the intersection of one technology with another, or from the unexpected consequences of putting a technique to work." (Rose and Miller, 1992: 190).

${ }^{41}$ In explaining how governing occurs "at a distance," ANG seem to picture governing "agents," "entities," or "spheres" - it is unclear has to who governs what - as self-referential systems: "Yet entities and agents within governmental networks are not faithful relays, mere creatures of a controller situated in some central hub. They utilise and deploy whatever resources they have for their own purposes, and the extent to which they carry out the will of another is always conditional on the particular balance of force, energy and meaning at any time and at any point. [...]. Experts and academics will seize upon the tactical possibilities open to them and seek to deflect them to their own advantage." (Rose and Miller, 1992: 190). In addition, it is also important to point out that governing is thus not a matter of "personal" or "private" interests, but of specific "ends" and "purposes" in terms of problem solving. 
identifies a domain outside 'politics,' and seeks to manage it without destroying its existence and its autonomy. This is made possible through the activities and calculations of a proliferation of independent agents, including philanthropists, doctors, hygienists, managers, planners, parents and social workers." (ibid.: 180). In a neo-functionalist fashion, the farthest ANG goes in acknowledging any form of state and political power over economic practices and processes is limited to the regulation of the "economic environment." ${ }^{42}$ In the last analysis, ANG overemphasizes the function of ideas, knowledge and discourses within power relations and institutional arrangements. In other words, in accordance with Foucault's governmentality, ANG's nominalist ontology rests on an idealist epistemology according to which reality is constituted by discourses and ideas, for instance by economic knowledge. Consequently, the existence and construction of the economy would mainly be a matter of performativity:

In a very real sense, 'the economy' is brought into being by economic theories themselves, which define and individuate a set of characteristics, laws and processes designated economic rather than, say, political or natural. This enables 'the economy' to become something which politicians, academics, industrialists and others think can be governed and managed, evaluated and programmed, in order to increase wealth, profit and the life. (ibid.: 182; my emphasis)

For ANG, the state, the institutions and society as a whole do not possess in fine any ontological existence..$^{43}$

\footnotetext{
42 "Financial and economic controls established by central government set key dimensions of environment in which private enterprises and other economic actors must calculate." (ibid.: 189).

${ }^{43}$ ANG actually addresses a critique to "realism" in IR by refusing "to treat states as unified actors with considerable autonomy, ruling domestically and pursuing their interests upon the world stage by means of diplomacy and warfare." (ibid.: 176). It suggests that state "has no essential necessity or functionality. Rather, the state can be seen as a specific way in which the problem of government is discursively codified, a way of dividing a 'political sphere,' [...] from other 'non-political spheres' to which it must be related, and a way in which certain technologies of government are given a temporary institutional durability [...]." (ibid.: 176-7).
} 


\section{b) Callon and the theory of performativity: the network paradigm}

The theory of performativity represents one of the major approaches in CES. It perhaps constitutes the latest post-structuralist framework borrowed from economic sociology to have been applied to the study of private insurance. ${ }^{44}$ Inspired by the anthropology of sciences and techniques (or Science and Technology Studies) developed by ANT (see Callon and Latour, 1991), it focuses on the analysis of expert knowledge and technical devices produced by economics and required in the construction and functioning of markets (Callon et al., 2007; MacKenzie et al., 2007; Muniesa and Callon, 2009). First introduced in economic sociology by Callon (1998b), the concept of performativity has itself been borrowed from linguistics. "When extended and adapted to sciences, this intuition illuminates situations within which the object of scientific work is not simply observed or described, but modified, and even called into existence." (Muniesa and Callon, 2009: 289; my trans.). Based on the post-structuralist notion of network - a concept resulting from the hybridization of the structure and the market (Supiot, 2007: 69) -, the theory of performativity breaks with the institutionalist tradition in that it "leads to the refusal to use social categories (institution, convention, social norm, etc.) in the explanations it produces." (Brisset, 2014: 217; my trans.).

In ANT and performativity-inspired approaches, human institutions and institutionalizations as well as the subject and its agency tend to disappear through networked relations between various subject-object hybrids. In attempting to analyze how ideas "become real," the theory of performativity paradoxically disconnects ideas and

\footnotetext{
${ }^{44}$ See Van Hoyweghen $(2007,2014)$ and Van Hoyweghen and Horstman (2010).
} 
knowledge from their material, institutional and societal conditions of production. ${ }^{45}$ Under its radical version, the theory of performativity risks only describing the effects and circulation of ideas and knowledge. ANT indeed construes ideas and knowledge as "actants," thus conferring agency to non-humans instead of understanding why, when, by and for whom given ideas and knowledge are produced and institutionalized.

c) Granovetter and new economic sociology: overlooking the institutionalist tradition

Despite the influence of the theory of performativity and the growing recognition of ANG, the revival of economic sociology initially occurred mainly around the new economic sociology (NES) developed by Mark Granovetter since the turn of the 1980s. According to the Granovetterian framework, and due to the influence of Parsons's (1937) structural functionalism, the main task of economic sociology would consist in studying the embeddedness of economic actions within the "ongoing structures of social relations" (Granovetter, 1985: 481). On the one hand, NES borrows from Weberian methodological individualism a focus on the social contextualization of personal actions. On the other hand, it reduces social relations and structures to networks - following the idea of "weak ties" (see Granovetter, 1973) - and endeavors to analyze the social embeddedness of interpersonal economic relations in such networks. While it has become "the core concept - or lowest common denominator - of economic sociology" (Frerichs, 2009: 20), one can identify two main problems with this concept of embeddedness: its implications

\footnotetext{
${ }^{45}$ Concerning the influence of economic discourses on social phenomena, see Brisset (2012). On the
} institutional production of knowledge, see Haggerty et al. (2011). 
for the category of the economic and the excessive prominence it confers to interpersonal networks. ${ }^{46}$

First, NES's concept of embeddedness can be seen as "oxymoronic because, in speaking of the economic as (embedded in) the social, we suggest that they are at once distinct and the same. Perhaps more troubling is the potential of the concept of embeddedness to obscure the co-constitutive nature of the social and economic by presenting 'the social' as ameliorating the excesses of 'the market'." (Ashiagbor et al, 2013: 4). Second, NES hence tends to dissolve "the reality of market societies into interpersonal networks, and does not take into account the diverging interests" (Plociniczak, 2007: 209; my trans.). In fact, by putting emphasis on a weak and subjectivist concept of embeddedness, it neglects power relations and conflicting interests within markets. Furthermore, and as a result, "both formal economics and the standard [Granovetterian] interpretation of Polanyi tend to obscure the influence of political decisions and public laws over logics of action" (ibid.: 210 ; my trans.). ${ }^{47}$

\subsubsection{Classical sociology and the institutionalist tradition}

On the theoretical level, an institutional economic sociology of private insurance must challenge the orthodox, economistic, utilitarian and insurer-biased moral hazard paradigm (see Chapter 3). As a consequence, it must thus challenge methodological individualism, the network paradigm and, above all, the separation between the economic and the political found in Weberian and post-structuralist CES. The next discussion goes

\footnotetext{
46 To be fair, Granovetter recently admitted that he "rarely use[s] "embeddedness" anymore, it has become [...] stretched to mean almost anything, so that it therefore means nothing." (Krippner et al., 2004: 113).

${ }^{47}$ For a similar interpretation of the Polanyian idea of embeddedness as a metaphor, see Block and Somers (2014).
} 
back to classical sociology and the institutionalist tradition in order to build the theoretical bases of a Polanyian institutional economic sociology of private insurance. Against the materialist, marginalist, neoliberal and post-structuralist theories, such an approach reaffirms the reality of society and of its institutions and the political and juridical constitution of the economic. Building on some recent reinterpretations (Block and Somers, 2014; Plociniczak, 2007), I argue that the Polanyian framework enables us to construct a synthesis of the institutionalist tradition - mainly of Durkheim and Veblen - in line with the project of "the science of institutions" (Mauss and Fauconnet, 1901). Before doing so, Section 2.2.2 begins with a brief discussion of Marx's ambiguous contributions to the institutional analysis and then explains why Weber's theory must be rejected as inadequate in terms of the analytical requirements of the study of the institutional construction and maintenance of markets.

\section{a) Marx: an ambiguous institutionalist?}

On of the institutional economic sociology's first aims consists in asserting the centrality of positive law against the naturalistic (Ricardo), bio-demographic (Malthus), historicist (Marx) and economistic (Menger) concepts of law. ${ }^{48}$ From the perspective of the history of sociology, observers do not agree as to whether or not Karl Marx (1818-1883) should be considered as a founder of classical sociology, economic sociology and the institutionalist tradition. ${ }^{49}$ While Marx contributed to the institutional analysis by using the concept of relation instead of institution (Chavance, 2009: 85), he offered a rather

\footnotetext{
${ }^{48}$ A similar theoretical project is formulated by Supiot's (2007) approach to the "anthropological function of law."

${ }^{49}$ See for example the contrast between Chavance (2009) and Steiner (Gislain and Steiner, 1995; Steiner, 2005a; Steiner and Vatin, 2009), versus Fligstein (2001).
} 
ambiguous contribution. For instance, as often recalled, Marx "did not offer a theoretical analysis of the capitalist state to match the scope and rigour of Das Kapital. His work on the state comprises a fragmented and unsystematic series of philosophical reflections, contemporary history, journalism and incidental remarks." (Jessop, 2007a). This is perhaps why one of the most famous Marxian debates concerning state theory - the Miliband-Poulanztas debate - can be described as a "dialogue of the deaf." ${ }^{\text {"50 }}$ In order to move beyond this theoretical dead end, one could turn to two of Marx's most quoted passage.

In the first book of Capital, Marx appears to acknowledge the political-legal constitution of the economy by shedding light on the legislation over the working day's lenght. Commenting the Factory Acts of 1833, 1844 and 1847, Marx (1867: 178-179) suggests that

[t]he establishment of a normal working day is the result of centuries of struggle between capitalist and labourer. The history of this struggle shows two opposed tendencies. Compare, e.g., the English factory legislation of our time with the English labour Statutes from the 14th century to well into the middle of the 18th. Whilst the modern Factory Acts compulsorily shortened the working day, the earlier statutes tried to lengthen it by compulsion. Of course the pretensions of capital in embryo - when, beginning to grow, it secures the right of absorbing a quantum sufficit [sufficient quantity] of surplus labour, not merely by the force of economic relations, but by the help of the State - appear very modest when put face to face with the concessions that, growling and struggling, it has to make in its adult condition. It takes centuries where the "free" labourer, thanks to the development of capitalistic production, agrees, i.e., is compelled by social conditions, to sell the whole of his active life. His very capacity for work, for the price of the necessaries of life, his birth-right for a mess of pottage. Hence it is natural that the lengthening of the working day, which capital, from the middle of the 14th to the end of the 17th century, tries to impose by State-measures on adult labourers, approximately coincides with the shortening of the working day

\footnotetext{
${ }^{50}$ Representing the climax of the orthodox Marxists' discussions of state theory, the Miliband-Poulantzas debate featured Ralph Miliband and Nico Poulantzas, respectively representing instrumental Marxism and structural Marxism. At the risk of oversimplifying, in The State in Capitalist Society, Miliband (1969) defended an instrumentalist model of the capitalist state according to which the state constitutes an instrument of bourgeois class interests due to the class position of state agents and their close personal relationships with ruling classes. Against the instrumental theory, Poulantzas developed the structural theory suggesting that the state had no other function than protecting the capitalist mode of production, pointing to a coincidence between the interests of the ruling class and the state apparatus (see Poulantzas and Miliband, 1972). On the Miliband-Poulantzas debate, see Barrow (2002) and Jessop (2007a). On the different orthodox Marxian approaches to state theory, see Barrow (1993). For an interesting reading and systematization of Marx in terms of a sociology of the state, see Artous (2000).
} 
which, in the second half of the 19th century, has here and there been effected by the State to prevent the coining of children's blood into capital. That which to-day, e.g., in the State of Massachusetts, until recently the freest State of the North-American Republic, has been proclaimed as the statutory limit of the labour of children under 12, was in England, even in the middle of the 17th century, the normal working day of able-bodied artisans, robust labourers, athletic blacksmiths.

Thus seemingly recognizing that the conflict between capital and labor is mediated by the state and society as a whole and cannot be explained by some natural laws of the economy, Marx concludes that positive laws, and even individual capitalists, are in fine subjected to the inherent laws of the capitalist mode of production. Still commenting the Factory acts, Marx (1867: 178) adds:

Hence Capital is reckless of the health or length of life of the labourer, unless under compulsion from society. To the out-cry as to the physical and mental degradation, the premature death, the torture of over-work, it answers: Ought these to trouble us since they increase our profits? But looking at things as a whole, all this does not, indeed, depend on the good or ill will of the individual capitalist. Free competition brings out the inherent laws of capitalist production, in the shape of external coercive laws having power over every individual capitalist.

Marx's economism appears even clearer in the Contribution to the Critique of

Political Economy in which the concepts of economy and market are not problematized, as "production" constitutes the pivotal concept in the analysis of the material and natural mediations of human life. In a famous passage which greatly contributed to the orthodox materialistic reading of Marx (1859: 11-12), the economy is reified as the base - "the economic structure of society - the real foundation, on which rise legal and political superstructures and to which correspond definite forms of consciousness" (ibid.: 11) and the superstructure, that is the "legal, political, religious, aesthetic or philosophic" (ibid.: 12), is defined as the "ideological forms" of the underlying material conflicts. In other words, through the emergence of capitalism, Marx observes the

un-weaving of property relations from sovereign relations. Or, to use modern categories, the separation of economic power - where this specific relation of dependence, which Marx calls factory despotism, is structured - from political power: the sovereign relation crystallizes itself in a specific institution, the State, in the modern sense of the term (which does not mean that this state does not play a decisive role in structuring social relations, in this case, the wage relation). (Artous, 2000: 122; my trans.) 
To be fair, like Durkheim and Polanyi, Marx "challenges the self-evident quality of homo oeconomicus by demonstrating through anthropological [and historical] evidence the fundamentally social nature of human agency." (Block and Somers, 2014: 226). ${ }^{51}$ Perhaps due to his position as a direct witness of the intensity of the $19^{\text {th }}$ century industrial capitalism, Marx nonetheless tends to reduce political agency to capital/labor relationships and class conflicts.

\section{b) Weber: individual methodology and nominalism}

Like Durkheim and Veblen, Max Weber (1864-1920) considered historical investigation as a fundamental component of the sociological method. But unlike both Durkheim and Veblen, the Weberian approach to economic sociology "seeks to complement [classical] political economy" (Steiner, 2005: 9; my trans.). Weber also diverges from the other founders of classical and economic sociology by accepting to define the category of "the economic" from a subjective standpoint (Steiner and Vatin, 2009: 4). Three reasons thus lead to conclude that Weberian economic sociology is inadequate in studying the institutional construction and maintenance of the economy: Weber's defense of methodological individualism, his definition of economic activity, and the ensuing separation between "the economic" on the one side, and "the social" and "the political," on the other.

In terms of method, Weber's major contribution resides in the idea of the necessity for an "interpretative sociology." In order avoid empiricist reifications and

\footnotetext{
${ }^{51}$ On Polanyi's ambiguous relationship with Marxism, see Block and Somers (2014: 74-85). On Polanyi and Gramsci, see Burawoy (2003).
} 
before attempting to explain social phenomena, sociology and social sciences must interpret or "understand" (verstehen) the meaning that the actors give to their own behavior. According to Weber (1978: 4), "[s]ociology [...] is a science concerning itself with the interpretive understanding of social action and thereby with causal explanation of its courses and consequences. We shall speak of "action" insofar as the acting individual attaches a subjective meaning to his behavior." 52 But this foundational component of Weber's sociological method is closely connected with another essential feature of the Weberian approach: methodological individualism. Strongly inspired by Menger's (1883) marginalist theory, Weber accepts to approach social phenomena as involuntary results of aggregated individual actions, denouncing the treatment of "social collectivities, such as states, associations, business corporations, foundations, as if they were individual persons" (Weber, 1978: 13). ${ }^{53}$

First coined by Joseph Schumpeter (1908) - one of Weber's most famous student $^{54}$ - in describing the Weberian approach, methodological individualism represents a direct import from Mengerian marginalism, itself importing and naturalizing classical liberalism's theory of natural law (see Charbonneau, 2009). In other words, in consistency with the tradition of classical liberalism and in contrast to Durkheim and Veblen, Weber refuses to acknowledge that "the whole is bigger that the sum of its parts." In doing so, he rejects any form of subjectivity and agency to groups, institutions

\footnotetext{
52 "Understanding" is not the exact translation of the German term verstehen - closer to "interpretative understanding" or "grasping" - a problem comprehensively analyzed mainly in the German tradition, at least since Schmoller and then more explicitly by Weber, Simmel, Dilthey and their followers. On Weber's interpretative sociology, see Fulbrook (1978).

${ }^{53}$ For a comparative analysis of Weber's and Foucault's treatments of the "economic subject," see Steiner (2008a).

${ }^{54}$ Schumpeter (1909) was the first to use the term "methodological individualism" in English in an article publish in The Quarterly Journal of Economics.
} 
and societies: "in sociological work these collectivities must be treated as solely the resultants and modes of organization of the particular acts of individual persons, since these alone can be treated as agents in a course of subjectively understandable action" (Weber, 1978: 13). While the interpretative moment in the Weberian sociological method is definitely compatible with the institutional analysis, its methodological individualism appears in contradiction with the institutionalist tradition - from Schmoller, Durkheim and Veblen to Polanyi - and its recognition of the reality of society and its institutions. ${ }^{55}$

Methodological individualism hence leads Weber (ibid.: 63) to accept Menger's definition of economic activity as the rational action oriented "according to its subjective meaning, $[\ldots]$ concerned with the satisfaction of a desire for 'utilities' (Nutzleistungen). 'Economic action' (Wirtschaften) is any peaceful exercise of an actor's control over resources which is in its main impulse oriented towards economic ends." On the one hand, one could ask: should war be considered as being a purely "non-economic" activity? On the other hand, in accordance with this definition, Weber suggests that for an activity to be deemed as "social," the actor's behavior needs to be directed towards the behavior of another actor; hence the theoretical possibility of a non-social economic activity (ibid.). ${ }^{56}$ As Steiner and Vatin explain (2009: 5; my trans.):

All in all, like Durkheim, but without any discomfort, Weber observes that one cannot clearly produce a definition of the economy through a set of objective signs which would characterize a separate sphere of social activity. [...]. The concept of the economy is passive [or lifeless] and only the meaning that the actor - and not simply the economist or the sociologist economist grants to the issue of scarcity confers an economic nature to a particular event [...].

\footnotetext{
${ }^{55}$ For example, the Durkheimian idea of "pre-notions" (pré-notions) (see Durkheim, 1894), provides the bases for the constructive critique of Weberian nominalist "ideal-types."

56 As Steiner and Vatin (2009: 3) conclude, "[w]hile logically coherent, this argument appears however rhetorical since Weber does not provide any example to illustrate this case."
} 
Of course, Weber does not naturalize this category of economic objects, defined as useful and scarce goods in the same way as liberal economists do. But the Weberian sociological methodology and its definition of economic activity actually imply a separation between "the economic," on the one side, and "the social, "the political" and the "legal," on the other. Three examples of this disconnection appear throughout Weber's works.

First, Weber's historical theory of modernity understood as a process of rationalization and the ensuing disenchantment of the world - the "iron cage" of instrumental calculation and control - results in the analysis of law as a component of the "rational-legal authority," mostly disconnected from the possibility of some autonomous political forces and decisions. In his sociology of law, Weber (1978) considers that the process of legal rationalization must be explained by the tension between formal and material rationalities (Treiber, 2011: 60). However, as Sterling and Moore (1987: 74-5) point out,

[f]ormal rationality involves the application of explicit, universal rules. Weber argued that rules are not from a source external to the legal system; they are intrinsically legal. Here he neglects both the legislative function of rule-making, a political process, and the executive function of rule enforcement. This carries the idea of legal autonomy too far. To the extent that legal analyses emphasize the development of closed systems of rationality, it would follow that political, economic, and legal systems would have entirely separate spheres of logic. The reality of the overlap of logic and rationality in the three systems does not support this view.

In other words, Weber's approach to the rationalization of the modern world seems to restrict the sociological analysis of law to a component of the self-sustaining and quasi self-referential system of bureaucracy constituted by formal rationalization. It is as if bureaucracy's historical evolution could not be structured by historical contingency, human agency, power relations or, at the very least, by some finality of a different, "nonlegal" nature. 
Second, Weber's (1905) study of protestant ethics as the "spirit of capitalism" stems from an interpretative and cultural analysis, and claims to highlight "elective affinities" between the development of Protestantism and the emergence capitalism. Weber thus describes and interprets social reality but does not genuinely explain social interactions by considering, for example, political power and the evolution of institutional arrangements as explanatory variables in the birth of capitalism. ${ }^{57}$ Despite recognizing that ascetic Protestantism is instituted into actual individual practices, the Weberian study of the emergence of capitalism focuses on interpretation and neglects explanations. Third, and relatedly, Weber's methodological individualism implies the reduction of power to a matter of charismatic, traditional or legal-rational authorities. In a nutshell, the Weberian theory appears unable to acknowledge any other variables between personal leadership and systemic logics in the study of power and the political. Producing mostly descriptions and despite stimulating promises, the Weberian theory inadequately recognizes power relations and institutional arrangements as being at the heart of the construction and maintenance of economies and markets.

\section{c) Durkheim and Veblen: classical sociology and the institutionalist tradition}

In contrast to Marx and Weber, Durkheim and Veblen offered unequivocal and foundational contributions to the analysis of the institutional constitution of the economy.$^{58}$ Despite the absence of a proper political sociology ${ }^{59}$ and of considerations for

\footnotetext{
${ }^{57}$ See, in contrast, Carruthers' (1996) major book on the political construction of financial capitalism.

${ }^{58}$ It is worth mentioning that, for a matter of purpose, I will not discuss major contributions to the "institutionalist tradition" from other classical sociologists such as Georg Simmel (1858-1918) and Marcel Mauss (1872-1950), and of the leader of the "young" German Historical school, Gustav Schmoller (18381917).
} 
economic agency and change, the Durkheimian theory provides an analysis of the role of economic facts and institutions - for instance the division of labor (see Durkheim, 1893) - in constituting social bond and solidarity, and in the socio-legal foundations of economy (Steiner, 2005: 14-6). For Durkheim, law - whether penal or commercial - is societal by nature. Furthermore, Durkheim refuses to recognize the existence of an isolated "economic sphere" separated from the social, the political, the juridical and the religious. ${ }^{60}$

For its part, Veblen's evolutionary historical theory of institutions is built on a concept of institutions extremely similar to Durkheim's (Steiner, 2005a). ${ }^{61}$ However, in contrast to Durkheim, the Veblenian approach provides means to account for individual and collective agencies in the reproduction or transformation of institutional arrangements (Chavance, 2009; Steiner, 2005a). For example, Veblen's (1904) “theory of business enterprise" builds on a non-productivist and socio-legal understanding of the economy, capital and the firm, and hence enables economic sociology to move from the Durkheimian emphasis on the social bond (lien social) and to rather address the predatory strategies of business institutions over industrious activities and technologies ("workmanship") as well as over communities, under corporate capitalism. ${ }^{62}$ In other

\footnotetext{
59 While this is true, Durkheim did stress the centrality of professional groups and their political construction (see Didry, 1990; Steiner, 2015).

${ }^{60}$ This aspect of the Durkheimian ontological realism can be illustrated by Durkheim's theory of value and its refusal to distinguish between different, isolated forms of value: "Of course, there are different types of values, by they are species of a same kind" (Durkheim, 1911: 101; quoted in Orléan, 2009: 244; my trans.). For Durkheim, "[t]he authority which, in each values, commands by imposing its respect to individuals, constitutes what he calls 'society's moral power,' of which the Melanesian mana is an expression. The values share a same common base: they are all an expression of the obedience to the community." (Orléan, 2009: 223; my trans.).

${ }^{61}$ See Veblen (1899: 61).

${ }^{62}$ See for instance the contemporary Veblenian institutionalist approach Capital as Power, according to which "the total dollar value of capitalization maps the power that capitalists exert over society. Any given fraction of this totality denotes a corresponding, undifferentiated share of that power. Individual or groups
} 
words, the Veblenian empirical analysis of interested market practices and institutions investigates the corporate economy by shedding light on socio-institutional powers based on various intangible assets such as prestige, knowledge and state regulations, and crystallized in the institutional form of the corporation (see Gagnon, 2007). In the last analysis, both Durkheim and Veblen provide theoretical and analytical tools required in order to move beyond classical political economy's materialism and the subjectivism of both Weberian and neo-classical marginalist theories, first and foremost through the recognition of the institutional construction and maintenance of the economy.

\section{d) Polanyi before new economic sociology}

Despite diverging on various levels, Durkheim and Veblen shared the recognition of the reality of society and the ensuing refusal to treat "the economic" and "the social" as autonomous categories. Following Durkheim and Veblen, Karl Polanyi (1886-1964) later challenged the idea of the autonomous economy by analyzing "the always and everywhere embedded economy" (Block and Somers, 2014: 31). As Block and Somers (2014: 93) notes, Polanyi actually builds on and expands Durkheim's idea of the "noncontractual bases of contract."

Warning against its reduction to the Granovetterian analysis of the contextualisation of interpersonal relations within networks, Plociniczak (2007) suggests that the Polanyian idea of embeddedness represents a mere metaphor and ultimately refers to the institutional arrangements necessary to the existence and functioning of any

of capitalists secure their claims through particular organizations, institutions and processes, so the content of their power is always qualitatively unique. But because this power is exercised over society as a whole, its form can be quantified in universal monetary units; that is, as claims on the entire process of social restructuring." (Nitzan and Bichler, 2009: 311). 
form of economy. ${ }^{63}$ The Polanyian institutional analysis actually stems from the recognition of the "reality of society" - that is to say the interdependence of individuals and societies or "persons and institutions" -, the co-constitutive nature of the material and ideal interests and the political-legal construction and regulation of economic and market practices and institutions (Block, 2001; Block and Somers, 2014; Plociniczak, 2007). ${ }^{64}$ While the following discussion presents Polanyi's general approach, a Polanyian institutional economic sociology, and its concept of fictitious commodity, will be presented as a theoretical framework for the study of insurance markets in Chapter 3.

Drawing on economic history and anthropology, the Polanyian approach builds on the diagnosis and denunciation of the "economistic fallacy," defined as the conflation of the economic activity as a whole with the market form and the retrospective application of this fallacy across time and space. ${ }^{65}$ Against this "double error" (Steiner

${ }^{63}$ As Plociniczak (2007: 242) explains, the embeddedness metaphor is used only twice in The Great Transformation; while its first usage refers to the interpersonal dimension of the three forms of institutional integration - reciprocity, redistribution and exchange - it then designates the ways in which institutions both constitute markets and allow for their functioning. Interestingly, throughout Polanyi's works, "embeddedness" is translated into diverse terms such as "submerged," "absorbed," "subordination," "enclosed," "enmeshed," and "interwoven" (see ibid.: 208). It is worth mentioning that the following definition of Polanyi et al.'s (1957b: 242) "institutional analysis" might have constituted a source of ambiguity - perhaps due to the use of the past tense - concerning the idea of embeddedness: "We must rid ourselves of the ingrained notion that the economy is a field of experience of which human beings have necessarily always been conscious. To employ a metaphor, the facts of the economy were originally embedded in situations that were not in themselves of an economic nature, neither the ends nor the means being primarily material. The crystallization of the concept of the economy was a matter of time and history. But neither time nor history have provided us with those conceptual tools required to penetrate the maze of social relationships in which the economy was embedded. This is the task of what we will call institutional analysis."

${ }^{64}$ On Polanyi and "the reality of society," see Block and Somers (2014: 218-240).

${ }^{65}$ In The Livelihood of Man, Polanyi (1977: 5-6) summarizes the economistic fallacy as follow: "[...] the central illusion of an age in terms of a logical error is rarely to the point; yet conceptually the economistic fallacy, $[\ldots]$, cannot be described otherwise. [...] the error was in equating the human economy in general with its market form (a mistake that may have been facilitated by the basic ambiguity of the term economic [...]). The fallacy itself is patent: the physical aspect of man's needs is part of the human condition; no society can exist that does not possess some kind of substantive economy. The supply-demand-price mechanism, on the one hand (which we popularly call the market), is a comparatively modern institution of specific structure, which is easy neither to establish nor to keep going. To narrow the sphere of the genus economic specifically to market phenomena is to eliminate the greatest part of man's history from the 
and Vatin, 2009) reproduced in both academic research and ordinary life, Polanyi suggests that the reduction of the economic to its market form constitutes the formal conception, in contrast to the substantive definition. While the formal concept is the product of rationalism, rests on a logical relation between means and ends, and conflates subsistence with scarcity, Polanyi states that the substantive meaning is a matter of empirical evidence, relates to the human dependence on nature and society and points to the connection of subsistence with recognition. ${ }^{66}$ These features defines the Polanyian idea of the human "livelihood" (Polanyi, 1957: 243). The distinction between the formal and substantive meanings of the economic implies a dichotomy between, on the one side, the abstract and ahistorical Market seen as an impersonal force and its metaphoric Handrepresenting its "natural" and formal laws and constructed by liberal theorists of natural law and neo-classical economists - and, on the other, the empirical and historicallysituated markets as institutions within which diverse hands (i.e. individuals and groups) and their converging and conflicting material and ideal interests interact.

Against the economistic fallacy, the recognition of the reality of society thus led Polanyi to define the economy as an "instituted process." ${ }^{97}$ Furthermore, through the comparative study of different historical types of societies (see Polanyi et al., 1957b),

scene. On the other hand, to stretch the concept of the market until it embraces all economic phenomena is artificially to invest all things with the peculiar characteristics that accompany the phenomenon of the market."

${ }^{66}$ According to Polanyi (1957: 244), "[1]aymen accepted this compound concept as a matter of course; as Marshall, Pareto or Durkheim equally adhered to it. Menger alone in his posthumous work criticized the term, but neither he nor Max Weber, nor Talcott Parsons after him, apprehended the significance of the distinction for sociological analysis. Indeed, there seemed to be no valid reason for distinguishing between two roots meanings of a term which, as we said, were bound to coincide in practice."

${ }^{67}$ More precisely, the economy as an instituted process means that "[t]he human economy, $[\ldots]$, is embedded and enmeshed in institutions, economic and noneconomic. The inclusion of the noneconomic is vital. For religion or government may be as important for the structure and functioning of the economy as monetary institutions or the availability of tools and machines themselves that lighten the toil of labor." (Polanyi, 1957: 250). 
Polanyi (1977: 35) distinguished three institutional modes of economic integration reciprocity, redistribution and exchange - defined as "the institutionalized movements through which the elements of the economic process - from material resources and labour to the transportation, storage and distribution of goods - are connected." ${ }^{98}$

Understanding the economy as an instituted process entails, for example, that there is no such thing as a "free market"; the economic has never been autonomous, not even under the modern market system. As Polanyi (1944) showed in The Great Transformation (TGT), the long historical construction of the first market economy in England from the late $16^{\text {th }}$ century to the mid- $19^{\text {th }}$ century required the constitution of a market society through constant political and legal interventions. ${ }^{69}$ Often misinterpreted, the Polanyian analysis of the "Great Transformation" suggests that the self-regulating market (SRM) is actually an utopian representation (Block and Somers, 2014; Plociniczak, 2007). In Polanyi’s (1944: 144) view, the "dogma of laissez-faire" is constituted by the three co-constitutive utopias of "competitive labor market, automatic gold standard, and international free trade." TGT indeed analyses how state institutions and political movements are located at the core of the four institutions characterizing the "Nineteenth-Century civilization": the balance-of-power system, the international gold standard, the liberal state and the idea of the SRM. The utopia of the SRM is thus key in understanding the crisis of the other three foundational institutions of the market economy since it would indirectly lead to the nightmares of WWI, the Great Depression of the 1930s and WWII.

\footnotetext{
${ }^{68}$ On these the institutional modes of economic integration, see Polanyi (1957: 250) and Chapter 3.

69 TGT is considered as "a classic exposition of heterodox institutional analysis" (Chavance, 2009: 28; Maucourant, 2005). For a critique of TGT, see for example Lacher (1999a, 1999b, 2007) and Steiner (2008b).
} 
For Polanyi (1944: 3), a self-adjusting market "could not exist for any length of time without annihilating the human and nature substance of society." As he explains, "[n]ot until 1834 was a competitive labor market established in England; hence industrial capitalism as a social system cannot be said to have existed before that date. Yet almost simultaneously the self-protection of society set in: factory laws and social legislation, and a political and industrial working-class movement sprang into being" (ibid.: 87). In other words, the history of the attempted institutionalization of the SRM is the history of the active and forced commoditization of land, money and labor - the three basic Polanyian fictitious commodities - through active political and legislative interventions. Hence, this history is also the history of the counter-movement of society's selfprotection against the destabilizing and potentially destructive utopian project of the SRM (Block and Somers, 2014; Plociniczak, 2007).

Understood as the three constitutive "fictitious commodities" of the market economy, "[1]abor is only another name for a human activity which goes with life itself $[\ldots]$; land is only another name for nature $[\ldots]$; actual money, finally, is merely a token of purchasing power [...]." (Polanyi, 1944: 75). ${ }^{70}$ Through the historical analysis of the constitution and regulation of the fictitious commodities, Polanyi debunks the myth of the "liberal creed" by shedding light on what he calls the "double movement." On the one hand, the laissez-faire movement and its will to institutionalize the SRM by fictitiously constituting human life, nature and money as commodities requires constant and growing

\footnotetext{
${ }^{70}$ For a detailed discussion of the Polanyian concept of fictitious commodity, and especially of the idea of money as a fictitious commodity, see Section 3.2.2.
} 
state and legislative interventions. ${ }^{71}$ As capitalists themselves seek the certainty and stability of profit-making, "the role of managing fictitious commodities places the state inside three of the most important markets; it become utterly impossible to sustain market liberalism's view that the state is 'outside' of the economy." (Block, 2001: xxvi) ${ }^{72}$ On the other hand, the utopia of the SRM and its disruptive consequences for land, money, labor and society as a whole (social dislocations, growing inequality, speculation, ecological destructions, etc.) triggers protective counter-movements throughout society: working class, women and social movements, labor laws, social insurance and the welfare state, anti-trust laws, and cooperative and social economy. Polanyi moreover warns against dangerous counter-movements - first and foremost authoritarian regimes and ultimately totalitarianism - representing reactions to the utopia of SRM posing a threat to democratic institutions and individual freedoms. As Block and Somers (2014: 10) explain,

Polanyi's always-embedded economy leads directly to his concept of the double-movement. As market fundamentalists and their allies attempt to construct their ideal world of a self-regulating market system, the destabilizing consequences set off countervailing movements by other groups in society who recognize the need to protect themselves and others from exposure to unmediated market forces. These countermovements are just as likely to be conservative, even populist and fascist, as market destabilizations will mobilize the right no less than the left, [...]. But in Polanyi's framework, [...], particular policy ideas create shifting constituencies of groups that favor or oppose expanding or constraining markets. And since the project of creating a selfregulating market is ultimately impossible, [...] the largest businesses will defect and openly embrace the use of government for protection against market turmoil.

\footnotetext{
71 "Just as, contrary to expectation, the invention of labor-saving machinery had not diminished but actually increased the uses of human labor, the introduction of free markets, far from doing away with the need for control, regulation, and intervention, enormously increased their range." (Polanyi, 1944: 147).

72 As Block (2001: xxvi-xxvii) adds, "[t]he fictitious commodities explain the impossibility of disembedding the economy. Real market societies need the state to play an active role in managing markets, and that role requires political decision making; it cannot be reduced to some kind of technical or administrative function. When state policies move in the direction of disembedding through placing greater reliance on market self-regulation, ordinary people are forced to bear higher costs. Workers and their families are made more vulnerable to unemployment, farmers are exposed to greater competition from imports, and both groups are required to get by with reduced entitlements to assistance. It often takes greater state efforts to assure that these groups will bear these increased costs without engaging in disruptive political actions."
} 
Hence this famous passage of TGT concerning the $19^{\text {th }}$ century market economy: "While laissez-faire economy was the product of deliberate state action, subsequent restrictions on laissez-faire started in a spontaneous way. Laissez-faire was planned; planning was not." (Polanyi, 1944: 147).

\subsubsection{Partial conclusions: classical sociology and the institutionalist tradition}

Three frameworks have dominated economic sociology since its revival in the 1980s. The most recent one, anglo-neo governmentality (ANG), has not yet been acknowledged as such in literature. ANG borrows mainly from Foucault's (2004a, 2004b) idea of governmentality and has been formulated under a strong post-structuralist version by Rose and Miller (1992). One of the main aims of Foucault's posthumous publications on governmentality consists in the critique of the model of sovereignty (Grenier and Orléan, 2007). This overarching Foucauldian concern leads both Foucault and ANG to separate the economic from the political, and to assert the primacy of the former over the latter. ${ }^{73}$ ANG rests on an idealist epistemology according to which reality is constituted by discourses and ideas, and in which the state, institutions and society as a whole do not possess in fine any substantial ontological existence.

Second, the theory of performativity (Callon, 1998b) has been highly influential in contemporary economic sociology (CES). In part informed by the actor-network

\footnotetext{
${ }^{73}$ The Foucauldian nominalist ontology is partly grounded in a theoretical credit implicitly given to Hayek's theory of radical uncertainty according to which "the state does not possess the cognitive means required for an effective intervention in the market economy." (Grenier and Orléan, 2007: 1169 my trans.). By considering the competitive mechanism as essentially opposed to any type of interventions outside of the realm of private interests, Foucault refers to the Hayekian model of the spontaneous or "catalectic" order in approaching economic knowledge and political economy. ANG follows Foucault's nominalism and accepts the Hayekian distrust of the power, capabilities and resources of state, government and public institutions.
} 
theory, it breaks with the institutionalist tradition in that it "leads to the refusal to use social categories (institution, convention, social norm, etc.) in the explanations it produces." (Brisset, 2014: 217; my trans.). By investigating how ideas "become real," the theory of performativity paradoxically disconnects ideas and knowledge from their material, institutional and societal conditions of production and confers agency to "nonhumans" instead of understanding why, when, by and for whom given ideas and knowledge are produced and institutionalized.

Third, since the 1980s, the revival of economic sociology first occurred around new economic sociology (NES) (Granovetter, 1973, 1985). As with the performativity theory, NES abandons the focus on institutions and rather turns to the study of networks. It borrows from the Weberian methodological individualism a focus on the social contextualization of personal actions. NES reduces social relations and structures to networks of "weak ties" and endeavors to analyze the social embeddedness of interpersonal economic relations within such networks. By putting emphasis on a Weberian and Parsonsian conception of the Polanyian embeddedness metaphor, NES neglects the power relations and conflicting interests within markets and obscures the role of the political and legal interventions in the economy (Plociniczak, 2007). "Perhaps more troubling is the potential of the concept of embeddedness to obscure the coconstitutive nature of the social and economic by presenting 'the social' as ameliorating the excesses of 'the market'." (Ashiagbor et al, 2013: 4).

In order to theoretically ground the institutional analysis of private insurance, it is hence necessary to overcome the oversight of the institutionalist tradition in CES by exploring the contributions of classical sociology as the "first economic sociology" (see 
Gislain and Steiner, 1995). First, while Marx can be said to be belonging to the institutionalist tradition (Chavance, 2009), he occupies a rather ambiguous position within it. In Capital, Marx (1867) seemingly recognizes that the conflict between capital and labor is mediated by the state and society as a whole, and cannot thus be determined by some natural laws of the economy. Marx nonetheless concludes that positive laws, and even individual capitalists, are subjected to the inherent laws of the capitalist mode of production. In the Contribution to the Critique of Political Economy (Marx, 1859), the economy is reified as the base and the ideological superstructure - including, the legal and the political - is defined as the "ideological forms" of underlying material conflicts. Perhaps due to his position as a direct witness of the $19^{\text {th }}$ century industrial capitalism, Marx tends to reduce political agency to the capital/labor relationships and to see in class conflict an historical law.

Second, three reasons point to Weber's sociology as inadequate for the study of the institutional construction and maintenance of the economy. (1) While the interpretative moment in Weber's sociological method is definitely compatible with the institutional analysis, the Weberian methodological individualism appears in contradiction with the institutionalist tradition. Following Menger's neo-classical theory, Weber conceives social phenomena as the involuntary results of aggregated individual actions. (2) Weber (1978: 63) hence accepts the Mengerian definition of the economic activity as a rational action oriented "according to its subjective meaning [...] concerned with the satisfaction of a desire for 'utilities"" and as "any peaceful exercise of an actor's control over resources which is in its main impulse oriented towards economic ends." (3) The Weberian sociological methodology and its definition of economic activity imply a 
separation between the economic, on the one side, and the social, the political and the juridical on the other. ${ }^{74}$

Third, in contrast with Marx and Weber, Durkheim and Veblen offered foundational contributions to the study of the institutional construction and maintenance of the economy. Durkheim and Veblen provide theoretical and analytical tools required in order to move beyond the materialism of classical political economy and the subjectivism of both Weberian and neo-classical theories, first and foremost through the recognition of the reality of society and its institutions. Moreover, Polanyi further developed such a research agenda around the mid- $20^{\text {th }}$ century, just as the first economic sociology had lost vigor in Europe and as Parson's structural functionalist reading of classical sociology was spreading in the US.

Finally, Section 2.2.2 ended by presenting recent non-Weberian and postembeddedness interpretations of the Polanyian institutional analysis. During the retreat of continental economic sociology between the 1930s and 1970s (see Gislain and Steiner, 1995), Polanyi (1944) was one of the few social scientists to clearly (re)assert the reality of society. In the 1980s, the revival of economic sociology occurred under the influence of Weberian sociology, of Parsonsian structural functionalism and later of poststructuralist philosophy. As a result, the more or less tacit acceptance of standard economics' theoretical hegemony over the economic would lead NES to both

\footnotetext{
${ }^{74}$ Three examples of this disconnection appear throughout Weber's works. First, the Weberian theory of modernity understood as a process of rationalization leads to a theory of law as part of the "rational-legal authority," disconnected from the possibility of autonomous political forces and decisions. The Weberian rationalization of the world seems to be reducing the analysis of law as a component of the self-sustaining and quasi self-referential bureaucratic system. Second, Weber's study of protestant ethics as the "spirit of capitalism" provides an interpretative and cultural analysis, but does not genuinely explain the birth of capitalism. Third, the Weberian theory of power appears unable to acknowledge any other variables besides personal leadership and systemic logics in the study of authority and the political.
} 
overemphasize and misinterpret the Polanyian idea of embeddedness. According to NES, the socio-economic analysis should focus on the ways in which the economic is embedded in and conversely disembedded from the social. For Polanyi, however, the term "embeddedness" actually represented a mere metaphor and ultimately referred to the institutional arrangements necessary to the existence and functioning of any form of economy. In fact, following Durkheim and Veblen, Polanyi actually challenged the idea of the autonomous economy by pointing to "the always and everywhere embedded economy" (Block and Somers, 2014: 31).

The Polanyian institutional analysis stems from the recognition of the "reality of society" - that is to say the interdependence between individuals and societies (or "persons and institutions") -, the co-constitutive nature of material and ideal interests and the political-legal construction and regulation of the economic practices and institutions. Against the economistic fallacy, the recognition of the reality of society thus led Polanyi to approach the economy as an instituted process. This definition entails that there is no such thing as a "free market": the economic has never been autonomous, not even under the capitalist market system. Furthermore, the Polanyian analysis of the "Great Transformation" actually suggests that the self-regulating market (SRM) constitutes an utopian representation (Block and Somers, 2014; Plociniczak, 2007). The history of the attempted institutionalization of the SRM utopia is the history of the active and forced commoditization of the fictitious commodities through policies and legislation, and hence of the counter-movement of society's self-protection against this destabilizing and potentially destructive utopian project. ${ }^{75}$

\footnotetext{
${ }^{75}$ For more details on the Polanyian concept of fictitious commodity, see Section 3.2.2.
} 


\subsection{Conclusions: towards the Polanyian sociology of private insurance}

This chapter first sought to assess the emerging field of the sociology of insurance. Two main paths seem to have been taken so far. On the one hand, some authors have basically reproduced Zelizer's (1979) Weberian emphasis on the moral resistance to and cultural legitimization of economic innovations, as if market construction mainly entailed the removal or transformation of cultural obstacles in order to succeed. On the other, Foucauldian governmentality and its radical anglo-neo version appear as dominant theoretical strands within the emerging sociology of insurance literature. Thanks to the emphasis on the power/knowledge interplay and to a theory of power as governance beyond the state, Foucauldian governmentality can be considered as the foundational framework for the sociology of insurance.

But along with Weberian economic sociology, Beck's theory of risk society, and performativity and actor-network theories, governmentality studies and its hybrid versions are characterized by an inability to closely articulate the economic and the political in addressing the fundamental relations between private insurers and public institutions. One noteworthy exception is the institutional ethnographic sociology (Ericson et al., 2003) which analyzed private insurance as "the institution of governance beyond the state" while also acknowledging the symbiotic relations between the insurance industry and state institutions. Still, Part 2.1 concluded that the emerging sociology of insurance literature has not yet focused on (A) the relationships between private and public insurance and (B) on the ways in which state and public institutions contribute to the construction and maintenance of the insurance industry. 
Chapter 2 then sought to lay the bases of a novel theoretical framework for the sociology of risk and insurance at the intersection of economic sociology, sociology of law and historical institutionalism. Part 2.2 started by diagnosing the oversight of the institutionalist tradition in contemporary economic sociology. Three frameworks have dominated economic sociology since its revival in the 1980s: new economic sociology, performativity and actor-network theories, and anglo-neo governmentality. These Weberian, Parsonsian and post-structuralist approaches tend to disconnect the economic from the political, to abandon the focus on institutions by rather turning to the analysis of networks, thus neglecting the role of state institutions within economic activities and processes.

In order to theoretically ground the institutional analysis of private insurance, Chapter 2 then explored contributions from classical sociology and old institutionalism as the "first economic sociology" (see Gislain and Steiner, 1995). It concluded with a general presentation of Polanyian institutional analysis, suggesting that such a framework can overcome the neglects of the emerging sociology of insurance literature by shedding light on the institutional construction and maintenance of private insurance. The next chapter constructs a Polanyian institutional economic sociology of private insurance through the theory of the institutional constitution of markets and its core concept of insurance risks as fictitious commodities. 


\section{Chapter 3. Theoretical framework and research design: the institutional constitution of markets}

This chapter aims at building a theoretical framework able to overcome two of the main neglects of the emerging sociology of insurance literature: the analysis of the interplays between private and public insurance (see Baker and McElrath, 1996: 231) and the study of the institutional constitution of the insurance industry. Following the influence of Zelizer (1979), previous research on the emergence and construction of insurance markets has focused mainly on the moral resistance to and the legitimization of economic and financial innovations, as if market construction mainly entailed the removal of cultural obstacles (see Chan, 2012b; Quinn, 2008). Other authors have focused on the use of genetic data in life insurance risk classification and on the political dimension of the "calculating devices" within underwriting processes requiring the performativity of economic, managerial, accountancy, actuarial and medical knowledge (see Van Hoyweghen, 2007, 2014; Van Hoyweghen and Horstman, 2010).

The following presentation seeks to contribute to the emerging sociology of insurance literature by formulating a Polanyian institutional economic sociology through the theory of the institutional constitution (IC) of insurance markets. This Polanyian framework provides the first comprehensive approach to the political and legal construction and maintenance of the insurance industry and produces the first systematized analysis of the relationships between private and public insurance. In addition, the analysis of insurance markets as institutions thus sheds light on the function of the different institutional modes of economic integration in the constitution of insurance markets. 
Following the socio-legal studies literature, Chapter 3 begins with a critique of the orthodox moral hazards $(\mathrm{MH})$ paradigm. As a sophisticated private insurance version of the self-regulating market (SRM) utopia, the $\mathrm{MH}$ paradigm allows insurers to epistemologically legitimize private risk classication and contractual incentive-based controls of the insured while, at the same time, alleviating most, if not all responsibility for the destabilization of the insurantial relationship from the insurers' back. Against this orthodox representation, the institutional ethnographic sociology's moral risks paradigm sheds light on the culture of the insurance industry and its institutionalized practices as the main sources of destabilization of the insurantial relationship. Most importantly, the moral risks paradigm broadens the analysis of private insurance governance beyond risk classification and contractual incentives-based controls in that it reconstructs the ideal form of private insurance governance as involving various institutions and society as a whole. State and public institutions appear as central actors in the construction and maintenance of the insurance industry, for instance through public-private collaborations in risk control and reduction, by the public construction of insurance markets through the partial underwriting of risks, and with the state as the insurer of last resort (see Ericson \& Doyle, 2004c; Ericson et al., 2003). The private insurance business is indeed far from being a self-sustaining process; its integrity and functioning require non-actuarial types of knowledge and non-competitive institutional arrangements.

Building on the recent wave of post-embeddedness Polanyian literature, Chapter 3 then undertakes a reconstruction the core conceptual apparatus of The Great Transformation (Polanyi, 1944) in order to develop a theoretical framework for the sectoral analysis of capitalism in general and insurance markets in particular. By defining 
insurance markets as politically and legally constructed and maintained institutions designed for private capitalization of uncertainties experienced by individuals and threatening the political institutionalization of society, the modes of social provisioning, nature, and the market economy itself, the theory of the IC of markets is formulated through the Polanyian concepts of (1) the necessarily incomplete and destabilizing institutionalization of the SRM utopia, (2) insurance risks as fictitious commodities and (3) the diversity of the institutional modes of economic integration. These Polanyian conceptual tools respectively enable us to dissect three interrelated processes in the IC of insurance markets: (i) the institutional production of uncertainty, (ii) the institutional mediation of uncertainty into fictitiously commoditized insurance risk and (iii) the decommoditization of private insurance risks by virtue of their unloading on individuals, institutions and throughout citizenries.

Chapter 3 ends with a presentation of the research questions, the hypotheses, the methods and methodologies employed, and a discussion of the nature of the data analysed in the historical (Chapter 4) and the central (Chapter 5) case studies presented in this dissertation.

\subsection{The critique of the moral hazard paradigm}

The critique of the moral hazard (MH) paradigm represents one of most basic moments in the heterodox analysis of the insurance industry. Moreover, it also reveals the fundamental role of public institutions in the construction of private insurability. Part 3.1 first seeks to present and critique the MH paradigm in private insurance. Following the socio-legal studies literature (Baker, 1996, 2003; Glenn, 2000; Heimer, 1985; Stone, 
2002), it starts by critically reconstructing the MH paradigm, its origins and usage. Building on economics of information, the $\mathrm{MH}$ paradigm portrays the uncertainty and instability inherent to the insurantial relationship as being generated by the behavior of the insured, pictured as highly aware, knowledgeable, calculative, and self-interested. The MH paradigm constitutes the orthodox, one-sided, insurer-biased, and atomistic or "institution-less" theoretical representation of private insurance. Part 3.1 then turns to empirical evidence provided by the institutional ethnographic sociology of private insurance (Doyle and Ericson, 2010; Ericson et al., 2003; Ericson and Doyle, 2004c, 2006). Revealing institutionalized deceptive practices and ironies of private insurance, this approach offers a definitive alternative to the $\mathrm{MH}$ paradigm through the concept of "moral risks." The moral risks paradigm better account for the reality of private insurance as a social relationship by pointing both to the insured and the insurer as generating risks to one another. Above all, the moral risks paradigm allows us to hypothesize that private insurance governance is not a self-sustaining process and actually requires the interventions of state and public institutions in order to profitably operate.

\subsubsection{The moral hazard paradigm in private insurance}

On the insured side, moral hazard continued to be a conceptual lens underwriters used to decide who would be offered how much insurance. On the insurer side, moral hazard was a counterweight used to oppose state regulation in much the same way that the "rate story" of the immoral insured was used to justify high premiums. Whenever the autonomy of the "private" insurance enterprise came into question, insurers could be counted upon to explain how (immoral) insureds [sic] would take advantage of the proposed regulation to the detriment of the (moral) members of the public who depended upon strong [private] insurance institutions. (Baker, 1996: 265)

In socio-legal and sociological literatures, the issue of $\mathrm{MH}$ in insurance has been the

object of a limited number of investigations. For example, Heimer (1985) rejects the market-inspired rational action notion of insurance decision-making by suggesting that 
$\mathrm{MH}$ can be explained by the inherent reactivity of insurance risks; the decision of a single party modifies the likelihood of gain or loss. As a result, insurance underwriting and pricing have to react to $\mathrm{MH}$ by organizationally controlling uncertain behavior in order to turn reactive risks into fixed risks. According to Baker's (1996) genealogy, the term MH was first used by $19^{\text {th }}$ century insurers in order to base coverage decision-making on moral judgments of the character of the individual seeking insurance. Then, the economics of MH (Arrow, 1968; Pauly, 1968) replaced the moral assessment of character with the concept of incentive. Leaver (2015) recently used citation data analysis in order to contradict Baker's claim of a shift in the 1960s and rather suggests that MH represents a form of polysemic, discontinuous and "fuzzy" economic knowledge. While further research is required in order to definitely resolve this disagreement, the following discussion sides with Baker's (1996) genealogy and Heimer's (1985) critique of the rational action approach to $\mathrm{MH}$ and seeks to present, define and critique the $\mathrm{MH}$ paradigm in the field of insurance.

The MH paradigm essentially rests on (1) a formalist approach based on the neoclassical axiom of market efficiency (i.e. private insurers are capable of autonomously ensuring the functioning and profitability of their business), (2) methodological individualism as the foundation of a rationalistic and utilitarian theory of action (i.e. the insured is a maximizing and opportunistic agent) and (3) deductions based on optimization calculus seeking to shape the insured's behavior (i.e. the insurer can selfsufficiently exert profitable incentive-based controls over the insured). Section 3.1.1 presents the origins of the term MH and of the related idea of "adverse selection" (AS) before discussing the economics of MH as defined by Baker (1996). 


\section{Moral hazard and adverse selection: origins and usage}

The companies that carry the risk of fire must get, in the form of premiums, (1) enough to pay the true value of the normal hazard, (2) a sum covering the expenses of carrying on the business, and (3) an amount that will offset the abnormal hazard created by the laxity or dishonesty of insured owners. (Clark, 1892: 51)

According to Moss (2002: 38), the terms MH and AS "were familiar to practitioners long before they were named and defined in published sources." While both terms originated in the late $19^{\text {th }}$ century insurance industry, they were then both theorized and systematized mainly by economics of information during the 1960s and 1970s. From the perspective of the $\mathrm{MH}$ paradigm, the issue of access to information connects $\mathrm{MH}$ with AS: the former arises when a contracting party modifies its behavior ex post due to asymmetric information while the latter arises due to ex ante asymmetric information between the parties involved. But how can MH and AS be defined?

In non-insurance specific risk management, economics and discourse, $\mathrm{MH}$ nowadays broadly refers "to any situation in which one person makes the decision about how much risk to take, while someone else bears the cost if things for badly." (Krugman, 2009: 63). ${ }^{76}$ According to Pearson (2002b: 6), "no clear definition [of MH] was used by insurance offices before 1850 , and it is not known when the term itself came into vogue." It seems actually reasonable to date the first usage of the term MH back from the second half of the $19^{\text {th }}$ century (Baker, 1996; Glenn, 2000; Moss, 2002). While implicit concerns

\footnotetext{
${ }^{76}$ For instance, proponents of the SRM utopia often blame regulations, governmental guarantee funds and backstops (i.e. potential public bailout by the state as the lender and insurer of last resort), deposit insurance, as well as government-sponsored for-profit enterprises - such as Fannie Mae and Freddie Mac in the US - for distorting market efficiency by creating MH-generating incentives and opportunities within financial systems (see e.g. Greenberg and Cunningham, 2013: 251). Defending a vision of capitalism in which losing parties in financial risk-taking must simply collapse, this usage of $\mathrm{MH}$ is ironic since it does not recognize that markets actually presupposes institutional constitutions (see below) and that individual and corporate vested interests benefit from regulatory capture and the "government as the ultimate risk manager" (see Carpenter and Moss, 2014; Moss, 2002). See for instance Lawrence Summers' (U.S. Deputy Secretary of Treasury from 1995 to 1999 and Secretary of the Treasury from 1999 to 2001) critique of the "moral hazard fundamentalists" (Summers, 2007).
} 
for MH emerged out of the English origins of the insurance industry between the late $17^{\text {th }}$ and $18^{\text {th }}$ centuries (see Chapter 4), private insurers explicitly started using the idea as the industry was undergoing a major transition. From a business dominated by mutual societies, private insurance got increasingly corporatized and massified during the $19^{\text {th }}$ century. ${ }^{77}$ As insurers were losing grip on the observational and reputational knowledge characterizing their former business model based on mutuality, interpersonal trust and insurable interest laws, the term $\mathrm{MH}$ emerged as a means for insurers to blame the immoral "character" of certain individuals and groups characterized by a "temptation" to put the insurance contract at risk (Baker, 1996) ${ }^{78}$ In fact, the idea "had a nonrational, performative dimension for the nineteenth-century insurers who coined the term, just as it [still] does today." (ibid.: 239). From its inception onward, the idea and use of MH have been based both on moral judgments and economic rationales (Glenn, 2000: 784).

Private insurers started to make use of the term as a way to question the morality of the insured individuals in order to bolster the societal recognition of their own business (Baker, 1996: 239; Moss, 2002: 37). The insurance industry's risk sharing principle was actually perceived as being at odds with the very ideological bases of the nascent liberal society and its ideal of individual responsibility (Baker, 1996) ${ }^{79}$ For private insurers,

\footnotetext{
${ }^{77}$ For instance, as Alborn (2009: 5) explains, "[e]ven after life insurance had reached [...] far into British society, the vast majority of the population remained uninsured. From the 1850s a new type of company emerged, called 'industrial' offices, which mainly sold small policies to cover working families' funeral expenses." See also Pearson (2002b) and Zelizer (1979).

${ }^{78}$ As American economist John Haynes (birth/death unknown) (1895: 412; quoted in Moss, 2002, p. 37) wrote: "Lack of moral character gives rise to a class of risks known by insurance men as moral hazards. The most familiar example of this class of risks is the danger of incendiary fires. Dishonest failures, bad debts, etc. would all fall in this class." See also Clark (1892: 51).

${ }^{79}$ While Moss (2002: 37) claims that the "identification of moral hazard was a necessary first step toward eliminating it, which was in turn a prerequisite for legitimizing their industry in the eyes of the public," Chapter 4 (see below) suggests that the institutionalization of the insurable interest principle constituted the first institutional effort at regulating insured-generated moral hazards, themselves generated by the moral
} 
[t]he idea was that there were certain types of individuals whose characteristics or immorality led them to be less cautious, or worse, to cause losses in search of payments (cf. Smith, Trieschmann \& Wiening 1987: 208; Vaughan 1992: 629). [...] moral hazards were also depicted as individuals whose irresponsibility led to financial problems, and who saw an insurance payment as a way out [...]. (Glenn, 2000: 788)

In contrast to physical hazards such as fire, shipwreck, shipment losses and accidents which could be managed through increased premium rates and which generally led to underwriting exclusions only in extreme cases referred to as "acts of God" by insurers (see Pearson, 2002b: 6), MH usually first backed the refusal to insure (Baker, 1996). The $\mathrm{MH}$ was uninsurable. With the introduction of actuarial data and techniques based on the law of large numbers in the industry at large during the mid- $19^{\text {th }}$ century, ${ }^{80}$ excluding individuals as "moral hazards" on the basis of moral judgments meant that insurers actually denied coverage to whole groups of society classified as "bad" or "high" insurance risks. The idea of $\mathrm{MH}$ allowed insurance underwriters to formalize risk classification or risk selection, that is "the process of sorting insurance applicants into categories believed to correspond to differences in expected risk" (Baker, 2003: 262). The risk classification process seeks to ensure the "actuarial soundness" of risk pools, paradoxically constructed both through mutualization thanks to the law of large numbers and by the exclusion of $\mathrm{MH}$ - the "bad" or "high" insurance risks - jeopardizing the pools' profitability (see Doyle and Ericson, 2010). ${ }^{81}$ In this sense, the actuarial rationality improved the certainty of the insurance pools' profitability (Glenn, 2000: 788; Pradier,

risks inherent to the private insurantial relationship (see Section 3.1.2), in order for the insurance industry to gain political, legal and societal recognition as a relatively autonomous business.

${ }^{80}$ It was not until the turn of the $19^{\text {th }}$ century that the actuarial rationality began to spread in the industry (Pradier, 2006). As the outdated Northampton tables of mortality computed between 1735 and 1780 by Richard Price (1723-1791) were still then being used (Alborn, 2002: 72), "the [British] actuarial profession itself was not organized until 1848." (Pearson, 1997: 246).

${ }^{81}$ See Section 3.1.2. 
2006: 21) by exerting class and race discrimination based on subjective judgments appearing as objective underwriting (Baker, 1996; Glenn, 2000; Squires, 1997a). ${ }^{82}$

Through this growing focus on $\mathrm{MH}$, private insurers got increasingly concerned with a related issue supposedly facing private risk classification: adverse selection (AS). While the exact origins of the term are also unclear, life insurers might have been the first to explicitly employ "AS" during the last decades of the $19^{\text {th }}$ century (Baker, 2003: 261; Moss, 2002: 36). Also called anti-selection, AS "refers to the theoretical tendency for low-risks individuals to avoid or drop out of voluntary insurance pools, with the result that, absent countervailing efforts by administrators, insurance pools can be expected to contain a disproportionate percentage of high-risk individuals (Rothschild and Stiglitz 1976)" (Baker, 2003: 261). ${ }^{83}$ Insurers and actuaries then started to pay closer attention to risk selection and classification in the construction of life insurance risk pools by ensuring that the healthiest individuals would not opt-out. To sum up, the rationale backed by the idea of AS goes as follow: "1) without risk classification, low risks are unfairly forced to subsidize high risks; 2) risk classification promotes socially beneficial efforts to prevent loss; and 3) risk classification promotes individuals responsibility."

\footnotetext{
${ }^{82}$ For example, statistician at Prudential and future president of the American Economics Association Frederick L. Hoffman's (1865-1946) published a book titled The Race Traits and Tendencies of the American Negro (Hoffman, 1896) aiming at scientifically proving that black people were purely uninsurable (Glenn, 2000: 790-1). On racial discrimination and redlining in private insurance, see Heimer (1982) and Squire (1997a).

${ }^{83}$ In theory, the use of mortality tables and actuarial data would provide life insurers with objective bases for the classification of risks and the construction of risk pools in order to ensure their actuarial soundness and profitability. In practice, actuaries and underwriters discovered that some adverse forces actually jeopardized risk classification. On the one hand, underwriters feared that without a priori medical examination, the weakest and most vulnerable individuals would tend to overload insurance pools. On the other hand, the a posteriori detection of unhealthy insured led to a decrease in the average risk of the insurance pools (Baker, 2003: 261-2).
} 
(ibid.: 267). Protecting private insurance risk pools against AS thus meant protecting the "actuarial fairness" of these same pools (see Lehtonen and Liukko, 2011).

As with MH, AS provided moral justifications for enhancing private classification and underwriting of risks by: (i) including and setting a risk premium, that is the "part of the insurance premium which is determined in relation to the insured's likelihood of encountering an accident" (ibid.: 37$)^{84}$; (ii) using deductibles (i.e. the out-of-pocket expenses before coverage kicks in); (iii) extending coinsurance (i.e. the sharing between insured and insurer of a given percentage of the costs claimed above the deductible); (iv) excluding specific risks and exerting other contractual controls over the insured ${ }^{85}$; and in some cases (v) simply refusing to insure. From the end of the $19^{\text {th }}$ century onward, private insurers understood that insurance marketing and contracts had to be designed in such a way so the "good risks" could be retained into insurance pools in order to protect their actuarial soundness. In doing so, the insurance industry also started claiming that the "insured always ha[d] a financial incentive to act in a risk-averse manner." (Glenn, 2000: 794).

\footnotetext{
${ }^{84}$ As Lehtonen and Liukko (2011: 37) explain, "[i]n its most elementary form, insurance functions in such a way that all the insured pay exactly the same amount in relation to risk. For example, think about forest owners who take out an insurance policy against forest fires and who all pay exactly the same price in relation to the amount of wood insured. To secure the solidity and profitability of the insurance company, it has to demand higher fees as the risk of an accident increases. Hence, the price of private insurance is usually, at least in principle, directly dependent on the risk class of the insured."

${ }^{85}$ As Baker (2003: 266) explains, "[w]aiting periods before coverage takes effect, pre-existing conditions exclusions in health insurance, discounts that apply only after a period of continuous insurance coverage, and penalties for early termination of accumulating value forms for life insurance are all methods for keeping low risks in the pool." Annual policy auto-renewals as well as monthly, annual and lifetime maximums should be added to this list.
} 
From character and temptation to incentives: the economics of moral hazard

Throughout the $20^{\text {th }}$ century, insurers sought to developed an increasingly evidence-based approach to underwriting (Lobo-Guerrero, 2011). After the mid-20 ${ }^{\text {th }}$ century, the evidence-based underwriting was progressively devised through the formulation of economics of $M H$ (Baker, 1996: 266). According to the socio-legal studies literature (Baker, 1996, 2003; Glenn, 2000; Stone, 2002), the economics of MH have had a pivotal impact on the way private insurers defined $\mathrm{MH}$ and implemented MH-based controls in insurance contracts. The economics of MH was first developed from the standpoint of neo-classical economics of information, starting with the debate between Kenneth $\mathrm{J}$. Arrow (1963, 1968) and Mark V. Pauly (1968) on MH in public and private health insurance (see Baker, 1996: 267-9). Interestingly, this debate did not last long and its outcomes were unexpectedly decisive for the development of economics of $\mathrm{MH}$ : "the subsequent economics literature (including Arrow's own contributions) exclusively address[ed] external incentives, not 'internalized moral principles.' Indeed, despite Arrow's pointed criticism, Pauly's observation that $[\mathrm{MH}]$ has little to do with morality has become the conventional wisdom." (ibid.: 269).

While insurers were previously concerned with the character of the insured deemed as a "MH" due to the supposed moral temptation to fraudulently gain from loss, economics of MH rather abandoned the character rationale after Arrow's 1963 article and transformed the temptation argument into an incentive-based approach (Baker, 1996: 271).$^{86}$ In other words, $\mathrm{MH}$ defined as the moral character of the insured came to be seen as a defining feature of private insurance organization and the moral temptation

\footnotetext{
${ }^{86}$ Concerning economics of MH's influential publications, Baker (1996) refers to Ehrlich and Becker
} (1972), Pauly (1974), Marshall (1976), Shavell (1979), Holmström (1979) and Stiglitz (1983). 
pressuring the individual's behavior was replaced by the incentive defined as "a force that acts on a population." (ibid.). As Glenn (2000: 794) explains, [f]or an economist, a $[\mathrm{MH}]$ is a condition in which a rational actor faces a set of incentives that reward him or her for acting in a less risk-averse manner once insurance coverage has been granted. This is why underwriters take such special care to ensure that insurance will never pay the policyholder more than the value of the loss. ${ }^{187}$ Economics of $\mathrm{MH}$ allowed insurers to employ the term without any theological reference to morality by turning the insured into an opportunistic cost-benefit calculating machine facing various contract incentives and dis-incentives (Baker, 1996). In this sense, economics of MH in private insurance is built on the following assumptions: "1) money compensates for loss; 2) people are rational loss minimizers; 3) taking care requires effort; 4) taking care is effective; 5) people with insurance have control over themselves and their property; and 6) insurance payments are not conditioned on a given level of care." (ibid.: 276).

Soon after the Arrow-Pauly debate lost any significance within the field of economics, economics of information expanded the concept of MH beyond the field of insurance and applied it to all principle-agent contexts in contract theory. Following Arrow (1968) and especially Stiglitz (1983), economics of information generalized and universalized the idea of $\mathrm{MH}$ and consequently expanded the meaning of "insurance" to any situations where "one party's actions have consequences for the risk of loss borne by another." (Baker, 1996: 272). For example, the neo-classical Law and economics

\footnotetext{
${ }^{87}$ Economics of $\mathrm{MH}$ usually distinguish ex post from ex ante $\mathrm{MH}$. "Ex ante $[\mathrm{MH}]$ is the theoretical tendency for insurance to reduce the incentive to preserve property of life from loss, and it is akin to the arson or carelessness aspect of the fire insurance temptation problem. Ex post $[\mathrm{MH}]$ is the theoretical tendency for insurance to reduce the incentive to minimize the cost of recovering from loss, and it is akin to the malingering aspect of the disability insurance temptation problem. With ex post $[\mathrm{MH}]$, the 'problem' is not an increase in the frequency of accidents, but rather an increase in the consumption of the benefits provided by insurers, such as paid time off in the case of disability insurance." (Baker, 1996: 270).
} 
literature (e.g. Epstein, 1985) has analyzed various warranties, liabilities and compensations - for instance products and shareholder liabilities, workers compensation as well as bankruptcy regimes - as different forms of insurance (see Baker, 1996: 272-4). By generalizing the concept of $\mathrm{MH}$, economics of information pictured it as being systematically generated by the insured, worker and consumer, hence strengthening the insurers, employers and manufacturers' legitimacy and rights to privately manage risks and enforce controls (see ibid.: 275).

Nowadays, economics of $\mathrm{MH}$ still constitute a major field of research, for instance in the case of health insurance (e.g. Finkelstein, 2014a). Analyzing largely privatized health insurance jurisdictions such as the US and facing exploding healthcare costs, economics of $\mathrm{MH}$ in healthcare still employ a formalist approach based on methodological individualism and rational action theory in order to set optimal incentives and controls of the insured. For instance, building on experimental data from the 1970s and 1980s RAND Health Insurance Experiment and the 2008 Oregon Health Insurance Experiment, Finkelstein (2014b) attempts to provide evidence suggesting that $\mathrm{MH}$ in health insurance is not a myth and that economics of $\mathrm{MH}$ must be able to influence policy making. The explicit goal here is to enhance private risk classification and to fine-tune contractual incentive-based controls of the insured from the perspective of private insurance as a bilateral contractual relationship, all things being equal. But as Baker (1996: 282; emphasis added) points out:

If insurance institutions can manage insurance incentives, then expanding the reach of insurance will not necessarily increase loss. Indeed, and this is a crucial point, the success of insurers in managing insurance incentives may well mean that the most important "moral hazard" effect is not increased loss, but rather increased social control." 


\section{Partial conclusions: the moral hazard paradigm and beyond}

In insurance, banking and other business sectors, the MH paradigm is regularly invoked by some self-regulating market (SRM) utopians in order to advocate for market-friendly financial regulation reforms and to oppose non-market service provisions and, in some cases, the state as the insurer of last resort. ${ }^{88}$ The previous discussion has however showed that the MH paradigm initially originated in the insurance industry before being further formalized and universalized by economics of $\mathrm{MH}$. "In the economics literature and in the law and policy debate that draws upon this literature, "moral hazard" refers to the tendency for insurance against loss to reduce incentives to prevent or minimize the cost of loss." (Baker, 1996: 239). Economics of MH is characterized by (A) a formalist approach based on the market efficiency axiom and (B) on methodological individualism as the foundation of a rationalistic and utilitarian theory of action in order to (C) shape the behaviour of the insured from the perspective of optimal incentives and controls. As Stone (2002: 74) explains, "[e]conomics is the dominant paradigm for analyzing insurance. Within that paradigm, all social processes are understood to be the aggregate result of individuals' rational, self-interested, interest-maximizing behavior.”

The MH paradigm is in fact consistent with neoclassical economist and pioneer of the marginalist revolution John Bates Clark (1846-1938) and his concept of MH referring to the necessary responsibilization of the insured seen as the embodiment of the utilitarian and egoistic homo oeconomicus (Clark, 1892: 51). Moreover, in conformity

\footnotetext{
${ }^{88}$ For instance, Brewer et al. (1997) suggest that state guarantee funds for life insurers' liabilities generate $\mathrm{MH}$ in the same way that deposit insurance does for the banking system, hence blaming public institutions for failures and crises. This analysis is based on the option pricing theory (Black and Scholes, 1973; Merton, 1977) which postulates the efficiency of the SRM in order to construct mathematical models for the design of financial and derivative products.
} 
with neoclassical economics' "all things being equal" (caeteris paribus sic stantibus) methodological clause (see Marshall, 1920), the MH paradigm's formalism and its optimization aim rely on the deductive model of the opportunistic insured putting the insurance contract at risk. It indeed portrays the uncertainty and instability inherent to the insurantial relationship as being first and foremost generated by the insured, pictured as highly aware, knowledgeable, calculative and self-interested. These features allow the proponents of the $\mathrm{MH}$ paradigm and private insurers themselves to epistemologically legitimize private risk classication and contractual incentive-based controls of the insured while also alleviating most, if not all responsibility for the production of $\mathrm{MH}$ from the insurer's back.

Following Baker (1996, 2003), Glenn (2000), Heimer (1985) and Stone (2002), the previous discussion indicates that the $\mathrm{MH}$ paradigm constitutes a sophisticated version of the SRM utopia: through private risk classification and contractual incentives and controls (risk premiums, deductibles, coinsurance, maximums, etc.), the insurers' private governance would autonomously be able to ensure the profitability of the insurance business and the functioning of the insurance industry. From the insurer's perspective, the $\mathrm{MH}$ paradigm pictures $\mathrm{MH}$ and $\mathrm{AS}$ as two sides of the same rationale concerning the threats to the insurantial contract and legitimizing the incentive-based controls of the insured. Through the idea of actuarial fairness ${ }^{89}$ the $\mathrm{MH}$ paradigm thus defends a "watered-down form of liberalism that privileges individual interests over the

\footnotetext{
89 "Actuarial fairness" can be defined as the situation in which "each and everyone pays a price which is in line with an individual's risk level, but independently of who will receive future indemnities." (Lehtonen and Liukko, 2011: 39).
} 
common good and that privileges, above all, the interests of insurance institutions organized on its terms.” (Baker, 2003: 277).

Over the past few decades, the issue of the empirical adequacy of $\mathrm{MH}$ and AS has received growing attention from researchers. For example, market efficiency approaches seeking to construct optimal risk pooling modelizations have explored the possibility of propitious selection - the opposite of AS - that is "more risk averse agents buying more insurance while being less risky." (De Donder and Hindriks, 2009: 73). On the one hand, some authors wonder if propitious selection might even help to stabilize insurance markets (Karagyozova and Siegelman, 2012). On the other, it is suggested that the MH paradigm might have exaggerated the impact of AS on insurance pools (Cohen and Siegelman, 2010). Perhaps most interesting from the perspective of economic sociology is the evidence of performativity generated by the $\mathrm{MH}$ paradigm since insurance laws and regulations have been influenced by discourses concerning the threats of $\mathrm{MH}$ and AS (see Siegelman, 2004).

Beyond the issue of the empirical evidence supporting or contradicting the realworld prevalence of $\mathrm{MH}$ and $\mathrm{AS}$, private insurers actually take great care in designing their insurance products by creating incentives ensuring that insurance pools retain "good risks" and that "bad risks" can be managed, controlled and even unloaded on politicallegal and non-competitive institutional arrangements. Moreover, state institutions and legislative interventions greatly contribute to reducing, controlling and eliminating $\mathrm{MH}$ and AS, for instance by mandating public and universal insurance (e.g. healthcare), by institutionalizing the mandatory purchase of private insurance (e.g. car, health and liability insurance) and by limiting or prohibiting certain levels and types of underwriting 
exclusions and pricing discriminations (e.g. gender and genetic discriminations) (see Baker, 2003). ${ }^{90}$ State and public institutions in fact regulate "the fairness of risk pooling practices, and the manner in which insurance policies are sold and claims are compensated" (Ericson et al., 2003: 7). In contrast to the MH paradigm as the insurancesector version of the SRM utopia, state interventions, legislation and regulations might actually help stabilize, expand and perhaps constitute private insurance markets.

\subsubsection{Beyond moral hazards: the moral risks paradigm}

As the previous section showed, the socio-legal studies literature has revealed various reasons why the $\mathrm{MH}$ paradigm does not accurately represent the deep nature of the insurantial relationship. The reality of private insurance, like any private transactions, cannot be reduced to a bilateral contract, a notion so fundamental to classical sociologists like Durkheim (1893). While socio-legal studies have suggested that the reactivity of insurance risks, not rational action, explains the management of $\mathrm{MH}$ by private insurers (Heimer, 1985), they have not offered an alternative model in conceptualizing private insurance as a social relationship. In contrast, the ethnographic institutional sociology of the Anglo-American insurance industry suggests that moral risks better account for the insurantial relationship, that is "the ways in which an insurance relationship fosters behavior by any party in the relationship that immorally increases risk to others." (Ericson et al., 2000: 537). The moral risks paradigm was formulated following some empirical evidence of institutionalized market misconducts and fraud construction in the insurance industry. This evidence can be summed up by the five institutionalized ironies

\footnotetext{
${ }^{90}$ On the principle of gender non-discrimination in European Union regulations, see Mabbett (2015). On genetic discrimination and insurance, see Joly et al (2010) and Lander and Van Hoyweghen (2014).
} 
of private insurance uncovered by Ericson and his collaborators. ${ }^{91}$ As a result, ethnographic institutional sociology was able to reconstruct an ideal form of private insurance governance and to provide important insights on the role of public institutions for the insurance industry.

\section{Market misconducts, the construction of fraud and the ironies of insurance}

In contrast to the $\mathrm{MH}$ paradigm, the moral risks paradigm first accounts for five sources of market misconduct institutionalized in the insurance industry (Ericson and Doyle, 2006). First, the complexity of certain insurance policies and the apparent certainty of the returns they are expected to generate - especially when insurance coverage is combined with other investment products - can leave the insured individuals and organizations insufficiently knowledgeable about what their coverage and about the specific price they are paying for each investment components. In this context, insurers "try to cover themselves by developing a very complex system involving various charges, incentives and risk management mechanisms, $[\ldots]$, in order to manage their financial risks with these products. Even so, insurers are often wrong because these forms of financial risk management are likewise speculatively based on limited knowledge and uncertainty." (ibid.: 998). ${ }^{92}$ Second, despite numerous scandals revealed over the years (see e.g. Gerst, 2008), the commission selling structure constitutes an important source of market misconducts in the insurance industry. As Ericson and Doyle (2006: 1000-1) explain,

\footnotetext{
${ }^{91}$ Doyle and Ericson (2010: 227) define the concept of "irony" as a "reversal of expectations." They add that "[a]ctions have unintended consequences and often produce ironic results. Irony can stem from deliberate attempt by insurers to intervene in the risk environment, attempts that backfire. It is a fact of organizational life that new risks are unintentionally created through the very processes by which other risks are managed."

${ }^{92}$ See also Ericson et al. (2004c).
} 
[t]he life insurance industry continues to rely so heavily on commission-based selling because of the peculiar properties of the insurance product. Life insurance is a tough sell: it is expensive, arcane, addresses remote future possibilities that people prefer not to dwell on, is intangible and does not have the commodity appeal of material goods. Therefore, it must be sold proactively and aggressively. Commissions at the point of sale can be in excess of 100 per cent of initial premiums, loaded upfront. This creates an enormous incentive to make bigger sales, even if those sales entail too much insurance or inappropriate products.

More specifically, commission selling contributes to the institutionalization of misselling (i.e. deliberately or negligently selling a product not adapted to the needs of the insured), overselling (i.e. selling coverage above the needs of the insured) and churning (i.e. introducing products in order to convince policyholders to switch coverage).

Third, the insurance industry's workforce is fuelled by "a revolving door of shortterm employees who will sell to their social networks and then leave when these networks are exhausted." (ibid.: 1002). Labour turnover rate is high in private insurance, recruitment is rather lax, and employee training is quick, often more akin to corporate propaganda than genuine education. Furthermore, "[w]hile sales agents are to prospect for new clients among family and friends, managers are to prospect for new agents in their social networks. Managers' prospecting is rewarded with a fee or bonus for each new agent recruited, placing onus on quantity over quality." (ibid.: 1003). Fourth, along with misleading advertising and marketing, the private insurance's aggressive sale culture also generates market misconducts.

Agents face a constant barrage of motivational messages aimed at augmenting their production. Motivational booklets and training guides published by industry associations, company manuals and meetings, conventions for top producers and everyday monitoring by managers in the work environment are all designed to make the agent rationalize rejection and sell more. (ibid.: 1005)

Finally, institutional ethnographic sociology points out that the regulation of private insurance market misconduct is consistent with the neoliberal policies as public regulators tend to rely on the industry's associations and self-regulation. "Government and industry market conduct regulators are almost entirely reactive to public complaints. 
They tend to respond to complaints by reiterating the rules of conduct and urging future compliance. [...]. Furthermore, except when major scandals erupt, market misconduct complaints by consumers are rare." (ibid.: 1007). ${ }^{93}$

In addition to these institutionalized deceptive practices, ethnographic institutional sociology has also observed the privatization of justice and policing in workers' compensation and property and casualty insurance as insurers privately define, construct and manage fraud.

If security of profits is not unduly threatened, or if it can be addressed through other means, such as increased prices and sales-contract conditions, padding of claims is tolerated. Economic pressures on insurers, and the inability to pass costs on to consumers, have been some of the key factors leading to an industry crackdown in which much more claimant behaviour has been defined as 'fraud' in the last two decades than previously. [...]. A private insurance company is in the business not of redistributing resources among the insured but of discriminating in favour of those who contribute to the goodness of the pool and the prosperity of the company (Ericson and Doyle, 2004b: 121-2)

Like crime in general, insurance fraud usually goes undisclosed. But unlike other forms of crime, while the definition of insurance fraud is slippery and manipulated and its costs are hardly measurable, it can ultimately affect both the insurer and the insured. Insurance fraud "crackdown mostly deploys the notion that fraud is a 'crime' as a way to deny claims, particularly form less desirable customers, and to cut costs." (ibid.: 122). Simply put, insurance fraud is not necessarily a bad thing for the insurers' bottom line.

Furthermore, Doyle and Ericson (2010) have summed up these institutionalized practices through "five ironies of private insurance." First, as just mentioned, insurance fraud crackdown produces insurance fraud. "When you crackdown on fraud, the irony is

93 Ericson and Doyle (2006: 1008) moreover claim that the neoliberal society amplifies these institutionalized deceptive practices: "the responsibilization of the individual consumer, the fraying of a social safety net leading consumers to rely more on insurance as an investment product, a flexible labor market feeding into a revolving-door system of career agents, increasing individualism and the loosening of family loyalty making it easier to sell to family members, and the downloading of regulatory responsibility from the state limiting any efforts to regulate these practices." 
you find more and more fraud. Insurers say the numbers are up dramatically, but, of course, if you go looking for insurance fraud you will find it, as the social reaction perspective indicates with crime in general." (Doyle and Ericson, 2010: 243). Moreover, the crackdown of insurance fraud exacerbates inequalities since marginalized and racialized populations are usually the first groups to be suspected of defrauding insurers (see Squires, 1997a). Second, the structure of private insurance governance - for example commission selling, which generates misselling and overselling - creates "incentives for its own people also to cheat and lie, not just the consumer. This irony here stems from the tension between managing the consumer's risk and the profit motive." (Doyle \& Ericson, 2010: 234). Third, private insurance ironically produces and transforms the risks it faces and manages due to the reactivity of insurance risks and the unintended consequences produced by the mere availability of insurance coverage. For instance, through accident and disability insurance, "the insured sometimes may even internalize the disability themselves and come to understand they have a disability. [...] the insured may see claiming a fictionalized disability as more than a matter of convenience. [...] disability claims increase with recession, layoffs, and rightsizing of companies." (ibid.).

The last two institutionalized ironies of private insurance might be even more significant for the moral risks critique of the $\mathrm{MH}$ paradigm. On the one hand, one of the main ironies of insurance

is that in the very process of pooling risk it also constantly unpools it. Insurance sells good risk pools. In order to protect the integrity of a given pool it must deselect those who pose too great moral risk. This process of deselection creates more and more specialized risk pools - with highly variable premiums, contract conditions, and surveillance mechanism - and excludes a substantial number of people entirely. (Ericson et al., 2003: 12; emphasis added)

Following Gowri (1977), institutional ethnographic sociology reveals that the profit motive leads private insurers to constantly create market segmentations, for example by 
constructing "super-", "standard" and "sub-standard" pools. "The increasing risk segmentation and unpooling [...] undercut the risk socializing potential of insurance." (Doyle and Ericson, 2010: 232). Finally, on the other hand, insurers ironically "insure the uninsurable." "Insurers have long insured risks that are of a huge scale and not very calculable." (ibid.: 239). Even without robust actuarial data about risks, the insurance industry regularly covers highly unpredictable and potentially irreversible uncertainties such as terrorist attacks (see Ericson and Doyle, 2004c). In this context, "[i]nsurers copy each others' products $[\ldots]$ without much understanding of the risks they may be taking on. There is also a proliferation of financial product features tied to life insurance policies, again without actuarial history and much understanding of the risks involved." (Doyle and Ericson, 2010: 238).

Following the diagnosis of institutionalized ironies of private insurance, Ericson et al. (Doyle and Ericson, 2010; Ericson et al., 2000, 2003, Ericson and Doyle, 2004b, 2006) suggest to move beyond the $\mathrm{MH}$ paradigm which pictures the calculative and selfinterested insured as the main, if not the only source of threats to the stability of the insurance contract. Against this one-side and insurer-biased model, institutional ethnographic sociology suggests that moral risk better describes the nature of private insurance, that is "the paradoxical tendency of the structure and culture of the insurance institution to facilitate and encourage risky behavior on behalf of the various players in the insurance relationship." (Ericson and Doyle, 2006: 993). ${ }^{94}$ The moral risks paradigm represents a major step forward in the conceptual understanding of private insurance both as a social relationship and as an institution.

\footnotetext{
${ }^{94}$ See also Ericson et al. (2003: 11).
} 
Outside closed doors: the ideal form of the private insurance governance

The previous critical reconstruction of the $\mathrm{MH}$ paradigm following the socio-legal studies literature has shed light on the specific contractual incentives and controls through which insurers privately manage the insured's behavior in order to ensure profitability: premium levels, risk premiums, deductibles, coinsurance, exclusions, waiting periods, autorenewals, long-time customer discounts, and maximums. Against the MH paradigm, institutional ethnographic sociology offers an alternative model, the moral risks paradigm, indicating that the "insurance relationship fosters behaviour by any party in the relationship that immorally increases risk to others." (Ericson et al., 2003: 11). For example, while the MH paradigm points to the need for insurers to combat adverse selection (or anti-selection) - that is the presumed tendency in voluntary insurance pools to lose low-risks and amass high-risks -, the moral risks paradigm points out that insurers ironically proceed to deselection by depooling risks and constructing differentiated pools "with highly variable premiums, contract conditions, and surveillance mechanism" (ibid.: 12).

In doing so, the moral risks paradigm illuminates the broader private insurance governance, outside of the closed doors of the private insurance firm. Institutional ethnographic sociology thus characterizes the ideal-form of private insurance governance through nine interrelated dimensions:

First, it attempts to produce knowledge of risk by objectifying everything into degrees of chance of harms. Second, it makes everything it objectifies calculable and thereby subject to commodification. It uses techniques to convert the concrete facts of objective risks it produces into probability classifications. Each classification is then assigned its respective costs so that prices can be set and compensation for the effects of chance can be paid. Third, actuarialism creates a risk pool, a population that has a stake in the identified risks and the specific harms they entail. This stake transforms the population into a collective with an interest in minimizing loss and compensating those who have suffered loss. Fourth, insurance protects against loss of capital. What is actually insured is not the particular event that causes harm to a member of the risk pool, but the capital against which the insurer offers indemnification. Fifth, insurance is managerial. It 
manages risks on the basis of surveillance and audit for a population dispersed in space and time but nevertheless bound together by the collective interests noted above. Sixth, the population is also bound legally. Insurance objectifies risk by making it subject to contract and adjudication. At the same time, it helps the law to assign liability to the party most able to distribute the loss through insurance. Seventh, in providing a futures market in security, insurance offers a cultural framework for conceptions of time, destiny, providence, responsibility, economic utility, and justice. Eighth, insurance is a social technology of justice. It bridges individual and social responsibility through distributive justice (collective sharing of loss) and restorative justice (financial indemnification). Ninth, insurance is therefore political, combining aspects of collective well-being and individual liberty in a state of perpetual tension. (ibid.: 5-6)

Against the MH paradigm, it now appears increasingly clear that not only is the insured's behavior not the primary source of instability in the insurantial relationship, but also that the insurer's private governance cannot autonomously ensure the profitability of the insurance contract and the functioning of the insurance industry. In other words, this ideal form of private insurance governance entails that:

(a) Insurers rely on both actuarial and non-actuarial data and knowledge in constructing insurable risks (see Ericson and Doyle, 2004c);

(b) In order to classify, price and hence commodify risks, the insurers objectify the underlying uncertainties as a given level of capital against which a promise of future indemnification or reimbursement is offered, notwithstanding the specific nature of the covered uncertainties (see Ericson and Doyle, 2003; Ewald, 1986);

(c) While the actuarially constructed pools create collective interests, the insured is generally not aware of this "community of fate" (see Glenn, 2000; Simon, 1988 ) and the profit motive ironically leads insurers to unpool risks;

(d) Private insurance structures the psychological, cultural and societal conceptions of danger, opportunity, temporality, responsibility, efficiency and justice;

(e) The insurantial relationship is materialized as a contract (i.e. the insurance policy) - providing a "pre-defined compensation rule" (Lehtonen and Liukko, 2011: 35) - which itself requires laws and a judicial system.

\section{Partial conclusions: private insurance and public institutions}

While the MH paradigm claims that private insurance governance ensures the stability and profitability of the insurantial relationship through the private classification of risks 
and contractual incentives and controls of the insured, the moral risks paradigm complicates this picture. On the one hand, despite claiming to be based on mutualization as an organizational principle, private insurers' struggle for profit-making ironically leads to risk unpooling, to risk creation, to financial risk-taking, to insuring highly "uncertain risks" and to the creation of fraud (Doyle and Ericson, 2010). As Lehtonen and Liukko (2011) explain, while private insurance can embody different forms of solidarity, it can also radically limit it. On the other hand, the institutional ethnographic sociology's ideal form of private insurance governance moreover reveals that the insurantial relationship requires non-actuarial types of knowledge and non-competitive institutional arrangements. The side effects and costs of the institutionalized ironies and deceptive practices of private insurance might well inevitably fall back unto the shoulders of the insured and, ultimately, on the citizenry and on society as a whole.

On the one side, institutional ethnographic sociology points out that "[w]hile the state regulates what is seen to be unfair discrimination in risk pooling, its effectiveness is limited, and state regulation of equitable pricing of insurance policies is routinely sidestepped. One approach is for the insurer to create subsidiary companies, each of which targets a different market/risk pool segment." (Doyle and Ericson, 2010: 229). On the other side, while defining the insurance industry as "the institution of governance beyond the state," Ericson et al. (2003) nonetheless acknowledge that the state: (1) contributes to the constitution of the private insurers' power, (2) shapes insurers as institutional and speculative investors, (3) regulates private insurance risk pooling, and (4) can even construct insurance markets, for instance by partially underwriting risks and with the state as the insurer of last resort. As institutional economist David A. Moss 
(2002: 36) notes, "the failure within the private marketplace represents one of the core justifications for public risk management." It would therefore not be surprising for state and public institutions to be central actors in the construction and maintenance of insurance markets.

\subsubsection{Summary and conclusions: theorizing uncertainty and risk}

When uncertainty is organized it becomes a 'risk' to be managed. (Power, 2007: 6)

Through the lenses of methodological individualism and utilitarianism, the MH paradigm portrays the instability inherent to the insurance contract as being primarily generated by the behavior of the insured, pictured as highly aware, knowledgeable, calculative, and self-interested. The MH paradigm constitutes the orthodox, one-sided, and atomistic or "institutions-less" theoretical representation of private insurance. As a sophisticated version of the SRM utopia, it allows insurers to epistemologically legitimize private risk classification and contractual incentive-based controls of the insured while, at the same time, alleviating most, if not all responsibility for the production of $\mathrm{MH}$ from the insurer's back. Against this orthodox representation, institutional ethnographic sociology (Doyle and Ericson, 2010; Ericson et al., 2003; Ericson and Doyle, 2004c, 2006) suggests that moral risk better renders the nature of private insurance as a social relationship, that is "the paradoxical tendency of the structure and culture of the insurance institution to facilitate and encourage risky behavior on behalf of the various players in the insurance relationship." (Ericson and Doyle, 2006: 993).

The moral risk paradigm sheds light on various institutionalized deceptive practices and ironies of private insurance. In so doing, it broadens the analysis of private insurance governance beyond risk classification and contractual incentives-based controls 
by reconstructing the broader ideal form of private insurance governance. According to the moral risk paradigm, insurers rely on both actuarial and non-actuarial data and knowledge in constructing insurable risks; when risk cannot be actuarially computed, insurers turn to other sciences as well as speculative, lay and other forms of knowledge in order to mediate uncertainty through the underwriting process. Perhaps most importantly, the insurantial relationship is objectified as a contract (i.e. the insurance policy) which itself requires laws and regulations within legal, judicial and political systems. State and public institutions thus appear as central actors in the functioning of the insurance industry, for instance through public-private collaborations in risk control and reduction, through the public construction of insurance markets by the partial underwriting of risks, and with the state as the insurer of last resort. It is hence reasonable to presume that private insurance governance is far from being a self-sustaining process; it requires nonactuarial types of knowledge and non-competitive institutional arrangements. On the theoretical level, what is at stake here from the perspective of economic sociology is the capacity of institutions, and especially of private actors and markets, to mediate uncertainties as risks to be covered, commodified and hence traded.

Various social and economic theorists have taken into account the issue of uncertainty in analyzing the dynamics of the capitalist economy (Phelps, 2007). For instance, Marx pointed to the imbalance and uncertainty generated by the "constant revolution of the means of production" as the logic through which the bourgeois class can reproduce itself and expand its power (see Marx and Engels, 1848: 45).$^{95}$ As a reader of

\footnotetext{
95 As Marx and Engels (1848: 45-6) state in this famous passage of the Manifesto: "Constant revolutionising of production, uninterrupted disturbance of all social conditions, everlasting uncertainty and agitation distinguish the bourgeois epoch from all earlier ones. All fixed, fast-frozen relations, with their
} 
Marx, Joseph A. Schumpeter (1883-1950) also acknowledged the disruptive nature of capitalist dynamics but rather stressed the central function of the entrepreneur in triggering growth through innovation. Schumpeter (1942) referred to this process as "creative destruction." 96

The orthodox definition of risk, as opposed to uncertainty, was however first formulated by neoclassical economics. In an article rarely commented in economic and sociological literatures, American pioneer of the marginalist revolution John B. Clark (1847-1938) claimed that, borne whether by an insurance company or spread through the "socialized capital" (see Roy, 1997) of the corporation, risk is always managed as per its subjective actuarial value by a reversal of the marginal utility calculus (i.e. each new losses becoming increasingly costly) (Clark, 1892). Trying to make sense, from the point of view of the SRM utopia, of the purpose of insurance and of the corporation in the context of the rise of corporate capitalism in the late $19^{\text {th }}$ century US, ${ }^{97}$ Clark claimed that both of these institutions perform the reduction of subjective risks to personal capital while encouraging more risk-taking by entrepreneurs, leading to more investments by

train of ancient and venerable prejudices and opinions, are swept away, all new-formed ones become antiquated before they can ossify. All that is solid melts into air, all that is holy is profaned, and man is at last compelled to face with sober senses his real conditions of life, and his relations with his kind."

96 According to Schumpeter (1942: 82-3), "[c]apitalism, [...], is by nature a form or method of economic change and not only never is but never can be stationary. And this evolutionary character of the capitalist process is not merely due to the fact that economic life goes on in a social and natural environment which changes and by its change alters the data of economic action; this fact is important and these changes (wars, revolutions and so on) often condition industrial change, but they are not its prime movers. Nor is this evolutionary character due to a quasi-automatic increase in population and capital or to the vagaries of monetary systems of which exactly the same thing holds true. The fundamental impulse that sets and keeps the capitalist engine in motion comes from the new consumers' goods, the new methods of production or transportation, the new markets, the new forms of industrial organization that capitalist enterprise creates." The idea of creative destruction was actually first coined by conservative economist and sociologist and member of the "young German historical school" Werner Sombart (1863-1941). See Sombart (1913).

${ }^{97}$ As Clark (1892: 52) claims, "[ $t$ ]he corporate form of business organization makes its possible to more widely distribute business losses than is practicable under other forms. The suppression of insurance companies would force even well-established business more and more into the corporate form." 
capitalists and innovations by managers, hence ensuring a greater distribution of risks and higher profits in the economic system as a whole. ${ }^{98}$

While there is no uncertainty as such in Clark's marginalist theory, Frank H. Knight (1885-1972) pushed the neoclassical concept of risk further by explicitly opposing it to uncertainty. ${ }^{99}$ Having provided the canonical opposition between risk and uncertainty, Knight (1921) defined risk as an actuarially calculable occurrence, in contrast to uncertainty understood as decisions concerning which no historical statistics are available. ${ }^{100}$ Moving from the epistemology of probability to business decisionmaking, Knight concludes that the strictly moral issue of distribution is futile since profitmaking relies both on planned risk-taking by the entrepreneur and on the mitigation of unpredictable events and uncertainty by the firm. The Knightian approach thus represents a defense of the SRM utopia by claiming that competitive markets would be most

98 Clark thus laid the foundations of the neoclassical theory-inspired neo-institutional economics and its evolutionist theory of institutional change (see Coase, 1937; North, 1990; Williamson, 1975). He indeed proposes that "[o]f all the fields in which the struggle for survival is in process, the one in which a quick and beneficent outcome can most surely be counted on is that in which an assorted lot of business establishments, as organized on various plans, are testing their efficiency in a competitive struggle." (Clark, 1892: 50). The "utilitarian functionalism" of the neo-institutional economics must be rejected as a framework in the study of institutional construction and change since it suggests that the existence of a given institution depends only its function in optimally protecting specific interests (Steiner, 2005a).

${ }_{99}$ Head of the Economics Department of the University of Chicago until the 1940s and president of the American Economic Association in 1950, Frank H. Knight has been among the founders of the Mont Pèlerin Society along with F. Hayek, L. Mises, M. Polanyi, K. Popper and M. Friedman. For instance as the doctoral supervisor of G. Stigler, he had a strong influence on the 1980s "Chicago Boys" (see Pradier, 2006).

100 "Uncertainty must be taken in a sense radically distinct from the familiar notion of Risk, from which it has never been properly separated. The term 'risk', as loosely used in everyday speech and in economic discussion, really covers two things which, functionally at least, in their causal relations to the phenomena of economic organization, are categorically different. [...]. The essential fact is that 'risk' means in some cases a quantity susceptible of measurement, while at other times it is something distinctly not of this character [...]. It will appear that a measurable uncertainty, or 'risk' proper, as we shall use the term, is so far different from an unmeasurable one that it is not in effect an uncertainty at all. We shall accordingly restrict the term 'uncertainty' to cases of the non-quantitative type. It is this 'true' uncertainty, and not risk [...] which forms the basis of a valid theory of profit and accounts for the divergence between actual and theoretical competition." (Knight, 1921: 19-20). 
efficient in prompting entrepreneurs to take risks and firms to mitigate uncertainty (see Dostaler, 2005: 132; Moureau and Rivaud-Danset, 2004).

In his 1921 Treatise on Probability, John M. Keynes (1883-1946) showed that the actuarial calculus of risk is actually built on the rationalization of Benthamian utilitarianism, hence concealing the radical epistemic uncertainty. Against the neoclassical concept of risk and the standard numerical approach to probability (including both mathematical and frequentist probabilities), Keynes (1921) developed the concept of logical probability. Since the large of large numbers is empirically limited in the real world and considering the epistemic importance of ignorance, Keynes suggested that probability first and foremost rests on various degrees of beliefs concerning specific statements previously judged as reasonable.

Rejecting the opposition between normative and positive economics, Keynes hence placed ethical concerns and historical contingency at the core of probability; the future is by definition uncertain and contingent upon human decisions and actions. The central position of temporality in the Keynesian theory of probability thus points to the fundamental function of normative judgments in conditions of anticipation and fear (see Dostaler, 2005: 141-54). For example, this perspective inspired Keynes' idea of “animal spirits" for the analysis of money and liquidity preference in The General Theory (see Keynes, 1936). Moreover, the Keynesian critique of standard probabilism resulted in the idea of epistemic uncertainty, referring not to the improbable but to the unknown. ${ }^{101}$ By

\footnotetext{
101 "By 'uncertain' knowledge [...] I do not mean merely to distinguish what is known for certain from what is only probable. The game of roulette is not subject, in this sense, to uncertainty; nor is the prospect of a Victory bond being drawn. Or, again, the expectation of life is only slightly uncertain. Even the weather is only moderately uncertain. The sense in which I am using the term is that in which the prospect of a European war is uncertain, or the price of copper and the rate of interest twenty years hence, or the
} 
rejecting the neoclassical concept of risk and the dichotomy between risk and uncertainty, the Keynesian theory of epistemic uncertainty indicates that social conventions and power better explain decision-making under conditions of uncertainty than utilitarian calculus and actuarial rationality (Lavoie, 1985: 202). ${ }^{102}$

Friedrich A. Hayek's (1899-1992) neoliberal theory might constitute one last major contribution to the socio-economic discussions of uncertainty. Against the neoclassical concept of risk and the Keynesian theory of uncertainty, Hayek (1988) claimed that the complexity of the market economy entails that no centralized authoritywhether the firm or the state - can possess the cognitive means required in order to intervene in the economy. Defending a form of nominalism through methodological individualism, Hayek claimed that only some isolated and selfish individual private owners can acquire the "dispersed knowledge" of the most efficient means and the most desired ends, and only the market economy can create the resulting "spontaneous order" in the allocation of resources. As Hayek (1988: 77) suggested:

It is often objected that the institution of property is selfish in that it benefits only those who own some, and that it was indeed "invented" by some persons who, having acquired some individual possessions, wished for their exclusive benefit to protect these from others. Such notions, which of course underlie Rousseau's resentment, and his allegation that our "shackles" have been imposed by selfish and exploitative interests, fail to take into account that the size of our overall product is so large only because we can, through market exchange of severally owned property, use widely dispersed knowledge of particular facts to allocate severally owned resources. The market is the only known method of providing information enabling individuals to judge comparative advantages of different uses of resources of which they have immediate knowledge and through whose use, whether they so intend or not, they serve the needs of distant unknown individuals. This dispersed knowledge is essentially dispersed, and cannot possibly be gathered together and conveyed to an authority charged with the task of deliberately creating order. Thus the institution

obsolescence of a new invention, or the position of private wealth-owners in the social system in 1970 . About these matters, there is no scientific basis on which to form any calculable probability whatever. We simply do not know." (Keynes, 1937 : 213-4).

102 It is worth noting that the critique of the axiomatization of economics by the early Keynes appears in contradiction with his later emphasis on the importance of econometrics and on the use of statistics in scientific description (Dostaler, 2005: 149). On the rejection both of the Kightian distinction between risk and uncertainty and of the Keynesian theory of uncertainty in standard economics, see Dupuy (2002: 107 and following) and Lavoie (1985: 502 and following). 
of several property is not selfish, nor was it, nor could it have been, "invented" to impose the will of property-owners upon the rest.

This neoliberal theory of uncertainty thus represents a radical version of the SRM utopia in that it claims that the free-market generates an order in which actions and decisions do not depend on conscious or deliberate ends. As a result, the Hayekian nihilism not only elevates radical uncertainty as a defining and desirable component of the SRM utopia thus implicitly considering the concept of risk as a pure analytical dead end - but also entirely refuses to admit that the market economy is institutionally constructed and maintained.

In order to clarify the socio-economic discussions over uncertainty, the next presentation argues that the Polanyian framework allows us to empirically analyze the institutional interplays between risk and uncertainty as two co-constitutive concepts. It provides the theoretical and methodological foundations for the study of the institutional production of uncertainty, the institutional mediation of uncertainties into fictitiously commoditized insurance risks, and the distribution of risks through specific institutional arrangements. From the Polanyian perspective, the concept of insurance risks as fictitious commodities points to the institutional construction and maintenance of markets - or their constitution - as generating instability and uncertainty which must in turn be institutionally organized and distributed through political-legal interventions and noncompetitive institutional arrangements. 


\subsection{Theoretical framework: the institutional constitution of markets}

Insurance is an institution that should be central to sociological investigation because it is a key component of political economy. (Ericson et al., 2003: 4)

In order to move beyond the orthodox moral hazard paradigm, the institutional ethnographic sociology's moral risks paradigm (Ericson and Doyle, 2006) broadens the analysis of private insurance governance beyond risk classification and contractual incentives-based controls. Following evidence of deceptive practices and institutionalized ironies in the insurance industry (Doyle and Ericson, 2010), ${ }^{103}$ it appears that private insurance governance is far from being a self-sustaining process. Institutional ethnographic sociology of private insurance indeed points to state and public institutions as essential actors in the functioning of the insurance industry, for instance through public-private collaborations in risk control or reduction, by the public construction of insurance markets through the partial underwriting of risks, and with the state as the insurer of last resort (Ericson et al., 2003). Considering that the study of the institutional construction and maintenance of the insurance industry has been neglected by the emerging sociology of private insurance (see Chapter 2), Part 3.2 builds on Karl Polanyi's (1944) institutional analysis in order to shed light on the institutional constitution (IC) of insurance markets.

Over the past few decades, several institutionalist scholars ranging from sociologists and political scientists to heterodox economists - especially from the historical institutionalist literature - have referred to Polanyi beyond the Weberian and post-structuralist concept of embeddedness in building different versions of the

${ }^{103}$ See also Gerst (2008). 
institutional analysis. ${ }^{104}$ Other Polanyian approaches, such as the francophone "social economy" approach (économie sociale et solidaire) and the French MAUSS (Mouvement anti-utilitariste en sciences sociales), ${ }^{105}$ have focused on the diversity of the institutional modes of economic integration in order to highlight the production and provision of goods and services by "third sector" associations and non-profit organizations (Steiner, 2008b: 106). More recently, while some Polanyian scholars have suggested to focus on law and policy as constitutive of economies and markets (Frerichs, 2009; Veitch, 2013), others have applied this insight to the insurance industry (Mabbett, 2015; Ossandon, 2015). This growing renewal of the Polanyian literature, along with recent calls for the formulation of an "economic sociology of law" 106 have nonetheless either remained in the spirit of the embeddedness-centered reading of Polanyi or neglected to offer a systematic interpretation and reconstruction of Polanyi's core conceptual apparatus.

The Polanyian institutional economic sociology of private insurance herein formulated moves further by going back to Polanyi in conceptualizing one of the theoretical pillars of The Great Transformation (TGT). Through the concept of insurance risks as fictitious commodities, it sheds light on insurance markets as institutions requiring political and legal construction and maintenance. On the one hand, Polanyian institutional economic sociology seeks to contribute to the socio-economic discussions of risk and uncertainty by clarifying both concepts and the nature of their relationships. On the other hand, it provides an innovative framework for the sectoral analysis of capitalism

\footnotetext{
${ }^{104}$ See for instance Bourdieu (2000), Cioffi (2010), Fligstein (2001), Mazzucato (2013), Roy (1997), Streeck and Thelen (2005) and Vogel (1996).

${ }^{105}$ See for example Laville (2009) and Caillé (2009).

106 See especially Ashiagbor et al. (2013), Cotterrell (2013), Frerichs (2009) and Swedberg (2003). This project of the "economic sociology of law" appears rather surprising to the avid reader of classical sociology since the "first economic sociology" and the institutionalist tradition have refused to isolate the legal from the economic from their inception.
} 
in general and the insurance industry in particular. By investigating how insurance markets are constituted - that is constructed and maintained -, the Polanyian analysis dissects how and why the constitution of insurance markets depends on (1) the institutional production of uncertainty, (2) the institutional mediation of substantive uncertainties into insurance risks and (3) the unloading or discharging of insurance risks as empirical uncertainties on individuals, institutions and throughout the citizenry. These three interrelated processes of the IC of insurance markets are respectively analysed through three Polanyian-inspired concepts: (i) the necessarily incomplete and destabilizing institutionalization of the SRM utopia, (ii) private insurance risks as fictitious commodities and (iii) the diversity of the institutional modes of economic integration.

\subsubsection{Insurance markets as institutions}

Le riche tient la loi dans sa bourse. (Rousseau, 1764: 287)

One of the main achievements of contemporary economic sociology (CES) has been to provide alternative approaches to the study of markets as opposed to the one offered by the neoclassical synthesis-inspired economics of the second half of the $20^{\text {th }}$ century (see Blanchard, 2008). Nowadays, a standard economics textbook definition usually roughly suggests that a "market is a mechanism through which buyers and sellers interact to determine prices and exchange goods, services, and assets." (Samuelson and Nordhaus, 2010: 26). As the concrete of markets, prices are seen as the main mode of coordination through which isolated producers will adjust their offer and consumers will set their 
preferences. The interactions between producers and consumers, and especially the consumers' preferences, would thus push prices toward equilibrium, albeit imperfect. ${ }^{107}$

This abstract conception of the market as an impersonal force thus claims that markets provide "the appropriate space to give free rein to the equally abstract behavior of the homo oeconomicus seeking solely economic gains and following the "economic" rule consisting in using given means in order to maximize ends (or minimalizing the use of means for a given result)." (Steiner, 2005a: 30; my trans.). Standard economics hence normatively employ this representation in order to determine how production could be optimally organized and how consumers should maximally behave. This abstract conception actually depends on a specific vision of the social world based on at least two questionable hypotheses. First, agents must be aware of the different possible future conditions of reality, but also of their likelihood. Second, agents must also be knowledgeable about the availability and quality of the different goods and services, excluding any form of uncertainty (ibid.: 34$).{ }^{108}$

But how did CES and the Polanyian concept of markets as institutions overcome these problematic neo-classical assumptions? In order to conceptualize the theory of the IC of markets as a framework for the study of the insurance industry, Section 3.2.1 starts by discussing the contributions from CES to the study of markets as social formations before presenting a Polanyian definition of markets as politically and legally constituted

\footnotetext{
${ }^{107}$ As Samuelson and Nordhaus (2010: 27) propose, "[p]rices coordinate the decisions of producers and consumers in a market. Higher prices tend to reduce consumer purchases and encourage production. Lower prices encourage consumption and discourage production. Prices are the balance wheel of the market mechanism."

${ }^{108}$ See also Orléan $(2004,2005)$.
} 
institutions. Then, the analytical function of uncertainty within the theory of the IC of markets is presented through a discussion of the concept of double-movement.

\section{Markets beyond neo-classical theory}

Against the neo-classical concept of market, CES initially conceptualized markets as social formations. ${ }^{109}$ First, new economic sociology suggested that markets originate from the fact that agents have to manage uncertainty through mutual observation and comparison (see White, 1981). This approach focuses on networked processes of differentiation in terms of quality and niches. Second, CES also investigated the ideational and technical construction of markets understood as performative accomplishments requiring specific forms of knowledge and calculative devices (see Callon, 1998a; MacKenzie et al., 2007). From the perspective of the theory of performativity, attention is paid to economic knowledge and technical devices enabling private exchange by constructing both the agents' calculative ability and the calculability of goods. Third, the political-cultural approach (Fligstein, 2001) analyses markets as fields in which regulations are the object of political struggles. It sheds light on markets as requiring stabilization through political processes resulting in specific histories of struggles over property rights and corporate governance structures. Throughout political struggles, firm-level strategies emerge and industry-level "conceptions of controls" become dominant (see Fligstein, 1990).

In contrast to White (1981) and the idea that markets enable agents to deal with uncertainty through differential interactions, but also against neo-classical (Clark, 1892;

\footnotetext{
109 For more extensive reviews of the economic sociology of markets, see Fligstein and Dauter (2007), Krippner (2001) and Steiner (2005b).
} 
Knight, 1921) and neo-liberal theories of uncertainty (Hayek, 1988), the Polanyian analysis claims that markets actually generate uncertainty due to the necessarily incomplete and destabilizing institutionalization of the SRM utopia (see below). Second, while the theory of the IC of markets considers knowledge and technical devices as central components in the construction of markets (see Block and Somers, 2014: 107), it nevertheless claims that they are both insufficient in constituting markets and that they themselves require political and legal constitution. ${ }^{110}$ The Polanyian theory of the IC of markets rather focuses on the epistemic forms of the SRM utopia, their necessarily incomplete and destabilizing institutionalizations, and the gaps between these forms as theoretical representations of the functioning of markets and the reality of the politicallegal and non-competitive constitution of empirical markets. It has also been suggested to adopt a "multi-perspective" on insurance markets as differential social formations, as performative constructions, and as fields of struggles (Ossandon, 2015). But the politicalcultural approach to markets as fields (Fligstein, 2001) indicates that markets are more than results of the interactions between agents and that market making requires more than performative epistemic and technical constructions.

On the one hand, the theory of the IC of markets shares several theoretical positions and analytical orientations with Fligstein's (2001) political-cultural approach. The first of these is the centrality of the political in market construction and maintenance. Both frameworks shed light on the necessity for state interventions in market making, on the legal foundation of markets, on the role of political and economic elites as well as on

\footnotetext{
${ }^{110}$ See for instance Mazzucato's (2013) analysis of the constitutive function of the "entrepreneurial state" for major innovative and technological markets. See also Block and Keller (2011).
} 
the empirical normality and analytical significance of recurring crises in the study of markets.

On the other hand, these two frameworks also diverge. While the political-cultural approach focuses on markets' internal stabilization - for instance by stressing the interplay between state institutions and firms in providing shared understandings, rules of the game and conceptions of control -, the Polanyian theory of the IC of markets sheds light on the "external" or constitutive institutional interventions and arrangements required in order to render possible the existence of markets. In other words, while the political-cultural approach "privileges the bottom-up perspective by way of focusing on actors and relations in a specific field" (Frerichs, 2009: 23-4), the IC of markets focuses on markets' institutional and societal conditions of possibility. ${ }^{111}$ Moreover, despite shedding light on the political construction and maintenance of markets, the politicalcultural approach does not offer a systematic interpretation and reconstruction of Polanyi's core conceptual apparatus. This theoretical reconstruction is required in order to make sense of the functioning and constitution of insurance markets.

\section{Insurance markets as politically and legally constituted institutions}

Real market societies need the state to play an active role in managing markets, and that role requires political decision making; it cannot be reduced to some kind of technical or administrative function. (Block, 2001: xxvi)

The recent renewal of Polanyian institutional analysis has slowly begun focusing on the legal and political constitution of the economy in general and markets in particular.

\footnotetext{
111 In this manner, the theory of the IC of markets analytically shields the institutional analysis from numerous taken-for-granted assumptions of the political-cultural approach, namely: the intra-firms competition, the use of nonpredatory business strategies as a general rule, the assumption that market actors seek the survival of their firm (not profit-stability or maximization), the inherent dynamism and innovative creativity of market economy, and the variety of (national) capitalisms (see Fligstein, 2001).
} 
Frerichs (2009) argues that "the law is constitutive, supportive or restrictive of many, if not most, economic phenomena; it affects the economy on the level of actors, relations, regimes and rationalities." Stressing the necessity for state intervention in the construction of markets, Veitch (2013) observes the "constitutive role" of law and social policy in the creation and maintenance of profit-making opportunities within public healthcare and workfare schemes under neoliberalism. ${ }^{12}$ Finally, in examining the reregulation of private insurance sexual discrimination in the European Union, Mabbett (2015: 25) observes that "regulation is constitutive for insurance markets." Following this literature, the theory of the IC of markets defines markets as politically and legally constructed and maintained institutions designed for private capitalization. But how should the Polanyian-inspired concepts of constitution and institution be defined?

Through the critique of the economistic fallacy (Polanyi, 1977: 5-6), the Polanyian conception of the economy as being always and everywhere embedded "means that even "free" market economies consist of cultural understandings, shared values, legal rules, and a wide range of governmental actions that make market exchange possible." (Block and Somers, 2014: 9). As Maucourant and Plociniczak (2013: 527) likewise note, "without state intervention, markets cannot emerge, expand and survive. Market society thus rests on particular ideological, political and legal arrangements, which are the social requirement of the market as an institution." While the theory of the IC of markets places the epistemic and cultural constitution of markets in the analytical background, it stresses political and legal interventions as being constitutive of markets. Borrowing from Hunt

\footnotetext{
${ }^{112}$ As Veitch (2013: 137) explains, the welfare state, "[t]he institution that once contributed to ensuring the embeddedness of the market economy in society now play an important role in processes of disembedding - with potentially detrimental consequences for those seeking assistance from the welfare state."
} 
(1993: 310-11), the terms "constitution," "to constitute" and "constitutive" herein refer to institutions and practices creating or directing other institutions and practices. Following the Polanyian institutional analysis, constitution hence refers to both construction and maintenance.

Furthermore, while it resides at the core of the Polanyian framework, the concept of institution has never been explicitly defined by Polanyi himself (Maucourant and Plociniczak, 2013). According to Maucourant (1995: 7), from the Polanyian perspective, “institutions are collective mental entities made rigid by history. [...], institutions, as regularities of collective behaviour which create individual expectations, are the matrix of social order." The institutionalist tradition, for instance starting with Veblen (see O'Hara, 2002: 83), indeed tends to shift between a concept of institutions as "habits of thoughts" and as "established social practices" or "forms of organized collective life."113 At least in the TGT (Polanyi, 1944), it can be suggested that the Polanyian analysis actually integrates both of these definitions (see Maucourant, 1995: 7).

As a matter of fact, TGT's general method consists in articulating the study of the history of liberal thought with the historical analysis of the political-legal construction and maintenance of markets as institutional structures. As a result, the Polanyian concept of institutions should be understood as relations and structures performing the coconstitution of individuals and collectivities through the transformation of habits of thought into relatively stable and regular collective behaviors following a given purpose. Simply put, from the Polanyian perspective, institutions are epistemic and structural

\footnotetext{
113 The interpretation of the Veblenian concept of institutions as "habits of thoughts" might stems from the reading of The Theory of Leisure Class (Veblen, 1899: 61) where Veblen proposed that "institutions are, in substance, prevalent habits of though with respect to particular relations and particular functions of the individual and of the community".
} 
mediations through which individuals and collectivities are co-constituted, hence making up the very fabric of the reality of society. ${ }^{114}$

Building on socio-legal studies and institutional ethnographic sociology of private insurance literatures (see Part 3.1), conceptualizing insurance markets as politically and legally constituted institutions comes as no surprise. In fact, private insurance is a lawintensive business (Baker, 2010). The insurantial relationship is objectified as a contract (i.e. the insurance policy) which itself requires laws and regulations within political, legal and judicial systems. State and public institutions are thus central actors in the functioning of the insurance industry, for instance through public-private collaborations in risk control or reduction, by the public construction of insurance markets through the partial underwriting of risks, and with the state as the insurer of last resort (Ericson et al., 2003). Private insurance governance is not a self-sustaining process since it constitutively requires non-actuarial types of knowledge and non-competitive institutional arrangements.

More specifically, from the Polanyian perspective, insurance markets are hence politically and legally constituted institutions designed for private capitalization on uncertainties of the market economy (organizations of production and business), of the modes of social provisioning and, potentially, of various aspects of the human livelihood. On the one side, the theory of the IC of insurance markets reveals the fact that business and technological innovations, as well as the growth of third-party markets requiring

\footnotetext{
114 Following Durkheim and Veblen, Polanyi thus challenges the idea of the autonomous economy by shedding light on "the always and everywhere embedded economy" (see Block and Somers, 2014: 31) through the recognition of the economy as an instituted process as a constituent of the "reality of society" understood as the interdependence between individuals and societies or "persons and institutions" (ibid.: 227). For more details on Polanyi's concept of "the reality of society," see Block and Somers (ibid.: 218 240).
} 
insurance coverage, lead to the quasi-automatic expansion of insurance profit opportunities (see Strange, 1996). On the other, private insurers do not only capitalize market and business uncertainties, but also what Polanyi defined as the substantive economy, that is the human livelihood understood as the dependence of human beings as individual persons on nature and society as sources of subsistence, social provisioning and recognition (see Polanyi, 1957: 243). ${ }^{115}$ In order to further conceptualize this Polanyian definition of insurance markets, the following subsection turns to the issue of the institutional analysis of uncertainty before presenting, in Section 3.2.2, the concept of insurance risks as fictitious commodities as the central conceptual tool of the theory of the IC of insurance markets.

\section{Uncertainty and the double-movement}

While Marx focused on production (Marx and Engels, 1848) and Schumpeter (1942) on innovation, the Polanyian framework sheds light on uncertainty as institutionally generated by the necessarily incomplete and destabilizing institutionalization of the SRM utopia. In this way, it brings into analytical foreground the institutional arrangements allowing controlling, reducing, eliminating and capitalizing various substantive forms of uncertainty. Polanyian commentators have so far failed to notice that TGT can provide

\footnotetext{
${ }^{115}$ From the Polanyian perspective, the livelihood of human beings depends both on material relations and symbolic recognition, and the economy as an instituted process ensures the mediation between humans and nature, often even contributing to the fulfillment of spiritual and moral needs. This Polanyian theoretical stance is similar to Durkheim's refusal to distinguish an isolated economic form of value (see Durkheim, 1911: 101).
} 
the bases on which to expand the Keynesian theory of epistemic uncertainty through a theory of the institutional production of uncertainty. ${ }^{116}$

Often misinterpreted, the Polanyian analysis actually suggests that the SRM is an utopian representation, and that the history of its attempted institutionalization is the history of the active, necessarily incomplete and destabilizing commoditization of nature, human life and the political institutionalization of society (Block and Somers, 2014; Plociniczak, 2007). ${ }^{117}$ TGT focuses on the political-legal attempts to build a SRM for land, labor and money- the three basic fictitious commodities (see below) - in England throughout the $18^{\text {th }}$ and $19^{\text {th }}$ centuries, and also on the political and legal interventions in mitigating the ensuing disruptions and dislocations in order to both empirically constitute uncertainty-generating markets and to counter-protect society as a whole. TGT points out that the attempted political and juridical institutionalization of the SRM utopia leads to instability, and that state interventions and socio-political struggles set in protective counter-movements - the "double-movement" in Polanyi's terms - seeking to avoid the disruption and potential destruction of the very foundations of society, but also of markets themselves. As Block and Somers (2014: 10) explain,

Polanyi's always-embedded economy leads directly to his concept of the double-movement. As market fundamentalists and their allies attempt to construct their ideal world of a self-regulating market system, the destabilizing consequences set off countervailing movements by other groups in society who recognize the need to protect themselves and others from exposure to unmediated market forces. These countermovements are just as likely to be conservative, even populist and fascist, as market destabilizations will mobilize the right no less than the left, [...]. But in Polanyi's framework, [...], particular policy ideas create shifting constituencies of groups that favor or oppose expanding or constraining markets. And since the project of creating a self-

\footnotetext{
${ }^{116}$ On Keynes and Polanyi, see for instance Block and Somers (2014: 21-8).

117 As Plociniczak (2007: 209 and 214; my trans.) explains, TGT "reveals, more than the effective institutionalization of a SRM, the attempt and failure at institutionalizing a form of socially formulated acting knowledge." In other words, TGT claims that the utopia of the SRM does not lead to the totalizing institutionalization of such an abstract notion of market; rather, "it remains in the realm of beliefs and social representations." Hence, only within the capitalist society and through the lens of the SRM utopia could "the economic" be conceived as an isolated sphere of human activity.
} 
regulating market is ultimately impossible, $[\ldots]$ the largest businesses will defect and openly embrace the use of government for protection against market turmoil.

To sum up, along with Fligstein's political-cultural approach and other institutionalist frameworks, the theory of the IC of markets accounts for the articulation between state politics and the political in market making. With the concept of the doublemovement, it follows the power-distributional theory's approach to institutions as objects of power struggles structured by the evolution of changing social-political movements and coalitions (see Hacker, 1998, 2006; Thelen, 2004). Similarly, the Regulation school of economics (Boyer, 2003, 2004) understand institutions - institutional or structural forms in regulationist terms - as products of institutionalized compromises structured by political struggles between various social groups and the resulting balance of power (rapports de force). Along with the Regulation school, the Polanyian institutional analysis rejects the neo-classical general equilibrium model and places the issue of uncertainty at the heart of market constitution. ${ }^{118}$

The Polanyian theory of the IC of markets considers uncertainty as the consequence of the necessarily incomplete and destabilizing institutionalization of the SRM utopia. In this context, private insurers aim at managing the uncertainties of "the society of the SRM utopia" by privately capitalizing uncertainties of the market economy (productive and business organizations), of the modes of social provisioning and of various aspects of human livelihood. Accordingly, insurers are not alone in insurance markets since private capitalization over uncertainties both requires and faces political

\footnotetext{
118 As Boyer (2004: 23-6) points out, the regulationist framework complements the idea of regulation with the concept of crisis, and thus provide an understanding of the transformations of capitalism by simultaneously including the possibility of a stable economic regime and its various forms of destabilization. On the institutional-historical approach as a critique and alternative to standard, neoclassical economics' general equilibrium model, see also Aglietta (1976: 9).
} 
institutions and struggles. Insurance markets thus involve insurers, politicians, legislators, various public and regulatory authorities, lawyers, jurists and judges, scholars, women, social and citizen movements, and unions, but also accountants, auditors, brokers and third-party businesses and markets involved in or requiring a given type of insurance coverage. Since private insurance governance is not self-sustainable, insurance markets are furthermore themselves generating instability and uncertainty. Through the concept of insurance risks as fictitious commodities, the Polanyian institutional analysis allows us to empirically investigate the ways in which the constitution of insurance markets requires political-legal interventions and other non-competitive institutional arrangements in order to mediate uncertainty as risk, to control and reduce uncertainty, and to distribute risks to individuals, institutions and throughout society.

\subsubsection{Insurance risks as fictitious commodities}

The critique of the $\mathrm{MH}$ paradigm has provided evidence that the insurance industry's private governance through risk classifications and contractual incentives-based controls is not a self-sustaining process (see Part 3.1). Against the $\mathrm{MH}$ paradigm and the neoclassical dichotomy between calculable risks and unmeasurable uncertainty, the theory of the IC of insurance markets borrows from the Keynesian theory of epistemic uncertainty the insight that social conventions and power better explain decision-making under conditions of uncertainty than utilitarian calculus and actuarial rationality (Keynes, 1921; Lavoie, 1985; see also Orléan, 1999). ${ }^{119}$ While Keynes turned to the idea of "animal spirits" after the Treatise on Probability in order to stress that human nature generally

\footnotetext{
119 See Section 3.1.3.
} 
leads individuals to act "on spontaneous optimism rather than mathematical expectations" (Keynes, 1936: 161), Polanyi (1944) rather considered uncertainty as generated by the necessarily incomplete and destabilizing institutionalization of the SRM utopia and located it the core of the institutional analysis through the concept of fictitious commodity. The following presentation begins by quickly reconstructing Polanyi's discussion of the fictitious commodities in TGT before discussing a literature exploring the concept of fictitious commodity (see Jessop, 2007b; Paton, 2010). Then, the concept of insurance risks as fictitious commodities is defined.

\section{The fictitious commodities in The Great Transformation: an update}

As previously mentioned, Polanyian institutional analysis claims that the utopia of the SRM is by definition incompletely institutionalized into empirical markets by the political and legal constitution of the three basic fictitious commodities: land, labor and money. Polanyi (1944: 75) defines these commodities as fictitious since they are not in substance produced for sale; land represents nature, labor is generic human activity or human life per se, and money constitutes one of the modalities of the political institutionalization of society. ${ }^{120}$ And as Polanyi (ibid.: 3) suggests, a self-adjusting market "could not exist for any length of time without annihilating the human and natural substance of society". Although the concepts of land and labor as fictitious commodities are rather clearly operationalized in TGT, the historical and analytical status of money is

\footnotetext{
${ }^{120}$ In a footnote, Polanyi (1944: 76) suggests that "Marx's assertion of the fetish character of the value of commodities refers to the exchange value of genuine commodities and has nothing to in common with the fictitious commodities mentioned in th[is] text." For more details on the evolution of Polanyi's attitude towards Marx, see Block and Somers (2014: 77-81) and Maucourant (1995).
} 
more ambiguous. Two different, but complementary interpretations of the implications of money as a fictitious commodity can be considered as valid.

First, in a similar fashion to Simmel (1900), Polanyi recognizes money as a politically established economic institution through which the co-constitutive relations between individuals and collectivities are objectified. In this sense, money represents one modality of the political objectivation of societally recognized values. ${ }^{121}$ The second interpretation arises from a conceptual ambivalence present in TGT concerning the nature of the third fictitious commodity; while Polanyi (1944: 71) uses the term "money" in the sixth chapter, he then alternatively uses "business organization" (starting ibid.: 77) and "productive organization" (ibid.: 136). Hence, from the Polanyian perspective, the political institutionalization of society, on the one side, and the organization of production in general (macroeconomic level) and of business in particular (firm level) as two empirical forms of the market economy, on the other, can be put at risk by the organizing principle of the SRM utopia. Table 3.1 presents a summary of this updated interpretation of the concept of fictitious commodity as presented in TGT.

\footnotetext{
121 For Polanyi, money is a politically constituted economic institution allowing for the societal objectivation of value on which the four classical functions of money (medium of exchange, unit of account, store of value and standard of deferred payment) depend in the last instance (see Orléan, 2009). While remaining somewhat ambiguous in TGT concerning the issue of money, Polanyi actually refuses to analytically isolate these functions as liberal economists do (see Servet, 1993: 1136-7). The theory of regulation and the economics of conventions have developed a theory of money compatible with Polanyi's approach (see Aglietta and Orléan, 1998, 2002).
} 
Table 3.1. The updated Polanyian fictitious commodities

\begin{tabular}{|c|c|}
\hline \multicolumn{1}{|c|}{ Empirical forms } & Organizing principles \\
\hline Human livelihood: Reality of society & SRM utopia: Fictitious commodity \\
\hline Nature & Land \\
\hline $\begin{aligned} \text { Generic human activity } \\
\text { Political institutionalization of society } \\
\text { (Political objectivation of societal values) }\end{aligned}$ & Labor \\
\hline Market economy & Money \\
\hline $\begin{aligned} \text { Productive organization } \\
\text { (Macroeconomic level) }\end{aligned}$ & \\
\cline { 1 - 2 } $\begin{array}{c}\text { Business organization } \\
\text { (Firms and markets level) }\end{array}$ & \\
\hline
\end{tabular}

While the fictitious commodities are effectively constitutive components of the market economy, Polanyi argues that "the fiction of their being so produced became the organizing principle of society." (ibid.: 79). In other words, markets as institutions for private capitalization of the empirical forms underlying the fictitious commodities are organized through the SRM utopia according to which private actors allegedly produce fictitious commodities and efficiently regulate their allocation and trade. In contrast to this organizing principle, TGT points to the IC of markets both as the attempted institutionalization of the SRM utopia and as the counter-protections from the instability and uncertainty this utopian project generates for the underlying substantive constituents of society (nature, human beings and the political institutionalization), but also for the organizations of production (macro-economic level) and business (firm-level). For Polanyi, the commoditization of land, labor and money is never total, and its extent and configuration depend on political struggles and state interventions.

Through political and juridical means, the "making-fictitious" of nature, human activity and money as commodities generates potential disruptions and dislocations such 
as labor exploitation, injury, disease, ecological destruction, speculation, crisis and war. On the one hand, the "liberal creed" of the SRM conceals the fact that "the state establishes the noncontractual bases of contract and is centrally involved in constructing the markets for the fictitious commodities." (Block and Somers, 2014: 96). ${ }^{122}$ On the other hand, the Polanyian analysis rejects the assumption of pure competition in favour of the study of competition/collaboration dynamics within institutionally constituted empirical markets. As Polanyi (1944: 63) suggests, "[...] if competition would tend to disorganize trade, there is no contradiction in eliminating it." ${ }^{123}$ Simply put, the concept of fictitious commodity sheds light on the fact that private capitalization within markets as institutions generates instability and uncertainty, and thus depends both on politicallegal interventions and on non-competitive institutional arrangements.

The literature focusing on the concept of fictitious commodity is surprisingly thin. For instance, Jessop (2007b: 115) suggests that this Polanyian concept exposes "the liberal propensity to treat [land, labor and money] as if they were real commodities [as] a major source of contradictions and crisis-tendencies in capitalist development." More precisely, Paton (2010: 79) corroborates the SRM utopia reading of the TGT by arguing that the concept

highlights a structural contradiction stemming from the tension between concrete reality and the idealist construction of the economy in neoclassical theory. This contradiction directly challenges the idea that, in capitalism, the state is 'outside' the market and that market instruments are the most 'efficient' means for regulating the production and distribution of commodities. On the

\footnotetext{
${ }^{122}$ As the authors add: "Moreover, Polanyi also lays the basis for understanding that tax policies, technology policies, competition policies, and trade policies are not incidentals, but fundamental to structuring how different market societies operate." (Block and Somers, 2014: 96).

${ }^{123}$ Further, Polanyi (1944: 69) adds, concerning the construction of the market economy in $18^{\text {th }}$ and $19^{\text {th }}$ centuries England: "State intervention, which had freed trade from the confines of the privileged town, was now called to deal with two closely connected dangers which the town had successfully met, namely, monopoly and competition. That competition must ultimately lead to monopoly was a truth well understood at the time, while monopoly was feared even more than later as it often concerned the necessaries of life and thus easily waxed into a peril to the community."
} 
contrary, the commodification of labour generates systemic requirements for extra-market regulation if the market system is to be made compatible with the on going reproduction of society.

As Polanyi (1944: 75) pointed out, the fictitious commodity's underlying substantive form is not and cannot be produced for sale on the market. This empirical form cannot thus be totally privatized and commodified; while being privately appropriated and capitalized, the production, regulation and distribution of the fictitious commodity cannot be completely private and intrinsically generates instability and uncertainty. The underlying empirical forms are being privately appropriated and capitalized as if private actors could efficiently produce, regulate, allocate and trade the fictitious commodities. But there is a gap between this organizing principle of the fictitious commodities and the empirical functioning of markets as institutions. This explains why the fictitious commoditization process depends both on political-legal interventions and on noncompetitive institutional arrangements. Building on this Polanyian concept, how can insurance risks be conceptualized as fictitious commodities?

\section{Insurance risks as fictitious commodities}

At the core of the theory of the IC of insurance markets, the concept of insurance risks as fictitious commodities account for the fact that private insurance capitalization of empirical uncertainties depends on the fictitious commoditization of these underlying uncertainties as insurance risks by virtue of political-legal interventions and other noncompetitive institutional arrangements. Building on three central concepts, Polanyian institutional economic sociology sheds light on the three central processes in the institutional constitution of insurance markets: (A) the necessary incomplete and destabilizing institutionalization of the SRM utopia enables us to study the institutional 
production of uncertainty; (B) the concept of insurance risks as fictitious commodities illuminates the institutional mediation of empirical uncertainties into fictitiously commoditized insurance risks; and (C) the diversity of the institutional modes of economic integration sheds light on the constitutive decommoditization and individualization of insurance risks. Before discussing these concepts and processes, the next subsection first presents three main reasons, provided by the emerging sociology of insurance literature, as to why insurance risks should be conceptualized as fictitious commodities.

First, since private insurance is the business of transforming uncertainty into knowable risk (see Ericson and Doyle, 2004c), the financial and organizational incentives the insurance industry deals with prevent insurers from seeking the elimination of the underlying uncertainties. ${ }^{124}$ Second, the constitution of an insurance market requires certain levels of uncertainty control and, sometimes, reduction. ${ }^{125}$ In this context, the insurers' private risk classifications and incentives-based controls ultimately have to be supported by collaborations with public authorities, regulators and legislators. Finally, despite claiming to be based on risk mutualization as the organizing principle of insurance governance, the private insurers' struggle for profit-making ironically leads to risk unpooling, to risk creation, to financial risk-taking, to insuring highly uncertain risks and to the creation of fraud (Doyle and Ericson, 2010). The ironies of the insurance

\footnotetext{
${ }^{124}$ For example, life and health insurers face no financial interests in comprehensively fighting rising prescription drug costs in Canada (see Chapter 5) and insurers and reinsurers are far from being leaders in the fight against climate change (see AODP, 2016).

${ }^{125}$ See, for instance, the case of terrorism insurance markets (see Bougen, 2003, 2009; Ericson and Doyle, 2004a).
} 
industry can be considered as externalities that private insurance governance ejects on individuals, institutions and the citizenry.

At its most abstract level, the construction of an insurance market could be seen as stemming from a specific "insurantial imaginary" (see Ewald, 1991). ${ }^{126}$ But concretely, the classification, pricing and underwriting of insurance risks presume that insurers objectify underlying uncertainties as a given level of capital against which a promise of future indemnification or reimbursement is offered through a contract providing a "predefined compensation rule" (Lehtonen and Liukko, 2011: 35), notwithstanding the specific nature of the covered uncertainty (see Ericson and Doyle, 2003; Ewald, 1986). As François Ewald (1991: 199) famously pointed out, "[n]othing is a risk in itself; there is no risk in reality. But on the other hand, anything can be a risk $[\ldots]$ insurance is first and foremost a schema of rationality, a way of breaking down, rearranging, ordering certain elements of reality." 127

Uncertainty, however, actually represents the essential condition of possibility for the operation of private insurance (see Courbage and Liedtke, 2003). As Chapter 4 explains in details, the insurance industry initially emerged in England between the late $17^{\text {th }}$ and the late $18^{\text {th }}$ centuries as life and fire mutual insurance societies. The first insurers provided a response to and constituted a component of the novel and growing uncertainties characterizing the new English economy and society. Traditional forms of solidarity typical of feudalism such as customary rights and obligations as well as village

\footnotetext{
${ }^{126}$ For a great example of the insurantial imaginary at work, see Shiller (1993).

127 The gap between, on the one side, the potential pains, losses and damages experienced as empirical uncertainties and the actual injuries and illnesses, theft, accidents or any other covered occurrence and, on the other side, the indemnification or reimbursement as capital is indeed a source of both symbolic and material conflicts between the insurer and the insured (see Ewald, 1986: 178).
} 
reciprocity schemes had started weakening following the agrarian revolution and the ensuing rapid urbanization. From the English origins of the market society until the present day, the insurance industry has developed an increasingly wide and complex set of insurance products covering - in Polanyian terms - the uncertainties generated by the necessarily incomplete and destabilizing institutionalization of the "society of the SRM utopia" over the human livelihood, the modes of social provisioning and the market economy itself. ${ }^{128}$

(A) From the Polanyian perspective, the SRM constitutes a utopian representation and the history of the attempted institutionalization of this utopia is the history of the active and forced commoditization of land, labor and money - the three basic Polanyian fictitious commodities - through political and legal interventions. In turn, through the double-movement, political-legal interventions and diverse social movements counterprotect the different conflicting constituents of society against this destabilizing utopian project (Plociniczak, 2007). Furthermore, capitalists themselves selectively request state interventions seeking to ensure the certainty and stability of their own profitability (Block and Somers, 2014). But Polanyian commentators have so far failed to notice that the Polanyian diagnosis of the necessarily incomplete and destabilizing institutionalization of the SRM utopia can be understood as providing the implicit bases of a theory of the institutional production of uncertainty. Rather than focusing on uncertainty through

\footnotetext{
${ }^{128}$ Here is an non-exhaustive list of private insurance coverage of the uncertainties of the market economy, social provisioning and the human livelihood: life, death, workers compensation, disability and health insurance (labour); fire, crops and climate-risks (re-)insurance (nature); life and fire insurance for credit and property (money); credit and political risk insurance, product malfunction liability (productive organization); various liabilities, Director and Officer (D\&O) and Errors and Omissions (E\&O) insurance (business organization). It is worth noting that these types of insurance might be required in order to gain access to property and other financial product such as credit (e.g. life and fire insurance as conditions to access to mortgage).
} 
either production (Marx) or innovation (Schumpeter), the Polanyian approach can build upon the Keynesian insight and consider that institutions and power must be independent variables in the socio-economic analysis of uncertainty.

Accordingly, the institutional interventions and arrangements providing means to control, reduce, eliminate and capitalize various uncertainties are brought into the analytical foreground. Through the study of this first process of the IC of insurance markets, Polanyian institutional economic sociology sheds light on the epistemic forms of the SRM utopia, their incomplete and destabilizing institutionalization, and the gaps between these forms as abstract representations of the functioning of markets and the reality of the political-legal and non-competitive constitution of markets as institutions.

(B) As Polanyi (1944) pointed out, the fictitious commodities' underlying empirical forms - nature, human life and the political institutionalization of society - are not and cannot be produced for sale on the market. In other words, the production, distribution and regulation of these underlying empirical forms cannot be totally privatized and marketized. Private capitalization of the fictitious commodity intrinsically generates instability at best, and destruction, at worst. Interestingly, uncertainty represents the insurer's "raw material." The classification, pricing and underwriting of insurance risks presume that insurers objectify the underlying uncertainties as a given level of capital against which a promise of future indemnification or reimbursement is offered, notwithstanding the specific nature of the covered uncertainty (see Ericson and Doyle, 2003; Ewald, 1986). The gap between the potential pains, losses and damages experienced as empirical uncertainties and the actual injuries and illnesses, theft, accidents or any other covered occurrences, and their indemnification or reimbursement 
as capital is indeed a source of both symbolic and material conflicts between the insurer and the insured. But this basic conflict between the insurer and the insured stems from the fact that the uncertainties underlying insurance risks are initially generated and mediated in wider institutional and societal settings, out of the scope of private insurance governance.

Before being institutionally mediated as insurance risks, these uncertainties are substantive since they are empirically experienced in non-insurance settings through various non-insurantial modes of perception, organization and provisioning. From the Polanyian perspective, the uncertainties experienced by individuals and threatening social provisioning, nature, and the market economy - both at the firm and macro-economic levels - provide a quasi-infinite array of uncertainties which private insurers can capitalize. ${ }^{129}$ While different non-private insurance institutions and arrangements can perform the removal, reduction and control of substantive uncertainties, the financial and organizational incentives the insurance industry deals with nonetheless prevent insurers from seeking the complete removal of uncertainties they cover as insurance risks. Moreover, private insurance governance cannot autonomously ensure the specific levels of uncertainty reduction and control it requires in order ensuring the relatively stable and profitable capitalization of underlying uncertainties.

Under these conditions, private capitalization of substantive uncertainties through their necessarily destabilizing and incomplete commoditization as insurance risks - depends on the political-legal and non-competitive control and reduction of uncertainty.

\footnotetext{
129 As previously mentioned, business and technological innovations, as well as the growth of third-party markets requiring insurance coverage, lead to the expansion of insurance profit opportunities (see Strange, 1996: 130-1).
} 
Through its core concept of insurance risks as fictitious commodities, the theory of the institutional constitution of markets allows us to study a second process, vital to the insurance industry: the institutional mediation of substantive uncertainties into insurance risks. The concept of insurance risks as fictitious commodities highlights the gap between "insurance risk" as the organizing principle of private insurance governance and its destabilizing and uncertainty generating attempt at autonomously covering and commoditizing empirical uncertainties, on the one side, and the necessary political and legal constitution of insurance markets as institutions, on the other.

With or without available and robust actuarial data and extra-actuarial knowledge, it is not sufficient for the insurance industry to privately organize, commoditize and control uncertainties through risks classification and contractual incentive-based controls, and to financially hedge and spread insurance risks onto reinsurance and financial markets. Private insurers have to collaborate with legislators, policy-makers, and regulators as well as with each other in order to ensure the relative stabilization of their capitalization of substantive uncertainties they cover as fictitiously commoditized insurance risks. Table 3.2 summarizes the Polanyian concept of insurance risks as fictitious commodities.

Table 3.2. Insurance risks as fictitious commodities

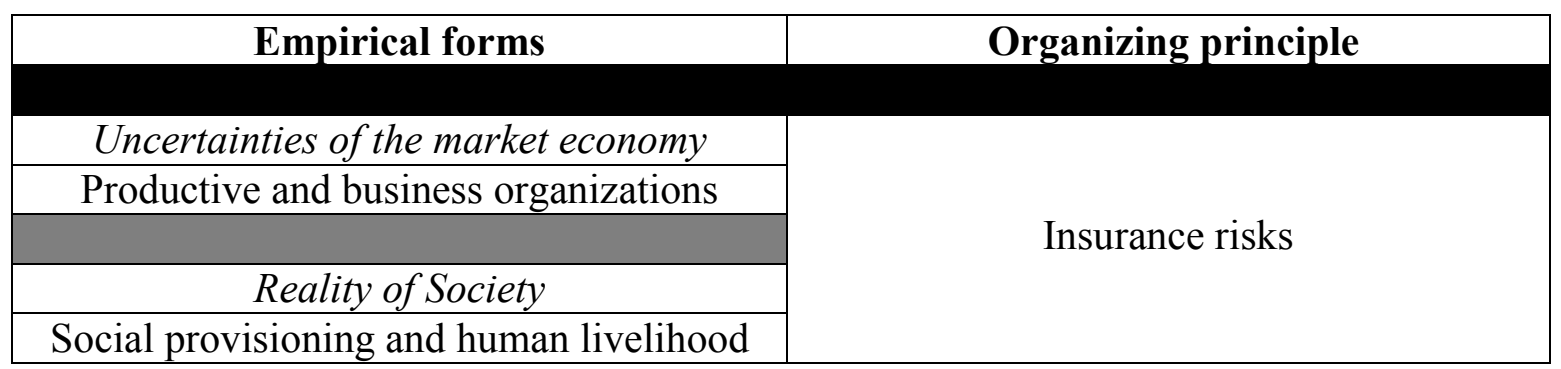


(C) Accordingly, the concept of insurance risks as fictitious commodities points to the third process in the IC of insurance markets: the decommoditization and individualization of insurance risks. The constitution of insurance markets can require the unloading of insurance risks as empirical uncertainties on individuals, institutions and throughout the citizenry. The status of private insurance risks as fictitious commodities leads to the analysis of the constitution of insurance markets as relying on the diversity of the institutional modes of economic integration (reciprocity-mutuality, redistributionintervention and relative autarchy) necessary for the decommoditization of insurance risks. The fictitious commoditization of insurance risks thus also means that the integrity of private insurance capitalization of underlying substantive uncertainties can entail the decommoditization of insurance risks - generally those insurance risks deemed as "bad," "high" or even "uninsurable" by insurers - through redistributive and reciprocal-mutual institutional interventions and arrangements.

As Chavance (2009: 30) notes, "Polanyi's theory can be regarded as among the principal sources of the institutionalist theses that place the emphasis on the diversity of modes of co-ordination that coexist in an economic system (Hollingsworth, Boyer, Kornai), unlike the theories of economic co-ordination that call on essentially dualistic models (market/State or market/organization)." In the case of the insurance industry, the fictitious commoditization of empirical uncertainties means that the private insurers' capitalization of these underlying uncertainties entails the decommoditization of insurance risks through the diversity of the institutional modes of economic integration. Since the private insurance governance cannot alone proceed to the reduction and control of the underlying uncertainties it covers as capital, the integrity of insurance markets 
indeed relies on the unloading of insurance risks - generally the "bad" or "high" risks on redistributive (e.g. policy, law, the state as the insurer-of-last-resort) and reciprocalmutual (e.g. industry-wide agreements, social economy, etc.).

In contrast to reciprocity, redistribution and exchange, TGT nevertheless includes a much less discussed institutional mode of economic integration: autarchy. While Jessop (2007b: 116) refers to autarchy as the "household based on autarkic production to satisfy the needs of a largely self-sufficient unit such as a family, a settlement, or manor," the theory of the IC of insurance markets considers autarchy as the forced financial selfsufficiently due to the individualization of insurance risks. The fictitious status of insurance risks as commodities can indeed lead the insurers to unload risk directly on individuals by compelling the insured to resort to out-of-pocket funds in place of insurance indemnity or reimbursement.

In practice, private insurers leave the insured in conditions of relative autarchy when coverage is denied, when specific or correlated risks are excluded, when paying a deductible is required, and when annual or lifetime maximum coverage is imposed and out-of-pocket spending ensues. While this occurs to some extent ex ante through decisions of uninsurability, contractual exclusions and contractual controls (i.e. deductibles, co-payments and co-insurance and maximums), the insured can also face ex post situations in which the insurer determines that specific conditions and circumstances authorize the denial of a claim. This individualization of insurance risks can moreover be a signal that the state as the insurer of last resort must or will jump in and intervene as a market maker. Figure 3.1 outlines how the analysis of insurance risks as fictitious 
commodities sheds light on the diversity of the institutional mode of economic integration on which relies the constitution of insurance markets.

Figure 3.1. Insurance markets and the modes of economic integration

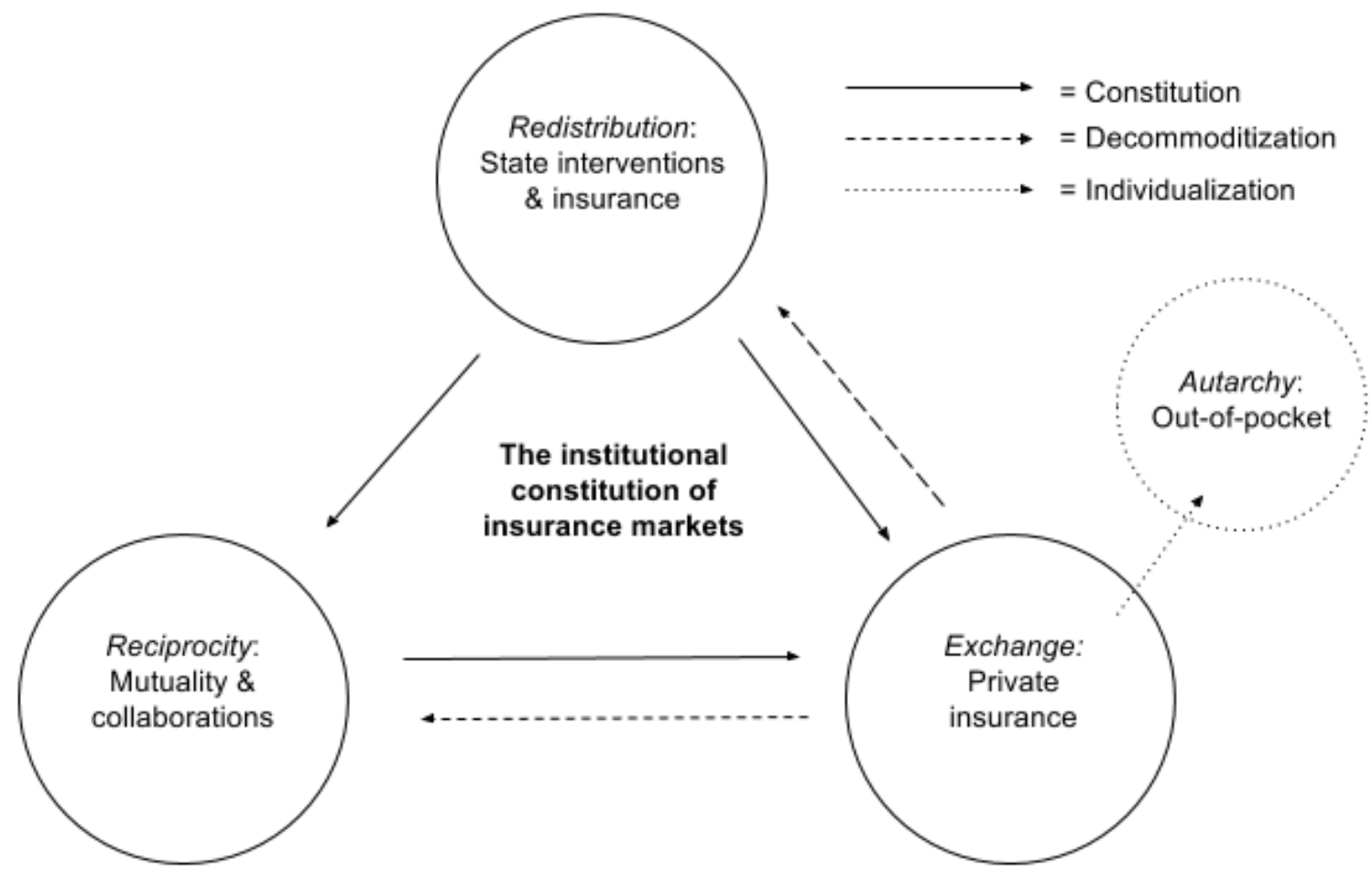

\subsubsection{Partial conclusions: the institutional constitution of insurance markets}

From the formulation of new economic sociology until very recently, the Polanyian literature has failed to reconstruct the core conceptual apparatus of TGT beyond the embeddedness-centered interpretation. The recent renewal of the Polanyian institutional analysis has slowly begun stressing the legal and political constitution of the economy in general and markets in particular (Block and Somers, 2014; Frerichs, 2009; Mabbett, 2015; Plociniczak, 2007; Veitch, 2013). Building on this literature, the theory of the IC of markets defines markets as politically and legally constructed and maintained institutions designed for private capitalization. The theory of the IC of markets nonetheless moves 
one step further in developing a framework for the sectoral analysis of capitalism in general and the insurance industry in particular through the Polanyian concept of “insurance risks as fictitious commodities.” Following TGT (Polanyi, 1944), the concept of fictitious commodity considers that private capitalization within markets as institutions generates instability and uncertainty, and thus depends both on political-legal interventions and on other non-competitive institutional arrangements.

Instead of investigating how private insurers mediate unmeasurable uncertainties into knowable and thus insurable risks (see Ericson and Doyle, 2004c), the analysis of insurance risks as fictitious commodities rather focuses on the institutional mediation and constitution of various substantive uncertainties into insurance risks, whether or not actuarial data concerning risks and extra-actuarial knowledge concerning the underlying uncertainties is available. To sum up, through this core concept, the theory of the IC of insurance markets considers that private insurance capitalization of empirical uncertainties depends on the fictitious commoditization of theses underlying uncertainties as insurance risks by virtue of (A) the political-legal and non-competitive reduction and control of substantive uncertainties insurers cover as capital and (B) the decommoditization and individualization of insurance risks by their unloading as empirical uncertainties through the diversity of the institutional modes of economic integration.

Along with the Polanyian concept of the necessarily incomplete and destabilizing institutionalization of the SRM utopia and the diversity of the institutional modes of economic integration, the Polanyian institutional analysis of insurance risks as fictitious commodities sheds light on the three processes of the IC of insurance markets: (i) the 
institutional production of uncertainty, (ii) the institutional mediation of uncertainty into insurance risk and (iii) the unloading of private insurance risks on individuals, institutions and throughout the citizenry.

First, the Polanyian commentators have so far failed to notice that, in contrast to the Marxian focus on production and the Schumpeterian emphasis on innovation, TGT enables us to expand the Keynesian theory of epistemic uncertainty - according to which social conventions and power better explain decision-making under conditions of uncertainty than the utilitarian calculus and the actuarial rationality - by providing the implicit bases of a theory of the institutional production of uncertainty. The Polanyian framework sheds light on uncertainty as institutionally generated by the necessarily incomplete and destabilizing institutionalization of the SRM utopia, both in the insurance industry and in the third-party businesses and markets requiring insurance coverage. ${ }^{130} \mathrm{In}$ accordance with the Polanyian institutional analysis, the theory of the IC of markets suggests that the attempted political-legal institutionalization of the SRM utopia leads to instability, and that political-legal interventions and socio-political struggles in turn set in protective counter-movements - the "double-movement" in Polanyi's terms - seeking to avoid the disruption and destruction of societies and markets. From the Polanyian perspective, insurance markets are hence politically and legally constituted institutions designed for private capitalization of the uncertainties of the market economy (productive

\footnotetext{
${ }^{130}$ More specifically, the theory of the IC of markets points to the epistemic forms of the SRM utopia, their incomplete and destabilizing political-legal institutionalization, and the gaps between these abstract representations of the functioning of markets and the reality of the political-legal constitution of empirical markets. In doing so, it directs the analysis towards the institutional arrangements allowing controlling, reducing, eliminating and capitalizing on various substantive uncertainties.
} 
and business organizations), of the modes of social provisioning and, potentially, of various aspects of human livelihood.

Second, while Keynes later turned to the idea of "animal spirits" after the Treatise on Probability in order to stress that human nature generally leads individuals to act "on spontaneous optimism rather than mathematical expectations" (Keynes, 1936: 161), Polanyi (1944) rather considered uncertainty as generated by the necessarily incomplete and destabilizing institutionalization of the SRM utopia and located it at the core of the institutional analysis through the concept of fictitious commodity. ${ }^{131}$ Markets as institutions designed for private capitalization are organized through the SRM utopia, as if private actors actually produced the fictitious commodities and efficiently regulated their allocation and trade. In contrast to this organizing principle, TGT points to the IC of markets both through the attempted institutionalization of the SRM utopia and the counter-protections from the instability and uncertainty this utopian project generates for human beings, nature, the political institutionalization of society, and the market economy. To sum up, the concept of fictitious commodity sheds light on the fact that private capitalization within markets as institutions produces instability and uncertainty, and thus depends both on political-legal interventions and non-competitive institutional arrangements.

Furthermore, the study of insurance risks as fictitious commodities reveals that private insurers have to maintain or at least control the underlying uncertainties they

\footnotetext{
${ }^{131}$ For Polanyi, the commoditization of land, labor and money - as the empirical forms constituting both the "reality of society" and the market economy - is never total and risks destabilizing nature, human life, the political institutionalization of society, and the market economy itself. In addition, through the doublemovement, the extent and configuration of commoditization depend on state interventions and socialpolitical struggles.
} 
profitably cover. Since uncertainty actually represents the condition of possibility for the operation of private, a sense of "pragmatist conservatism" is therefore engrained in the insurance industry. The classification, pricing and commoditizing of insurance risks presume that insurers objectify the underlying uncertainty as a given level of capital covered through a promise to repay or reimburse, notwithstanding the specific nature of the covered uncertainty (see Ericson and Doyle, 2003; Ewald, 1986). As such, the various uncertainties of human livelihood, of the modes of social provisioning and of the market economy are the empirical forms which private insurers capitalize as fictitiously commoditized risks within institutionally constituted insurance markets. As a rule, the financial and organizational incentives the insurance industry deals with prevent insurers from seeking the complete elimination of covered uncertainties, thus potentially putting individuals, institutions, nature and even the market economy itself at risk. Since the constitution of certain insurance markets can necessitate specific levels of uncertainty control and reduction, private insurance governance ultimately has to resort to noncompetitive institutional arrangements and, most importantly, to collaborations with public authorities, regulators and legislators.

Third, the concept of insurance risks as fictitious commodities hence account for the fact that the insurance industry's private governance cannot alone ensure the reduction and control of the underlying uncertainties its covers as capital. Without political-legal interventions and non-competitive institutional arrangements, insurance markets could not survive and function. In this context, the analysis of insurance risks as fictitious commodities sheds light on the constitution of insurance markets as requiring the diversity of the institutional modes of economic integration. With or without available 
and robust actuarial data and extra-actuarial knowledge, it is not sufficient for the insurance industry to privately organize uncertainties through risk classification and contractual incentive-based controls and to privately spread risks in reinsurance and financial markets. Private insurance governance and the integrity of insurance markets can requires the decommoditization and individualization of insurance risks through their unloading as empirical uncertainties on redistributive, reciprocal, and relatively autarchic institutional arrangements.

\section{Normative and political implications}

L'approche "substantive," [...], en distinguant l'économie en général de sa forme "de marché," est en condition de considérer le système économique dans son interrelation avec son environnement - la société, les individus et le monde non humain - et donc d'évaluer [...] l'efficacité de son organisation. C'est de ce point de vue que Polanyi soulève la question politique de la "productivité sociale" de l'économie. Une telle redéfinition de la science économique a été, d'ailleurs, constamment poursuivie par la pensée institutionnaliste, à partir du problème qui traverse l'œuvre de Veblen : la divergence croissante entre, d'une part, la détermination de la valeur des biens sur la base de leur possibilité d'être vendus avec profit et, d'autre part, leur utilité (serviceability) pour la société. (Cangiani and Maucourant, 2008: 38)

By throwing light on insurance risks as fictitious commodities, the theory of the IC of insurance markets is equipped with an analytical apparatus enabling the empirical evaluation of the impacts that the institutional arrangements required by private insurers' capitalization of specific uncertainties have on individuals, institutions and citizenries. On the one hand, it reveals that insurance markets generate instabilities, and investigates how public institutions, social movements, and individuals bear, manage or resist these uncertainties. On the other hand, the study of the IC of insurance markets through the diversity of the institutional modes of economic integration provides a comparative assessment of the extent to and the ways in which each institutional arrangement either promote or prevent the removal, reduction or control of substantive uncertainties. 


\subsection{Research design}

This final presentation of Chapter 3 expounds the operationalization of the theory of the IC of insurance markets. First, it formulates working hypotheses and research questions. Second, the Polanyian historical and political-legal method is presented. Third, the research methodology in data gathering and production is clarified. Part 3.3 finally concludes by displaying the design of this dissertation.

\subsubsection{General question, working hypotheses and secondary questions}

General research question: which political-legal interventions and non-competitive institutional arrangements contribute to ensuring the constitution of insurance markets?

Working hypotheses (WH) and secondary research questions (SRQ)

WH 1. The theory of the IC of markets sheds light on the epistemic forms of the SRM utopia, their incomplete and destabilizing political-legal institutionalization, and the gaps between these forms as abstract representations of the functioning of markets and the reality of the political-legal constitution of markets.

SRQ 1.1. What is(are) the epistemic form(s) of the SRM utopia involved in the constitution of the insurance market?

SRQ 1.2. Which empirical form(s) of uncertainty is being generated?

SRQ 1.3. Which third-party (i.e. non-insurance) innovation or market - requiring or seeking insurance coverage - is involved in the constitution of the insurance market?

SRQ 1.4. Which political-legal interventions and social-political struggles are involved in the attempted institutionalization of the epistemic form(s) of the SRM utopia?

WH 2.1. Insurance markets are politically and legally constituted institutions designed for private capitalization of the empirical uncertainties of the market economy (productive 
and business organizations), of the modes of social provisioning and, potentially, of various aspects of human livelihood, as fictitiously commoditized insurance risks.

WH 2.2. The concept of insurance risks as fictitious commodities sheds light on private capitalization of uncertainties within insurance markets as necessitating political-legal interventions and non-competitive institutional in order to control, reduce, eliminate and capitalize empirical uncertainties.

SRQ 2.1.1. Which empirical form(s) of uncertainty is being capitalized as insurance $\operatorname{risk}(\mathrm{s})$ ?

SRQ 2.1.2. Which political-legal interventions and social-political struggles constitute the insurance market?

SRQ 2.2.1 Which non-competitive institutional arrangements constitute the insurance market?

SRQ 2.2.2. Which collaborations with public authorities, regulators and legislators constitute the insurance market?

SRQ 2.2.3. Does the insurance market lead to the elimination, control or reduction of the empirical uncertainty capitalized as insurance risk?

SRQ 2.2.4. What type of uncertainty is being generated by the insurance market?

WH 3. The constitution of the insurance market can require the decommoditization and individualization of insurance risks through their unloading on redistributive, reciprocal and relatively autarchic modes of economic integration.

SRQ 3.1. Which insurance risks are being unloaded and on which institutional modes of economic integration?

SRQ 3.2. Are the interplays between the institutional modes of economic integration reinforcing-complementary, conflictual and/or producing regulatory capture?

\subsubsection{Methods, case studies, methodologies and data}

Generally speaking, the Polanyian institutional analysis operates in accordance with the historical institutionalist's method according to which once an institution is constructed, it generates both constraints and opportunities shaping future decisions and actions 
(Cioffi, 2010; Streeck and Thelen, 2005). More specifically, the theory of the IC of markets must be operationalized through a historical and political-legal method. On the one hand, it uses a historical method consisting in tracking market constitution through time, space and decisions as experienced by actors (see Aglietta, 1976: 9). On the other hand, it also uses a political-legal method consisting in the investigation of socio-political struggles, as well as legislative and policy interventions involved in the constitution of markets as institutions. The historical and political-legal method can be best applied through Polanyi's (1944) four institutional forms of the market economy: the SRM utopia (the "organizing principle" or form of knowledge); the gold standard (the monetary regime); the liberal state (the form of state) and the international balance of power (the form of the international system). ${ }^{132}$

The analytical relevance of the theory of the IC of markets can be demonstrated both by its capacity to shed light on the historical development of private insurance and to investigate current issues and dynamics in the insurance industry. By reconstructing the historical construction of insurance law through the institutionalization of the insurable interest principle in England between the late $17^{\text {th }}$ and the late $18^{\text {th }}$ centuries, Chapter 4 reveals the modern origins of the insurance industry and shows that more than three quarters of a century before the first explicit formulation of the moral hazard paradigm as the insurance version of the SRM utopia, private insurance governance

\footnotetext{
${ }^{132}$ In the TGT, Polanyi shows how the origins of the market economy (the " $19^{\text {th }}$ century civilization") were built on the idea of the SRM, on the international automatic gold standard, on the liberal state and on the balance-of-power system. These four institutional forms are similar to the theory of regulation's five institutional forms characterizing different "modes of regulation" understood as the bases of each concrete national experiences of a capitalist accumulation regime: 1) the form of monetary constraints (monetary and financial regime), 2) the form of competition (administered competition, monopolistic, competitive, etc.), 3) the configuration of the wage-labor nexus, 4) the form of the state (embedded, limited, etc.) and 5) the modalities of insertion into the international regime (see Boyer, 2003, 2004: 9 and further; Chavance, 2009: 63).
} 
already proved unstable and uncertainty generating. In the current context of the growing public debates over the sustainability of prescription drug coverage in Canada, Chapter 5 presents the central case study of this dissertation and analyses how the Canadian prescription drug insurance market responds to the new nichebuster pharmaceutical business model featuring the arrival of high costs specialty drugs. In doing so, the theory of the IC of markets provides a better understanding of the interactions between private and public insurance coverage and of the interplays between the various institutional modes of economic integration in the context of the emergence of uncertainty in the Canadian prescription drug insurance market.

As a historical primer for the theory of the IC of insurance markets, Chapter 4 brings into focus the legal aspect of the constitution of private insurance through the lens of the historical institutional method. In doing so, it first offers a concrete illustration of the Polanyian critique of the economistic fallacy and aims at debunking the ancient origins of insurance thesis defined as the assumption that private insurance originated as marine insurance in ancient history. Second, building on the social and economic history of insurance literature, Chapter 4 reconstructs the process through which the insurance industry originated between the late $17^{\text {th }}$ and late $18^{\text {th }}$ centuries within the novel English commercial and financial system. Against the ancient origins thesis, a Polanyian institutional analysis of the historical construction of insurance law in England from 1664 to 1774 reveals the modern origins of the insurance industry. It is only in late $17^{\text {th }}$ century emerging English financial capitalism that insurance emerged by gaining its autonomy under novel institutional arrangements: the primacy of private property and the first modern financial system. 
The theory of the IC of markets allows a reconstruction of the 110-year-long process through which private insurance emerged as a relatively autonomous business in England by virtue of the legislative institutionalization of the insurable interest principle. By requiring that the beneficiary of the insurance coverage can demonstrate an objective financial or emotional interest in the insured property or life, the insurable interest principle allowed the political-legal recognition of insurance against widespread insurantial speculation and especially against gambling over human lives. Chapter 4 highlights that the insurance industry emerged as a politically and legally constituted institution before slowly incorporating actuarialism and getting increasingly corporatized by the mid- $19^{\text {th }}$ century. It moreover claims that more than a century before the first formulation of the moral hazard paradigm by the insurance industry as the insurance version of the SRM utopia, financial sector insiders, political and legal actors, and even members of the English public were already implicitly aware that the moral risks conception better describes the nature of the insurantial relationship and that private insurers were themselves a major source of destabilization of the insurance industry. From its origins, private insurance governance already proved unstable and uncertainty generating, and hence required political-legal interventions and non-competitive institutional arrangements in order to ensure its own integrity.

I chose the case of prescription drug insurance coverage in Canada as the central study to examine my research questions. This contemporary case study provides an opportunity to observe a changing insurance market. Despite the fact that health and prescription drug insurers can easily compute actuarial data based on populational health statistics and probabilistic models, the Canadian prescription drug insurance market has 
recently been fundamentally destabilized due to the emergence of "bad" insurance risks generated by new, highly priced drugs for rare conditions. Over the past few years, various stakeholders have raised concerns over the sustainability of the Canadian fragmented public-private prescription drug coverage system (Gagnon, 2014; Morgan, Martin, et al., 2015), and especially of the private employer-sponsored health and prescription drug benefits group plans (CLHIA, 2013a; Coughlin \& Associates Ltd., 2013). These concerns, formulated by health policy academics, health sector unions, healthcare professional associations, and even by the Canadian life and health insurance industry have fuelled growing public debates as to how to reform prescription drug coverage in Canada in the context of the shift from the old "blockbuster" pharmaceutical business model to the new "nichebuster" model. The new nichebuster pharmaceutical business model entails the rise of high costs specialty drugs, now representing the new structural driver of the overall growth in drug expenditures. Generating the emergence of new "bad" insurance risks from the point of view of the private insurance governance, these new specialty drugs constitute a major challenge for the Canadian patchwork system of hybrid public/private prescription drug coverage in general and for the Canadian life and health insurance industry in particular. In fact, the arrival of specialty medicines generates a crisis among the employer-sponsored private health benefits group plans offered and managed by the Canadian life and health insurers.

Presenting the central, present-day case study of this dissertation, Chapter 5 thus brings the political aspect of the IC of private insurance and the analysis of insurance markets as politically and legally constituted institutions into the analytical foreground through the lens of the political-legal institutional method. Its aims at finding how the 
Canadian prescription drug insurance market responds to the rise of the nichebuster pharmaceutical business model and the new high cost specialty drugs. Through the lens of the theory of the IC of markets and the concept of insurance risks as fictitious commodities, it raises the following specific research question: which political-legal interventions and non-competitive institutional arrangements contribute to ensuring the constitution of the Canadian prescription drug insurance market in the context of the rise of high price specialty drugs? By answering this specific question, this central case study moreover attempts to provide answers to the secondary research questions formulated above.

In accordance with Polanyi's multidisciplinary approach, the theory of the IC of markets rests on a pluralist methodology combining (a) library-based secondary research (historical investigations), (b) first- and second-hand legislative, policy and regulatory analyses, (c) analyses of macroeconomic, sectorial and firm-level information and data produced by private organizations and public institutions, and (d) grey literature from the insurance industry and non-insurance organizations involved in insurance markets.

Due to the status of private insurance data as financially valuable commercial information - which causes private insurance data to be either unavailable or extremely expansive to obtain - and due also to the major limitations of official statistical databases in term of disaggregated private insurance data (for instance at Statscan and Institut de la Statistique du Québec), grey literature form the insurance industry will be mainly used in Chapter 5. This grey literature is generally produced by the insurance industry trade 
associations, by private health benefits and data managers, as well as by some single insurance market actors such as brokerage firms and other insurance industry insiders. ${ }^{133}$

\subsection{Conclusion}

In the last analysis, through the core concept of insurance risks as fictitious commodities, the theory of the IC of insurance markets considers that private insurance capitalization depends on the fictitious commoditization of substantive uncertainties as insurance risks by virtue of (A) the political-legal and non-competitive reduction, control and configuration of the underlying uncertainties insurers cover as capital and (B) the decommoditization and individualization of insurance risks through their unloading as empirical uncertainties across the diversity of the institutional modes of economic integration.

The theory of the IC of markets builds on Durkheim (1893) and expands the study of the non-contractual bases of the contract understood as "the set of legal rules and institutions required to formalize property rights and contractual obligations" (Block and Somers, 2014: 93). Following the Durkheimian warning that the anomic division of labour may exacerbate the conflict between labour and capital, generate crisis and lead to the over-specialization of knowledge and science, and in line with Veblen's (1904) investigation into the conflict between industry regulated by the "instinct of workmanship" and business dominated by "predatory instincts," Polanyian institutional analysis ultimately investigates the societal impacts of the institutional interventions and

\footnotetext{
${ }^{133}$ On the issue of grey literature, see Farace and Schöpfel (2010) and Lawrence et al. (2014).
} 
arrangements required by private capitalization within markets as a political issue (see Cangiani and Maucourant, 2008: 38). 


\section{Chapter 4. The modern origins of private insurance: institutionalizing the insurable interest principle in England, 1664-1774}

In accordance with the theory of the IC of markets, Chapter 4 brings into focus the legal aspect of the IC of private insurance through the lens of the historical institutional method. In doing so, it first aims at debunking the ancient origins of insurance thesis. Since the 1990s, historians of insurance have greatly focused on the early history of the insurance industry (see Clark, 1999, 2002, 2010; Lobo-Guerrero, 2011; Pearson, 2004, 2010a), but have left unquestioned the ancient origins of insurance thesis: the assumption that private insurance originated under the form of marine insurance in ancient history. This prevented historians from observing that, from ancient commercial empires to late mercantilism, marine risks coverage was undistinguishable from credit and currency exchange.

Second, building on the history of insurance literature, this chapter aims at reconstructing the process through the insurance industry originated between the late $17^{\text {th }}$ and late $18^{\text {th }}$ centuries within the novel English commercial and financial systems. Against the ancient origins thesis, the Polanyian analysis of the IC of private insurance and the case study of the historical construction of insurance law in England from 1664 to 1774 reveal the modern origins of the insurance industry. It is only in late $17^{\text {th }}$ century emerging English financial capitalism that insurance emerged by gaining its autonomy under novel institutional arrangements: the primacy of private property and the first modern financial system. The theory of the IC of markets allows us to reconstruct the 110-year-long process - starting with pieces of legislation enacted in 1664 (Gaming Act) and 1720 (Bubble Act) and culminating with the legal institutionalization of the insurable 
interest principle (IIP) in 1746 (Marine Insurance Act) and 1774 (Gambling Act) through which private insurance emerged as a relatively autonomous business in England. By requiring that the beneficiary of insurance coverage can demonstrate an objective financial or emotional interest in the insured property or life, the IIP performed the political-legal recognition of insurance against widespread insurantial speculation and especially against gambling over human lives. Simply put, the insurance industry emerged as a politically and legally constituted institution before becoming an actuarially based corporate organization by the mid- $19^{\text {th }}$ century. Before analyzing, in Part 4.2 , the three initial moments in the construction of insurance law in England - mutuality, uncertainty and recognition -, this chapter starts by discussing and debunking the ancient origins thesis.

\subsection{Debunking the ancient origins thesis}

In both lay knowledge and academic debates, it is often believed that the existence of insurance dates back to ancient times. Scholarly discussions concerning the origins of insurance have actually been pursued at least since the turn of the $20^{\text {th }}$ century. ${ }^{134}$ Based on a broad definition of insurance understood as the financial mutualization of risks of perils to which a given group is exposed, the ancient origins thesis is most common in historiography (e.g. Bernstein, 1996; Holdsworth, 1917; Lobo-Guerrero, 2011; Trenerry, 1926). This transhistorical approach tends to conflate Roman Collegia and other types of

\footnotetext{
134 According to de Roover (1945: 172), such a literature could date back to as late as late $19^{\text {th }}$ century Italian, German and French historiographies. A simple review of literature reveals that a significant number of studies on the issue were published, perhaps especially in American academic law journals, during the first half the $20^{\text {th }}$ century (Bensa, 1897; De Roover, 1945; Holdsworth, 1917; Kopf, 1929; Prudential, 1915; Trenerry, 1926; Vance, 1908).
} 
institutions aiming at helping the unfortunate and providing burial in ancient Greece, China and India, with medieval guilds and governmental protections against military and commercial perils. More importantly, the ancient origins thesis and its different versions generally consider that marine insurance represents the origins of insurance per se and attempt to discover embryonic forms of statistical and probabilistic rationalities as conditions of possibility for insurantial practices. A deeper historical analysis of actors, relations and institutions involved in ancient economies and mercantile trade however reveals that insuring, lending and currency exchange could not then be isolated. Part 4.1 claims that when distinguished both from the mere mutualization of risks and from the forms of traditional and communal solidarity, insurance cannot be seen as a transhistorical phenomenon.

\subsubsection{The ancient contracts of bottomry}

The earliest instances of financial operations resembling the modern notion of insurance were intrinsically tied to credit and currency exchange. For example, the Code of Hammurabi $(\approx 1772 \mathrm{BC})$ regulated the contract of bottomry "which is, strictly speaking, a loan made by a shipmaster for repairs to his ship in a foreign port. Such loan is contracted by the master but is repayable by the owners, if the ship reaches its destination." (De Roover, 1945: 175). Through such contracts, shipmasters sought to secure ship maintenance, purchase of cargo and currency exchange at final destination by taking a mortgage upon the keel and freightage (or "bottom") of the ship, pars pro toto. The investments of both ship owner and lender were therefore at risk since the loan would be repaid with a maritime or extraordinary interest only if the ship survived the contractually 
stipulated voyage, period or risks (Lobo-Guerrero, 2011: 15; Trenerry, 1926; Vance, 1908: 6).

As Kaplan and Kaplan (2006: 94) explain, "[i]t is an arrangement that is easy to describe but difficult to characterize: not a pure loan, because the lender accepts part of the risk; not a partnership, because the money to be repaid is specified; not true insurance, because it does not specifically secure the risk to the merchant's goods." As a primitive form of sea loan, the ancient contracts of bottomry hence illustrate the nonexistence of insurance in pre-modern societies. In fact, from ancient commercial empires until Late Middle Ages mercantile long-distance sea trade, the distinction between insurance, credit and currency exchange was absent since premiums, interests and exchange rates were parts of the same financial interactions.

In 1236, Pope Gregory IX (1145-1241) issued the decretal Naviganti in order to prohibit sea loans (foenus nauticum). ${ }^{135}$ Through this evolution of Canon law, the Church was reprobating risk-taking as a title to profit in a loan or partnership (Wood, 2002). Even if the lender faced risk (periculum), receiving interest on capital was considered as usury and was prohibited. ${ }^{136}$ Following Lobo-Guerrero (2011), it can be suggested that proto-modern forms of financial operations have been elaborated in the Western Mediterranean region during the $13^{\text {th }}$ and $14^{\text {th }}$ centuries through the mercantile resistance to the power of the Church. The Commercial revolution constituted the context within

\footnotetext{
135 On the sea loan, see Hoover (1926).

${ }^{136}$ Requiring lending investors to have objective interests in the ownership and use of the property at risk, a central principle to the Church's prohibition of usury, mirrors $18^{\text {th }}$ century English legislation over the principle of insurable interest (see sections 4.2.2 and 4.2.3) as well as $20^{\text {th }}$ century evidence-based underwriting principles (see Lobo-Guerrero, 2011, p. 25).
} 
which the concept of uncertainty was progressively integrated into Christian ethics. ${ }^{137}$ Beyond the Church's moral condemnation of the power exerted by the usurious lender over the needy debtor, the uncertainty intrinsic to insuring, lending and currency exchange ran against the belief in the certainty of God's temporal ordering of the world. In fact, the Catholic Church forbade risk hedging operations due to the belief that "no one should interfere with Providence" (Dockès, 2007: 246; my trans.). The moral and legal status of sea loans was hence questioned in catholic theology as merchants were accused of selling time (Le Goff, 1982). Since uncertainty constitutes insurance's ontological condition of possibility (see Courbage and Liedtke, 2003), it had to be "rendered fungible" by virtue of a transformation of temporality as a cultural category. This process of rendering uncertainty fungible into risk got instantiated mainly through the invention of the third party premium risk-hedging operation.

\subsubsection{The mercantile third-party risk hedging}

During the $14^{\text {th }}$ century, merchants seeking to render uncertainty fungible and tradable developed the maritime exchange (cambium nauticum) consisting in a loan involving a third party to which the insured-borrower paid a premium. The maritime exchange constituted a more sophisticated form of sea loan and allowed the prohibition of usury to be avoided as the interest on the money the borrower received from the lender, including a risk-adjusted premium, was to be repaid as the rate of exchange in final port. In order to do so, the foreign currency was undervalued at the time the loan was issued and, despite profiting from the operation, the lender was still exposed to credit risk (Van Nierkerk,

\footnotetext{
137 The following discussion of the process of "rendering uncertainty fungible" into risk through the development of third party premium hedging operations rests on Lobo-Guerrero (ibid.: 13-33).
} 
1998: 53). ${ }^{138}$ While this type of transaction could not constitute usurious capitalizing over time or speculation over the uncertain future given that the contract unambiguously resulted in a sale, ethical concerns within scholastic debates then turned to the "just pricing" of risks instead of the purely moral issue of the leceity of doing commerce over temporal uncertainty (Ceccarelli, 2001; Lobo-Guerrero, 2011). But as third party riskhedging operations allowed for credit and insurance to be better distinguished, the maritime exchange contract was still intertwined with currency exchange. These transformations in mercantile practices during late Middle Ages illustrate that pre-modern forms of insurance-like operations were still reliant upon credit and currency exchange. For instance, proponents of the ancient origins thesis such as Holdsworth (1917: 88) even acknowledges that "it is only necessary to split up such arrangements into their component parts in order to arrive at the idea of an independent contract of insurance."

Soon, the maritime exchange evolved and was replaced by the ordinary exchange contract (cambium). In such operations, foreign trade was financed through the increasing use of bills of exchange (cambio) which the borrower had to repay at final destination unconditional of losing goods at sea (Van Nierkerk, 1998). The borrower was hence left at risk and compelled to find extra liquidity or coverage. With the first marine insuringlending contracts underwritten in Genoa in 1347 and Palermo in 1350, a fundamental

\footnotetext{
138 As Lobo-Guerrero (ibid., p. 29) notes, "[t]he cambium nauticum or "maritime exchange" [...] is still used today as an instrument for the transfer of sea risks to the lender. [...]. The exchange rate between currencies was usually inflated in order to compensate for the "price' of the risks the lender incurred."
} 
proto-modern form of financial operation was born as insurance became the main motives of some risk-hedging contracts, not a simple clause (Lobo-Guerrero, 2011). ${ }^{139}$

\subsubsection{The early modern insurance on lives}

While the first third party financial hedging of risks on transported goods occurred in the Italian region, the first early modern instances of insuring the life of other persons - or insurance on lives - also involved merchants from the same area. Since insurance on persons was prohibited in all European jurisdictions besides in the Italian Peninsula, the absence of legal restrictions in England on insurance on lives allowed English merchants to gain early control of the emerging business (Clark, 1999). On the one hand, $14^{\text {th }}$ century English slave-owners had begun to cover themselves against the liability of impregnating someone else's slave (Clark, 2010). In this case, insurance represented a protection against the risk of potential financial costs resulting from the rape of a slavewomen, that is the costs of having to buy the slave-women and potentially those related to taking care of the slave-born child. On the other, starting in the $16^{\text {th }}$ century, English merchants initiated underwriting of the lives of English captains and striving or important debtors (Clark, 1999, 2002). Resembling modern key person insurance, insurance on lives represents an early form of insurance but differs from modern life insurance as it will emerge in England at the turn of the 18th century. Such insurance over the lives of important individuals represented, in some cases, a financial protection for lenders. As

\footnotetext{
139 On the history of marine insurance, see Boîteux (1968), Martin (1876), de Roover (1945) and especially Van Nierkerk (1998: 54) on the fuzzy distinction between maritime partnerships and insurance in late Middle Ages.
} 
Lobo-Guerrero (2011: 36) states concerning what is herein referred to as insurance on lives, it

was depicted as a compensatory system by which nations could insure the life of men who died during their voyage by paying certain sums to their heirs or creditors. Creditors were mentioned as being able to insure the life of their debtors if they were to travel abroad. Individuals could also insure their own rents and pensions so that in the event of death they would pass on to their heirs. $[\ldots]$ all of these forms of insurance practices, except against kidnap and ransom, were [then] illegal in France.

Even though these first instances of insurance on lives represent early forms of insurance, they were still responding to the needs of and were still structured under a commercial economy and a credit system characterized by long-distance sea trade and emerging modern colonialism. It hence appears that in ancient commercial empires in which trade was by definition a matter of collective action (Polanyi, 1977; Polanyi et al., 1957a), insurance as such never emerged as a relatively autonomous profit-making activity.

\subsection{The construction of insurance law in $18^{\text {th }}$ century England}

Life insurance was conceived as a vehicle for the amplification of British power abroad, for the stimulation of undercapitalized industries, for social security, moral improvement, the propagation of Christianity, and for turning the uncertainties of life into opportunities for enrichment. (Clark, 2002: 93)

The early modern English commercial and financial systems were very different from continental mercantilist networks since they did not rest on the extensive development of foreign trade, but first and foremost depended on the intensive growth of England's new internal market (Meiksins Wood, 1991). Up until the $17^{\text {th }}$ century, English merchants had developed ad hoc financial operations created for long-distance trade (Knafo, 2008). In the context of the transition from mercantilism and feudalism to capitalism, these practices could not contribute to the new requirements of domestic growth. "Seeking ways to supply liquidity and credit without currency exchange, merchants were 
compelled to devise new techniques of banking." (ibid.: 181). Both the Agrarian and the Financial revolutions indeed structured the origins of insurance in England as the security of land ownership and access to credit and liquidity became dependent upon the insurability of lives (see Lobo-Guerrero, 2011). The modern origins of insurance indeed lie in the initial function of life and fire insurance as a money creating and investment facilitating private institution providing a "license to borrow." Part 4.2 argues that the construction of insurance law in England from 1664 to 1774 reveals these modern origins of private insurance as such.

Between the late $17^{\text {th }}$ and the late $18^{\text {th }}$ centuries, insurance emerged in England both as a response to and as a component of novel and growing uncertainties now characterizing economy and society. Life and fire insurance will first appear in a society in which traditional forms of solidarity typical of Feudalism such as customary rights and obligations as well as village reciprocity schemes had started weakening due to the $16^{\text {th }}$ century Agrarian revolution and the ensuing rapid urbanization. ${ }^{140}$ As these increasingly unstable socio-economic conditions were somehow mirrored in an English taste for gambling (see Clark, 2002), the Act against Deceitful, Disorderly and Excessive Gaming (16 Charles 2, c. 7) was enacted in 1664. Representing a symptom of material uncertainty, moral unease and growing political and legal awareness towards gambling practices in English society, ${ }^{141}$ this act emphasized the distinction between contractual agreements and debts on games such as card games, table games, sports and animal fights

\footnotetext{
${ }^{140}$ For example, dating back to the $16^{\text {th }}$ century, the first Poor Laws represent legislative interventions accompanying the agrarian origins of English capitalism and contributing to the urbanization of society and the construction of wage labor, as peasants were now freed from Feudal dependence relations but constrained to sale their work force on the market due to a lost of access to land as a result of the enclosures (see Meiksins Wood, 2002).

${ }^{141}$ On the close interplay between gambling and finance before, during and after the development of English financial capitalism, see De Goede (2005: 50-57).
} 
on the one side, and other types of legitimate betting that had to be enforced, on the other (O’Malley, 2003).

For the next 110 years or so, the financial productivity of risk hedging operations, not their pure immorality, would provide English judges and courts with the rationale for distinguishing legal from illegal risky contracts under common law, hence allowing for the construction of insurance law. Culminating with the institutionalization of the insurable interest principle through legislation of 1746 and 1774, the construction of insurance law went through three distinct moments: mutuality, uncertainty and recognition. The emergence of the insurance industry hence predates the development of actuarial rationality and its implementation in the insurance industry by the mid-19 century. Despite its institutionalization as a relatively autonomous business vis-à-vis gambling and speculation by the last quarter of the $18^{\text {th }}$ century, private insurance will of course remain in close relations with credit and speculation until present time.

\subsubsection{Mutuality: financial capitalism and insurance mutual societies}

Britain experienced a brief wave of interests in life insurance in the three decades after 1690, when associations like the Amicable Society for a Perpetual Assurance Office and the Society for Widows and Orphans attracted thousands of middle-class Londoners with the promise of mutual protection against financial risk and mutual sharing in a growing investment fund. (Alborn and Murphy, 2013c: xiv-xv)

The emergence of private insurance initially occurred through the co-development of life and fire insurance from the late $17^{\text {th }}$ to the mid- $18^{\text {th }}$ centuries. In the context of chaotic urbanization, catastrophic urban fires such as the 1666 Great Fire of London led to the creation of fire prevention efforts and fire-fighting forces such as parish brigades and night watchmen. Such community-based efforts however quickly failed and, as a result, private fire brigades were soon established by new London insurers (Pearson, 2010a: 87). 
With the institutionalization of the primacy of private property in the constitution of 1688 and the increasing value of properties in the south of England and inside London, the creation of fire insurance responded to a need for owning classes to ensure both financial predictability and social order (Pearson, 2010a). To an even greater extent, life insurance would provide answers to such needs, and it is thus unsurprising that the world's first insurance organizations were mutual societies: the Hand in Hand Fire and Life Insurance Society (1696), the Friendly Society for Widows (1696) and the Amicable Society for a Perpetual Assurance Office (1706). ${ }^{142}$

The immediate political context within which the first insurers emerged was indeed the aftermath of the Glorious Revolution of 1688 (Clark, 1999). By creating the first nationally collateralized debt in 1693 and founding the first modern central bank in 1694, the English state had established the bases of modern banking, credit money and institutional investing (see Knafo, 2008). While literature does not provide much evidence regarding the function of the first insurers in the rise of financial capitalism, Clark's (1999: 7) remarks are significant:

The state's new techniques of public finance in turn prompted financial innovation in the private sector. Company promoters emulated the state's designs or ingeniously piggy-backed their enterprises on the new system of public finance by establishing land-banks, insurance firms, and investment companies of various kinds.

\footnotetext{
142 On the earliest mutual insurance societies, see Clark (1999: 73-6). First mentioned in 1688 in the London Gazette, Lloyd's is oftentimes considered as one of the oldest insurer. Its first activities were informally held in Edward Lloyd's coffee house located in the City and consisted in providing valuable information concerning marine trade risks (De Goede, 2005: 52). Individuals willing to cover shipowners at Lloyd's had to put their names and the amount they covered on a slip, and hence came to be known as underwriters (Abraham and Schwarcz, 2015: 13). Capitalizing on England's growing imperial power, Lloyd's soon offered ship and cargo insurance and is now a leading global specialty insurer (Lloyd's of London, unknown). Since Lloyd's first constituted a community-like marketplace, not a mutual society or a joint-stock partnership (see Kingston, 2007), it falls out of the scope of the current discussion. On the history of Lloyd's, see Cockerell (1984) and Luessenhop and Mayer (1995).
} 
Contrary to what common sense might suggest, private insurers did not initially seek "to protect widows and orphans." The mutual societies provided the first insurers with an institutional form allowing securing capitalist and patriarchal interests of a growing gentlemen middle-class seeking greater access to liquidity, credit and property. ${ }^{143}$ The initial moment in the emergence of insurance has been its pre-actuarial phase characterized by the foundation of "permanent life insurance collectives" (Clark, 2002).

\section{The insurance mutual society}

Constituting the central institutional innovation of the pre-actuarial phase, insurance mutual societies were self-governed by members through elected boards of directors. Instead of predetermining future benefits by calculating levels of premiums as with later actuarial life insurance, these institutions "periodically redistributed membership fees in favor of the beneficiaries of dying members, share and share alike." (ibid.: 82). Yet, insurance societies appeared especially attractive since they combined the individual benefits of financial protection with the advantage of creating a collective capital fund unofficially qualified as "joint-stock" by some early proponents. In that sense, they represented a type financial institution adapted to the needs and security of the expanding landless gentlemen middle-class growing out of the previous Agrarian revolution (LoboGuerrero, 2011). Clark (2002: 92) similarly observes that "insurance societies aspired to fulfill the role played by land in securing the fortunes of grandee families by furnishing a

\footnotetext{
${ }^{143}$ The Friendly Society for Widows' full name was actually The Friendly Society for Widows being a Proposal for Supplying the Defect of Joyntures, and Securing Women from falling into Poverty and Distress at the Death of their Husbands (Clark, 1999: 106, n. 5). Within early English capitalism, members of the first mutual societies were indeed men seeking to hedge the financial risks related to their own death, to the death of another wage-earner, to their own indebtedness and to their inheritance, while women were exploited as they ensured the reproduction of the conditions of production and capitalistic accumulation. On this last point, see Frederici (2004).
} 
durable vehicle for the transmission of commercial fortunes down the generations." Indemnifying members' families in case of death was in fact far from being the primary function of these organizations since they constituted collectively held estates founded in perpetuity. As Clark (ibid.: 90) adds, "participants in early life insurance schemes seem to have responded in part to the promise of conservative management and a security of investment rivaling even estates in land, normally the safest and most highly esteemed of assets."

Banking mechanisms were constitutive components of mutual societies since insurance policies were used as security for loans made to members (Clark, 1999, 2002). While some early proponents of insurance societies envisioned the practical reconciliation of commercial and individualistic ethics with Christian morals of benevolence and charity, these institutions definitely aimed at increasing access to credit, liquidity and property. In this respect, insurance mutual societies embodied the institutionalization of class and patriarchal solidarity by providing banking facilities to their members. ${ }^{144}$ This picture clearly clashes with the way the first mutual societies were describing themselves, that is as an improved market-based solution "superseding traditional forms of poor relief such as charitable trusts, individual bequests, and almsgiving" (Clark, 1999: 83).

\footnotetext{
${ }^{144}$ One can already observe the historical and institutional relatedness of banking and insurance. Backed by state finance and an impersonal sovereign debt, both are able to lend, borrow and invest - with the accumulated capital stemming from deposits for banks and premiums for insurers - through the power of creating credit money and the capacity to financially collateralize uncertainty as risks.
} 


\section{Mutual euphoria: insurance boom and the South Sea Bubble}

Until the early $18^{\text {th }}$ century, marine risks were underwritten by wealthy individuals and merchants in London's coffee houses such as Lloyd's (see Note 9), close by the Thames (Kingston, 2007). But from 1696 to 1721, the British insurance industry experienced a boom with the foundation of around 60 insurance organizations (Alborn and Murphy, 2013c: xiv). ${ }^{145}$ With instability and many failures in marine insurance during the Great Northern War (1700-1720) and the War of Spanish Succession (1701-1714), fire and life insurance societies also got involved in the speculative euphoria leading to the South Sea Bubble.

On June 29 1720, following rapid monetary expansion and intense speculation, the British Parliament passed the Royal Exchange and London Assurance Corporation Act 1719 (6 Geo I, c. 18). Commonly known as the Bubble Act, its "primary objective $[\ldots]$ was to repress competitors of the South Sea Company because $[\ldots]$ other bubbles were draining cash.” (Kindleberger and Aliber, 2011: 88). In fact, both the British government and the South Sea Company appear to have been highly concerned by the explosive growth of the insurance industry as a whole. On the one hand, the Bubble Act created a private duopoly in marine insurance constituted by the Royal Exchange and the London Assurance Company (Harris, 1994). Only a small portion of these organizations' operations involved selling short-term life insurance arrangements (Daston, 1988). On the other hand, and most importantly, while the Bubble Act prohibited all non-chartered joint-stock companies in marine insurance, it permitted private marine underwriting by

\footnotetext{
${ }^{145}$ As Cockerell (1984: 12) explains, "moves were made in 1718 to form marine insurance companies with substantial capital to transact marine insurance. The proposal were opposed by the office-keepers (as brokers were then known) and by many merchants and ship-owners who feared that the proposed companies would constitute an expensive monopoly."
} 
individuals and non-marine insurance unincorporated companies like trusts and partnerships (Kingston, 2007: 384). ${ }^{146}$

As mutual societies, pre-actuarial insurers were indeed mostly unincorporated joint-stock partnerships.

Such partnerships were commonly formed under the law of trusts, based on a ruling of 1673 which stipulated that assets held on trust could not be claimed by the trustees' creditors. The court of chancery permitted unincorporated companies to vest their assets in trustees through a deed of settlement, thus allowing the liability of such a limitation was always in doubt after the passage of the Bubble Act in 1720. Trust law also did not cover the question of transferable shares, which were prohibited by the Act unless a company obtained a specific royal or parliamentary charter. Nevertheless, the lack of formal incorporation did not prevent hundreds of joint-stock partnerships forming satisfactorily under the law of trusts, raising capital and even inserting clauses into their constitutions which purported to protect the liability of their investor. (Pearson, 2004, p. 235)

Most of the two hundred insurance organizations founded in Great Britain from 1700 to 1850 were established as unchartered joint-stock partnerships; before the $1830 \mathrm{~s}$, the British insurance industry was the main industry still relying on unincorporated organizations (Pearson, 2002c). Despite the enactment of the Bubble Act, growing uncertainties in all lines of insurance, continuing insurance-related speculation and, as will be seen, insurantial gambling would lead to a "mid-century shift" in the emergence of the insurance industry (Clark, 2002). But in the first half of the $18^{\text {th }}$ century, the criticisms over insurantial speculation and gambling were not based on a purely moralistic rationale. They instead concentrated on the fraudulent and criminal intents and ramifications of widespread insurance industry practices.

\footnotetext{
146 This might explain why Lloyd's, then still a marketplace for marine risks coverage, would continue to thrive on during the $18^{\text {th }}$ century. For a similar explanation, see Alborn and Murphy (2013c: xiv). On why Lloyd's eventually succeeded over the publicly created private duopoly, see Kingston (2007).
} 


\subsubsection{Uncertainty: insurance, gambling, speculation and the mid-century shift}

Le Comte de Stairs Ambassadeur d'Angleterre paria, selon le génie de sa nation, que le Roi ne passerait pas le mois de septembre. (Voltaire, 1753: 351; my trans.) ${ }^{147}$

In the context of continuing general financial euphoria, insurers soon faced additional uncertainty and instability, not due to a lack of actuarial data, but due to the practical conflation of insurance with speculative ventures and gambling operations - especially on human lives. As Clark (2002: 83) points out, "[1]ife insurance provided [...] the most institutionalized setting for what was in England a rampant habit of gambling on life contingencies." It is also during this period, in 1710, that the governance of state lotteries and lottery-annuities got transferred to the new Bank of England from the Government Lottery Office (De Goede, 2005).

While tontines were still more common than life insurance at the time (Daston, 1988), the first members of insurance mutual societies were directly interested in insurance as a gambling device, as a speculative instrument and first and foremost as a banking facility. By the mid- $18^{\text {th }}$ century, one however observes a transformation getting set in motion: public authorities began to examine more closely the activities of the insurance industry. Starting with the 1746 Marine Insurance Act (19 Geo 2, c. 37), British authorities begun to scrutinize marine insurers in order to prohibit contracts in which the insurer's interest in the insured property could not be proven (O'Malley, 2003; Vance, 1908). In addition, this piece of legislation prohibited marine reinsurance and hindered the underwriting of reinsurance by fire insurers up until the beginning of the $19^{\text {th }}$ century (Pearson, 1997).

\footnotetext{
${ }^{147}$ This quotation is translated from old French. In this excerpt, Voltaire was commenting the reaction of Field Marshal John Dalrymple, second Earl of Stair (1673-1747), then British ambassador in Paris, to Louis XIV's illness which, according to Voltaire (1753: 351), erupted during the month of August 1715.
} 
As a first formulation of the insurable interest principle (IIP) concerning property (or "indemnity strand") insurance (Atmeh, 2011), the Marine Insurance Act constituted a clear sign of growing political concerns towards the practices of the insurance industry. Before the political-legal institutionalization of the IIP, the profit motive provided both life and non-life insurers with incentives to underwrite risks that would most surely lead to deaths or losses. But under common law, the moral character of gambling and speculation was not of first concern to courts and legislators as the protection of commercial value and economic productivity appeared as the main motives backing such interventions (O’Malley, 2003). Thus, the first serious considerations for the IIP were not mainly generated by a "sacred revulsion" (see Quinn, 2008). Of course, the lack of insurable interest could appear much more immoral when concerning the practice of insuring human lives, at least in some specific groups and classes of a still largely religious English society. Apparently, such was not the case in the whole of England. From the mid- $18^{\text {th }}$ century to the early 1770 s, historians of insurance observe a major shift in the evolution of the insurance industry.

While criticisms towards gambling on life contingencies concerned the criminal and fraudulent components of such practices up until the mid- $18^{\text {th }}$ century, animosity then quickly grew towards insurantial betting on lives per se; following the pre-actuarial phase, a "mid-century shift" occurred (Clark, 2002). First, when William Murray $1^{\text {st }}$ Earl of Mansfield (1705-1793), known as Lord Mansfield, was appointed Chief Justice of the Court of King's Bench in 1756 - a nomination representing "the beginning of the development of the modern law of insurance as a part of the common law system" 
(Vance, 1908: 16) ${ }^{148}$ - British legislators, judges and courts had already started acknowledging insurable interest as a major issue. Second, the mid-century shift can be observed in the fact that, as the industry expanded, from being mostly member-owners of self-governed societies most policyholders became customers of corporate third party insurers (Clark, 1999, 2002). As Alborn (2009: 304-305) explains, "the rise of new governance structures (joint-stock insurance companies and mutuals with tighter executive controls) and the passage of the Gambling Act in $1774[\ldots]$ assisted in this transition." ${ }^{149}$ In other words, three quarters of a century before actuarial rationality got institutionalized in the industry at large, the origins of the insurance industry were to be provided first by political-legal interventions and institutional innovations.

The mid-century shift came to an end in the 1770 s when a series of cases - for example the D'Eon Case (gambling over someone's actual sex) and the Pigot Case (betting on family members' moment of death) - sparkled public debates and led to court battles over the proper way in which law had to deal with human life as capital, thus inducing an "attitudinal shift" towards both gambling and insurance (Clark, 2002). As Alborn (2010: 107-8) points out, lawmakers became increasingly worried with "the slippery slope between life insurance and gambling during the third quarter of the

\footnotetext{
${ }^{148}$ See also Abraham and Schwarcz (2015).

149 As mentioned above, "[f]ull incorporation was little used by early British insurers, in sharp contrast to the US where there were nearly 40 corporations selling fire, life, and marine insurance by the $1800 \mathrm{~s}$. The Joint Stock Companies Act of 1844 did release a boom in company foundations which included new lines such as railway accident insurance." (Pearson, 1997: 244). By the mid-1850s and perhaps even more so by the early-1870s, life insurance's foundational principle of mutuality had definitely given way to the corporatization of the industry. "In insurance, the diffusion of shared ownership on a greater scale, the safeguards by the limited liability legislation of 1856 and the Life Assurance Companies Acts of 1870 and 1872 , the growth of company branch networks, expansion overseas, and the institutionalization of interfirm cooperation in the shape of the Fire Offices Committee of 1868 helped determine the rise of "imperial practice' and the final demise of 'voluntarism' and 'participatory politics' among joint-stock companies." (Pearson, 2002c: 12-3).
} 
eighteenth century, when the industry still catered to a relatively small, mostly aristocratic market. Their concern grew out of a rash of cases in which people had taken out policies on the lives of perfect strangers, often celebrities, on the morbid chance that they would die prematurely."

\subsubsection{Recognition: the institutionalization of the insurable interest principle}

Late $17^{\text {th }}$ and early $18^{\text {th }}$ centuries English law and courts construed gambling as moral and thus legal insofar as it contributed to monetary exchange and wealth creation, despite risks of reduction or even destruction of another party's financial interests. Facing growing political scrutiny and public animosity from the mid- $18^{\text {th }}$ century to the 1770 s, promoters of the insurance industry sought means to ensure the recognition of private insurance as a relatively autonomous business. As a matter of fact, "the reality was not that gambling had invaded legitimate business; rather, legitimate business was now being defined against the long-established practice of speculation on the continuance of human life." (Clark, 2002: 85). As will be seen, the last two steps in the initial institutional constitution of private insurance were to be provided by the slow and progressive implementation of actuarial rationality into life insurance from 1762 to the mid-19 $9^{\text {th }}$ century and, first and foremost, by the Gambling Act of 1774 .

\section{The slow institutionalization of actuarial rationality}

The systematic implementation of actuarial rationality into the insurance industry based on statistical demography and probability has long lagged behind its theoretical and technical formulations (see Alborn, 2002; Clark, 2002; Daston, 1987, 1988; Ewald, 
1986). As credit, speculation and gambling resided at the core of the first insurance mutual societies, the slow transfer of political arithmetic from the field of government and its articulation with probabilistic rationality resulted in the development of actuarial life insurance (Lobo-Guerrero, 2011). This process thus furthered the distinction between insurance on the one side and gambling and speculation on the other.

The world's first actuarial life insurer, The Equitable Life Assurance Society, was founded in 1762. Richard Price (1723-1791), writer of Observations on Reversionary Payments (1771) - the classical actuarial work -, was actually working at The Equitable between 1768 and 1775 (Pradier, 2003: 150). In fact, “[t]he Equitable's rates, which nearly all life offices copied prior to 1820 , had been based on Richard Price's investigation into mortality records from a Northampton parish between 1735 and 1780" (Alborn, 2002: 72). ${ }^{150}$ As actuarial rationality could increased the certainty of the insurance contract and thus of insurers' profitability (Pradier, 2006: 21), it also contributed to render life insurance fungible as such. Simply put, it provided the cognitive means to further construct the liquidity of life insurance policies which could now be easily converted into cash and sold as a fungible security (Lobo-Guerrero, 2011). ${ }^{151}$ But it was not until the turn of the $19^{\text {th }}$ century that actuarial rationality begun to spread in the industry at large (Pradier, 2006). As outdated Northampton tables of mortality were still being used, "the actuarial profession itself was not organized until 1848." (Pearson, 1997: 246). ${ }^{152}$

\footnotetext{
${ }^{150}$ On The Equitable, see also Alborn and Murphy (2013c: xv) and Lobo-Guerrero (2011: 48ff).

${ }^{151}$ Hence, the development of the secondary markets for the trade of life insurance (see Quinn, 2008) and the centrality of financial securitization in reinsurance markets are deeply rooted in the early history of the insurance industry.

${ }^{152}$ On actuaries in the Victorian era, see Alborn (1994).
} 


\section{The Gambling Act of 1774}

The final moment in the construction of insurance law in England occurred in 1774 with the enactment by the British Parliament of the Life Assurance Act (14 Geo. 3, c. 48). Perhaps the most important law in the origins of the insurance industry, this piece of legislation known as the Gambling Act was enacted in the context of growing scrutiny and animosity towards the insurance industry as a whole. In contrast to the 1746 Marine Insurance Act, the Gambling Act institutionalized the IIP concerning life insurance as a non-indemnity strand of insurance (Atmeh, 2011) by requiring that the beneficiary of insurance coverage had to demonstrate an objective financial interest as creditor or heir, or an emotional interest in or consanguine relation with the insured life. O'Malley (2003: 252) lists the main provisions of the Gambling Act:

1 No insurance shall be made ... wherein the person or persons for whose use, benefit or on whose account the policy or policies shall be made, shall have no interest, or by way of gaming or wagering. And every assurance made contrary to the true intent and meaning thereof, shall be null and void ... 2 It shall not be lawful to make any policy or policies on the life or lives of any person or persons or other event or events without inserting in such policy or policies the person or persons' name or names interested therein, for whose use or benefit or on whose account such policy is made or under-wrote. 3 In all cases where the insured hath interest in such life or lives, event or events, no greater sum shall be recovered or received from the insurer or insurers than the amount or value of the interest of the insured in such life of lives, or other event or events.

According to Clark (2002: 87-8), "[s]imply put the Gambling Act limited the extent to which the substance of human life could be converted into a commodity."

But in terms of juridical doctrine, while some explain this enactment as mainly grounded on moral motives (see Clark, 2002; Lobo-Guerrero, 2011), others stress a commercial and material rationale. According to O'Malley (2003), the integration of this principle into common law was based on a theory of material value - independently from the theory of classical political economy - according to which the distinction between insurance and gambling was to be made on bases of commercial value and economic 
productivity. As with "the commodity theory of labor [which] was first stated emphatically not by economists but by lawyers" (Polanyi, 1944: 190), the theory of material value on which the legislative institutionalization of the IIP rested was firstly formulated by courts and legislators, not philosophers nor political economists.

In the last analysis, the Gambling Act can be understood as a response to growing physical and moral hazards faced by private insurers as their early $18^{\text {th }}$ century business model relying on interpersonal trust and reputational knowledge was giving way to an increasingly massified and corporatized industry (Pearson, 2002b). As the standard moral hazard paradigm points to the insured as the main threat to the stability of the insurantial relationship (see e.g. Abraham and Schwarcz, 2015: 298), the Gambling Act was actually aiming at the insurance industry as a whole by seeking to remove incentives for underwriting highly risky and highly profitable gambling-like and speculative policies often involving fraudulent schemes and potentially criminal actions (see Clark, 2002).

Against the utilitarian and insurer-biased concept of moral hazard (see Chapter 3), the early history of the insurance industry and the enactment of the Gambling Act provide further evidence that the moral risk paradigm model better describes the nature of private insurance, that is "the ways in which an insurance relationship fosters behavior by any party in the relationship that immorally increases risk to others." (Ericson et al., 2000: 537). Indeed, it seems highly probable that late $18^{\text {th }}$ century British lawmakers and courts were well aware that the organizational structure and financial incentives of private insurers, not the irresponsible insured, were the sources of the deep moral, legal and material conflicts generated by the insurantial relationship. When Lord Mansfield retired 
in 1788, Great Britain had constructed "a complete system of insurance law" (Vance, 1908: 17). ${ }^{153}$

\subsection{Conclusions: the insurable interest principle today}

As historians of finance have mostly remained silent concerning the insurance industry (see Ardent, 1976; Carruthers, 1996; Graeber, 2011; Kim, 2013; Knafo, 2008; Norel, 2004; Quinn, 2007; Wennerlind, 2011), historians of insurance have put little to no emphasis on the centrality of private insurance in the rise of financial capitalism. In addition, while historians of statistics and probabilities have merely touched on insurance (see Desrosières, 1993; Hacking, 1975, 1990), the development of statistical probabilities and the formulation of actuarial rationality have often been pictured as the determinant factors in the emergence of private insurance (see Daston, 1987, 1988; Lobo-Guerrero, 2011). Some hence pointed to the foundation of the Equitable in 1762 and the birth of actuarial life insurance as the decisive moment in the early history of insurance (see Alborn and Murphy, 2013c). It has also been suggested that the development of the insurance industry, understood as a "global safety net," occurred at the end of $18^{\text {th }}$ century through the European colonial expansion (see Borscheid, 2012). All and all, both the ancient origins of insurance thesis and the analytical focus on rationalities have

\footnotetext{
153 The year 1788 also marks the enactment of the Slave Trade Act (28 Geo. III, c. 54) better known as the Dolben's Act. Following the 1781 Zong Massacre (see Krikler, 2007), the Dolben's Act stated that in slave cargo insurance policies "no loss or damage shall be recoverable on account of the mortality of slaves by natural death or ill treatment, or against loss by throwing overboard of slaves on any account whatsoever" (quote in Clark, 2010: 69; Shyllon, 1974: 190). While construing individuals as objects of property predates $18^{\text {th }}$ century transatlantic slavery, insurance on slaves generated troubles for maritime law to formally articulate insurance on goods and insurance on persons, as illustrated by English law's ambiguity in dealing with this kind of mercantile practice. As 18th century English observers tended to consider insurance policies on slaves as marine insurance, the French avoided the legal prohibition of life insurance and covered slave cargoes by resorting to ransom insurance (Clark, 2010). On present day ransom insurance, see Lobo-Guerrero (2011: 93-107).
} 
remained unquestioned in historiography, especially by Weberian and Foucauldian approaches. Through the Polanyian analysis of the IC of private insurance, the case study of the historical construction of insurance law in England from 1664 to 1774 has however revealed the modern origins of the insurance industry within emerging English financial capitalism. The institutionalization of the insurable interest principle (IIP) by the British government with the laws of 1746 and 1774 has allowed for the recognition of private insurance as relatively autonomous business. Political and legal interventions, not statistical probabilities nor actuarial rationality, have initially contributed to the constitution of private insurance's societal recognition, hence ensuring its commercial and financial value.

By debunking the ancient origins of insurance thesis, Part 4.1 first provided a concrete illustration of the Polanyian critique of the economistic fallacy. In ancient commercial empires and late medieval mercantilism - in which trade was by definition a matter of collective action (Polanyi, 1977; Polanyi et al., 1957a) - insurance as such never emerged as a relatively autonomous profit-making activity. Within pre-modern societies, insurance could not be distinguished from credit nor currency exchange. The institutional analysis of ancient commercial empires, Mediterranean long-distance sea trade and early European mercantilism indeed provides evidence that insurance is not a transhistorical practice and that marine insurance does not represent the origins of insurance per se. Even during late Middle Ages, the first instances of third-party marine risks hedging and of insurance on the lives of other persons represented mere prototypical forms of insurance since they were still structured under a commercial economy and a credit system characterized by long-distance sea trade and emerging modern colonialism. 
While previously conflated, insurance, credit and currency exchange only slowly became relatively autonomous financial operations following the Agrarian revolution in $16^{\text {th }}$ century England and especially with the rise of English financial capitalism at the turn of the $18^{\text {th }}$ century. Through this differentiation, insurance emerged as a distinct profitmaking activity allowing securing private property and expanding access to liquidity and credit.

Then, Part 4.2 demonstrated that the Polanyian concept of the diversity of the institutional modes of economic integration allows clearly making sense of the modern origins of private insurance. First, through reciprocity, the insurance industry initially emerged as life and fire insurance mutual societies. These mutual societies permitted the institutionalization of class and patriarchal solidarity by providing banking facilities to their members, and employing pre-actuarial risk management based on mutuality and observational knowledge as core organizational principles. Second, thanks to state intervention and redistribution, these first insurers quickly emerged as central institutional investors following the political-legal institutionalization of the primacy of private property (1688), of the first nationally collateralized debt (1693) and of the first modern central bank (1694). Moreover, the insurance industry greatly contributed to the rise of Great Britain's imperial power on the international scene. In other words, as a core institution in the constitution of the early institutional arrangements of the English market society, the insurance industry was an active component in the attempted institutionalization and global expansion of the first "society of the SRM utopia" since it contributed to the extension of opportunities for private capitalization on property and credit, by facilitating the preservation of inheritance and access to liquidity. In fact, the 
English insurance industry appeared as a condition of possibility for the rapid urbanization of England in late $17^{\text {th }}$ century and, furthermore, for the late $18^{\text {th }}$ century Industrial revolution (see Pearson, 2004, 2010a).

During this period, the initial IC of the insurance industry both generated and allowed for the capitalization of specific uncertainties. On the one hand, from the creation of the first insurance mutual societies from the 1690s until the 1720s, the British insurance industry experienced an intense boom in the context of a monetary regime characterized by the rapid growth of credit, as it got involved in the speculative euphoria leading to the South Sea Bubble. While literature does not provide detailed evidence and further research is thus required, the enactment of the Bubble Act in 1720 reveals that both the British government and the South Sea Company were highly concerned with the explosive growth of the insurance industry as a whole and the financial uncertainty it contributed at generating. On the other hand, following its takeoff in the first half of the $18^{\text {th }}$ century, the insurance industry generated increasing moral and legal uncertainties. Once distinguished from lending and currency exchange, private insurance's proximity with speculative ventures and gambling operations - especially on human lives - would require more than a century of political and legal constitution in order to become a legitimate and relatively autonomous business. While the early $18^{\text {th }}$ century criticisms over insurantial speculation and gambling were not purely moralistic and instead concentrated on fraudulent and criminal intents and ramifications of widespread insurance industry practices, a series of cases increasingly sparkled public debates and led to court battles over the way in which law had to deal with human life as capital. 
Facing these uncertainties, the IC of private insurance required the enactment of four pieces of legislation $(1664,1720,1746$ and 1774) culminating with the institutionalization of the insurable interest principle (IIP). By requiring that the beneficiary of insurance coverage can demonstrate an objective financial or emotional interest in the insured property or life, the IIP performed the political-legal recognition of insurance against widespread insurantial speculation and especially against gambling over lives. The integration of this principle into common law through the 1746 Marine Insurance Act and the 1774 Gambling Act was based on a theory of material value according to which the distinction between insurance and gambling was to be made on bases of commercial value and economic productivity (O'Malley, 2003). Notwithstanding the dubious moral character of some insurance contracts, especially those on the continuation of human life, these constituted the bases on which political and legal actors would distinguish legitimate and legal insurance contracts from undesirable and illegal gambling and risk hedging agreements. By the end of the $18^{\text {th }}$ century, one of the basic principles of insurance law - the IPP - was formulated and institutionalized under common law, three quarters of a century before the implementation of actuarial rationality in the British insurance industry at large. Chapter 4 thus provides institutional evidence of the fact that the systematic implementation of actuarial rationality into the insurance industry based on statistical demography and probabilities has long lagged behind its theoretical and technical formulations (see Alborn, 2002; Clark, 2002; Daston, 1987, 1988; Ewald, 1986).

The institutionalization of the IPP was actually aiming at the insurance industry as a whole by seeking to remove incentives for underwriting highly risky and highly 
profitable gambling-like and speculative policies often involving fraudulent schemes and potentially criminal actions. From around 1664 to 1774, legislators, judges and courts seem to have become aware that the organizational structure of private insurance and the financial incentives ingrained in the insurance industry - not the irresponsible insured were the sources of the deep moral, legal and material conflicts generated by the insurantial relationship. Against the utilitarian and insurer-biased concept of moral hazard (see Chapter 3), the early history of the insurance industry and the enactment of insurable interest laws provide further evidence that the moral risk paradigm (see Ericson et al., 2003) better describes the nature of private insurance.

From the Polanyian perspective of the IC of markets, this is especially significant. Three quarters of a century before the explicit formulation of the moral hazard paradigm as the insurance version of the SRM utopia during the last half the $19^{\text {th }}$ century, private insurance governance already proved unstable and uncertainty generating. Hence, in terms of the theory of economic sociology, this chapter argues that the epistemic constitution of the insurance industry long lagged behind its political-legal constitution.

\section{Recent evolution: the dusk of the insurable interest principle?}

The IIP was further strengthened under British common law in 1845 concerning property indemnity insurance and then, in 1906 and 1909, concerning marine insurance (Atmeh, 2011: 99-100). More recently, it was however eliminated intentionally in Australia (1984 and 1995) and indirectly in England (2005). Opposition to the insurable interest requirement under common law seems to have been growing fast in the past few years (see Atmeh, 2011; Loshin, 2007; Swisher, 2005). According to one opponent, "[i]n theory, the rule prevents both wagering on individual lives and moral hazard. In practice, 
the doctrine is avoided by complex insurance transactions structuring to effectuate both origination and transfers of insurance by individual without an insurance interest." (Atmeh, 2011: 93). On the normative level, this approach aim at making business easier for both insured-consumers and insurers by encouraging the expansion of secondary markets for the trade of life insurance. Stemming from the Law and economics perspective (see Baird et al., 2006; Friedman, 1987), opponents claim that the insurable interest rules duplicate anti-fraud laws, generates black markets shielded by the complexity of trust law and produces significant transactions costs due to the need for various intermediaries, the uncertainty and costs of potential litigation as well as information inequality involved in secondary life insurance markets (see Atmeh, 2011).

Based on the liquidity of life insurance policies achieved both through financial securitization and the arbitration by an investor between the policy's face value and its cash surrender value, such markets enable the sale of life insurance policies and their exchange as pooled components of specific financial titles (Quinn, 2008). Having emerged in the US during the first decades of the $20^{\text {th }}$ century, secondary life insurance markets mostly consist of viatical settlements, life settlements and stranger-originated life insurance (or "STOLI") policies. This business gained momentum during the 1980s and 1990s as the AIDS epidemics, the aging population and the growth in chronic illnesses required major medical expenses in a context of rapidly rising healthcare and prescription drug costs and high level of indebtedness. Even more recently, less needy groups such as wealthy retired baby boomers also turned to secondary life insurance markets in order to quickly acquire cash flow. 
Against the backdrop of the English origins of the insurance industry with the institutionalization of the IIP during the $18^{\text {th }}$ century, this recent expansion of secondary markets for life insurance appears as a striking reversal; while the rich English gentlemen middle class then turned to insurance mutual societies as an institutional form of class security, sick and aging late $20^{\text {th }}$ century American working classes would now resort to the liquidity of life insurance policies in order to provide for decent healthcare and retirement. Calls for the "regulation, not prohibition" (Atmeh, 2011) of financial products lacking insurable interest risk masking major institutional and policy challenges concerning lacking and insufficient healthcare coverage, rising healthcare costs, broken pension systems and bubbling debt economy. In a similar fashion to the securitization of credit risks having underlaid the subprime mortgage crisis, what could surely "prevent the creation of a futures market on a pool of individuals' lives" (Atmeh, 2011: 94), that is financial and insurantial speculation on uncertainties facing vulnerable ill, ageing and indebted classes, besides a clear and enforced IIP? 


\section{Chapter 5. The institutional constitution of the Canadian prescription drug insurance market: when private plans face high price specialty drugs}

From the perspective of the theory of the institutional constitution (IC) of markets, Chapter 5 brings the political aspect of the IC of private insurance into the foreground through the lens of the political-legal institutional method. In doing so, it sheds light on the IC of the prescription drug (PD) insurance market in Canada in the context of the shift from the old "blockbuster" pharmaceutical business model to the new "nichebuster" model. The nichebuster pharmaceutical business model results notably in the arrival of high costs specialty medicines for rare conditions, which now represent the new structural driver of the overall growth in drug expenditures. Since the Canadian pharmaceutical system had been repeatedly characterized as having complex drug regulations, pro-pharmaceutical industry official pricing, inefficient innovation policies and fragmented drug purchasing power in Canada (Gagnon, 2015; Lexchin, 2015; Morgan, Martin, et al., 2015), these new specialty drugs constitute a major challenge for the Canadian hybrid patchwork system of public and private PD coverage in general and for the private life and health $(\mathrm{L} \& \mathrm{H})$ insurers in particular. Despite the fact that insurers can easily compute actuarial data concerning PD usage based on populational health statistics and probabilistic modeling, the emergence of the nichebuster pharmaceutical business model and the rise of high cost specialty drugs generate a crisis among employer-sponsored private health benefits group plans offered and managed by Canadian L\&H insurers.

The main aim of this chapter thus consists in finding how the Canadian PD insurance market responds to the arrival of specialty medicines. Through the lens of the 
theory of the IC of insurance markets and the concept of insurance risks as fictitious commodities, it raises the following specific question: which political-legal interventions and non-competitive institutional arrangements contribute at ensuring the constitution of the Canadian PD insurance market in the context of the rise of high price specialty drugs? By answering this chapter's main question, the following case study of the Canadian PD insurance market in the context of the emergence of the nichebuster pharmaceutical business model moreover attempts to provide answers to the secondary research questions raised in Chapter 3 (see Section 3.3.1). On the empirical level, the issue of the interplays within the diversity of the institutional modes of economic integration will be raised. On the theoretical level, this chapter attempts to clarify the nature and the relations between the concepts of uncertainty and risk by developing a better understanding of the functioning of the insurance industry.

First, Part 5.1 describes the historical evolution of the political-legal decisions and institutional arrangements underlying the current Canadian PD insurance market. In order to do so, it first presents a brief history of health care in Canada shedding light on the IC of Canadian health care and the exclusion of PD coverage from the provincially administered universal health care systems. Second, Part 5.1 discusses the resulting patchwork system of public and private drug plans in Canada. While the focus is set on data concerning the patchwork PD coverage and on the structure of the provincially administered public drug plans, the structure and organization of private PD insurance in Canada is presented in details in Part 5.2. Part 5.1 concludes by problematizing the arrival of high cost specialty drugs as a major challenge for the Canadian patchwork PD coverage and especially for the PD insurance market in Canada. 
Second, Part 5.2 aims at assessing the (A) ability of private PD insurance at facing the new nichebuster pharmaceutical business model, and (B) the responses from the Canadian L\&H insurance industry to the rise of high price specialty medicines. From the perspective of the IC of insurance markets framework, Part 5.2 seeks to provide answers to one of the two components of Chapter 5's central question: which non-competitive institutional arrangements contribute at ensuring the constitution of the Canadian PD insurance market in the context of the arrival of high price specialty drugs?

Third, considering the will from the L\&H insurance industry to increasingly integrate private PD coverage with public plans, Part 5.3 attempts to provide answers to the second component of chapter 5's central question: which political-legal interventions contribute at ensuring the constitution of the Canadian PD insurance market in the context of the rise of high price specialty medicines? In order to do so, it first sheds light on the calls from the major PD insurance market stakeholders for the creation of public catastrophic drug coverage in Canada. Second, it presents a brief overview of the available public catastrophic PD coverage and of its recent evolution.

Finally, Part 5.4 begins with a summary of Chapter 5. Then, it presents the research results by answering both the central question and this thesis' specific research questions (see Section 3.3.1). Part 5.4 concludes with a recommendation.

\subsection{Prescription drug insurance in Canada: the patchwork system and the arrival of specialty drugs}

Part 5.1 aims at describing the historical evolution of the institutional decisions and arrangements underlying the current Canadian PD insurance market. In order to do so, it 
first presents a brief history of health care in Canada in order to better understand the institutional constitution of Canadian health care and the exclusion of PD coverage from the provincially administered universal health care systems in Canada. Second, Part 5.1 discusses the resulting patchwork system of public and private drug plans in Canada. While the focus is set on data concerning the patchwork PD coverage and on the structure of the provincially administered public drug plans, the structure of private PD plans in Canada is presented in Part 5.2. In conclusion, the rise of high cost specialty drugs is analyzed as a major challenge for the Canadian patchwork PD coverage and especially for the PD insurance market. As will be seen, since "the balance of power between the seller and the buyer" (Gagnon, 2015: 193) ultimately determines PD prices, the Canadian fragmented PD coverage contributes to the high and rising PD expenditure in Canada.

\subsubsection{A brief history of healthcare in Canada: the exclusion of PD coverage}

Among the Organisation for Economic Co-operation and Development (OECD) countries, Canada is the only jurisdiction not having integrated PD insurance coverage within its universal public health care system (Gagnon, 2014). In order to better understand why Canada's PD insurance system can be characterized as a "patchwork system" of public and private PD insurance plans (Boothe, 2015; Daw and Morgan, 2012), Section 5.1.1 presents a brief descriptive contextualisation of the role of private insurance and the position of PD insurance within the broader historical evolution of health care in Canada. While Table 5.1 presents the important dates in the general evolution of Canadian health care according to Fierlbeck (2011), the following discussion focuses on the moments in the history of Canadian health policy and law having 
contributed to the exclusion of PD from the public universal health coverage. By determining the design of the provincially administered universal health care systems in Canada and the exclusion of PD, these political and legal interventions have hence indirectly contributed to the institutional constitution of the current Canadian PD insurance market analyzed in parts 5.2 and 5.3.

\section{Table 5.1. Important dates in the development of health care in Canada ${ }^{154}$}

\begin{tabular}{|l|l|}
\hline $\mathbf{1 9 1 9}$ & First articulation of federal support for national health insurance \\
\hline $\mathbf{1 9 1 9}$ & B.C. Royal Commission on Public Health Insurance \\
\hline $\mathbf{1 9 3 3}$ & Canadian Commonwealth Federation (CCF) calls for socialized medicine in its Regina Manifesto \\
\hline $\mathbf{1 9 3 6}$ & Public health insurance legislation passed in British Columbia (not implemented) \\
\hline $\mathbf{1 9 3 7}$ & Public health insurance legislation passed in Alberta (not implemented) \\
\hline $\mathbf{1 9 3 7}$ & Rowell-Sirois Royal Commission on Dominion-Provincial Relations (reported 1940) \\
\hline $\mathbf{1 9 4 2}$ & Heagerty Report on health insurance (published 1943) \\
\hline $\mathbf{1 9 4 7}$ & Saskatchewan implements universal hospital insurance \\
\hline $\mathbf{1 9 5 7}$ & Federal Hospital Insurance and Diagnosis Services Act \\
\hline $\mathbf{1 9 6 1}$ & Saskatchewan introduces public insurance for primary care \\
\hline $\mathbf{1 9 6 4}$ & First Hall Report: Royal Commission on Health Services in Canada (published 1966) \\
\hline $\mathbf{1 9 6 6}$ & Federal Medical Care Act \\
\hline $\mathbf{1 9 7 4}$ & Lalonde report: A New Perspective on the Health of Canadians \\
\hline $\mathbf{1 9 7 7}$ & Established Program Financing (EPF) \\
\hline $\mathbf{1 9 8 0}$ & Second Hall Report: Canada's National-Provincial Health Program for the 1980s \\
\hline $\mathbf{1 9 8 4}$ & Canada Health Act (CHA) \\
\hline $\mathbf{1 9 9 6}$ & Canada Health and Social Transfer (CHS) \\
\hline $\mathbf{1 9 9 9}$ & Social Union Framework Agreement \\
\hline $\mathbf{1 9 9 9}$ & Kirby Report: Standing Senate Committee on Social Affairs, Science and Technology Study on the \\
& State of the Health Care System in Canada (reported 2002) \\
\hline $\mathbf{2 0 0 1}$ & Romanow Report: Royal Commission on the Future of Health Care in Canada (published 2002) \\
\hline $\mathbf{2 0 0 3}$ & Accord on Health Care Renewal \\
\hline $\mathbf{2 0 0 3}$ & Establishment of the Health Council of Canada (HCC) \\
\hline $\mathbf{2 0 0 4}$ & 10-Year Plan to Strengthen Health Care / Implementation of the National Pharmaceutical Strategy \\
\hline $\mathbf{2 0 0 5}$ & Establishment of the Public Health Agency of Canada (PHAC) \\
\hline $\mathbf{2 0 0 6}$ & Kirby Report on Mental Health: Out of the Shadows at Last \\
\hline $\mathbf{2 0 0 7}$ & Establishment of the Mental Health Council of Canada (MHCC) \\
\hline
\end{tabular}

${ }^{154}$ Based on Fierlbeck's (2011: 49) “Table 2.1. Key Dates in the Development of Canadian Health Care.” 
From 1867 to 1940

Given the historical context of the late $19^{\text {th }}$ century, The British North America Act of 1867 - officially known as the Constitution Act since 1982 - does not mention "health" among the legislative powers of neither the federal Parliament nor the provinces. "The Constitution, however, does contain some powers relating directly to health and health care. Section 91(11) assigns responsibility for "quarantine and the establishment and maintenance of marine hospitals" to the federal government. Section 92(7) assigns responsibility for most other hospitals to the provinces." (Butler and Tiedemann, 2011: 1). In fact, under the Canadian Constitution, the provinces had the responsibility for the establishment, maintenance and management of hospitals, asylums as well as charitable organizations (Health Canada, 2011). Soon after the establishment of the Confederation, the Canadian life and health (L\&H) insurers organized themselves in 1894 by creating the insurance industry trade association (CLHIA, unknown), the Canadian Life Insurance Officers Association (CLIOA) as was first known the current Canadian Life and Health Insurance Association (CLHIA). ${ }^{155}$

\footnotetext{
${ }^{155}$ As the Canadian L\&H insurance industry trade group, the CLHIA "is a voluntary non-profit association with member companies accounting for 99 per cent of Canada's life and health insurance business. The mission of the CLHIA is to serve its members in areas of common interest, need or concern." (CLHIA, unknown). The CLHIA's website does not mention that the Canadian life insurance industry trade association was first known as the CLIOA before changing its name to the Canadian Life Insurance Association (CLIA) in 1965. In 1981, the CLIA merged with the Canadian Association of Accident and Sickness Insurers and rebranded itself as the Canadian Life and Health Insurance Association Inc. (CLHIA) as it is still known today. See the Government of Canada's TERMIUM Plus database. Early archival traces of the original CLIOA can be found in the November 281902 edition of The Monetary Time where David Burke (birth/death unknown) reports the content of papers from B. Hal Brown (birth/death unknown) - at the time president of the CLIOA - titled "Helps and Hindrances" and submitted at a CLIOA's meeting. As Burke reports, two major resolutions were submitted at the end of the meeting "having for their object the more efficient conduct of the medical departments and the agency departments of life insurance companies." Burke then adds: "Some of the companies have felt for some time the need of increased powers in the investment of their funds, and it was decided to place this important question in the hands of a committee, with a view of bringing about some definite results at the present session of the Dominion Parliament. Another important matter which engaged the meeting's attention was 'Provincial and
} 
During the 1920s and 1930s, "municipal doctor schemes developed in some western provinces, first in Saskatchewan and then in parts of Alberta and Manitoba." (Boothe, 2015: 47). Before the WWII, these schemes functioned on the basis of a salary paid to individual doctors by each single communities (Hacker, 1998: 97). Then, starting in the 1930s, as the private insurers progressively started offering medical insurance policies as commodities and hospital- and physician-controlled plans were established, the first calls for public health insurance emerged (Hurley and Guindon, 2008; Jackman, 1995). ${ }^{156}$ As Jackman (1995: 55) explains, "[f]rom the 1930s onwards, a growing number of commercial insurance companies introduced medical insurance policies, using these fee schedules as a basis for their indemnity rates. The private plans generally provided for reimbursement at less than the official tariff, and for a fixed deductible before the insurance took effect." ${ }^{157}$ In 1932, Hugh H. Wolfenden's The Real Meaning of Social Insurance: Its Present Status and Tendencies was published thanks to the support of the CLIOA. Wolfenden (1932) was claiming that "governments should not create and fund universal insurance plans because they sapped individual initiative." (Canadian Museum of History, unknown). At around the same time, hospital prepayment plans started operating across Canada.

A survey conducted by the Canadian Medical Association [(CMA)] in 1934 identified 27 hospital pre-payment plans operating in six provinces (Hall 1964). Under pre-payment plans (akin to

Municipal Taxation.' All classes of insurance companies are beginning to feel the burden of taxation, and it was felt that some efforts should be made to secure a more fair and equitable base of taxation." (The Monetary Times, 1902: 692). No study of the history of the Canadian L\&H insurance industry trade association is currently available.

156 Despite a lack of evidence in literature, Hurley and Guindon (2008: 13) add that "insurance cooperatives played an important role, especially in the early part of this period and in the west." Further research is required.

157 "Life insurance companies and casualty insurance companies [...] began offering various types of health care and disability insurance during this period, with life insurance companies tending to focus on the group market while casualty insurers concentrated on the individual market.” (ibid.: 13). 
modern HMOs in the US), the hospital in return for the provision of specified services should they be needed during the period covered. The first 'Blue Cross' pre-paid plan for hospital services was established in Manitoba in 1937 (Hall 1964). This was quickly followed by Blue Cross plans in Ontario in 1941, Quebec in 1942, the Maritimes and British Columbia in 1943 and Alberta Blue Cross in 1948." (Hurley and Guindon, 2008: 13)

Finally, during the late 1930s, physicians in different provinces also jointly established some profession-controlled voluntary pre-payment plans for medical services. The development of hospital insurance accompanied the establishment of physiciansponsored and controlled pre-payment plans (ibid.). "Under these plans, in contrast to the commercial regimes, participating physicians accepted the plan's reimbursement as payment in full, so that subscribers effectively enjoyed a 100 percent coverage." (Jackman, 1995: 55). ${ }^{158}$ Calls for public insurance coverage then emerged, first in the western provinces, which were especially suffering from the Great Depression. The first province-wide medical plan, the Medical Services Associations of British Columbia, was established in 1940. "These initiatives often found considerable support within the medical profession, in part for purely economic reasons: many patients could not pay for care privately, making it difficult for a physician to maintain a practice." (Hurley and Guindon, 2008: 13).

Post-WWII and the 1950s: the therapeutic revolution and the public funding of hospital care

As Boothe (2015: 43) explains, while municipal doctor systems had been put in place by post-WWII, "physician-sponsored voluntary insurance schemes were not well established until after the failure of the 1945 proposals' of national health insurance resulting from

\footnotetext{
158 "The first such plan was offered in Toronto in 1937, followed by plans in Windsor, Ontario and Regina, Saskatchewan in 1939, and then a series of plans across Canada during the 1940s." (Hurley and Guindon, 2008: 13).
} 
the federal Liberals' Dominion-Provincial Conference on Reconstruction (see Hacker, 1998: 98; Shillington, 1972: 51). ${ }^{159}$ The same year, the idea of national health insurance was surprisingly endorsed by the CLIOA (see Boothe, 2015: 43; Taylor, 1978: 31). In fact, by the WWII

the Canadian medical establishment had fully approved the principles of health insurance. In 1943, the Canadian Medical Association formally endorsed the idea of a national health insurance plan, although it envisioned the role of government as limited to subsidizing the premiums of those who could not afford to make their own payments to the voluntary agencies. (Jackman, 1995: 55).

Most importantly in terms of PD insurance, the post-WWII period marks the beginning of the governmental participation in pharmaceutical funding, provision and regulation, for instance due to the arrival of antibiotics (Boothe, 2015; Quirke, 2005). As a matter of fact, a pharmaceutical therapeutic revolution occurred "[f]rom the 1940s to the 1960s, [as] the major part of the modern pharmacopoeia [...] appear[ed] on the pharmacist's shelves. Many of today's blockbusters are still improved versions of this generation of discoveries.” (Gagnon, 2009: 151). ${ }^{160}$ However, "drug insurance was [...] practically non-existent in Canada until the 1970s, after a national pharmaceutical program had been rejected a number of times." (Boothe, 2015: 9).

In 1947, the province of Saskatchewan implemented the first universal hospital insurance plan in Canada (Lexchin, 2015: 26). While the various not-for-profit physiciancontrolled voluntary plans were organized as the Trans-Canada Medical Plans (TCMP) in 1951 (Shillington, 1972: 109), the growing Canadian middle class increasingly had

159 As Hacker (1998: 98) notes concerning the 1945 Dominion-Provincial Conference, " $[t]$ he failure of the conference had several important consequences for subsequent Canadian health politics. The first and most obvious was that Canadians would have to wait another quarter-century for national health insurance. [...] the failure of those proposals meant that national health insurance would have to come about through a different route than the one envisioned by federal Liberals in 1945."

160 On the mid-century pharmaceutical therapeutic revolution, see also Pignarre (2003) and Redwood (1987). 
access to voluntary insurance during the next decade. As Hurley and Guindon (2008: 14)

suggest,

[t]his had a number of important impacts vis-à-vis public and private financing. It reduced the pressure for large-scale public action since a substantial proportion of the population had access to at least some insurance. It also weakened physician support for public insurance, especially public medical insurance. The medical profession strongly advocated for private plans, particularly physician-sponsored plans, which retained control and power for the profession. These developments altered the nature of the debate regarding public health insurance. Rather than public insurance, many analysts now advocated limiting the public role to public subsidy for low-income individuals that would enable them to purchase private insurance. [...]. The gap in private coverage (even in urban Ontario) suggested, however, that private insurance could never provide universal coverage, and the increasing demands on provincial and local resources and on hospitals themselves provided an opportunity for the federal government to act on its national vision.

The federal government hence passed the Hospital Insurance and Diagnosis Services Act (HIDSA) in 1957. The federal thus "offered to reimburse, or cost share, one-half of provincial and territorial costs for specified hospital and diagnostic services. This Act provided for publicly administered universal coverage for a specific set of services under uniform terms and conditions." (Health Canada, 2011). As a result, private insurance for medically necessary services was increasingly replaced by new provincial hospital insurance plans. "Hospital benefits offered by private insurance shrank to complementary, mostly non-medical, services associated with a hospitalization (e.g., room upgrade from ward to semi-private)." (Hurley and Guindon, 2008: 14). By 1961, non-compulsory publicly funded inpatient hospital and diagnosis services were provided by all the provinces and territories (Health Canada, 2011). 
The 1960s: resisting physicians, the Hall Commission and the Medical Care Act

Different sources of medical coverage - mainly physician voluntary plans and private insurance - were still being offered to Canadians in the beginning of the $1960 \mathrm{~s} .{ }^{161}$ In the early 1960s, a system of multiple voluntary insurance plans was actually in place in Canada, thus securing the interests of the medical profession, of the TCMP and of the insurance industry. For example, physicians feared that governmental insurance would made them "prisoners of $[\ldots]$ bureaucratic operations" (Shillington, 1972: 140). Against intense lobbying by medical and insurance groups and facing the absence of federal intervention, Saskatchewan introduced compulsory public insurance for primary care in 1961. Resembling the current Canadian public and universal hospital insurance, it triggered major resistance from the physicians in 1962 through the world-wide famous “doctor’s strike" (see Badgley and Wolfe, 1967; Maioni, 1998). ${ }^{162}$

Two years after its completion in 1964, the Royal Commission on Health Services in Canada published a report known as the first "Hall Report" from the name of its chair, Justice Emmett Hall (Government of Canada, 1964). Interestingly, the view that the insurance model could provide universal access to health care was not actually

\footnotetext{
${ }^{161}$ As Boothe (2015: 143) indicates, "[i]n 1961, about 4.5 million Canadians had some coverage through physician-sponsored plans, and an additional 4.2 million had coverage through for-profit agencies (for a combined total of about 48 per cent of the population with coverage), although some estimates indicate that these plans covered only 20 to 45 per cent of medical costs (Naylor 1986). The Canadian Conference on Health Care, an organization that combined the TCMP and the Canadian Health Insurance Association (CHIA), estimated that about 62 per cent of Canadians had voluntary surgical and/or medical insurance in 1965, and this figure went up to almost 67 per cent in 1966 (Shillington 1972, 200)."

162 In contrast, the provinces of British Columbia, Ontario and Alberta "were much more receptive to lobbying from the CMA, CHIA, and TCMP and moved to subsidize private, voluntary insurance starting in 1963 (Taylor 1987, 341). [...]. By 1966, no province had announced plans to take up the federal conditions and offer of medicare funds, and some federal Cabinet ministers began to speculate about including a role for the private plans as a way to break the stalemate (Bryden 1997, 151)." (Boothe, 2015: 143).
} 
challenged by the Hall Report and its recommendations. ${ }^{163}$ The commission recommended "that administration of health insurance plans be taken over from the private sector by provincial governments, and that the plans be fully and universally subsidized by federal and provincial governments, rather than paid for through individual subscriptions." (Jackman, 1995: 55). The Hall Report required that the provincially controlled health insurance plans fulfilled four conditions: comprehensiveness, universality, public administration and portability. In December of 1966, these recommendations were implemented by the federal government, which enacted the Medical Care Act (MCA). As Jackman (ibid.) explains,

[i]n essence, the Hall Commission and the Medical Care Act entrenched a national public health care system based upon a private insurance model. All Canadians became policy holders in a nationalized health insurance plan, with premiums paid through the tax system instead of directly, and with a general assumption that services would continue to be provided by individual physicians who would simply be reimbursed by the provinces instead of by profession-controlled or commercial insurers. Physicians also expected that they would continue to be reimbursed on a fee-for-service basis, at tariffs set largely by them, thereby preserving a significant degree of professional and economic independence from governments - now occupying the dual role of regulator and insurer.

Building on the 1957 HIDSA, the MCA included federal funding for $50 \%$ of the costs of universal public coverage for physicians services administered by the provinces (Lexchin, 2015: 26). According to Boothe (2015: 148), the resistance from the medical profession and private insurers was overcome by the electoral discourse of the New Democratic Party and its impact on the Liberal Party's strategy, which hence moved towards promoting the universal public health care system. Following the $1966 \mathrm{MCA}$, an agreement between the federal and the provinces was concluded in 1968 and provincial

\footnotetext{
${ }^{163}$ As Jackman (1995: 59) notes, following Taylor (1978), "the Canadian Labour Congress [CLC] was the only group to squarely address the insurance issue. It its brief to the Hall Commission the CLC argued that while prepayment plans had been useful, they were simply a convenient technique for the budgeting of health care costs. The CLC insisted that the real issue was Canada's health care system, which should be thought of as a public service, and not simply as an insurance mechanism [...]."
} 
public coverage for primary care was put in place over the next four years (Boothe, 2015).

Furthermore, the Hall Report recommended the creation of a national pharmacare plan covering all Canadian citizens on the basis of a public formulary of approved pharmaceuticals. "But the government chose to wait for drug prices to stabilize before designing such as system. It waits still." (Fierlbeck, 2011: 154). Despite demanding the inclusion of pharmaceutical coverage into the universal public health care coverage, most of the Hall Commission's “public reporting on pharmaceuticals focused on policies related to drug pricing, and governmental debates over the recommendations directed their attention to the controversial introduction of nationwide public medical insurance." (Boothe, 2015: 15).

\section{4: the Canada Health Act}

Shortly after the establishment of national hospital insurance, the advocates of public universal health care in Canada faced growing opposition by all provinces but Saskatchewan, and especially by the increasingly organized insurance industry and by worried physicians (ibid.: 143-4). As private insurers started selling drug insurance in the 1970s, the provinces also begun establishing partial pharmaceutical coverage during this period (Boothe, 2015; Grootendorst, 2002). While the 1975 HIDSA and the 1966 MCA had in principle already secured publicly funded and universally accessible hospital care and physician services across Canada, "extra-billing by physicians and the imposition of user fees by hospitals had become widespread" (Jackman, 1995: 55) by the early 1980s. With the 1984 Canada Health Act (CHA), the federal government consolidated the 
HIDSA and the MCA and added "accessibility" to the MCA's four conditions the provincial health care plans had to respect in order to remain eligible for federal funding:

portability (insurance continues when people move from province to province), accessibility (people cannot be charged extra for any service that is covered), universality (all Canadian citizens and permanent residents are automatically covered), comprehensiveness (all necessary medical services are covered), and public administration (the health care system is administered on a public not-for-profit basis) [...]. (Lexchin, 2015: 26)

While the CHA stipulates the criteria according to which the federal government bases its health transfers to provinces, it did not transform the federal government into a regulator of health care provisioning in Canada. As long as patients are not charged extra-billing, the CHA does not prohibit private and for-profit providers from being reimbursed for and delivering health services covered by the provinces. "Nor does the Act prevent the provinces from allowing private health care providers, whether individual or institutional, to operate outside the state subsidized health care system." (Jackman, 1995: 56). ${ }^{164}$ Indeed, the CHA 'does stipulate that health care insurance must be 'comprehensive,' but this refers only to medically necessary services that are provided within hospitals, and not on an outpatient basis (provinces are free to cover outpatient services if they choose to do so, but they are not required to).” (Fierlbeck, 2011: 7). The provinces are hence left with a rather arbitrary political power to determine which services must be considered as "medically necessary."

Moreover, the CHA does not prohibit private insurers from offering coverage for supplementary and non-insured services, nor from selling supplementary health insurance

164 As Lexchin (2015: 26) points out, "[a]lthough the CHA says nothing about the way that health care should be delivered almost all hospitals in Canada are run by private not-for profit corporations that are not investor owned and almost all of their funding comes from the provincial government (Sutherland et al. 2013). Doctors are not state employees but also receive nearly all of their income from the publicly run system)." (Lexchin, 2015: 26). 
above provincial plans coverage (Jackman, 1995). In this context, and perhaps unsurprisingly, the 1984 CHA - like the 1957 HIDSA and the 1966 MCA - does not cover pharmaceutical products. Under the current Canadian Medicare, "[m]edically necessary drugs are provided free at point of delivery to patients only within hospitals: once individuals are treated on an outpatient basis, they are generally required to fund their own course of drug treatment." (Fierlbeck, 2011: 153).

\section{Partial conclusions: the exclusion of PD coverage from Medicare}

The previous discussion first demonstrated that although the insurance industry is deeply entrenched both in Canadian history in general and in the history of health care in Canada in particular, historiography and public policy literature have neglected to focus extensively on it. Second, and most importantly, the major health legislation and policies in Canada have excluded PD drug coverage from the provincially administered public health care systems (Boothe, 2015; Fierlbeck, 2011). In this sense, it is right to consider that "[t]here actually is no Canadian national health care system." (Lexchin, 2015: 26). Throughout the history of health care in Canada, various health policy actors and groups have nevertheless frequently formulated calls for the establishment of national pharmacare.

As Boothe (2015: 14-5) recalls, "[p]harmaceuticals were first discussed and removed from the intergovernmental policy agenda in 1949, and federal officials consistently rejected further consideration of pharmaceutical insurance, instead focusing on the development of nationwide public hospital insurance." While the 1964 Royal Commission on Health Services and the resulting 1966 Hall Report recommended the creation of a public and universal pharmacare system, ensuing public and governmental 
debates rather focused on the issue of hospital and medical insurance. The 1997 National Forum on Health and the 2002 Romanow Commission Report then embraced the establishment of a national pharmacare plan. The Romanow Report moreover called for the creation of universal catastrophic coverage as a first step towards universal pharmacare (Boothe, 2015: 104). Published the same year, the Kirby Report also called for a national catastrophic drug program in Canada (see Table 5.1). Elaborated jointly by federal, provincial and territorial ministers, the 2004 10-Year Plan to Strengthen Health Care repeated the need for pharmacare. However, no concrete strategy originated from this initiative (Fierlbeck, 2011: 154). ${ }^{165}$ Nonetheless, the status quo was maintained and the patchwork of public and private PD coverage is still in place today in Canada.

Health policy literature points to one of the main reason for the limited expansion of public health insurance, and thus for the exclusion of PD coverage from the Canadian universal public health care system: the triad composed of the medical profession, the insurance industry and the pharmaceutical industry constitutes the most organized and powerful groups participating in the discussions and elaboration of health policies (see Abraham, 2002; Boothe, 2015; Hacker, 1998; Immergut, 1992). ${ }^{166}$

\footnotetext{
165 For more details concerning the obstacles to the establishment of a national pharmacare system in Canada, see Daw and Morgan (2012: 23), and Fierlbeck (2011: 155-59).

166 As Boothe (2015: 42) explains, "[t] he medical profession is concerned with protecting its professional autonomy and physicians' incomes, the private insurance industry with preserving a market for its products in health insurance, and the pharmaceutical industry, insofar as it has a typical business interest in profitability, would like to sell as many drugs as possible with as few regulations on prices and distribution as possible. However, the relevant groups do not necessarily have consistent preferences over time and across different options for broad health insurance or pharmaceutical insurance programs."
} 


\subsubsection{The patchwork system of public and private PD plans}

As a result from being the only OECD country having excluded PD coverage from its universal public health care system, the insurance coverage of PD in Canada can be best described as a fragmented "patchwork system" of public and private PD insurance plans (Boothe, 2015; Daw and Morgan, 2012). Generally speaking, this patchwork system first stems from the nature of the Canadian federalism. As a whole, "Canada's health care system is a fragmented system controlled by the provinces but coordinated by the federal government, with the provinces' consent." (Fierlbeck, 2011: 8). Without federal leadership in terms of pharmacare, and considering the power of the physicians-insurerspharmaceuticals triad, PD coverage in Canada consists in provincially administered public plans combined with employer provided private benefits group plans. The next section both seeks to briefly describe the general structure of this patchwork system and to provide data concerning PD coverage in Canada. While the focus is here set on the provincially-controlled public plans, Part 5.2 sheds light on private PD plans. This section concludes by introducing the issue of some inefficiencies and inequities resulting from the fragmented Canadian PD insurance system, namely gaps in coverage and low cost-containment.

The most recent data concerning PD drug expenditure by type of coverage in Canada comes from the Canadian Institute for Health Information's (CIHI) forecast for 2014 (see Figure 5.1). "In 2014, \$12.1 billion (42.0\%) of prescribed drug spending are expected to have been financed by the public sector [...]. In the private sector, prescribed

drug spending financed by private insurers is expected to have been $\$ 10.3$ billion 
(35.8\%), with the remaining $\$ 6.4$ billion (22.2\%) financed [out-of-pocket] by Canadian households." (CIHI, 2015: 8).

Figure 5.1. Prescription drug expenditure by type of coverage in Canada, 2014 (forecast) ${ }^{167}$

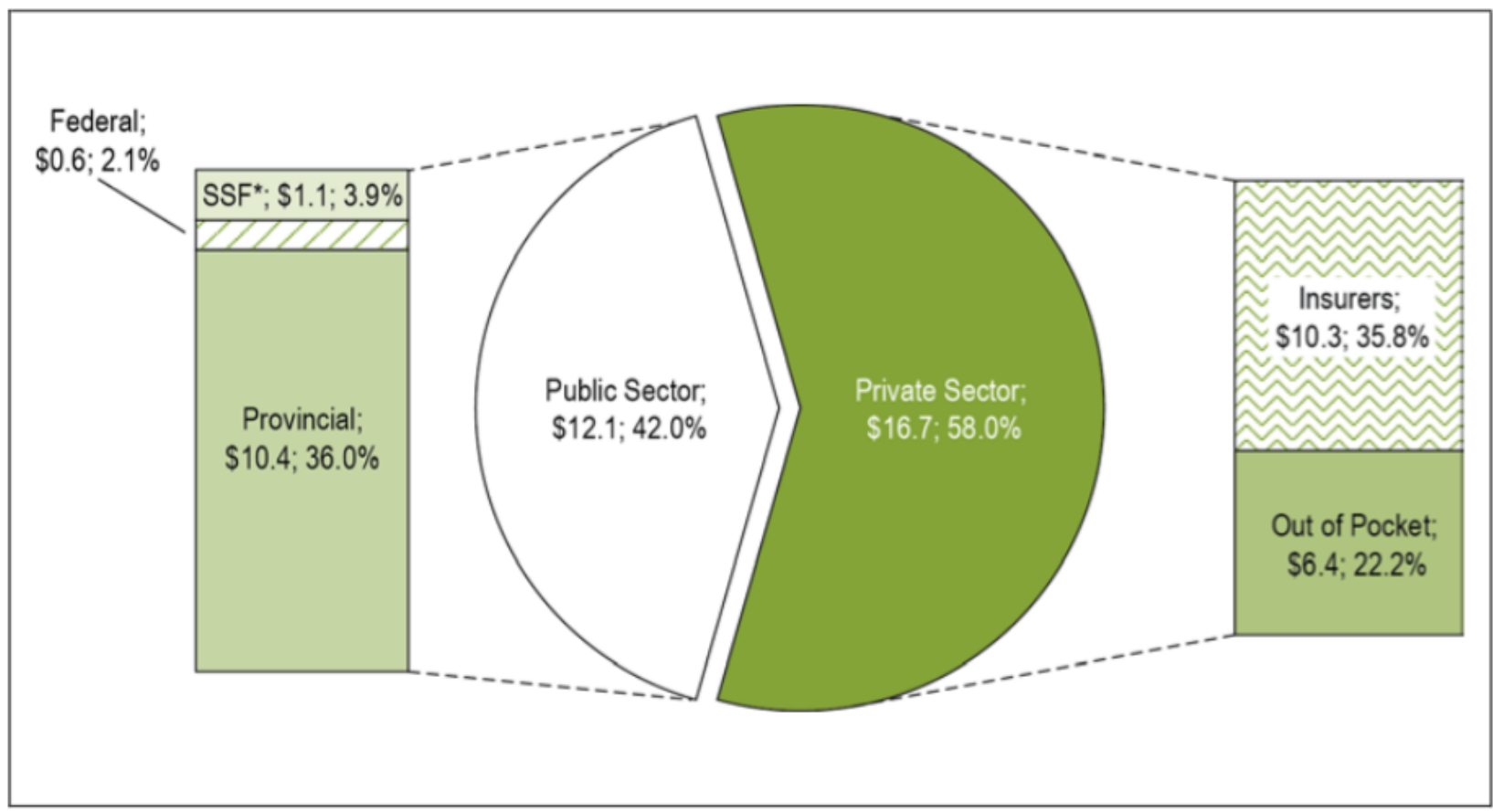

\section{Notes}

* Social Security Funds (SSFs) include health care spending by workers' compensation boards and the premium component of the Quebec Drug Insurance Fund.

f: Forecast.

$\$$ billions; percentage share of total prescribed drug expenditure.

\section{Source}

National Health Expenditure Database, 2014, Canadian Institute for Health Information.

Simply put, the Canadian patchwork system entails that "[c]overage of medicines in Canada [...] depends on a patient's age, income, workplace, and province of residence, but not necessarily on her or his medical needs.” (Morgan, et al., 2015: 5).

${ }^{167}$ From CIHI (2015: 9). 
While the provinces are the main provider of public PD coverage in Canada, the federal government is also involved in providing public drug benefit programs to specific eligible groups and private PD insurance to federal public sector employees. First, eligibility, premiums and costs-sharing mechanisms are the three main components characterizing public PD coverage provided by the provinces. "Eligibility refers to who is covered under a program and may be based on age, income, or other factors." (Daw and Morgan, 2012: 20). Most provinces provide specific eligible populations - the general non-senior population, seniors (65 and over) and social assistance recipients - with different PD benefits. "Premiums are fixed dollar amounts that must be paid (often monthly or annually) in order to receive coverage under a given plan: they are the "price" of coverage for eligible persons." (ibid.). As a basic mechanism of private insurance, "premiums are less common for public drug plans which are more often financed through general government revenue." (ibid.). Under public PD coverage, "three cost-sharing policies ultimately determine the expenses borne by the patient (or via supplementary private insurance: deductibles, co-payments/co-insurance, and out-of-pocket limits." (ibid.). Finally, while some provincial plans feature first-dollar coverage (i.e. excluding cost-sharing) and all provinces use formulary listing (i.e. the list of medicines covered by a drug plan), catastrophic coverage has recently emerged as the latest trend in the evolution of provincial PD plans across Canada (see ibid.). The issue of public catastrophic coverage, and its recent evolution, are discussed in Part 5.3. ${ }^{168}$

Among the Canadian provinces, Quebec represents the major exception in terms of PD insurance. On January first 1997, Quebec's government - through the Régie de

\footnotetext{
${ }^{168}$ For more details concerning the structure and evolution of each provincial PD programs between 2000 and 2010, see Daw and Morgan (2012: 20-3).
} 
l'assurance maladie du Québec - created the Régime général d'assurance médicaments (RGAM) (Portelance, 2014). Offering a basic PD coverage, the RGAM must nonetheless be described as being hybrid, general, mandatory and mixed. It is actually "based on a hybrid financing method combining social insurance and funding though income taxes." (Gagnon, 2014: 43). The RGAM is also a general program (i.e. not universal), mandatory covering all citizens of the province of Quebec not covered by an employer provided private plan. ${ }^{169}$ Finally, Québec's RGAM consists in a mixed public/private program since it legally mandates employer provided private health benefit plan to include PD coverage (ibid.: 29).

Second, the federal government provides public PD coverage for around one million Canadians from the following eligible groups: "First Nations and Inuit (through the Non-Insured Health Benefits Program provided by Health Canada's First Nations and Inuit Health Branch), inmates in federal penitentiaries (through Correctional Service of Canada), refugees (through the Interim Federal Health Program), members of the military through the Department of National Defense), members of the RCMP (through the RCMP), and veterans (through Veterans Affairs)." (M-A Gagnon, 2012: 164). In 2009, the direct expenditure in federal public PD coverage was estimated to be at around $\$ 666$

\footnotetext{
${ }^{169}$ More specifically, [t] he plan targets two categories of persons: those unable to work who do not depend financially on someone able to work (seniors and welfare recipients), and those able to work, and their dependents (which includes everybody else not covered by a private drug plan) (RAMQ website, 2013). Drug coverage for people unable to work rests on a rationale of social assistance. As in the other provinces, Quebec's drug coverage funding for this category comes first from taxes. Any person able to work and covered by the public drug plan (the participants) must have a premium based on his or her income, [...]. The amount of the premium for the participants is determined in such a way to cover all expenses for participants. (Gagnon, 2014: 43). However, as Gagnon (ibid.) adds, "seniors who do not benefit from an income supplement must pay a premium for their drug coverage, according to their income. Seniors who benefit from $94 \%$ or more in income supplement, as well as people on social assistance, do not pay any premium." For the July $1^{\text {st }} 2016$ to June $30^{\text {th }} 2017$, the maximum premium charged by the RAMQ amounts to $\$ 660 \quad$ (see $<$ http://www.ramq.gouv.qc.ca/fr/citoyens/assurance-medicaments/Pages/primeannuelle.aspx>; accessed September 29 2016). For more details on Quebec's RGAM, see also B. Gagnon (2012: 98) and Portelance (2014).
} 
million, including administration costs (see ibid.). The federal government also provides private PD insurance to federal public employees. Through the Public Service Health Care Plan (PSHCP), the federal government provides private PD insurance to its employees and their dependents for a total estimated cost of $\$ 590$ million in 2009 (see ibid.: 165). This number includes administration costs charged by Sun Life Financial, the private insurer administering the PSHCP. ${ }^{170}$ Phillips (2016) presents the structure of the federal government's involvement in PD coverage provision (see Table 5.2).

\footnotetext{
${ }^{170}$ Only the Interim Federal Health Program - providing temporary health care coverage to protected people (such as resettled refugees), refugees and specific other groups - is administered by Medavie Blue Cross (Phillips, 2016: i). For more details concerning federal spending in public and private PD coverage, see Gagnon (2012: 164-5).
} 


\section{Table 5.2. Federally provided public and private prescription drug coverage in 2016 $^{171}$}

\begin{tabular}{|c|c|c|c|}
\hline Department & Program & Population Group & Level of Coverage \\
\hline Health Canada & $\begin{array}{l}\text { Non-Insured } \\
\text { Health Benefits } \\
\text { Programa }\end{array}$ & $\begin{array}{l}\text { Registered First Nations under } \\
\text { the Indian Act and Inuk } \\
\text { recognized by one of the Inuit } \\
\text { land claim organizations. }\end{array}$ & $\begin{array}{l}\text { The program provides full } \\
\text { coverage to those who do not } \\
\text { have access to a private or } \\
\text { provincial/territorial drug plan. }\end{array}$ \\
\hline $\begin{array}{l}\text { Treasury Board of } \\
\text { Canada Secretariat, } \\
\text { administered by } \\
\text { Sun Life Financial }\end{array}$ & $\begin{array}{l}\text { Public Service } \\
\text { Health Care Plan }\end{array}$ & $\begin{array}{l}\text { Federal public service } \\
\text { employees and their } \\
\text { dependants. }\end{array}$ & $\begin{array}{l}\text { The program provides } \\
\text { catastrophic drug coverage } \\
\text { whereby members pay } 20 \% \text { of } \\
\text { drug costs up to a maximum of } \\
\$ 3,000 \text { per year. }\end{array}$ \\
\hline $\begin{array}{l}\text { Veterans Affairs } \\
\text { Canada, administered } \\
\text { by Sun Life Financial }\end{array}$ & $\begin{array}{l}\text { Group Health } \\
\text { Insurance }{ }^{c} \text { (under } \\
\text { the Public } \\
\text { Service Health } \\
\text { Care Plan) }\end{array}$ & $\begin{array}{l}\text { Eligible veterans and certain } \\
\text { survivors. }{ }^{d} \\
\text { Current and former members } \\
\text { of the RCMP who are eligible } \\
\text { for disability pension and } \\
\text { health benefit programs for a } \\
\text { service-related injury or } \\
\text { illness. }{ }^{\text {. }}\end{array}$ & $\begin{array}{l}\text { The program provides } \\
\text { catastrophic drug coverage } \\
\text { whereby members pay } 20 \% \text { of } \\
\text { drug costs up to a maximum of } \\
\$ 3,000 \text { per year. }\end{array}$ \\
\hline $\begin{array}{l}\text { Royal Canadian } \\
\text { Mounted Police, } \\
\text { administered by } \\
\text { Sun Life Financial }\end{array}$ & $\begin{array}{l}\text { Public Service } \\
\text { Health Care Plan }\end{array}$ & $\begin{array}{l}\text { RCMP members, their } \\
\text { dependants and civilian } \\
\text { employees. }\end{array}$ & $\begin{array}{l}\text { The program provides } \\
\text { catastrophic drug coverage } \\
\text { whereby members pay } 20 \% \text { of } \\
\text { drug costs up to a maximum of } \\
\$ 3,000 \text { per year. }\end{array}$ \\
\hline $\begin{array}{l}\text { Department of } \\
\text { National Defence }\end{array}$ & $\begin{array}{l}\text { Canadian Forces } \\
\text { Health Services }^{9}\end{array}$ & $\begin{array}{l}\text { Regular Canadian Forces } \\
\text { personnel. }\end{array}$ & $\begin{array}{l}\text { The program provides full } \\
\text { coverage for all prescription } \\
\text { drugs. }\end{array}$ \\
\hline $\begin{array}{l}\text { Immigration, } \\
\text { Refugees and } \\
\text { Citizenship Canada, } \\
\text { administered by } \\
\text { Medavie Blue Cross }\end{array}$ & $\begin{array}{l}\text { Interim Federal } \\
\text { Health Program }\end{array}$ & $\begin{array}{l}\text { Protected persons. } \\
\text { Refugee claimants. } \\
\text { Certain detained persons. }\end{array}$ & $\begin{array}{l}\text { The program offers varying levels } \\
\text { of drug coverage to individuals } \\
\text { according to their status under the } \\
\text { Immigration and Refugee } \\
\text { Protection } \text { Act. }^{\text {h }}\end{array}$ \\
\hline $\begin{array}{l}\text { Correctional Service } \\
\text { Canada }\end{array}$ & Health Services & Federal inmates. & $\begin{array}{l}\text { Full coverage of medications is } \\
\text { considered part of "essential } \\
\text { health care" services provided to } \\
\text { federal inmates. }\end{array}$ \\
\hline
\end{tabular}

In Canada, PD spending financed by the private sector - including private insurance and out-of-pocket spending - "accounted for $79.5 \%$ of expenditure for prescribed drugs in 1975 . This share decreased to $52.4 \%$ by 1992 and has remained

${ }^{171}$ From Phillips (2016: i). "Notes: a. Health Canada, "Benefits Information," First Nations and Inuit Health. b. National Joint Council of the Public Service of Canada, Public Service Health Care Plan Directive. c. Veterans Affairs Canada, Group Health Insurance. d. Ibid. e. Royal Canadian Mounted Police, "Help after a service-related injury or illness," VAC services \& benefits available to RCMP members. f. Royal Canadian Mounted Police, Health/Dental Claims \& Information. g. National Defence and the Canadian Forces, Supplemental Health Care. h. For further details, see Citizen and Immigration Canada, Interim Federal Health Benefits Program: Summary of Benefits. i. Correctional Service Canada, Health Services." (ibid.). 
relatively stable since." (CIHI, 2014: 50). As mentioned above, the most recent data from the CIHI estimated that, for 2014 , private insurers funded $\$ 10.3$ billion or $35.8 \%$ of total PD spending while $\$ 6.4$ billion or $22.2 \%$ of total spending was financed by out-of-pocket expenditure (CIHI, 2015: 8). As a result, 58\% of PD expenditure in 2014 was privately funded in Canada.

In recent years, a mounting literature has shed light on how and the extent to which the Canadian fragmented system results in inefficiencies and inequities. In Canada, private insurers have a central role in covering PD expense for the working population (and their dependents), but not for the non-working population. For instance, Law et al. (2012: 4) found that in 2007 "nearly 1 in 10 Canadians who received a prescription reported that out-of-pocket expenses led them to not fill a prescription, not renew a prescription, or try to make an existing prescription last longer." A 2013 EKOS survey suggested that $23 \%$ of Canadians admitted not having filled at least one prescription in the last five years due to financial constraints (EKOS, 2013). Simply put, as Gagnon explains (2014: 4), "private insurance does not cover all those without public coverage $[\ldots] . "$

The central role of private insurers in the fragmented PD insurance system is actually a major policy concern since "the percentage of private health insurance premiums paid out as benefits has decreased markedly over the past 20 years, leading to a gap between premiums collected and benefits paid of $\$ 6.8$ billion in 2011" (Law et al., 2014: 1). Moreover, Canadian private drug plans have been reluctant to implement costcontrol mechanisms over the past years (Kratzer et al., 2013). This is the reason why it can be said that Canadian private PD insurers tend to cover "everything at all cost." Since 
private insurers are paid a percentage of the total costs of the claims paid by private plans, Canadian private PD insurance thus usually functions with no incentives to control neither drug prices nor coverage expenditures (Lexchin, 2015; Silversides, 2009) ${ }^{172}$ But the lack of cost-containment measures from Canadian private insurers is especially worrying since the pharmaceutical industry has recently undergone a shift in its business model through the rise of high cost specialty medicines.

\subsubsection{Partial conclusions: the rise of high cost specialty drugs}

The Canadian PD insurance patchwork system results in Canada having the second lowest percentage of population publicly insured for PD coverage of all OECD countries, behind only the US (Gagnon, 2014: 5). Of course, from the perspective of the institutional constitution of insurance markets, the pharmaceutical industry represents the third-party non-insurance business involved in the private PD insurance market. Conversely, the pharmaceutical industry requires the insurance industry as an intermediary and a third-payer. Among OECD countries, Canada had the second highest PD expenditure per capita in 2011, again ranking second after the US where health care and health insurance is largely privately provisioned (ibid.: 6). In this context, the recent rise of high cost specialty drugs represents a major challenge for the Canadian patchwork system in general and for private health insurers in particular. The next section starts by presenting an overview of drug pricing and regulation in Canada. It then concludes on the new trends in drug prices and costs, and finally on the new "nichebuster" pharmaceutical business model characterized by the rise of high cost specialty drugs. As will be seen, the

\footnotetext{
172 The literature concerning the recent trends in the current Canadian private PD insurance market is discussed in greater details in Part 5.2.
} 
Canadian fragmented PD coverage contributes to high and rising PD expenditure since "the balance of power between the seller and the buyer" (Gagnon, 2015: 193) ultimately determines PD prices.

\section{Drug prices in Canada and the patchwork system: an overview}

Year after year, PD prices in Canada are "among the highest of all OECD countries" (Lexchin, 2015: 38). "From 2000 to 2010, the annual cost of prescription drugs increased more in Canada than in other countries with a similar level of economic development." (Gagnon, 2014: 7). But why are pharmaceutical prices and costs in PD expenditure so high in Canada? First and foremost, it is important to keep in mind that "there is little or no correlation between the price of a particular drug and the company's R\&D investment, no more than between a drug's price and the cost of its production" (Gagnon, 2015: 192). In this context, Gagnon (ibid.: 193) argues that "the balance of power between the seller and the buyer" ultimately determines PD prices: "[t]he aim of a pharmaceutical company is not to make drugs but to make profits. The prices of patented drugs are therefore set at the maximum amount that patients and the healthcare system will accept to pay." In addition to the insurance industry's lack of incentives to control costs, the Canadian patchwork PD coverage unsurprisingly contributes to the abnormally high costs of pharmaceutical products in Canada by fragmenting the purchasing power, hence leaving the pharmaceutical industry with the big end of the stick in setting and negotiating prices. Before discussing the recent trends in drug pricing in and the consequences of the Canadians patchwork PD coverage, the following subsection presents an outline of drug regulation and pricing in Canada. 
While Health Canada is responsible for the regulation and approval of drugs through the Therapeutic Products Directorate and the Biologics and Genetic Therapies Directorates, it is not involved in drug pricing (Lexchin, 2015: 28). Due to free trade agreements and political pressures from the US, Canada's compulsory licensing system was dropped in 1993 in favor of stronger patent rights (ibid.: 29). Canadian patented drug prices are regulated by a federal agency operating at arms length from the Ministry of Health, the Patented Medicine Prices Review Board (PMPRB). "Further complicating the situation is that prices for patented drugs, i.e., brand-name drugs, are controlled differently from prices for generic drugs.” (ibid.: 27).

On the one hand, although the PMPRB controls patented drugs' introductory prices and "limits the rate of rise of prices of individual products to the rate of rise in the Consumer Price Index (CPI) over any 3 year period" (ibid.: 30 ), the high total per capita expenditure in Canada can be partially explained by the increases in volume of use and by the shifts in the mix of treatments. ${ }^{173}$ Volume and mix effects can be "due in part to changes in treatment guidelines, increased disease prevalence and the uptake of new drugs." (CIHI, 2012: iii). On the other hand, public plans influence the price they pay for generic products by capping the formulary listed price "at a percentage of the brand name price and specifying a maximum reimbursable cost for a drug or group of interchangeable drugs. With a maximum reimbursable cost approach the plans obtain the cost of the generic from the manufacturer and use that cost to determine an appropriate formulary

\footnotetext{
${ }^{173}$ According to the PMPRB (2013: ii-iii), five categories of drivers determine drug costs: price effects (i.e. price changes of brand-name and generic products, and generic substitution); volume effects (i.e. changes in the volume of prescriptions, in the average amount of units per prescription, and in the composition and strengths of a molecule); drug-mix effects (i.e. changes in the usage of available medicines, also due to drugs exiting the market or new one entering); demographic effects (i.e. changes in the amount of people using drugs and in the distribution of age and gender groups); and dispensing fees (i.e. changes in dispensing fees, in the average amount of units per prescription and in the total volume prescribed).
} 
price" (Lexchin, 2015: 35-6). Finally, pharmaceutical products in Canada are also regulated through the Canadian Agency for Drugs and Technology in Health (CADTH) in charge of health technology assessment (HTA) ${ }^{174}$ - and its Common Drug Review (CDR). "The CDR provides advices to all of the provincial drug plans, except the one operated by the province of Quebec, the three territorial and six federal drug plans about the clinical efficacy and cost-effectiveness of drug against other drug therapies so that public funds are optimally used.” (ibid.: 32$).{ }^{175}$

Furthermore, the PMPRB's pricing guidelines - systematically ensuring that Canadian drugs prices are close to the fourth highest in the world - and the inefficient innovation policies directly contribute to the unusually high drug prices in Canada. First, Gagnon and Hébert (2010) showed that the PMPRB uses a list of seven comparator countries including Germany, Sweden, Switzerland, and the US where drug prices are the most expensive in the world. The PMPRB then sets Canadian prices according to the median of the comparator list, hence ensuring "that the prices of patented medicines in Canada are normally the fourth most expensive worldwide" (Lexchin, 2015: 32). Second, Gagnon (2012) and Gagnon and Gold (2011) argue that a number of innovation polices aiming at providing a good "business environment" to the pharmaceutical industry represent a major PD costs driver artificially inflating PD prices in Canada. ${ }^{176}$

\footnotetext{
${ }^{174}$ HTA can be defined as "the systematic evaluation of properties, effects, and/or impacts of health technology. It is a multidisciplinary process to evaluate the social, economic, organizational and ethical issues of a health intervention or health technology. The main purpose of conducting an assessment is to inform a policy decision making." (WHO, unknown).

${ }^{175}$ For more details on drug pricing in Canada, see Lexchin (2015).

176 As Gagnon (2012: 168) notes, "[i]t has been estimated that, because of these innovation polices to promote pharmaceutical research and development $(\mathrm{R} \& \mathrm{D})$ in Canada (excluding patent policy), Canadians pay a yearly supplement for prescription drugs up to $\$ 6$ billion, while generating only $\$ 662$ million in net private pharmaceutical $\mathrm{R} \& \mathrm{D}$ expenditures. These innovation polices are not only very costly, they are plainly inefficient. By eliminating these inefficient innovation policies, Canadians could save up to $42.8 \%$
} 
While complex drug regulations, pro-pharmaceutical industry official pricing and inefficient innovation policies contribute to the high costs of PD in Canada, four recent trends characterize drug pricings and purchasing in Canada (Gagnon, 2014: 10-23). First, since 2008, Canada has been hit particularly hard by the global wave of drug shortages (see ibid.: 20-2). Second, the recent reductions in generic prices have not been translated into savings for patients and insurers, but rather benefitted pharmacies. ${ }^{177}$ Third, confidential product listing agreements (PLAs) have proliferated. ${ }^{178}$ Unfortunately, the PLAs contributed at setting provinces against each other by generating a "whipsawing strategy" and the private plans ended up with artificially inflated official PD prices (ibid.: 15). Finally, in order to avoid such whipsawing strategies, the Council of the Federation established the pan-Canadian Pharmaceutical Alliance (pCPA) in 2010, a patented and generic drugs bulk purchasing inter-provincial organisation. As of August 31 2016, the pCPA completed 114 negotiations with pharmaceutical manufacturers including seven negotiations closed with no agreements reached (PCPA, 2016). Despite representing a step forward for the provinces, "[b]ulk purchasing does not ensure the savings for public plans will necessarily translate into savings for all Canadians since private plans and

on the total costs of prescription drugs." See Gagnon and Gold (2011), Light and Lexchin (2012) and Morgan et al. (2011).

${ }^{177}$ As Gagnon (2014: 11) explains, "market competition over prices among generic manufacturers results in price reductions not for buyers, but for pharmacies. Manufacturers provide financial incentives to pharmacies because they are the ones that decide which generic drugs will appear on their shelves. Even if prices are set, generic drug manufacturers must still convince pharmacies to purchase their product by offering generous rebates in order to increase their market share. Therefore, generic drug price reductions benefit pharmacies rather than insurers or patients."

178 "Since 2006, we have observed significant changes in the business model adopted by pharmaceutical companies to establish the price of patented drugs. We have gone from a transparent world where the listed price was the price paid, to a world of confidentiality and secret agreements. The reason for this strategy is that many countries, including Canada, regulate the price of patented drugs by comparing them to the official prices paid elsewhere in the world. To bypass these control mechanisms, pharmaceutical companies now in ate the suggested official international price and negotiate rebates with different buyers through confidential agreements. The official prices remain high because of the confidentiality of the negotiated rebates." (ibid.: 13). 
people without insurance will continue to pay their medicines at an increasing official price." (ibid.: 18).

In the context of the pharmaceutical regulations and innovation policies in place in Canada, the patchwork system of public and private PD coverage - despite initiatives such as the pCPA - and the insurance industry's lack of cost-control incentives (see also Part 5.2) both lead to a fragmentation of drug purchasing power and continuing high drug prices and expenditure in Canada.

From Blockbusters to Nichebusters: the rise of specialty medicines

A recent shift in the pharmaceutical industry's business model represents a major challenge for the Canadian patchwork PD coverage system. Before the first decade of the $21^{\text {st }}$ century, the central business model in the pharmaceutical industry operated around "blockbuster" drugs. The blockbuster model was characterized by a focus on high volume molecules generally leading to sales of at least USD 1 billion annually and developed for mass diseases and lifestyles-related illnesses (high blood pressure, high cholesterol, diabetes, etc.) (Montalban and Sakinç, 2013: 989). ${ }^{179}$ More specifically,

[t]he blockbuster model is primarily based on a profit strategy, which combines innovation with both volume and flexibility [...]. The blockbuster pairing is made possible by the monopolistic rents created by patent systems. For the strategy to work, however, drug companies must develop a product policy based on intense marketing that positions new ethical drugs at the center of the drug market to increase profits assuring the finance of $\mathrm{R} \& \mathrm{D}$. Blockbuster drugs represent the essential source of profits to be made that are complimented by increasing sales figures. Because of high R\&D expenditures, large companies focus on blockbusters to generate sufficient profits to recover their sunk costs. [...]. Given the opportunities, larger firms began to increase their advertising expenditures considerably, directing their armies of sales representatives at physicians and their patients. According to Gagnon and Lexchin (2008), large pharmaceutical companies spend twice on marketing what they spend, on average, on R\&D. Yet, a blockbuster is not necessarily an innovative drug. It can be a product of an incremental innovation over pre-existing drugs. (ibid.: 1002)

\footnotetext{
179 Atorvastatin is a good example of a blockbuster drug. Marketed as Lipitor by Pfizer and categorized in the statins drug class, it is used primarily to lower lipid level and prevent cardiovascular diseases.
} 
Due to the blockbuster model, the drug market eventually got saturated by so-called "metoo" drugs which pharmaceutical companies developed by slightly modifying existing molecules after patent expirations in order to gain access to new patents while reducing investment risks (see Gagnon, 2015: 194).

While the annual growth in drug spending has been rather constant since 2000, it has slowed down since 2010. "Prescribed drug spending in Canada grew rapidly in the early 2000s when many blockbuster drug classes expanded in terms of use and cost. More recently, growth rates have been lower as a result of patent expirations for many of the same drugs that led to higher growth in the previous years, as well as the introduction of generic pricing policies." (CIHI, 2015: 10). It is however important to understand that the relative stabilisation of annual growth rates since 2010 is due to conjuncture related price decreases generated by the "patent cliff" and the ensuing reduction in generics prices. As a matter of fact, according to Express Scripts Canada ${ }^{180}$ (2016: 42), many major blockbuster drugs lost market exclusivity due to the expiration of patents during the 2010s. As CIHI (2015: 6) notes, between 2008 and 2013, "[t]he expiration of patents [i.e. the patent cliff] and subsequent introduction of lower-cost generic drugs and the implementation of generic pricing policies contributed to a decline in spending in 5 of the top 10 drug classes in terms of public drug program spending."

Today, "[t]he era of blockbuster drugs losing market exclusivity as a result of patent expiries has come to an end." (Express Scripts Canada, 2016: 42). In the past few

\footnotetext{
180 Express Scripts Canada is the Canadian branch of Express Script Holding Company, a St. Louis (Missouri, US) based firm and the largest US pharmacy benefits manager. Express Script Holding Company operates mainly in pharmacy claims processing, benefits design consulting, and drug and medical data analysis. As of 2015, it was ranked $22^{\text {nd }}$ in Fortune 500 and $66^{\text {th }}$ in Fortune's Global500.
} 
years, in part due to the multiplication of me-too drugs and the patent cliff, a shift from the blockbuster model towards the "nichebuster" model has occurred in the global pharmaceutical industry (Collier, 2011; Dolgin, 2010; Gibson and Lemmens, 2014). This new pharmaceutical business model "is based on two complementary trends: the 'personalisation' of treatment in profitable niches, which also allows companies to obtain marketing approval on the basis of a pared-down evaluation (small trials of short duration); and a pricing level that would have been inconceivable 10 years ago." (Gagnon, 2015: 195). At the core of the new nichebuster model resides specialty drugs. Broadly "defined as high-cost injectable, infused, oral, or inhaled drugs that require close monitoring" (Kim et al., 2011: 598), specialty drugs are "[m]edications used to treat chronic, complex conditions such as rheumatoid arthritis, multiple sclerosis and cancer. Specialty drugs are usually costly, require special storage and handling, need intensive clinical monitoring and require frequent dosing adjustment." (Express Scripts Canada, 2016: 8). They are "often produced through biotechnology, [and] are mainly intended for the treatment of rare diseases and various forms of cancer. (Gagnon, 2015: 194).

In Canada, a good example of the nichebuster model is the specialty drug eculizumab use for treating rare blood disorders and marketed as Soliris by Alexion Pharma Canada, a subsidiary of the US-based Alexion Pharmaceuticals Inc. It was authorized by Health Canada in 2009 for the intravenous treatment of paroxysmal nocturnal haemoglobinuria and in 2013 for treating atypical haemolytic uraemic syndrome, two extremely rare chronic diseases. In Canada, Soliris' average cost per prescription was 7,533.02 CAD as of 2015 (Express Scripts Canada, 2016: 63) and it can 
cost up to 500,000 CAD a year depending of treatment and dosage required (Gallant, 2014).

In terms of business model, "by targeting specialty markets where no established therapy exists, [pharmaceutical] companies can demand higher prices than they can in already saturated markets." (Gagnon, 2015: 194). The new specialty medicines are actually the main drivers of the latest drug trend and rising expenditure, and this trend is not expected to cool down anytime soon. According to Express Scripts Canada (2016: 6), "[d]rug development activity and product approval continue to trend towards high-cost treatments and away from the lower-cost, widely used "blockbuster" drugs that formerly defined the industry. Similar to recent years, the majority of all products approved (58\%) in 2015 were considered specialty drugs." Despite representing only $2 \%$ of all claims made in Canada, the annual growth of specialty expenditure for 2015 remained in the double-digit at 18.6\% (ibid.: 61). Moreover, "[s]pecialty medications claims made up $29.9 \%$ of total drug spending, a figure that has doubled in eight years." In 2020, specialty drugs are expected to account for $42 \%$ of total drug spending in Canada with double-digit annual growth continuing of several years (ibid.: 72) (see Figure 5.2). 


\section{Figure 5.2. Evolution/forecast of specialty drugs spending as percentage of total PD expenditure in Canada ${ }^{181}$}

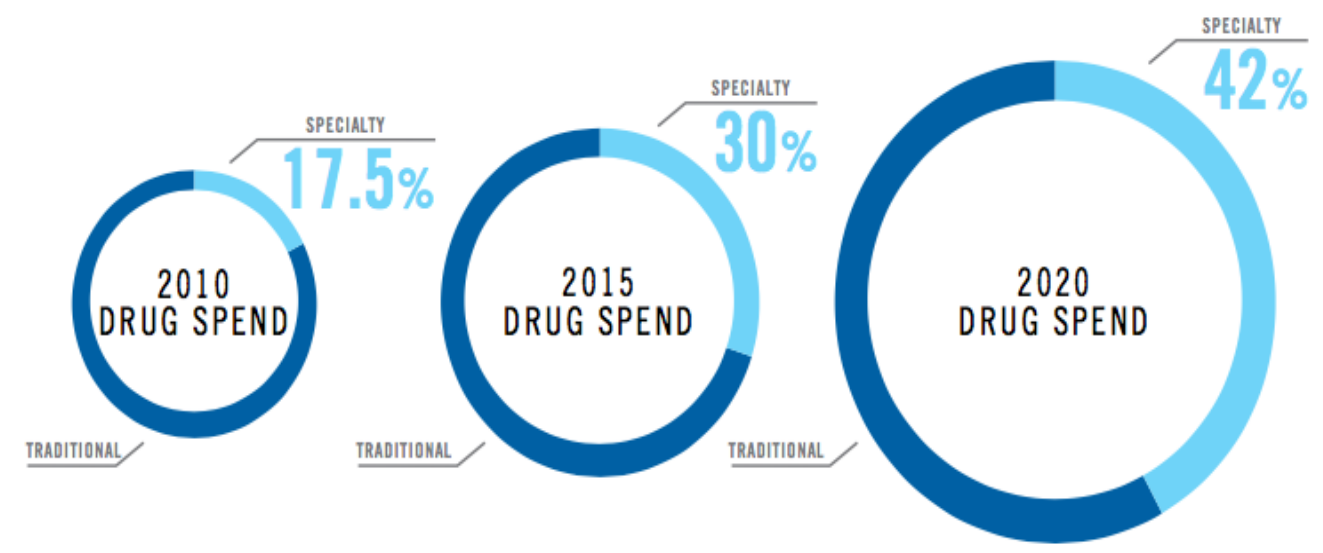

Also worrying are the rapid pace of introduction of new specialty drugs on the market and the growth driving effect of these new introductions. The new specialty drugs approved by Health Canada between January 2010 and December 2015 accounted for $30 \%$ of total expenditure driven by specialty medicines (ibid.: 44). Although the patent cliff led to a conjectural stabilisation of PD spending annual growth rates since 2010 (see above), the new nichebuster pharmaceutical business model epitomized by the rise of specialty drugs now represents the new structural driver of overall expenditure increase. As CIHI's (2015: 42) ${ }^{182}$ data concerning Canadian public plans suggest,

[a]mong the 7 jurisdictions for which data is available for 2008 and 2013, the proportion of drug program spending on beneficiaries for whom the drug program paid $\$ 10,000$ or more in drug spending increased from $15.9 \%$ in 2008 to $29.7 \%$ in 2013 , while the proportion of beneficiaries they accounted for increased by less than 1 percentage point (from $1.1 \%$ in 2008 to $1.8 \%$ in 2013) [...]. This increase is due in large part to the increased spending on more expensive drugs. In $2013,21.8 \%$ of public drug spending was on chemicals that cost $\$ 10,000$ or more per beneficiary, representing $5.6 \%$ of the total number of chemicals that were paid for by the public drug programs [...]. In $2008,2.6 \%$ of the chemicals paid for by public drug programs exceeded $\$ 10,000$ per beneficiary, accounting for only $9.1 \%$ of program spending.

\footnotetext{
${ }^{181}$ Source: Express Scripts Canada (2016: 72).

182 CIHI's (2015: 27) computation includes data concerning "10 jurisdictions submitting claims data to the NPDUIS Database as of January 2015 [which] are Newfoundland and Labrador, Prince Edward Island, Nova Scotia, New Brunswick, Ontario, Manitoba, Saskatchewan, Alberta, British Columbia and the First Nations and Inuit Health Branch."
} 
In other words, a small number of high-cost claims have clearly begun to put an important and growing pressure on Canadian public plans.

While the nichebuster model represents a major challenge for the inefficient Canadian patchwork PD coverage system as a whole, the rise of the specialty drugs is especially challenging for the employer-sponsored private health and PD benefits group plans offered by the Canadian life and health insurers. As John Anacleto (2016: 19) reports from Telus Health's private health insurance and employers' drug plans database, ${ }^{183}$ specialty drugs represented $0.5 \%$ of all claims but almost a quarter of total costs $(23 \%)$ as of 2015 . Figure 5.3 presents the comparative evolution of specialty drugs' percentage of total costs and total claims according to the Telus Health's private drug plans database.

\footnotetext{
183 John Anacleto is Business and Analysis Manager at Telus Health Analytics. The data presented by Anacleto (2016: 3) "is based on an analysis of [PD] claims processed by TELUS Health who adjucates for 12 million lives with private insurance. The data used for the analysis was sourced from the TELUS Health Data Warehouse as of March 2016, reflective of the age group 0 to 64." Owned by the Canadian telecommunications giant Telus Corporation, Telus Health offers health data and analytics, claims and benefits management, pharmacy management, patient and consumer health platforms, and electronic health and medical records services and infrastructure.
} 


\section{Figure 5.3. Evolution of specialty drugs share of total costs and claims at Telus} Health, 2008-15 184

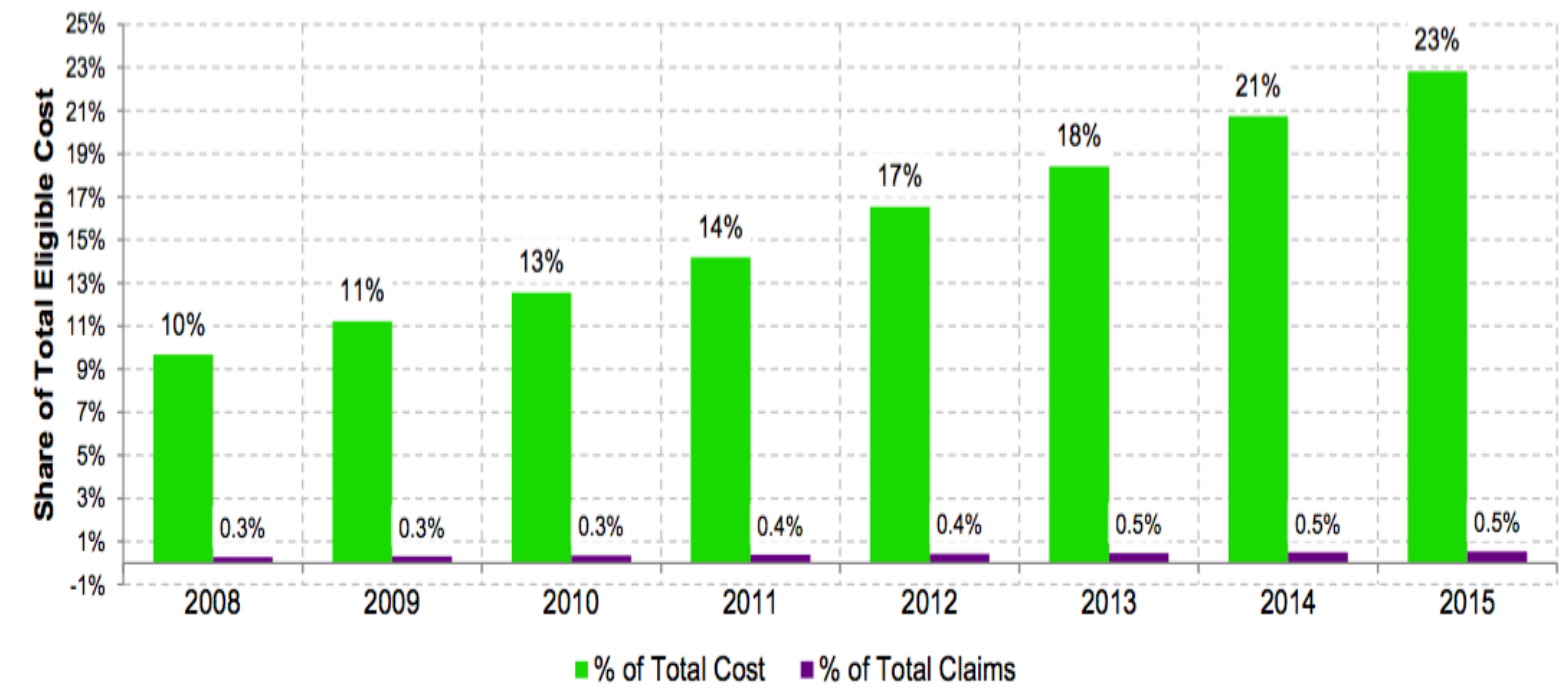

While the specialty drugs' share of total Telus Health claims increased by $66.7 \%$ from $2008(0.3 \%)$ to $2015(0.5 \%)$, their share of total eligible costs jumped by $130 \%$ during the same period (from $10 \%$ to $23 \%$ ).

According to the analysis of the IMS Brogan Private Pay Direct Drug Plan Database $^{185}$ by the National Prescription Drug Utilization Information System (NPDUIS), an independent research initiative operated under the PMPRB, "[i]n 2005, an average private drug plan of 100,000 active beneficiaries had about 263 beneficiaries with annual drug costs of $\$ 10,000$ or more. By 2015 , this number increased to 705 , representing a 3.7fold increase in beneficiaries and 5.1-fold increase in drug costs." (NPDUIS, 2016). Figure 5.4 presents the NPDUIS's results.

\footnotetext{
${ }^{184}$ From Anacleto (2016: 19).

${ }^{185}$ IMS Brogan is a Canadian subsidiary of IMS Health, a global healthcare information, technology and service provider based in Danbury (Connecticut, US). The IMS Brogan Private Pay Direct Drug Plan Database includes around 12.8 million beneficiaries for a total of 7.5 billion dollar in drug expenditures as of 2015.
} 
Figure 5.4. Number and costs of high-cost active beneficiaries in private drug plans, 2005-2015

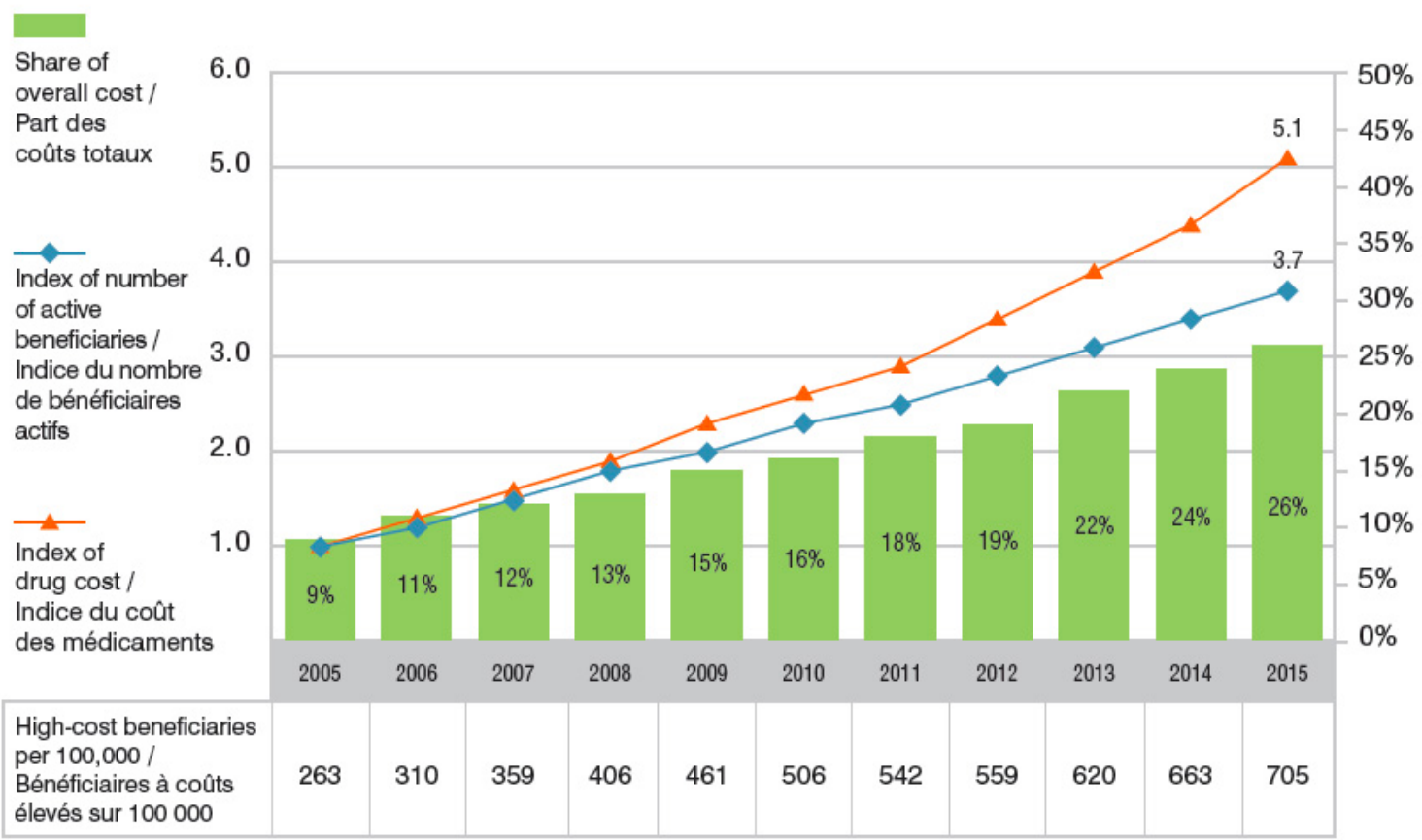

${ }^{*}$ Active beneficiaries with annual drug costs of $\$ 10,000$ or more. /

*Bénéficiaires actifs dont les coûts annuels en médicaments sont de 10000 ou plus.

The impact of the arrival of specialty medicines on the Canadian private insurance market can be best measured by the increasing costs generated by the high-cost beneficiaries - defined as those with annual PD costs of $\$ 10,000$ or more - over the overall cost incurred by private PD plans. As Figure 5.4 shows, the share of high-cost beneficiaries over the overall plan costs in the IMS Brogan's database jumped from 9\% in 2005 to $26 \%$ in 2015 , representing a total increase of $188 \%$ over 10 years and an average annual inflation of $11.3 \%$.

Facing the arrival of specialty medicines, the employer sponsored private health benefits group plans struggle at managing these cost increases and maintaining the same level of coverage. But how is the Canadian PD insurance market precisely responding to 
the rise of new high cost specialty drugs?

\subsection{Private insurance facing the rise of high price specialty drugs}

The facts that private insurers finance more than a third of Canadian PD expenditures (CIHI, 2015: 8) and that, as of 2014, around $77.8 \%$ of all Canadians are directly and indirectly privately covered for PD expenditure through group plans or individual policies - either as beneficiaries of an employer-provided group plan or as dependents of an employee with benefits (CLHIA, 2015b: 15) - are far from being the results of some self-regulated market forces. In addition to the historical exclusion of PD coverage from the provincially controlled Canadian universal healthcare systems (see Part 5.1), the taxsubsidies for private health benefits at the federal level represents another crucial component of the institutional constitution of private PD insurance in Canada. Except in the province of Quebec where employer health benefits group plans are mandatory, the federal government promotes private health insurance and the private provision of health services benefits by considering health and dental benefits offered by employers as nontaxable income for employees (M-A Gagnon, 2012). ${ }^{187}$

Unsurprisingly, the study of the insurance industry is made difficult due to the restricted access to insurance sector data. For instance, neither the major official database such as Statistics Canada and the Institut de la statistique du Québec, nor the Canadian life and health $(\mathrm{L} \& \mathrm{H})$ insurance industry trade association - the CLHIA - offer

\footnotetext{
187 As Gagnon (2012: 165-6) explains, “[s]uch a rule, [...], is problematic because as with many tax expenditures, it makes taxation more regressive. For example, $\$ 2000$ obtained in drug benefits represents a different tax saving depending on the level of income of the employee. For an employee gaining $\$ 39,000$ per year (plus health benefits) in Ontario, tax savings on $\$ 2000$ of drugs benefits due to the non-taxation of the employer's drug plan would be $\$ 401$ because the marginal tax rate applied is $20.25 \%$. For an employee earning $\$ 133,000$ per year with a marginal tax rate of $46.41 \%$, it represents tax savings of $\$ 928.20$. Marginal tax rates for the same salaries would vary between $15 \%$ and $29 \%$ for federal income tax alone."
} 
disaggregated data on health and PD benefits and private PD premiums spent in Canada. Access to L\&H insurance industry and employment benefits group plans database (Telus Health, Applied Management Consultants and Mercer) is especially restricted by virtue of being proprietary in nature and hence prohibitively priced for researchers without adequate research funding (see Section 5.2.2). Over the past years, Canadian healthcare and health policy researchers have gained access to significant L\&H insurance industry information and paved the way to a wave of academic studies of private health insurance in Canada (see Hurley and Guindon, 2008; Kratzer et al., 2013; Law et al., 2013, 2014; O’Brady et al., 2015).

Building of this literature and on some publicly available grey literature from the private insurance and health benefit, Part 5.2 aims at assessing (1) the ability of private PD insurance - through the employment benefits group plans - at facing the rise of high price specialty drugs and (2) the responses from the Canadian L\&H insurance industry to the new nichebuster pharmaceutical business model. From the perspective of the institutional constitution of insurance markets framework, Part 5.2 seeks to provide answers to one of the two components of this dissertation's specific question: which noncompetitive institutional arrangements contribute at ensuring the constitution of the Canadian PD insurance market in the context of the rise of high price specialty drugs?

Part 5.2 first presents overviews of the structure of the Canadian L\&H insurance industry and of the organization and design of employment health and PD benefits group plans in Canada. Second, it assesses the ability of the drug benefits group plans' design in facing the rise of high price specialty medicines. Finally, it analyzes the isolated 
initiatives from the Canadian L\&H insurers and the structural responses of the Canadian L\&H insurance industry to rising specialty drug costs.

As will be showed in Part 5.2, the emergence of the nichebuster pharmaceutical business model represents a major challenge for the Canadian PD insurance market since the arrival of high cost specialty medicines generates a crisis among the employersponsored private health benefits group plans offered and managed by the Canadian L\&H insurers. The private insurance governance proves unable to manage the instability and cost inflation generated by the emergence of "bad" risks constituted by the recurring and non-recurring catastrophic claims of high price specialty drugs. As a result, these new bad catastrophic insurance risks must be controlled and reduced through non-competitive institutional arrangements and insurers tend to shift costs directly towards patients.

\subsubsection{The Canadian PD insurance market: structure and organization}

In order to better assess the ability of private PD insurance to face and respond to the rise of high cost specialty medicines in Canada in Section 5.2.2, the next section presents overviews of the structure of the Canadian L\&H insurance industry and of the organization and design of the employment health and PD benefits group plans in Canada. These overviews are based on a body of grey literature composed of online articles from the employment benefits and group insurance consulting and administration industry, of documents available online from group benefits sector conferences and of online and on demand documents from L\&H insurers. The following overviews also rely on Benefits Canada's "Face to Face in Drug Plan Management" online survey released 
on December 22015 (Benefits Canada, 2015) and on an educational note from the Canadian Institute of Actuaries (see CIA, 2010).

In contrast to what the Canadian L\&H insurance association claims, both the L\&H insurance industry and the Canadian health benefits group plans market are rather concentrated. It should therefore not be surprising for the Canadian L\&H insurers to respond to a crisis of the employment PD benefits group plans, generated by the arrival of high cost specialty medicines, with non-competitive institutional arrangements.

\section{Structure: the L\&H insurance industry}

In Canada, the $\mathrm{L} \& \mathrm{H}$ insurers and, to a smaller extent, the property and casualty $(\mathrm{P} \& \mathrm{C})$ insurers provide private PD insurance. ${ }^{188}$ Although the CLHIA (2015b: 2) claims that the Canadian L\&H insurance industry "is highly competitive," the industry is actually "rather concentrated, no matter whether concentration is assessed in terms of assets, number of policies underwritten, or premiums written" (Cummins and Venard, 2007: 424). In 2003, the top five Canadian L\&H insurers comprised $39.5 \%$ of the total L\&H insurance market share by net premiums written (ibid.). In 2013, the top five L\&H insurers in Canada made up $73.9 \%$ of total net premiums written (The Insurance \& Investment Journal, 2014). This same year, the top three L\&H insurers in Canada - also known as the Big three, including Great-West Group (23.85\%), Sun Life Financial (17.59\%) and Manulife

\footnotetext{
188 As of 2014, "[t]he 127 companies active in the supplementary health insurance field include: 64 life insurance companies, 47 property and casualty insurers, 8 fraternal benefit societies and 8 not-for-profit health care benefit providers (e.g., provincial Blue Cross organizations). Of the total, 93 are Canadianincorporated, 23 are from the United States, and 11 are from Britain, Europe and elsewhere. In 2014, 91 were registered under federal laws and 36 were provincially incorporated. Although life insurance companies and not-for-profit health care benefit providers sold 99 per cent of these products, property and casualty companies and fraternal benefit societies were also active in this field during 2014." (CLHIA, 2015b: 30).
} 
Financial $(16.41 \%)$ - comprised $57.85 \%$ of total net premiums written. Table 5.3 presents the top 10 Canadian L\&H insurers by net premiums written.

\section{Table 5.3. Top $10 \mathrm{~L} \& H$ insurers in Canada by net premiums written, 2013 (thousand CAD) ${ }^{189}$}

\begin{tabular}{|c|c|c|c|c|}
\hline & COMPANY & PREMIUMS & SHARE & PREMIUM GROWTH \\
\hline 1 & GREAT-WEST GROUP & $12,667,305$ & $23.85 \%$ & $7.04 \%$ \\
\hline 2 & SUN LIFE FINANCIAL & $9,339,405$ & $17.59 \%$ & $7.88 \%$ \\
\hline 3 & MANULIFE FINANCIAL & $8,714,232$ & $16.41 \%$ & $-0.38 \%$ \\
\hline 4 & INDUSTRIAL ALLIANCE & $4,735,623$ & $8.92 \%$ & $43.21 \%$ \\
\hline 5 & DESJARDINS INSURANCE & $3,771,993$ & $7.10 \%$ & $8.17 \%$ \\
\hline 6 & SSQ LIFE & $1,629,632$ & $3.07 \%$ & $11.95 \%$ \\
\hline 7 & MEDAVIE BLUE CROSS & $1,416,281$ & $2.67 \%$ & $2.80 \%$ \\
\hline 8 & RBC LIFE & $1,241,608$ & $2.34 \%$ & $-3.07 \%$ \\
\hline 9 & STANDARD LIFE & $1,059,034$ & $1.99 \%$ & $4.33 \%$ \\
\hline 10 & AEGON GROUP & 944,020 & $1.78 \%$ & $2.17 \%$ \\
\hline & TOTAL & $45,519,133$ & $85.72 \%$ & \\
\hline
\end{tabular}

Source: MSA Research

Are part of the top 10 Canadian L\&H insurers: two joint-stock companies part of multinational holdings (Canada-based Great-West and Netherlands-based Aegon), one subsidiary of a major Canadian bank (RBC Life), one not-for-profit (Medavie Blue Cross), one cooperative (Desjardins Insurance), a joint-stock company controlled by a diversified financial group (SSQ Life; see below), and four ex-mutual societies now joint-stock companies (Sun Life Financial, Manulife, Industrial Alliance and Standard

\footnotetext{
${ }^{189}$ From The Insurance and Investment Journal (2014).
} 
Life, which was recently acquired by Manulife). ${ }^{190}$ In fact, the Big three only recently became fully joint-stock owned corporations since "[t]he enactment of federal legislation allowing demutualization in March 1999 gave the demutualizing companies the necessary process and regulations to move forward." (Lombardi, 2000: 3). ${ }^{191}$

In Canada, the vast majority of private PD coverage is offered as a component of Extended health care (EHC) insurance - also known as "supplemental health" insurance or coverage - provided through employment benefits group plans. ${ }^{192}$ According to the 2015 "Face to Face in Drug Plan Management" survey, 100\% of surveyed senior benefits decision makers $(\mathrm{n}=204)$ reported an employment health benefits group plan including PD coverage (Benefits Canada, 2015). ${ }^{193}$ EHC is itself a component of group L\&H insurance. According to the Canadian Institute of Actuaries (CIA), group L\&H insurance

\footnotetext{
190 On September 3 2014, Manulife Financial acquired The Standard Life Assurance Company of Canada for 4 billion CAD (as of 2014). On July 1st 2015, Manulife hence assumed Standard Life's Canadian individual policies and groups plans which, according to the 2013 data (see Table 5.3), would boost the top five by market share by $1.99 \%$, from $73.9 \%$ to $75.89 \%$ of total net $\mathrm{L} \& \mathrm{H}$ premiums written in Canada.

${ }^{191}$ As Lombardi (2000) explains, since 1999, the former five largest Canadian mutual insurers - Mutual Life (now Clarica Life), Manulife, Canada Life, Sun Life, and Industrial Alliance (a provincially registered company not operating under the federal Insurance Companies Act) - moved ahead with demutualization. As a result, "[t]he value of the windfall benefits to be shared by eligible policyholders worldwide may exceed[ed] \$25 billion Canadian [...], and is believed to [have] be[en] the largest transfer of wealth in Canadian history." (ibid.: 3).

${ }^{192}$ EHC insurance "[c]overs the following services where they are not publicly insured: hospital services, prescription drugs, non-physician providers, vision care, travel insurance and [...] other services. [...]. The set of included services varies across policies. The defining feature is that a single policy covers multiple types of services that are not publicly insured. All policies include hospital services; most include prescription drugs; the variation is largest for other services." (Hurley and Guindon, 2008: 18). Besides EHC, employee health benefit group plans can also include dental insurance, long-term disability insurance, accident death and dismemberment insurance. Usually offered as individual policies, critical illness insurance and long-term care insurance are increasingly integrated into group plans (see ibid.).

${ }^{193}$ Benefits Canada is the main magazine and website focusing on the Canadian group benefits and pension plans sector. Published by Rogers Media Inc., its advisory board is constituted by members of Accompass, Ontario Teachers Insurance Plan, Aon Hewitt, Rogers, Willis Towers Watson, Toronto Transit Commission, Sun Life Financial, State Street, Unisource Canada Inc., Towers Watson, Sun Life Global Investments, Franklin Templeton Investments, Desjardins Financial Security, Greystone Managed Investments Inc., and Foyston Gordon \& Payne Inc. (see < http://www.benefitscanada.com/advisoryboard $>$; accessed August 3 2016). Sponsored by private insurers (Desjardins, Great West, Green Shield and Manulife), a pharmacy benefits manager (Express Scripts), pharmaceutical and biotechnological firms (AMgen Inc., Innomar Strategies/AmerisourceBergen and Merck and Co. Inc.), Canada's largest retail
} 
is an arrangement whereby the members of a group, and sometimes their dependents, are insured under a master policy of contract. Typically, each insured member receives a certificate of insurance. The term "group insurance" includes: employment benefits - employee groups sponsored by their employers, association plans - employee or professional groups sponsored by their union or professional group, and creditor group insurance - creditor groups sponsored by the creditor of a group of debtors, where membership in the group qualifies the insured. Most group life and health coverage is provided as an employment benefit for the benefit of the company's employees and their dependents, and is at least partially paid for by the employer. Association plans generally cover associations of individuals or groups for group coverage. Benefits are provided to a group of people with a common link such as a profession or an aggregation of small groups to form one large group. In the former case, premiums are generally paid by the members and in the latter, premiums are generally paid by a combination of employer and employee contributions. Creditor group insurance is coverage provided to a collection of participants who have taken loans (including mortgages). (CIA, 2010: 5-6)

EHC “plans are voluntary in all provinces except Québec where employers are required

to provide private drug insurance for eligible employees." (Morgan et al., 2015: 5). ${ }^{194}$

According to the latest CLHIA (2015b: 15) data for 2014, close to 10.7 million Canadian workers and their 14.3 million dependents were covered by 124,000 EHC insurance group contracts, for a total of around $70.3 \%$ of the Canadian population. ${ }^{195}$ In contrast, only 772,000 workers and dependents $-2.2 \%$ of the Canadian population - were covered by PD only (i.e. non-EHC) group contracts in 2014. As a result, a total of around $72.5 \%$ of the Canadian population receives PD coverage through employment benefit group plans. Finally, 5.3\% of the Canadian population - or 1.9 million Canadians - was covered by individual (i.e. "non-group") EHC contracts in 2014. A total of around $77.8 \%$ of all Canadians are thus privately covered for PD expenditure through group plans or individual policies. However, the CIHI estimated that, for 2014, private insurers funded only $\$ 10.3$ billion or $35.8 \%$ of total PD spending (CIHI, 2015: 8) (see Section 5.1.2).

pharmacy chain (Shoppers Drug Mart Corp.) and the Canadian pharmaceutical industry trade association (i.e. Rx\&D, now Innovative Medicines Canada), the "Face to Face in Drug Plan Management" survey was conducted online in October 2015 and surveyed $(n=) 204$ senior benefits decision makers across Canada. The survey is weighted according to Canada's regions, public and private sectors, and company sizes.

${ }^{194}$ On Québec's provincial general and hybrid public-private PD plan, see section 5.1.2.

195 These calculations, based on the CLHIA (2015b) data for 2014, use Statistics Canada's (2014) estimated total population of 35,540,400 inhabitants as of July $1^{\text {st }} 2014$. 
As with the L\&H industry as a whole, the Canadian market for $\mathrm{L} \& \mathrm{H}$ insurance employment benefits group plans is also significantly concentrated. According to the Fraser Group's ${ }^{196}$ Group Universe Report for 2015 (Fraser Group, 2016a), the top 10 insurers made up $96.2 \%$ of the Canadian market, out of 36.8 billion CAD total revenues, up by $4.3 \%$ from 2014 (see Figure 5.4).

Figure 5.5. Top 10 Canadian group L\&H insurers' market share by total revenue, $\mathbf{2 0 1 5}^{197}$

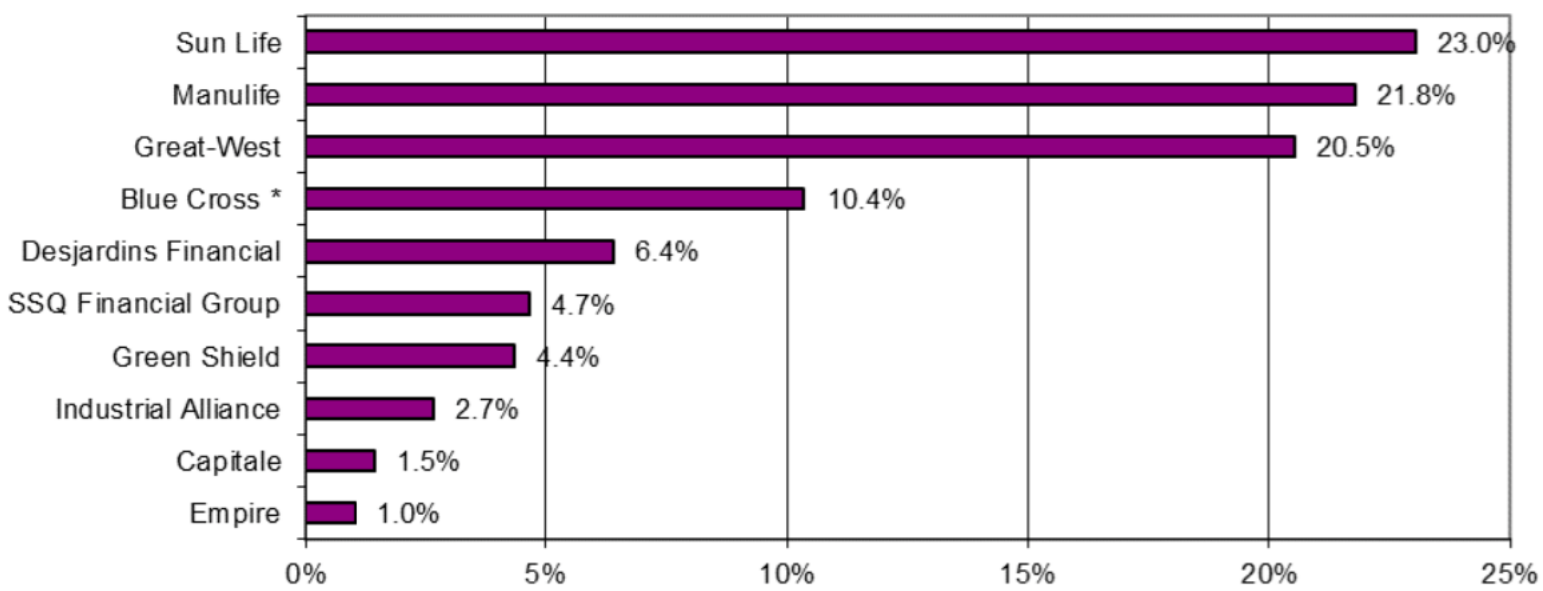

* Represents aggregate of all Blue Cross plans in Canada

While the top 5 made up $82.1 \%$ of total market revenues in 2015, the Big three alone comprised $65.3 \%$ of the market for employment benefits L\&H insurance group plans.

The situation in the province of Quebec is slightly different. Again according to data from the Fraser Group (2016b), although the market is only slightly less

\footnotetext{
196 The Fraser Group "is a market information and research firm working in the employee benefits and insurance markets in Canada." (Fraser Group, 2013).

${ }^{197}$ From Fraser Group (2016a).
} 
concentrated in Quebec compared with Canada as a whole with the top 10, top five and top three insurers respectively comprising $97.5 \%, 75.1 \%$ and $54.3 \%$ of total market revenue of $\$ 6.6$ billion in 2015 (up by $3.5 \%$ from 2014 ), the top two is composed of Desjardins Financial (a cooperative) and SSQ Financial Group, a diversified financial group owned mainly by a legislatively created union-controlled investment fund (Fonds de Solidarité FTQ) and including a not-for profit organization. ${ }^{198}$ Together, Desjardins and SSQ constituted 39.3\% of Quebec's PD group insurance market in 2015 (see Figure 5.5). Adding Blue Cross entities, $45.2 \%$ of the market in Québec is rooted in the social economy. $^{199}$

\footnotetext{
${ }^{198}$ Despite its cooperative and mutualist origins, only one component of SSQ Financial Group's (SSQ Groupe Financier) organizational structure - SSQ Mutuelle de Gestion - is still registered as a "not-forprofit moral person" (personne morale sans but lucratif) in the province of Quebec. Together with Fonds de Solidarité FTQ and Fonds distinct dédié SSQ (an investment fund owned by SSQ's senior managers), SSQ Mutuelle de Gestion owns SSQ Société de participation mutualiste inc. (i.e. a joint-stock company), itself controlling another joint-stock company, SSQ Société d'assurance-vie inc. which controls the balance of SSQ Groupe Financier's main components (SSQ Société d'assurance inc., SSQ Société d'assurances générales inc. and SSQ Société immobilière inc. See SSQ (2016) and Registre des Entreprises du Quebec (as of July 18 2016).
}

${ }^{199}$ On the social economy sector in Québec, see Lévesque et al. (2003) and Mendell and Neamtan (2010). 
Figure 5.6. Top 10 group L\&H insurers' market share by total revenue in Quebec, 2015 $^{200}$

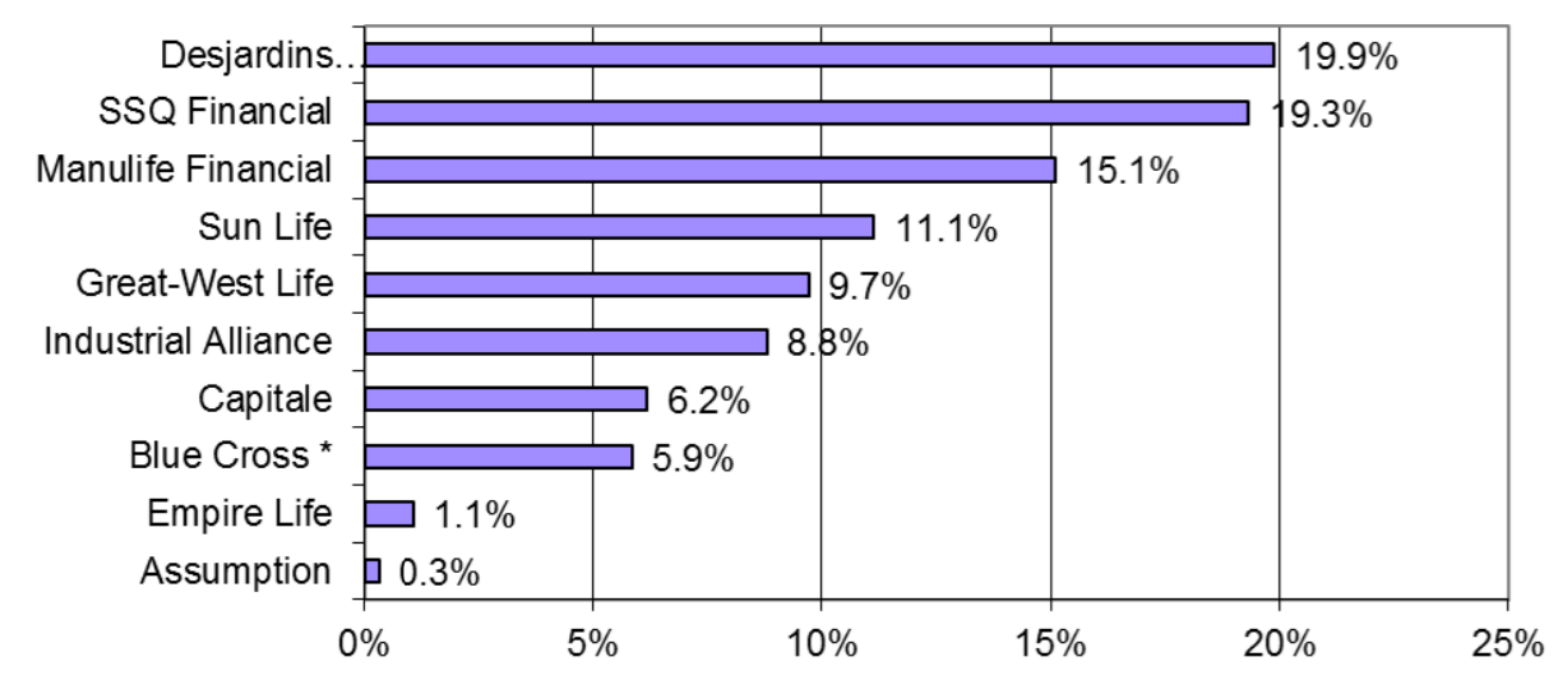

* Represents aggregate of all entities using the Blue Cross name in Quebec.

In contrast, the top Canadian group L\&H insurers stemming from social economy's organizational forms (Blue Cross, Desjardins Financial, SSQ Financial Group and Green Shield) comprised only $25.9 \%$ of the Canadian market in 2015 (see Figure 5.4).

As of 2015, group health insurance and PD coverage accounted for $46 \%$ of total revenues ( $\$ 6.9$ billion) in the Canadian market for employment benefits L\&H insurance group plans (Fraser Group, 2016a: 3). Most, if not all Canadian employment benefits group plans include PD coverage (Benefits Canada, 2015: 4). In fact, PDs account for most employment benefits plans' costs, as estimates range from $60 \%$ to $85 \%$ of total L\&H group plans costs (The Benefits Consultant, unknown) and from $70 \%$ to $75 \%$ of total medical plans costs alone (B Gagnon, 2012: 100). ${ }^{201}$

\footnotetext{
${ }^{200}$ From Fraser Group (2016b).

201 For example, a total of $62.6 \%$ of health benefits claims made to Sun Life between January $1^{\text {st }}$ and December 312011 consisted in PDs (Martinez, 2012: 2). At the time this presentation was given, Barbara
} 
Group plans organization and design

Access to employment benefits group plans data is especially difficult due to its proprietary nature. Such data is itself commercially valuable. For example, the Canadian private health insurance and employers' drug plans database at Telus Health, Applied Management Consultants and Mercer are prohibitively priced for researchers without sufficient research funding. ${ }^{202}$ In this context, the following overview of the organization of employment benefits PD group plans in Canada is first based on a body of grey literature ${ }^{203}$ composed of (1) online articles from the employment benefits and group insurance consulting and administration industry (see ADB\&IA Inc., unknown; Maximum Benefits, unknown; Smith, 2013; The Benefits Consultant, unknown, unknownb), ${ }^{204}$ of (2) documents available online following group benefits sector conferences (see Anacleto, 2016; Lepage, 2016; Martinez, 2012; Patriarche, 2016) and (3) of online or on demand documents from L\&H insurers (Empire Life, 2014; Great-

Martinez was principal Health \& Benefits at Mercer Human Resource Consulting (see $<$ https://www.cahspr.ca/en/conferences/past/2012/presentations/subplenary>; accessed August 8 2016).

202 Applied Management Consultants is a Canadian health care consulting firm. A subsidiary of global insurance broker and risk manager Marsh and McLennan Companies Inc., Mercer LLC is the world's largest retirement, health, investments and human resources consulting firm.

${ }^{203}$ On the use of grey literature in social science and public policy research, see Farace and Schöpfel (2010) and Lawrence et al. (2014).

204 Accurate Design Benefits \& Insurance Agencies, Inc. is a Mississauga, Ontario-based employment benefits consulting, designing and administrating agency and is self-described as providing "expert guidance for the design, costing, administration, communication and implementation of employee benefits; corporate life insurance solutions and retirement programs." (see $<$ http://www.accdesign.com/aboutus.htm>; accessed August 3 2016. Headquartered in Winnipeg (Manitoba), Maximum Benefits is “Johnston Group's large group benefit solution for companies with 25 or more employees. Johnston Group is a Third Party Administrator (TPA) providing group benefit services to 30,000 businesses and their employees from coast to coast." (see <http://www.maximumbenefit.ca/aboutus>; accessed August 3 2016). The Benefits Consultant's website ("BenefitsConsultant.ca") does not offer much information concerning which individual(s) or entity(ies) it is being run by. It only states that, as of 2016, BenefitsConsultant.ca is a part of "Benefits Medias Inc." According to CAN1 Business - an online directory of business and companies registered in Canada - Benefits Medias Inc. was incorporated under the federal Business Corporations Act on January 182015 and its registered office is located in Vancouver, British Columbia (see <https://www.canlbusiness.com/company/Active/Benefits-Media-Inc>; accessed August 3 2016). 
West Life, unknowna-b-c; Sun Life Financial, unknown). Of course, these organizations have vested interests in the business of health and PD employment benefits group plans. Finally, the following overview also relies on Benefits Canada's "Face to Face in Drug Plan Management" online survey released on December 22015 (Benefits Canada, 2015) and on an educational note from the Canadian Institute of Actuaries (CIA) published in 2010 and presenting detailed information concerning the various benefits available and the financial, underwriting and accounting organization of employment benefits group plans in Canada (see CIA, 2010).

As the largest component of employment benefits plan costs, drug and medicine benefits usually cover drugs "that: [a]re medically necessary[;] [a]re prescribed by a physician[;] [h]ave a drug identification number (DIN)[;] [a]re dispensed by a registered pharmacist." (The Benefits Consultant, unknownb). Drug benefits plans can cover prescription only ("restrictive plans" in which over the counter drugs are paid out-ofpocket by the employee) or any prescribed drugs ("broad plans" covering over the counter drugs). Hybrid plans can also cover both prescribed and over the counter drugs. While drug claims can be paid through reimbursement plans or pay-direct plans, medical and PD "benefits are usually provided on a direct-pay basis (the plan pays the provider directly)" (B Gagnon, 2012: 99), in contrast to other types of employment benefits such as life disability insurance provided through indemnification. ${ }^{205}$ As a result from being

\footnotetext{
205 "Under a reimbursement plan, the employee pays to the prescription once it is filled by the pharmacist and the completes and submits a claim form (including the receipt) to the insurance company for reimbursement. [...]. Under a pay-direct drug plan, the insurance company pays the participating pharmacist directly for the eligible cost of the drug. The insurance company or a third party that specializes in drugs claims paying establishes a network of pharmacists that are contractually bound to provide drugs to covered plan members. [...]. A pay-direct drug plan is more expensive to the employer than a reimbursement plan based on the following: There is higher utilization of the plan because the initial outof-pocket costs to the employee is minimal [and] There is no possibility of lost receipts or unsubmitted
} 
negotiated between insurance providers and employers - but also with employees in unionized settings (see O’Brady et al., 2015) - many provisions included in group L\&H plans' contracts are actually not standardized (CIA, 2010: 6). The vast majority of employment benefits such as PD coverage are organized either through fully insured group plans or as various customizable self-insured plans such as administrative services only (ASO).

According to the 2015 "Face to Face in Drug Plan Management" survey, 48\% of surveyed senior benefits decision makers reported sponsoring a fully insured health benefits group plan (Benefits Canada, 2015). In a conventional fully insured plan, the insurer bears all risks including uncontrollable expense, catastrophic claims and even potential liabilities stemming from lawsuits. Best suited for small- and mid-size employers, "fully insured" means that the group plan's risks are pooled in the insurer's own aggregated group business pools or, in the "case of catastrophic drug claims," in the insurance industry-wide pools (see 5.2.2.C). ${ }^{206}$ In terms of underwriting method, insurers manage fully insured plans for groups of up to 200 to 300 employees by fully pooling unpredictable and catastrophic benefits such life insurance, accidental death and dismemberment insurance, long term disability insurance and some types of PD coverage (ADB\&IA Inc., unknown; The Benefits Consultant, unknownc). ${ }^{207}$

claims[.] Pay-direct drug plans are adjudicated in real time at the point of sale between the pharmacist and the insurance company or third party provider [i.e. TPA]." (The Benefits Consultant, unknownb).

206 According to the latest Fraser Group (2016a: 3) report for 2015, groups of one to 49 employees comprise $11 \%$ of the total group L\&H benefits market' revenue. Groups from 50 to 999 represent $24 \%$ of the market and employers of more than 1000 employees represent $65 \%$ of total market revenue.

${ }^{207}$ Underwriting such benefits through "full pooling" means that the insurer takes into account (i) "[its] overall financial results $[\ldots]$ in its book of business for each line of benefit"; (ii) "Demographic Factor $[\ldots]$ the distribution changes in your particular group for: Weighted average age - as the average age rises, premium costs rise[;] Female/male ratio - Life insurance costs are higher for males and [long term 
Under a fully pooled underwriting arrangement, the insurance carrier does not review the claims experience of any one particular group, however focuses on analyzing the experience for their entire block of business to determine required premium rates and rate adjustments annually. Insurance companies will aggregate the claims experience of similar groups into a pool and derive a pooled rate. The claims experience of each individual group does not provide enough credible data to derive a rate so by combining the claims experience of many small groups into one pool, applying a credibility factor to that pool's experience, and blending with the insurance carriers block of business, a credible premium rate can be determined. The key distinguishing factor of the fully pooled underwriting method is that each individual group's past claims experience is not used in determining the rate or rate adjustment. If one group's plan experience has been unfavourable in any one 12-month period after the plan's inception, but the majority of the groups in the pool have favourable claims experience, then it is likely that the plan's premium rates will remain stable or decrease in that benefit year. On the other hand, if the pool's claims experience in aggregate is unfavourable, then the plan's premium rates may be subject to an increase in that benefit year even if the individual group had positive claims experience. (The Benefits Consultant, unknownc; emphasis added)

Above groups of 200 to 300 employees, most insurers use experience-rated underwriting - also known as prospective rating or prospectively rated plans - according to which the rate at renewal is established following the financial performance of a given group of employees for a specific benefit. ${ }^{208}$ Thus, “[a]11 claims incurred during a policy year are charged directly against the premium applicable to that year.” (ADB\&IA Inc., unknown). In contrast to pooled benefits, benefits with more predictable frequency and levels of claims such as health, dental and most PD coverage are experience-rated. Experiencerated benefit claims are covered "on a 'money-in, money-out' basis rather than requiring risk insurance." (Smith, 2012). ${ }^{209}$ Finally, in terms of accounting method, fully insured plans generally function through non-refund accounting. This type of plan

disability] costs are higher for females"; (iii) "Occupational characteristics - Ex. Heavy Labour industries represent a higher risk."

${ }^{208}$ Prospective or experience-rated underwriting represents a variation on fully pooled arrangements. They are both "similar in that, having set the premium for the contract period, the policyholder is required to either pay it or forfeit coverage. At the end of the period, the premium for the subsequent period is reset based on the insurer's best estimate of future experience, which takes into consideration the most recent experience. Alternatively, the insurer may choose not to renew the coverage. A fully pooled arrangement may be thought of as being merely a special case of prospective rating, where the credibility of the group is zero." (CIA, 2010: 11).

${ }^{209}$ As Smith (2012) adds, "[r]egardless of how [a] group benefits plan is funded, the health and dental component [including PDs] is strictly transaction based." 
does not share in the financial gains or losses attributed to the plan. There is no financial accounting of premium and claims, and as such the insurance company retains the risk for surpluses and deficits under the plan. The individual group's liability is limited to the cost of the premium. Once the premium is paid, regardless of the financial performance of the program, the insurance company must pay all eligible claims. (The Benefits Consultant, unknown)

In recent years, "[f]lexible benefits plans [have been] getting popular among employers with at least 100 employees." (B Gagnon, 2012: 104). In contrast to fully insured plans, a second type of more flexible group plans is described as "self-insured." Self-insured plans are more customizable and hybridized than fully insured plans since they can include various components and can operate according to different underwriting and accounting methods depending on what the employer is looking for. However, the employer bears some risks of both deficits and surpluses, again depending on the benefits, design and options chosen.

For example, administrative services only (ASO) group plans represent the most common type of self-insured arrangements. Usually selected by large private sector employers (O’Brady et al., 2015: 225), ASO consists in a arrangement through which an employer "funds its own employee benefits plan but hires another company to perform administrative services such as adjudicating and processing claims." (Empire Life, 2014: 3). "Because these plans are perceived as being part of a total compensation package, and since the experience of medical and dental plans for group of this size is fairly stable, the medical and dental component of many flexible benefits plans is provided on an ASO basis." (B Gagnon, 2012: 104). According to the 2015 "Face to Face in Drug Plan Management" survey, 37\% of surveyed senior benefits decision makers reported sponsoring an ASO plan (Benefits Canada, 2015).

In an ASO group contract, either a large insurer administers the plan or the employer providing benefits hires a third party administrator (TPA) managing the plan on 
its behalf. More specifically, "[u]nder an ASO plan, the employer is responsible for funding claims costs. A third party is appointed to administer the plan, charging fees for their services, but without requiring insurer reserves or applying insurer inflation factors." (Smith, 2012). The self-insured ASO group contracts generally include claims and general administration, commissions, reserve funding, risk charge, inflations trends, taxes and profits (see Carter, 2014). To sum up,

[i]n contrast to a fully insured plan, where funding is provided through the payment of nonrefundable premiums, an ASO plan treats claims as expenses. The employer retains the funds in their own account and only pays IF and WHEN a claim occurs. If claims do not materialize there is the potential for savings for the employer that would otherwise have been reflected as an underwriting gain to an insurer. The claims adjudication process is the same in a traditional fully insured program as an ASO plan. The difference is that with an ASO plan the employer holds the cash needed to fund the benefits. (Maximum Benefits, unknown: 3)

Self-insured plans thus generally operate through refund or retention accounting. "In years where the plan is performing well, the employer will benefit from plan surpluses and consequently, refunds from the plan. [...] when the plan's claims experience is unfavourable, the employer will be required to pay back deficits either through a lump sum payment or through a deficit recovery margin built into renewal rates." (The Benefits Consultant, unknown).

Table 5.4 presents an example, from a corporate brochure, comparing the extent of the spectrum of possible risk and surplus distribution between non-refund fully insured and refund self-insured ASO arrangements offered by a Big three Canadian L\&H insurer. This provides evidence of (A) the non-standardized design of plans and (B) of their degree of customizability (e.g. a non-refund arrangement can include a shared surplus option). ${ }^{210}$

\footnotetext{
210 "Client" stands for the employer sponsoring the group plan and "CFR" stands for "claims fluctuation reserves" also known as "rate stabilization fund." As a Mississauga, Ontario-based employment benefits
} 


\section{Table 5.4. Risk/surplus in refund/non-refund products offered by a top three Canadian L\&H insurer ${ }^{211}$}

\begin{tabular}{|c|c|c|c|c|c|c|}
\hline & Non-refund & $\begin{array}{l}\text { Non-refund } \\
\text { with Shared } \\
\text { Surplus }\end{array}$ & $\begin{array}{l}\text { Standard } \\
\text { Refund }\end{array}$ & 5/15 Refund & $\begin{array}{c}\text { Refund with } \\
\text { Full Terminal } \\
\text { Deficit } \\
\text { Recovery }\end{array}$ & ASO \\
\hline $\begin{array}{l}\text { Client's } \\
\text { portion of } \\
\text { the surplus }\end{array}$ & None & $50 \%$ & $100 \%$ & $100 \%$ & $100 \%$ & $100 \%$ \\
\hline \multicolumn{7}{|c|}{ Client's portion of the risk: } \\
\hline At renewal & None & None & Partial & Up to $5 \%$ & Partial & Full \\
\hline $\begin{array}{l}\text { At plan } \\
\text { termination }\end{array}$ & None & None & None & Up to $15 \%$ & Full & Full \\
\hline $\begin{array}{l}\text { Direct } \\
\text { premium } \\
\text { cost }\end{array}$ & None & $\begin{array}{c}\text { Additional risk } \\
\text { charge }\end{array}$ & $\begin{array}{c}\text { Additional risk } \\
\text { charge }\end{array}$ & $\begin{array}{l}\text { Additional risk } \\
\text { charge plus } \\
\text { payments in } \\
\text { years of deficit }\end{array}$ & $\begin{array}{c}\text { None } \\
\text { excluding } \\
\text { financial } \\
\text { contingency } \\
\text { charges }\end{array}$ & None \\
\hline $\begin{array}{l}\text { CFR } \\
\text { requirement }\end{array}$ & None & None & $\begin{array}{l}15 \% \text {. No } \\
\text { refunds are } \\
\text { issued until } \\
\text { the CFR is fully } \\
\text { funded. }\end{array}$ & None & None & None \\
\hline $\begin{array}{l}\text { CFR } \\
\text { treatment at } \\
\text { termination }\end{array}$ & $\mathrm{n} / \mathrm{a}$ & $\mathrm{n} / \mathrm{a}$ & $\begin{array}{l}\text { Refund to } \\
\text { client of } \\
\text { amount not } \\
\text { required to } \\
\text { offset deficits. }\end{array}$ & $\mathrm{n} / \mathrm{a}$ & $\mathrm{n} / \mathrm{a}$ & $\mathrm{n} / \mathrm{a}$ \\
\hline
\end{tabular}

By virtue of being more flexible and customizable than fully insured plans, selfinsured plans such as ASOs can indeed be hybridized and include various additional options, for instance in order for the employer to protect itself against some specific risks. For example, ASO plans can be budgeted: instead of possibly going through important monthly premium fluctuations, [w]ith a budgeted ASO plan, the employer pays a predictable fixed amount every month based on its own group's previous claims history." (Smith, 2013). Another example of customizable coverage are split funded plans,

consulting, designing and administrating agency suggests, "[r]etention [a]ccounting [or refund accounting] requires an additional side fund called a C.F.R. or 'Rate Stabilization Fund' which is generally established from surplus." (ADB\&IA Inc., unknown: 3).

${ }^{211}$ From Great-West Life (unknownb). 
consisting in "funding arrangements $[\ldots]$ involv[ing $]$ a combination of insured and ASO coverage" (CIA, 2010: 13). ${ }^{212}$ In fact, self-insured plans "are typically supplemented by aggregate, and sometimes specific, stop-loss insurance, especially for medical services outside Canada." (B Gagnon, 2012: 104). In order to cover catastrophic claims such as travel insurance and PD coverage, stop loss insurance represents an increasingly common self-insured plan option. ${ }^{213}$

Finally, besides the premium, the design of PD benefits group plans feature costsharing mechanisms such as deductibles (annual and/or per prescription), co-insurance and co-payments, and cost-control measures such as maximums and formulary management mechanisms (formularies, generic equivalent, generic substitution and therapeutic substitution). "A deductible is an amount of eligible health care expenses a covered person must incur before any reimbursement is payable on eligible expenses in excess of the deductible." (The Benefits Consultant, unknowna). ${ }^{214}$ Other cost-sharing mechanisms require "plan beneficiaries to pay a portion of each prescription. They come in two forms, either a percentage amount (co-insurance) or fixed dollar amount (copayment). In some cases, employees must pay both: a fixed amount per prescription, and then co-insurance on the remainder." (Kratzer et al., 2013: 38). Maximums can be

\footnotetext{
${ }^{212}$ Moreover, "[f]lexible plan options life core + options plans, health spending accounts, and benefit levels graded by seniority, can also easily be accommodated within an ASO plan." (Smith, 2012). A Health spending accounts (HSA) or "Private Health Services Plan" (PHSP) as known by Canada Revenue Agency "allows employees to pay for eligible health care expenses with pre-tax dollars. Employees receive tax-free reimbursement for eligible medical or dental expenses not covered under insured plans. HAS's must be funded by employers with pre-tax dollars and cannot be funded through payroll deduction. Contributions must be allocated during the year prior to the one in which expenses are claimed." (ADB\&IA Inc., unknown).

213 'Stop loss coverage is generally written to limit a policyholder's exposure to losses on an underlying policy administered by the insurer, policyholder or third party. The terms of the coverage may include liabilities for future experience rating refunds and deficit recoveries." (CIA, 2010: 104).

${ }^{214}$ Deductibles can be set per calendar year (usually from January $1^{\text {st }}$ to December $31^{\text {st }}$ ) and/or per prescription (only in pay-direct drug plans; see below). They are usually subjected to various clauses including family limits and three-month carry-over provisions.
} 
applied to annual, lifetime, or annual and lifetime coverage. "Maximum" or "cap" can also refer to out-of-pocket maximums, which are payment limits beyond which the insurer covers $100 \%$ of eligible expenses. ${ }^{215}$

The last type of cost control measure consists in formulary management mechanisms. These mechanisms "aim to lower costs while retaining the same levels of drug coverage." (Kratzer et al., 2013: 40). Private drug plans can operate following fixed/frozen or flexible/managed formularies, possibly including provisions such as generic equivalent, mandatory generic substitution and/or therapeutic substitution. ${ }^{216}$ In theory, managed formularies "can lower expenditures through encouraging the use of less expensive therapeutic alternatives." (ibid.). Some managed formularies include multitiered coverage in which "[d]rugs that are the best value when looking at cost and clinical effectiveness [...] fall into Tier 1, with the highest reimbursement," and so on (Sun Life Financial, unknown). In contrast, single-tiered plans "use the same co-payment for all the drugs they cover." (Kratzer et al., 2013: 39).

In the last analysis, dispensing fees - fees charged by the pharmacist for services rendered in dispensing the drug to the customer" (ibid.) - and, first and foremost, drug costs represent two major factors influencing PD benefits costs in private health group plans. Facing important health care costs inflation over the past few years and involving

\footnotetext{
215 "Typically, health plans have different coinsurance based on each benefit within the health plan (such as $100 \%$ coverage for hospital and out-of-country, and $80 \%$ on all other health benefits). Some health plans use a split level coinsurance covering, for example $80 \%$ until a certain out of pocket limit is reached, and they paying $100 \%$ of all eligible expenses." (The Benefits Consultant, unknowna).

216 "Benefit plans that implement a fixed formulary will cover only those drugs on the market or selected by the employer a the time the formulary is adopted. [...]. A flexible or managed formulary still has restrictions in coverage (like a fixed formulary) however, changes are constantly ongoing. [...]. Under a drug plan that includes a generic equivalent provision, the plan will cover the employee up to the cost of the generic equivalent cost of the drug if a brand name drug is purchased. [...]. Therapeutic substitutions assist in treating the same illness in a more cost effective manner. Drugs with different active ingredients but the same therapeutic classification as those prescribed are included in the formulary." (ibid.).
} 
particularly important catastrophic claims, travel insurance (including out-of-country medical coverage) and especially PD coverage "have evolved toward becoming more of less separate from the remainder of health insurance, with their own cost containment features (deductible, co-payment and/or coinsurance and maximums).” (B Gagnon, 2012: 99). But how are the structure of the L\&H insurance industry and the organization and design of the health benefits group plans responding to the rise of high cost specialty drugs?

\subsubsection{Private plans and high cost specialty drugs}

According to a group benefits consulting industry webzine, the past years have seen double-digit healthcare costs inflation (The Benefits Consultant, unknowna) and drug cost annual inflation has recently ran between $10 \%$ and $18 \%$ (The Benefits Consultant, unknownb). According to the 2015 "Face to Face in Drug Plan Management" survey, the senior benefits decision makers surveyed $(n=204)$ reported on average a $11.3 \%$ increase in drug plan costs and a $13.6 \%$ increase in their health benefits plan premiums over the last year (Benefits Canada, 2015: 12). Surveyed senior benefits decision makers sponsoring a pooled drug plan $(n=128)$ reported on average an annual increase of $14.3 \%$ in pooling costs (ibid.). Since private plans have also been able to benefit from the savings generated by the patent cliff, these double-digit increases in 2015 might not offer a totally accurate picture of the cost trend since 2010 (see Section 5.1.3). Still, according to the 2015 "Face to Face in Drug Plan Management" survey, 83\% of surveyed senior benefits decision makers agree that the "new drugs coming to market are too expensive for our plan to remain sustainable" (39\% "strongly agree" and 44\% "somewhat agree") 
and $70 \%$ admitted being “concerned that, in the long-term, our drug plan won't be sustainable" (29\% "strongly agree" and 41\% "somewhat agree") (Benefits Canada, 2015: 40).

Considering its past outcomes and performance, how is private PD insurance through employment benefits group plans - facing the rise of high cost specialty drugs? After a quick presentation of literature focusing of the recent past outcomes of private PD insurance in Canada, Section 5.2.2 first aims at assessing the ability of drug benefits group plans' design at facing cost increases generated in part by the arrival of specialty medicines. Then, the responses of the Canadian L\&H insurance industry to rising drug costs - namely a series of isolated initiatives and, above all, an industry-wide pooling agreement - are discussed. The following section claims that the private insurance governance proves unable to manage the instability and cost inflation generated by the emergence of "bad" risks constituted by the catastrophic claims of high price specialty drugs and, as a result, these new bad catastrophic insurance risks must be controlled and reduced through non-competitive institutional arrangements and insurers moreover tend to shift costs directly towards insured-patients.

\section{Evidence on the past outcomes of private health insurance and PD coverage}

As mentioned in Section 5.1.1, around two thirds of Canadians are covered by a private health insurance plan (Morgan, Martin, et al., 2015: 5) and more than a third of total PD expenditures are financed through private insurance in Canada (CIHI, 2015: 8). From 1998 to 2009, private payments for heath care by Canadian households - including private insurance premiums, dental care, PDs, eye care, non-physician practitioners, 
physicians and hospitals, and nursing homes - grew by $37 \%$, for an average annual growth rate of $2.9 \%$ above inflation (Law et al., 2013: 2). Over the same period, private insurance premiums expenditure grew by $52.8 \%$ (average annual growth rate of $3.9 \%$ above inflation) and PD expenditure grew by $27.2 \%$ (average annual growth rate of $2.2 \%$ above inflation) (ibid.: 3). ${ }^{217}$

According to Hurley and Guindon (2008: 29-30), "the private insurance industry has undertaken almost no efforts to improve the quality and efficiency of health care services in Canada. The private insurance industry continues to function largely as bill payers." Law et al. (2014: 1) actually pointed to the increasing inefficiency of Canadian private health insurance, finding that as a whole, "[t]he percentage of private health insurance premiums paid out as benefits has decreased markedly over the past 20 years, leading to a gap between premiums collected and benefits paid of $\$ 6.8$ billion in 2011." These authors also showed that the medical loss ratio ${ }^{218}$ of insured health group plans managed by for-profit insurers fell from 92\% in 1991 to $74 \%$ in 2011 (ibid.: 2). As Law et al. (ibid.) add, "[t]he [CLHIA] does not report dividend payments to policyholders by insurance type; however, even if one assumes that all policy dividends were paid out in the group insured market, the medical loss ratio was 77\% in 2011 - notably lower than the $80 \%$ or $85 \%$ minimum now in place for private health insurance in the US." 219

\footnotetext{
${ }^{217}$ Law et al. (2013: 2) used data from the annual survey of household spending from Statistics Canada and the 1998-2009 period was analyzed "because prior and subsequent years used different data collection methods and are thus not directly comparable."

${ }^{218}$ In private health insurance, the "medical loss ratio" is "[ $\left.\mathrm{t}\right]$ he proportion of premium income spent on benefits" (Law et al., 2014: 2).

219 This last number was criticized by the CLHIA since it includes some non-medical benefits (i.e. income replacement coverage such as Short- and Long-term disability, Creditor disability insurance, Critical illness and Accidental death \& dismemberment). As Stephen Frank (2014) - then VP Policy Development and Health at the CLHIA - explained in a letter published by the Canadian Medical Association Journal in response to Law et al. (2014): "I can confirm that the average medical loss ratio (as per the definition in the
} 
Perhaps most importantly in terms of the rise of specialty drugs as a challenge to PD benefits group plans, Kratzer et al. (2013: 36) "found that the use of common costcontrol measures is relatively low among Canadian private benefits programs. [...]. Canadian private benefits programs use few cost-control measures to respond to increasing costs, particularly in comparison to their public counterparts." In this context, both Kratzer et al. (2013) and Law et al. (2014) warn that the structure and design of private health and PD benefits group plans will likely lead both to reduced access to medicines and cost shifting toward individuals through increasing out-of-pocket payments, and to increasingly restrictive annual and lifetime maximums. Similar conclusions have been reached from research in the US (see Goldman et al., 2006; Stern and Reissman, 2006). Moreover, according to a qualitative study of large Canadian unionized workplaces with ASO plans, a consensus actually exists between private employers, unions, benefits consultancies and insurance companies over the need for the "external intervention from government to help transform established norms in terms of private drug plan design." (O’Brady et al., 2015: 230).

Interestingly, some insurance industry insiders seem to be supporting evidence from the academic literature. According to John Anacleto (2015: 6), Business and Analysis Manager at Telus Health Analytics, costs transfer to patients through coinsurance constitutes a central trend in recent years and is likely to continue. According to a Canadian insurance broker specialized in small and mid-sized group benefits plans, "[i]ncidence of capped drug plans will continue to rise and push more of the risk (and

paper) for insured supplemental health insurance plans between 1997 and 2012 was $85 \%$, with the medical loss ratio coming in at $82 \%$ in 2012. (I've provided the average back to 1997 rather than 1991 as per the paper, as the older CLHIA survey data of our membership did not include $100 \%$ of the market which makes dis-aggregating the numbers challenging.)" 
cost) for treatment on to employees" (Patriarche, 2016: 24). ${ }^{220}$ Furthermore, the 2015

"Face to Face in Drug Plan Management" survey suggests that 90\% of surveyed senior benefits decision makers agree (52\% "strongly agree" and 38\% "somewhat agree") that "[i]n order to keep drug plan costs manageable, employees need to share the costs in some way” (Benefits Canada, 2015: 29).

Plan design facing the rise of high cost specialty drugs

Building on literature assessing the outcomes of private health and PD insurance in Canada, the following subsection aims at evaluating the extent of the ability of Canadian PD group plans to control the impact of high costs specialty medicines through incentivebased contractual controls of the insured (cost-sharing and cost-shifting mechanisms) and other PD specific plan design components (formulary management measures and dispensing fee caps). In order to do so, data from the 2015 "Face to Face in Drug Plan Management" online survey (Benefits Canada, 2015) and from presentations from Martinez (2012) based on Mercer Plan Design Database ${ }^{221}$ and Anacleto (2015) based on Telus Health's drug claims dataset ${ }^{222}$ are used. Evidence from Mercer and Telus Health datasets and the 2015 "Face to Face in Drug Plan Management" survey is complemented

\footnotetext{
${ }^{220}$ Dave Patriarche is founder of Mainstay Insurance Brokerage Inc., an Ontario-based brokerage firm providing offering group plans to small and mid-sized businesses for over $\$ 3.8$ million in yearly premiums (Patriarche, 2016: 3).

${ }^{221}$ Martinez (2012) uses data from Mercer's Plan Design Database as of April 2012 and containing data "on more than 2,000 benefits plans of 1,000 organizations" (Mercer, unknown). Mercer claims that it is "the largest of its kind" and "the most comprehensive benefits survey in the industry."

222 The data presented by Anacleto (2015: 3) "is based on an analysis of [PD] claims processes by TELUS Health for 12 million lives for many private insurers." It is also mentioned that "[t]his analysis considered past drug claims data only and it does not represent or imply future trends for drug plans or health plans, including drug coverage, for specific group benefit plans or specific insurers. In forecasting future trends it is important to also consider, for example: Changes in demographics[;] Changes in utilization[;] [and] Government cost shifting."
} 
with both academic and grey literatures. When the most recent data is not available, Kratzer et al.'s (2013) analysis of Applied Management Consultants' private plan data from 1998 to 2010 is presented. Considering the proprietary nature of the major Canadian private health insurance and employment group plans database (Telus Health, Applied Management Consultants and Mercer), the following analysis of the impact of the rise of specialty drugs on the group plans' design is limited in terms of both chronological (i.e. annual) and non-standardized cross-database comparisons.

According to the Mercer Plan Design Database, $66 \%$ of plans did not share premium costs with employees as of 2012 (Martinez, 2012: 9). In terms of cost-sharing mechanisms, PD benefits group plans with deductibles appear as exceptions to the rule in Canada. From 1998 to 2010, the percentage of employees having to pay a deductible decreased from $48 \%$ to $12 \%$ according the Applied Management Consultants' data (Kratzer et al., 2013: 40). ${ }^{223}$ As of 2014, 89.5\% of cardholders ${ }^{224}$ had no annual deductibles and $86.1 \%$ had no per prescription deductibles according to Telus Health's drug claims dataset (Anacleto, 2015: 29-30). According to a group benefits consulting industry webzine, "[f]ew employers change their plan deductibles on annual basis which leads to the eroding impact of deductibles on plan utilization because deductibles have not kept pace with healthcare inflation overtime. Because of deductible erosion, the landscape has changed significantly to include deductibles that include a portion of the cost that changes with inflation." (The Benefits Consultant, unknowna).

\footnotetext{
${ }^{223}$ As Kratzer et al. (2013: 40) add, "[o]f the employees who paid a deductible in 2010, $65 \%$ paid $\$ 25$ or less and $91 \%$ paid $\$ 50$ or less."

${ }^{224}$ For Telus Health, a "cardholder" refers to "the covered employee and dependents" (Anacleto, 2015: 4).
} 
Following the Telus Health's drug claims dataset, cost transfer to patients through coinsurance represents a major trend in private PD coverage in recent years (Anacleto, 2015: 6). From the analysis of the Applied Management Consultants' database, Kratzer et al. (2013: 40) revealed that $58 \%$ of employees had to pay co-insurance in 1998 while the proportion slightly increased to $61 \%$ in 2010 ; over the same period, the percentage of employees paying a co-payments went from $12 \%$ to $13 \%$; and the proportion paying a combination of percentage (i.e. co-insurance) and fixed (i.e. co-payment) cost-sharing increased from $2 \%$ to $4 \%$ from 1998 to 2010 . According to Telus Health's drug claims dataset, $34.8 \%$ of lives covered by a private PD plan did not have to pay co-insurance as of 2014 (Anacleto, 2015: 28). ${ }^{225}$ Further detailed data concerning the use of both fixed, percentage and combined cost-sharing mechanisms is not currently accessible.

In terms of cost-control measures, according to the Mercer Plan Design Database as of April 2012, 99\% of Canadian group plans included no lifetime drug maximum (i.e. were featuring "unlimited liability") (Martinez, 2012: 9). From the analysis of the Applied Management Consultants data, Kratzer et al. (2013: 39) found that

[i]n 2010, 16\% of employees had an annual maximum benefit, a lifetime maximum or both. Compared to 1998, the use of lifetime maximums has doubled: less than $3 \%$ of enrollees had this type of limit in 1998 (Applied Management 2000), compared to 6\% of enrollees in 2010. Annual maximums increased more dramatically, more than doubling from 3\% (Applied Management 2000) of employees in 1998 to $12 \%$ in 2010.

In the Telus Health's drug claims dataset (Anacleto, 2015: 31), 78.3\% of cardholders had no annual and no lifetime maximums, while only $12.4 \%$ had an annual maximum and $8.5 \%$ had a lifetime maximum (only $0.8 \%$ had both annual and lifetime maximums) as of 2014. Simply put, around a quarter of Telus Health's cardholders had plan maximums in

\footnotetext{
${ }^{225}$ As of $2014,0.4 \%$ of total covered lives in Telus Health's drug claims dataset had a $5 \%$ co-insurance, $13.6 \%$ had a $10 \%$ co-insurance, $2.5 \%$ had a $15 \%$ co-insurance, $40.8 \%$ had a $20 \%$ co-insurance and $2.4 \%$ had a 25\% co-insurance (Anacleto, 2015: 28).
} 
2014. The results of the 2015 "Face to Face in Drug Plan Management" survey are similar as $30 \%$ of the senior benefits decision makers surveyed reported sponsoring a plan including maximums (Benefits Canada, 2015: 16). No data on out-of-pocket maximums is currently accessible.

In terms of formulary management mechanisms, according to Applied Management Consultants' data for 2010 , " $85 \%$ of plans provided coverage for all prescriptions, while a small proportion adopted formularies from a provincial government formulary $(2 \%)$ or an insurer-designed list $(6 \%)$, with the remainder being unknown." (Kratzer et al., 2013: 39). In the 2015 "Face to Face in Drug Plan Management" survey, only $20 \%$ of surveyed senior benefits decision makers reported a plan using a managed formulary as a means to control drug plan costs (Benefits Canada, 2015: 16). Moreover, only $9 \%$ reported a drug list mimicking a provincial formulary (ibid.).

The Applied Management Consultants' data reveals that, as of $2010,67 \%$ of employees were covered by a plan requiring generic substitution (Kratzer et al., 2013: 39). As of April 2012, the Mercer Plan Design Database reveals that 95\% of PD group plans had no mandatory generic substitution measure in place (Martinez, 2012: 9). Later in 2012, two top three Canadian L\&H insurers (Sun Life and Great West Life) implemented quasi-mandatory generic substitution measures "for all claimants, unless companies explicitly opt out" (Kratzer et al., 2013: 40). As the 2015 "Face to Face in Drug Plan Management" survey suggests, $71 \%$ of surveyed senior benefits decision makers reported a plan with generic substitution measures (Benefits Canada, 2015: 16). However, the Telus Health's drug claims dataset shows that from the first quarter of 2013 to the last quarter of 2014, [t]he proportion of [Ontarian] cardholders with mandatory 
generic substitution continued to increase but from regular substitution, not [from] plans without substitution." (Anacleto, 2015: 26). During this same period, the proportion of Ontarian Telus Health cardholders with regular generic substitution decreased from $48 \%$ to $34 \%$, those with mandatory generic substitution increased from $28 \%$ to $44 \%$, and the proportion without generic substitution remained relatively stable, from $24 \%$ to $22 \%$ (ibid.).

The most recent available data on the use of multi-tiered plans goes back to 2010 when $19 \%$ of plans included multi-tiered coverage, according to Applied Management Consultants' data (Kratzer et al., 2013: 39). In other words, the majority of plans required the same co-payments for the totality of drugs covered at that time (ibid.). No data on other therapeutic substitution measures is currently accessible.

Prior authorization is another formulary management measure increasingly implemented in PD group plans. It "is a program that requires pre-approval of selected drugs before they are eligible for coverage, to help make sure employees receive the most appropriate and cost-effective treatment." (Empire Life, 2015: 5). According to the 2015 "Face to Face in Drug Plan Management" survey, 45\% of surveyed senior benefits decision makers reported a plan using prior authorization (Benefits Canada, 2015: 16). ${ }^{226}$

\footnotetext{
226 Plans with prior authorization commonly include step therapy as an additional cost control measure. Step therapy is an "approach to prescription drug management where the member is initially prescribed a lower cost alternative which is effective for most people. If the first line therapy is ineffective, more potent/costly medications will be covered." (from Sun Life Financial's website: $<$ https:/www.sunlife.ca/Canada/sponsor/Group+benefits/Group+benefits+products+\&+services/Pharmace utical+benefits/Pharma+101?vgnLocale=en_CA $>$; accessed August 18 2016). Only 11\% of the senior benefits decision makers surveyed by the 2015 "Face to Face in Drug Plan Management" survey stated using step therapy in their group plan (Benefits Canada, 2015: 16). Out of the 47\% of surveyed senior benefits decision makers who admitted planning on modifying their group plans' cost controls $(n=100)$, only $5 \%$ declared planning on including step therapy (ibid.: 18).
} 
According to Kratzer et al.'s analysis of the Applied Management Consultants' data, while $3 \%$ of private plans used dispensing fee cost-control measures in 1998, the proportion increased to $27 \%$ in 2010. In April, 2012, data from the Mercer Plan Design Database nonetheless showed that $95 \%$ of plans had no dispensing fee cap (Martinez, 2012: 9). Earlier data on dispensing fee control measures is not currently accessible.

In conclusion, despite being fragmentary in terms of both years of reference (1998 to 2010, 2012 and 2015) and sources of datasets, the previous data synthesis corroborates Kratzer et al.'s (2013: 40) study suggesting that "private benefits plans in Canada continue to employ many cost-control measures at fairly low rates." While the use of deductibles seems to be diminishing, ${ }^{227}$ two main trends are noticeable. First, transferring costs to patients through the use of cost-sharing mechanisms (co-insurance and copayment) appears on the rise. Second, the use and evolution of cost-control mechanisms remain limited. In the 2015 "Face to Face in Drug Plan Management" survey, $12 \%$ of surveyed senior benefits decision makers reported a plan with no cost controls (Benefits Canada, 2015: 16). While maximums are increasingly implemented, their usage is still relatively low at around a quarter of plans. The vast majority of plans still do not use formulary management measures. While generic substitution measures are slowly increasing, the use of prior authorization is still limited, at less than half of the plans according to the 2015 "Face to Face in Drug Plan Management" survey. Concerning the capping of dispensing fees, the currently available data provides mixed evidence. Perhaps surprisingly, the 2015 "Face to Face in Drug Plan Management"

\footnotetext{
227 "One explanation could be that the decrease in the use of deductibles - a relatively low, one-off cost may have been offset by the increased percentage of employees required to pay the dispensing fee." (Kratzer et al., 2013: 41).
} 
survey revealed that out of the $47 \%$ of surveyed senior benefits decision makers who admitted planning on modifying their group plans' cost controls $(n=100), 16 \%$ declared planning on modifying generic substitution, $12 \%$ stated planning on reforming formulary administration, and only $6 \%$ revealed planning on changing the design of cost-sharing mechanisms (Benefits Canada, 2015: 18).

Simply put, private PD drug plans are either unable or unwilling to comprehensively control costs, and tend to shift costs towards patients. As Law et al. (2014: 3) explains,

[...] many private health insurance plans do not use cost-saving activities common to every public sector plan, such as requiring generic substitution or capping dispensing fees. There is also evidence that private health insurance firms pay higher prices for the same medicines than public plans: an analysis by the Competition Bureau found that private insurance health insurers pay $7 \%$ more for generic drugs and $10 \%$ more for brand-name drugs.

The limited use of formularies appears as a major factor in the inability of private PD insurance to control costs. In fact, "[n]ormally, private drug insurance plans do not negotiate rebates. [...]. More restrictive private plans generally rely on the provincial public formulary to reimburse medications when their therapeutic value is considered sufficient relative to the cost of the product." (Gagnon, 2014: 14). As a president of a consulting firm states in a publication from a pharmaceutical industry-funded cancer patients and survivors group - the Cancer Advocacy Coalition of Canada (CACC $)^{228}-$,

[p]rivate insurers, as a rule, have not invested the same way in reviewing new drugs as their provincial counterparts. Most regional Blue Cross organizations do provide rigorous review, as does Green Shield for their standard plans. All insurers offer more restrictive drug formularies or plan designs, through the big three (Great-West Life, Sun Life, and Manulife) still have generally open plans where almost all prescription drugs approved by Health Canada are soon made available to plan members. This is in stark contrast to most public Pharmacare and cancer agency plans, where new drugs are subjected to exhaustive review of clinical and economic

\footnotetext{
228 According to the CACC's website, its "Platinum level" sponsors and partners for 2013-2014 were four major pharmaceutical firms: AMgen, Pfizer, Roche and Novartis. Its "Gold level" sponsors and partners were $R x \& D$ (the Canadian pharmaceutical industry trade association) and pharmaceutical firms Boehringer Ingelheim, GlaxoSmithKline, Merck, Sanofi Aventis and Lilly (CACC, 2013).
} 
evidence...often taking years when joint (i.e., Joint Oncology Drug Review) and separate province reviews are completed. (Bonnett, 2010: 16)

Yet, further research is required, despite the issues of access to and analysis of PD benefits proprietary datasets. Access to comprehensive employment benefits group plans data should be a major concern to both researchers and policymakers. In order to support research, the establishment of a centralized, transparent, accessible and publicly managed PD benefits database - for instance at Statistics Canada - is recommended.

\section{Private insurers facing specialty drugs: from isolated to industry-wide initiatives}

In the recent past, the Canadian group L\&H insurance industry has regularly admitted being aware of the unsustainability of private PD plans. On June 3 2009, Frank Swedlove - then president of the CLHIA, the Canadian L\&H insurance industry trade group acknowledged the fact that PD costs and coverage represented major challenges for the healthcare system in Canada (see Swedlove, 2009). In May 2013, Barbara Martinez, then an executive in charge of group benefits at a top three Canadian L\&H group insurer, stated that "most [private] drug plans as they exist are not sustainable" (Coughlin \& Associates Ltd., 2013). ${ }^{229}$ In a report released in June of the same year and titled "Ensuring the accessibility, affordability and sustainability of prescription drugs in Canada," the CLHIA recognized the inequitable and unsustainable outcomes generated by the patchwork system of PD coverage in Canada (see CLHIA, 2013a). The Canadian L\&H industry trade association is especially worried about the impact of high cost

\footnotetext{
229 As of May 2013, Barbara Martinez was "Benefits Solutions Practice Leader" at Great-West Life (Coughlin \& Associates Ltd., 2013).
} 
medicines such as specialty drugs on employer sponsored group plans. As the CLHIA (ibid.: 1-2) stated:

\begin{abstract}
Better managing the overall cost of drugs going forward is critical. Plan sponsors, typically employers, include drug benefits as part of a competitive supplementary health plan in order to attract and retain employees, as well as to ensure a healthy and productive workforce and, ultimately, they must bear the costs of drugs. However, employers have limited resources and do not have to provide supplementary health plans with drug benefits to their employees. The key concern from a sustainability perspective is how to manage the recent and forecasted increase in the number of high cost drugs and drug therapies available and being prescribed to patients. [...]. If the growing burden of high cost drugs, in particular, is not addressed there is a real risk that employers will take steps to restrict their drug coverage.
\end{abstract}

In order to assess the ability of private PD insurance to face the rise of high cost specialty drugs, the following subsection presents the recent responses from the Canadian L\&H insurers to rising drug costs. First, drug co-pays cards offered by the pharmaceutical manufacturers are quickly discussed as a non-solution leading to increased overall spending by group plans and individuals. Second, isolated corporate initiatives from major Canadian L\&H insurers, such as communication efforts, health case management and drug assessments programs, are presented. Finally, the Canadian L\&H insurance industry's structural responses - the standardized industry guidelines for the coordination of benefits released by the CLHIA and the establishment by the CLHIA of an industry-wide drug pooling agreement through the Canadian Drug Insurance Pooling Corporation (CDIPC) - are discussed.

\title{
a) Drug co-pay cards: a non-solution from pharmaceutical manufacturers
}

In recent years, one way in which the pharmaceutical industry has attempted to dampen the financial pressures on patients generated by rising drug costs is drug co-pay cards. Also known as "drug coupons," drug co-pay cards consist in "drug manufacturer programs that offer reimbursement of an employee's coinsurance, deductible and/or co- 
pay for prescription drugs, and/or the costs difference between a brand name and generic drug." (Investment Guild, 2013: 1). ${ }^{230}$ But as Grande (2012: 2375; emphasis added) concludes from the analysis of the use of drug co-pay cards in the US, [f]irst, coupons can increase out-of-pocket spending for the coupon user in either the short or long term because co-pays may still be higher compared with therapeutic alternatives (ie, direct costs). Second, coupons can increase health care spending for coupon users and nonusers by increasing aggregate health spending and thus health insurance premiums (ie, indirect costs)." ${ }^{, 231}$ To put it simply, although claiming to be reducing costs with co-pay cards, pharmaceutical manufacturers use them in order to fight generic substitution, which results in increased financial pressures on PD benefits group plans.

\section{b) Isolated initiatives}

Even more recently, private insurers responded to rising drug costs in general and the arrival of specialty drugs in particular through various isolated initiatives such as informative newsletters, case management and assessment programs.

\footnotetext{
${ }^{230}$ The Investment Guild Insurance Inc. is a Markham, Ontario-based privately held group benefits and pension management consulting firm owned by the People Corporation Inc. Group.

${ }^{231}$ As a Canadian group benefits consultant (Investment Guild, 2013: 1) warns its plan sponsors clients: "If you have a co-pay on drugs, say $80 \%$ or $90 \%$ - the employee pays $20 \%$ or $10 \%$ at pharmacy for prescriptions, respectively. Most plans also have 'Generic Substitution' which means that if a generic equivalent is available, the plan will only pay that amount *UNLESS THE DOCTOR WRITE 'NO SUBSTITUTIONS' [sic], in which case the plan will pay for the Brand Name Drug. Drug companies are providing coupons to physicians (in the form of cards) to give to your employees that state two things; 1 ) No Substitutions, and 2) The DRUG COMPANY [sic] will pay the employee's co-pay. From the employee's point of view this looks like a good deal because; a) The employee gets a brand name instead of a generic; and b) The employee doesn't have to pay their $20 \%$ co-pay. However, from the Plan Sponsors' point of view it looks much different. The Plan Sponsor ends up paying much more needlessly." In the example used by this consulting firm, an employer could end up paying five more for a single prescription for the brand-name Lipitor instead of the generic equivalent Atorvastatin due to the use of a drug co-pay card (ibid.: 2).
} 
In attempting to face cost inflation, the major L\&H benefits insurers recently begun offering informative newsletters to plan sponsors and members. For instance, a top three Canadian L\&H insurer has put in place "DrugSolutions" consisting in "[u]pdate newsletters provid[ing] valuable information on some of the drug plan challenges facing plan sponsors and highlight[ing] the prescription drug management solution [it] is offering." (Great-West Life, unknowna). ${ }^{232}$ Such corporate communication efforts actually aim at informing plan sponsors and members about the initiatives created by $\mathrm{L} \& \mathrm{H}$ insurers in response to the rise of specialty drugs. Two programs established in isolation by the Canadian L\&H insurers exemplify theses initiatives claiming to be aiming at better controlling costs: case management and assessment programs.

Including communication and informative efforts, case management or "health case management" is increasingly offered as a service attached to health and PD benefits plans. For instance, according to a top three Canadian L\&H insurer, case management refers to a "combination of services" including

[s]upport for plan members and their physicians to help identify alternative treatment options[;] [a]ssistance in the coordination of treatment from the first point of contact with a plan member through many stages of treatment, in order to simplify the process and help promote the efficient distribution and access to specialty medications[;] [and] [e]nhanced communication with plan members about their treatment through education and monitoring to promote optimal lifestyle behavior and to help ensure that medication is taken appropriately." (Great-West Life, unknownc)

Through partnerships with a private healthcare provider designated as the "case manager," insurers seek to exert greater control over the health and lives of plan members. For example, another top three Canadian L\&H insurer states that the

\footnotetext{
${ }^{232}$ Great-West Life's DrugSolutions updates discuss topics such as "the changes in the [PD] landscape and the impact on drug plan coverage," "specialty medication management and how Great-West's process can help reduce the impact to drug plan costs," "quick facts, quotes from satisfied plan members and information about specialty drug coverage across Canada," and "the positive impact our programs have had on both plan sponsors and plan members" (Great-West Life, unknowna).
} 
designated case manager "will engage your plan members to actively participate in the management of their health condition through proven techniques such as motivational interviewing, goal setting and coaching. The primary goal of case management is to improve health outcomes, while ensuring you are not paying more than you should for the plan member's treatment." (Manulife, unknown). ${ }^{233}$ As of now, the effectiveness of case management is hard to assess since no data concerning its usage and outcomes is available. Close to a fifth (19\%) of senior benefits decision makers surveyed by the 2015 "Face to Face in Drug Plan Management" survey stated sponsoring a group plan including case management (Benefits Canada, 2015: 16). Out of the $47 \%$ of surveyed senior benefits decision makers who admitted planning on modifying their group plans ( $\mathrm{n}=100$ ), only $3 \%$ admitted planning on including case management (ibid.: 18).

Case management can be a component of the new assessment programs developed by L\&H group insurers in order to control health and PD costs. The top three Canadian L\&H insurer Manulife was the first to implement a major assessment program in late 2015. With DrugWatch, Manulife (2015a: 4) claims to be "providing oversight to help ensure that the drugs included in your plan have the potential to deliver the highest level of health outcome at the most prudent price." This assessment program must be understood as a corporate strategy aiming at building formulary listing and management capabilities in parallel with communication efforts with plan sponsors and control of plan

\footnotetext{
233 As another top three Canadian L\&H insurer states: "Where health case management applies under the terms of your group benefits plan, a health case manager may be assigned to your claim during the prior authorization process and you will be expected to participate in the program. A health case manager can provide valuable support and assistance and work closely with you and your physician during your treatment plan. This may include: working with you and your physician to understand different drug treatment options; assisting you in understanding and accessing available support programs such as patient assistance programs and any benefits or programs that may be available to you under your current benefit plan; and ongoing communication and follow-up throughout an approved coverage period to help assess the prescribed drug treatment plan." (Great-West Life, unknownc).
} 
members' health habits. Manulife thus seeks to assess Health Canada's newly approved drugs, to partially base its drug cost-effectiveness review efforts on the Canadian Agency for Drugs and Technologies in Health's (CADTH) health technology assessments (HTAs), and to improve the listed drugs screening process (ibid.). ${ }^{234}$ According to Manulife (ibid.: 7), DrugWatch is a part of an integrated strategy aiming at helping plan sponsors to manage drug costs, including expert negotiations with pharmaceutical manufacturers, specialty drug care, ${ }^{235}$ a preferred pharmacy network (except in Quebec where preferred pharmacy networks are prohibited by section 22 of Loi sur l'assurance médicament), active pharmacy services in collaboration with Express Scripts Canada, step therapy and mandatory or voluntary generic substitution.

\section{c) The Canadian Drug Insurance Pooling Corporation: an industry-wide agreement}

On the structural level, the Canadian L\&H insurance industry as a whole recently responded to the rise of specialty medicines with two collaborative industry-wide measures implemented through the CLHIA: the formulation of standardized guidelines for the coordination of benefits between private plans and the integration of private benefits with public programs and, most importantly, the establishment of an industrywide drug pooling agreement.

In 2013, the CLHIA released standardized industry guidelines for the coordination of benefits. Coordination of benefits consists in "determining the priority in

\footnotetext{
${ }^{234}$ In the last phase of a four steps review process, DrugWatch's "Oversight Committee of pharmacists, benefits and financial professionals" formulates one out of five potential drug review decisions: "listed," "listed with price adjustment," "listed with program introduced," "listed with price adjustment and program introduced," and "not listed" (Manulife, 2015a: 5).

${ }^{235}$ Manulife's (2015b) Specialty Drug Care strategy claims to be focusing on case management and specialty drug pharmacy services.
} 
which payments are made and to outline the minimum amount payable by each Group Plan in situations where a Covered Individual can submit a claim to more than one Group Plan." (CLHIA, 2013b: 1). The CLHIA formulated guidelines for the coordination of both group health and dental plans (Guideline G4) and out-of-country and out-ofprovince or territory benefits (Guideline G17) (see CLHIA, 2013b, 2013c). In 2015, the CLHIA then published "A guide to the coordination of benefits" (CLHIA, 2015a). Presumably, such initiatives from the Canadian L\&H insurance industry in part seek to promote greater distribution of the costs between different private group benefits plans and public PD coverage programs. As of now, the effectiveness of the CLHIA's coordination of benefits' guidelines is hard to assess since no data concerning its usage and outcomes is available.

Of analytical interest from the perspective of the institutional constitution of markets, Guideline G4 mentions the issue of the integration of private benefits with government health plans and programs: "Coverage available under a Government Health Plan or Program is provided first before coverage available under a private Group Plan, except where legislation, the plan or program provides otherwise [such as in Quebec]. When coverage is available under a Government Health Plan or Program, benefits may be integrated, if legally permitted." (CLHIA, 2013b: 2). As the CLHIA (ibid.: 3) adds, "integration" "is a method of calculating liability under a Group Plan which is different than coordination. When the Group Plan covered expense amount is reduced by the payment made by a Government Health Plan or Program, this process is commonly referred to as Integration." While the Guideline G4 does not explicitly suggests that the integration of benefits must applied to PD coverage, Part 5.3 (see below) discusses the 
calls from the Canadian L\&H insurance industry for the establishment of a national and public catastrophic PD program and shows how this type of public coverage has been recently put in place by most provinces. As of now, no data concerning the use and outcomes of private group benefit plans integration with public PD coverage is available.

Still, according to a Canadian insurance broker specialized in small- and mid-size group benefits plans, Ontario's public Trillium Drug Program acts as a first payer after the employee pays its private plans' out of pocket deductible (Patriarche, 2016: 19). As this broker suggests:

Most plans (58\% according to Telus) have high enough co-insurance levels that would suggest employees may already be applying for and receiving provincial support for themselves [...] Just as the employee portion is being paid by the province, the employer portion of the claim can also be paid [...] Insurers currently nullify this process by paying for the claim rather than declining it (and charging the clients experience). (ibid.)

Again according to this broker, the failure from insurers to integrate private PD benefits to public coverage on a systematic basis can be explain by the lack of an easily manageable electronic method for the auto adjudication with Trillium (ibid.: 20). Furthermore, he adds that "[m]any insurers [integrate their private benefits with public program] in other provinces by paying initial claim, having the employee apply to the provincial drug/support program, providing proof of coverage to the insurer and then having the province take over the claim."

Moreover, on April 3 2012, the Canadian L\&H insurance industry announced the establishment of an industry-wide pooling agreement with the creation of the Canadian Drug Insurance Pooling Corporation (CDIPC) in order to protect private insurers and 
insured against high cost catastrophic PD claims outside the province of Quebec (see B

Gagnon, 2012: 342). ${ }^{236}$ As the CLHIA (2012) stated in its initial press release:

In the absence of progress on a catastrophic drug program in Canada, insurers are banding together in order to share the costs of highly expensive and recurring drug treatments through an industry drug pooling framework. Going forward, participating insurers will set premiums for fully insured employer drug plans without including any pooled high cost drug claims. This will effectively shelter Canadians from potentially losing their employer-sponsored drug coverage due to a high cost claim - something that was increasingly a risk for those employed by small and medium sized businesses. Twenty-three insurance companies across Canada, that collectively represent 100 per cent of the supplementary drug market, have committed to joining this pooling framework.

According to the CDIPC's executive director, the CDIPC is a "[n]ot for profit corp[oration] established by CLHIA member companies to pool recurring catastrophic drug costs (paid claims) from individuals belonging to fully insured plan[; a] common agreement [and] framework to enable the CDIPC's guiding principles[; and a framework] provid[ing] for insurer pooling [...] and industry pools." (Berty, 2015: 3). As the Canadian L\&H insurance industry trade association recently explained:

In the absence of a [national pan-canadian] catastrophic drug program, the not-for-profit Canadian Drug Insurance Pooling Corporation (CDIPC) was voluntarily established by supplemental health insurers in Canada. Sharing the cost of highly expensive and recurring drugs [...] through industry pooling protects the sustainability of fully-insured group plans which would otherwise be jeopardized. This has been particularly beneficial to small- and medium-sized businesses, and their employees, where fully-insured plans are more prominent. In each of 2013 and 2014, insurers in Canada paid more than 4,000 claims for prescription drugs under the new pooling mechanism. (CLHIA, 2015b: 19)

Again according its executive director, the CDIPC seeks "[g]reater viability for insured plans in affording the impacts from catastrophic drug costs," "to improve the degree of predictability of impact risk from reoccurring catastrophic drug claims," and to increase

\footnotetext{
${ }^{236}$ In Quebec, section 43 of the 1997 Loi sur l'assurance médicament required L\&H insurers operating in the province to establish a drug risks pooling system. This same year, the Quebec Drug Insurance Pooling Corporation (QDIPC) was created. As B. Gagnon (2012: 342) explains, "[g]iven the success of the Quebec pooling model, the continuing trend of expensive [PDs], and the coming tide of even more expensive biological and specialty drugs, Canadian insurers decided to explore their own model, to protect both themselves and their [sic] residing outside of Quebec. [...] although the Quebec model emerged after an obligation was introduced through legislation, the Canadian model was an entirely private initiative." For details concerning QDIPC's 2016 terms and conditions, see QDIPC's website (online at $<$ http://mutualisation.ca/en/pooling/terms-and-conditions-of-pooling/>; accessed August 21 2016).
} 
"abilities to capture, trend, and share anonymous industry wide catastrophic drug information.” (Berty, 2016: 14).

Having taken effect on January $1^{\text {st }} 2013$, the CDIPC established a rather complex arrangement, which can be described as a two-level integrated system of pooling mechanisms of claims from fully insured plans: "1) at the insurance carrier level, a pool known as EP3 (Extended Care Policy Protection Plan), and 2) at the industry level, a national industry-wide catastrophic [PD] pool." (B Gagnon, 2012: 342). On the one side, through the CDIPC, the CLHIA formulated the standard rules for the EP3 arrangement pooling of non-recurring high cost drug claims from a single employer/plan sponsor at the level of a single insurer. Each insurer must implement at least one EP3 pool, which only covers fully insured plans and applies only to drug coverage (Berty, 2016: 4 and 6). Each insurer set the threshold above which it pools claims through an EP3 arrangement which cannot be anti-selective (i.e. cannot be rated from the experience of a single employer) and cannot pool excluded certificates (Berty, 2015: 7). Rates can however be established following the experience of the whole pool. "To safeguard against antiselection for refund or ASO plans becoming fully insured, pre-existing exclusions can be applied at plan member level for EP3s and must be at industry pool level [see below]." (Berty, 2015: 4). Finally, "[i]nsurers do not have to disclose EP3 makeup other than confidentially to CDIPC annually." (ibid.: 6) ${ }^{237}$ According to the 2015 "Face to Face in Drug Plan Management" survey, $60 \%$ of surveyed senior benefits decision makers reported sponsoring a plan with EP3 pooling (Benefits Canada, 2015: 8).

${ }^{237}$ For more details on EP3 pooling, see Berty $(2015,2016)$. 
While EP3 pooling purportedly represents the competitive component of the insurance industry's initiative, each insurer can also set up its own Large Amount Pooling (LAP). Extended health benefits and PD coverage policies "will have a LAP arrangement attached to their policy where they are not eligible to have an EP3, or where they have an EP3 and also have excluded certificates that need an alternate pooling mechanism." (Empire Life, 2014: 8). Not tied to CDIPC standards and representing the only pooling arrangement for self-insured plans, LAP works in a similar way than EP3 and both can be combined. ${ }^{238}$ It is also worth mentioning that, in this context, each individual insurer is responsible for the management of its own reinsurance arrangements.

On the other side, the CDIPC provides an industry-wide pooling arrangement of "recurring catastrophic drug costs (paid claims) from individuals belonging to fully insured plans." (Berty, 2016: 10). The CDIPC industry pool is described as a "risk mitigation tool" through which "[t]he cost of pooled drug claims [are] shared by all participating insurers (not premium based)" and participating pools are evaluated annually according to each insurer's claim experience and market share (Berty, 2015: 11 and 15). The industry pooling functions as follow:

Insurers will submit eligible and paid claim information to CDIPC once a year in May [...] [;] CDIPC determine [sic] which certificates qualify for the industry pools[;] Insurers share the costs of qualifying claims up to a limit[;] The carrier who issued the policy still bear substantial financial risk[;] Insurers will also bear responsibility for all pooled claims in relationship to their share of total paid drug claim annually. (ibid.: 13-14)

From the perspective of the insurers and the industry as a whole, the CDIPC's two-level system of distinct pooling mechanisms can be illustrated as follow (see Figure 5.6). ${ }^{239}$

\footnotetext{
${ }^{238}$ For an example of LAP and EP3 arrangements from a top 10 Canadian L\&H group insurer, see Empire Life (2014).

${ }^{239}$ For more details on the CDIPC's industry pooling, see Berty $(2015,2016)$ and Frank $(2012)$.
} 
Figure 5.7. The CDIPC pooling mechanism ${ }^{240}$
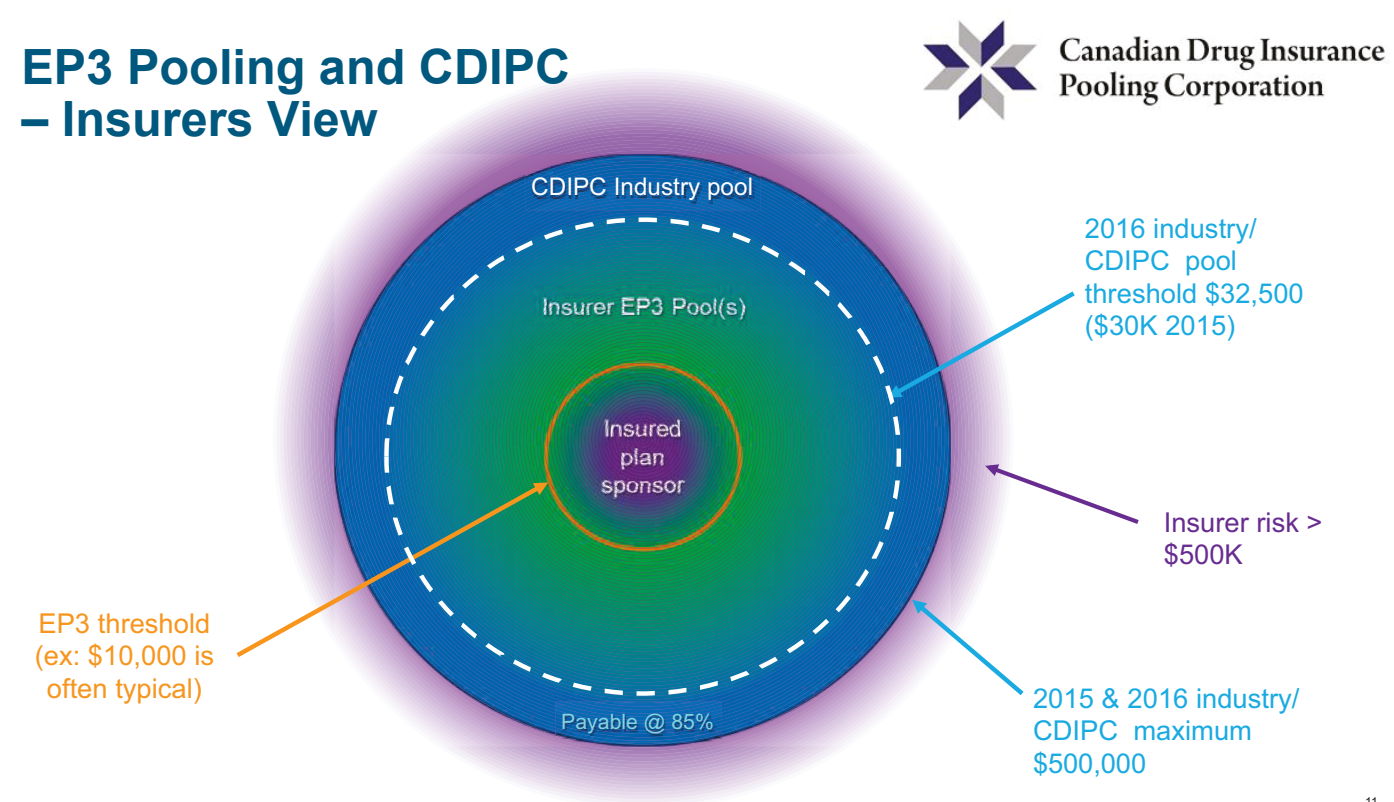

In the last analysis, and in contrast to the industry's claim, both the EP3 (an industry-wide standardized insurer-level pooling arrangement) and the CDIPC's industry pooling (a mutualization of industry-wide risks) represent non-competitive institutional arrangements developed by Canadian L\&H insurers in response to health care inflation in general and rising high cost specialty drugs in particular. Interestingly, the executive director of the CDIPC recently specified what CDIPC is not:

A vehicle to grow the number of plans that come to market[;] A means to neutralize drug cost growth. [...]. [;] A set of standards or guidelines applied to refund and ASO business[;] An instrument for insurers to reduce high cost drug prices through purchasing power[; A means to control or neutralize inflationary growth, utilization, and costs of expensive new drugs. (Berty, 2016: 15-6)

${ }^{240}$ From Berty (2015: 11). 


\subsubsection{Partial conclusions: private insurance and specialty drugs in Canada}

Part 5.2 attempted to provide answers to one of the two components of chapter 5's central question: which non-competitive institutional arrangements contribute at ensuring the constitution of the Canadian PD insurance market in the context of the rise of high price specialty drugs? In order to do so, it started by presenting overviews of the structure of the Canadian L\&H insurance industry and of the organization and design of employment health and PD benefits group plans in Canada.

In contrast to the CLHIA's (2015b: 2) claim, the Canadian L\&H insurance industry is "rather concentrated, no matter whether concentration is assessed in terms of assets, number of policies underwritten, or premiums written" (Cummins and Venard, 2007: 424). As a matter of fact, the top three Canadian L\&H insurers, known as the Big three (i.e. Sun Life, Manulife and Great-West Life), comprised $57.85 \%$ of total net premiums written in 2013. In Canada, L\&H insurers mainly offer private PD coverage through employer-sponsored health benefits group plans. As with the L\&H industry as a whole, the Canadian market for employment L\&H benefits insurance group plans is also significantly concentrated. In 2015, the Big three alone comprised $65.3 \%$ of market share by total revenue from employment benefits L\&H insurance group plans. Most, if not all Canadian employment benefits group plans include PD coverage. PDs account for most employment benefits plans' costs, as estimates range from $60 \%$ to $85 \%$ of total $\mathrm{L} \& \mathrm{H}$ group benefits costs in general and from $70 \%$ to $75 \%$ of total health benefits costs.

In terms of organization, as a result from being negotiated between insurance providers and employers - and also with employees in unionized settings - most provisions included in L\&H group plans' contracts are not standardized. The vast 
majority of employment benefits such as PD coverage are organized either through fully insured group plans or as various customizable self-insured plans such as administrative services only (ASO) ${ }^{241}$ In terms of design, PD benefits group plans feature the standard private insurance incentive-based controls - cost-sharing mechanisms such as deductibles (annual and/or per prescription), co-insurance, co-payments and maximums - as well as cost-control measures specific to pharmaceutical benefits such formulary management mechanisms and pharmacy dispensing fees controls.

Second, based on evidence from existing academic literature and insurance industry insiders concerning the past performance and outcomes of private health insurance in general and PD coverage in particular, Part 5.2 then assessed the ability of the drug benefits group plans' design at facing the rise of high price specialty medicines, before analyzing how the Canadian $\mathrm{L} \& \mathrm{H}$ insurers are responding to rising drug costs.

On the one hand, despite being fragmentary in terms of both years of reference and sources of datasets, the data analyzed corroborates Kratzer et al.'s (2013: 40) findings which suggest that "private benefits plans in Canada continue to employ many cost-control measures at fairly low rates." While the use of deductibles seems to be diminishing, two main trends can be observed. First, the transfer of costs to patients through the use of cost-sharing mechanisms (co-insurance and copayment) appears to be

\footnotetext{
${ }^{241}$ In a conventional fully insured, the insurer bears all risks including uncontrollable expense, catastrophic claims and even potential liabilities stemming from lawsuits. Best suited for small- and mid-size employers, fully insured plan means that the group plan's risks are pooled in the insurer's own aggregated group business pools or, in the "case of catastrophic drug claims," in the insurance industry-wide pools (i.e. the CDIPC's). In contrast to fully insured plans, self-insured plans are more customizable and hybridized since they can include various components and can operate according to different underwriting and accounting methods depending on what the employer is looking for. However, the employer bears some risks of both deficits and surpluses, again depending on the benefits, design and options chosen. For example, ASO group plans perhaps represent the most common type of self-insured arrangements. In an ASO group contract, either a large insurer administers the plan or the employer providing benefits hires a third party administrator (TPA) managing the plan on its behalf.
} 
on the rise. Second, the use and evolution of cost-control mechanisms remain limited. In fact, while maximums are increasingly implemented, their usage is still relatively low, at around a quarter of plans. The vast majority of plans still does not use formulary management measures. While generic substitution measures are slowly increasing, the use of prior authorization is also still limited. Simply put, private PD plans are either unable or unwilling to comprehensively control costs, and tend to shift costs towards insured-patients.

On the other hand, considering the limited evolution in plans' design, the L\&H insurance industry is responding to the rise of high cost specialty medicines through a series of isolated initiatives and, most importantly, through structural, industry-wide noncompetitive institutional arrangements. Seeking to better control costs, the Canadian L\&H insurers are creating corporate communication efforts - for instance through news letters - aiming at informing plan sponsors and members about initiatives created by insurers in response to the rise of specialty drugs. Two programs established in isolation by the Canadian L\&H insurers exemplify theses initiatives claiming to be better controlling costs: case management and assessment programs. ${ }^{242}$

On the structural level, the Canadian L\&H insurance industry as a whole recently responded to the arrival of specialty drugs with two collaborative industry-wide measures

\footnotetext{
242 Through partnerships with private healthcare providers designated as "case managers," insurers seek to exert greater control over the health and lives of plan members. As of now, the effectiveness of case management is hard to assess since no data concerning its usage and outcomes is available. Furthermore, case management can be a component of new assessment programs developed by the L\&H group insurers. Assessment programs consist in a corporate strategy aiming at building formulary listing and management capabilities in parallel with efforts at communicating with plan sponsors and controlling the health habits of plan members. Big three insurer Manulife's DrugWatch program illustrates this new trend by seeking to assess Health Canada's newly approved drugs, to partially base its drug cost-effectiveness review efforts on the health technology assessments (HTAs) of the Canadian Agency for Drugs and Technologies in Health's (CADTH), and to improve the listed drugs screening process.
} 
implemented through the CLHIA, its trade association: the formulation of standardized guidelines for the coordination of benefits and, first and foremost, the establishment of an industry-wide catastrophic drug pooling agreement.

In 2013, the CLHIA released standardized industry guidelines for the coordination of benefits which consist in "determining the priority in which payments are made and to outline the minimum amount payable by each Group Plan in situations where a Covered Individual can submit a claim to more than one Group Plan." (CLHIA, 2013b: 1). Presumably, such initiatives from the Canadian L\&H insurance industry in part seek to promote greater distribution of the costs between the different private group benefits plans available to employees and their dependents. ${ }^{243}$ Of analytical interest from the perspective of the institutional constitution of insurance markets, the CLHIA's Guideline G4 mentions the issue of "Integration" with government health plans and programs: "Coverage available under a Government Health Plan or Program is provided first before coverage available under a private Group Plan, except where legislation, the plan or program provides otherwise [such as in Quebec]. When coverage is available under a Government Health Plan or Program, benefits may be integrated, if legally permitted." (CLHIA, 2013b: 2). ${ }^{244}$

Most importantly, since 2013, the CLHIA implemented an industry-wide twolevel system of distinct catastrophic drug claims pooling mechanisms through the creation of the Canadian Drug Insurance Pooling Corporation (CDIPC): “1) at the

\footnotetext{
${ }^{243}$ As of now, the effectiveness of the CLHIA's coordination of benefits' guidelines is hard to assess since no data concerning its usage and outcomes is available.

${ }^{244}$ As the CLHIA adds, "integration" "is a method of calculating liability under a Group Plan which is different than coordination. When the Group Plan covered expense amount is reduced by the payment made by a Government Health Plan or Program, this process is commonly referred to as Integration." (2013b: 3).
} 
insurance carrier level, a pool known as EP3 (Extended Care Policy Protection Plan), and 2) at the industry level, a national industry-wide catastrophic [PD] pool." (B Gagnon, 2012: 342).

In the last analysis, and in contrast to the industry's claim, both the EP3 - as a industry-wide standardized insurer-level pooling arrangement of non-recurring catastrophic PD claims - and the CDIPC's industry pooling - as a mutualization of industry-wide recurring catastrophic PD claims - constitute non-competitive institutional arrangements developed by the Canadian L\&H insurance industry in response to healthcare inflation in general and rising high cost specialty drugs in particular. The most structural responses from the $\mathrm{L} \& \mathrm{H}$ insurers to the rise of high cost specialty medicines mainly aim at protecting the financial interests of the insurers and of the insurance industry as a whole. As the executive director of the CDIPC recently explained, the CDIPC is not a "means to neutralize drug cost growth," not an "instrument for insurers to reduce high cost drug prices through purchasing power," nor a "means to control or neutralize inflationary growth, utilization, and costs of expensive new drugs" (Berty, 2016: 15-6).

\section{3. ...with the help of public plans?}

As previous mentioned, the press release announcing the launch of the Canadian L\&H insurance industry's pooling agreement stated that "[i]n the absence of progress on a catastrophic drug program in Canada, insurers are banding together in order to share the costs of highly expensive and recurring drug treatments" (CLHIA, 2012; my emphasis). In 2013, the Canadian L\&H insurance industry trade association warned that the 
challenges facing private PD benefits group plans due to the rise of high cost medicines could ultimately also threaten governments:

Any significant reduction in coverage by employers would have dramatic implications, not only for individuals, but governments as well. Governments in Canada are increasingly looking to moderate the rate of growth of their health expenditures and, given their respective difficult fiscal situations, would be challenged to take on a significant proportion of the drug spend that is accounted for by private plans currently.

Even more recently, the CLHIA (2015b: 14) expressed a rather simplistic view of the nature of the interplays between the insurance industry and government coverage: "Supplementary health insurance takes over where government coverage ends. This partnership of private insurance and government programs contributes to the quality of life and health of Canadians."

As explained in greater details above (see 5.5.2.C), the CLHIA released in 2013 standardized industry guidelines for the coordination of benefits (in order to establish coverage priority when an individual covered by a plan can claim from more than one group plan). The CLHIA's guideline G4 also included standards for the integration of benefits, as distinct from the coordination of benefits. According to the integration of benefits guideline, “[c]overage available under a Government Health Plan or Program is provided first before coverage available under a private Group Plan, except where legislation [such as in Quebec], the plan or program provides otherwise." (CLHIA, 2013b: 2). Two examples from top 10 Canadian group L\&H insurers illustrate this tendency for private insurers to seek the integration of the private PD coverage they offer with public plans and programs. For instance, the top Canadian L\&H insurer features "Provincial Integration" into its "Enhanced claims management process" seeking "to ensure that, where appropriate, eligible plan members have applied to the available 
government programs for coverage." (Sun Life, unknown) ${ }^{245}$ Another example of the tendency towards the integration of private PD benefits with public coverage comes from the new prior authorization policy of a top ten Canadian group L\&H insurer which includes "Coordination Coverage with Provincial Health Plans": "When a drug on the Prior Authorization list is also covered by the employee's provincial health plan, we will direct the employee to the provincial plan.” (Empire Life, 2015: 4).

Considering the will from private insurers and the L\&H insurance industry as a whole to increasingly articulate private PD coverage with public plans, Part 5.3 attempts to provide answers to the second component of this chapter's central question: which political-legal interventions contribute at ensuring the constitution of the Canadian PD insurance market in the context of the rise of high price specialty drugs? In order to do so, it first sheds light on the calls from the major PD insurance market stakeholders for the creation of public catastrophic drug coverage in Canada. Second, it presents a brief overview of the available public catastrophic PD coverage in Canada and of its recent evolution.

\subsubsection{Calls for a universal public catastrophic coverage}

The emergence of the nichebuster pharmaceutical business model represents a major challenge for the Canadian PD insurance market since insured patients claiming new high cost specialty drugs constitute catastrophic "bad" risks from the perspective of the management of private insurance risk pools. In addition to being controlled and reduced

\footnotetext{
${ }^{245}$ Sun Life ('Pharma 101,' unknown) adds: "Directing drug claims to these programs helps manage the increases in the overall drug claims. It also enables plan members and their dependents to maximize their drug coverage."
} 
through a non-competitive industry-wide pooling agreement, these new bad insurance risks of recurring and non-recurring catastrophic PD claims generated by the rise of specialty drugs must be unloaded on other institutional modes of economic integration. In other words, a process of insurance risk decommoditization contributes at ensuring the constitution of the Canadian PD insurance market in the context of the emergence of the nichebuster pharmaceutical business model.

Facing the arrival of the high price specialty medicines and the ensuing unsustainable cost growth, the main Canadian PD insurance market stakeholders namely the CLHIA, the Canadian research-based pharmaceutical manufacturers trade association (Innovative Medicines Canada) and the Canadian Pharmacists Association (CPhA) - have publicly expressed calls in favor of the creation of a Canada-wide universal public catastrophic drug coverage program.

As mentioned in Section 5.1.1, the 2002 Romanow Report called for the creation of universal catastrophic coverage as a first step towards universal pharmacare. Published the same year, the Kirby Report also called for a national catastrophic drug program in Canada. ${ }^{246}$ As Booth (2015: 104-5) explains,

[t]he pharmacare proposals in both reports respond to some of the major concerns with earlier options by outlining a more limited goal of 'catastrophic drug coverage,' where citizens would be protected against drug expenses exceeding a certain portion of their incomes. Although catastrophic drug coverage had been discussed before, these two reports certainly contributed to its dominance of subsequent discussions. Senator Wilbert Keon, a member of the Senate committee, reported that they recommended catastrophic drug coverage because the committee believed that most people had reasonable coverage through private or provincial plans and that only those with very high drug costs were vulnerable. The former director of research for the Commission on the Future of Health Care in Canada has indicated that Romanow's recommendation for catastrophic drug coverage was strategic, and that the commission believed that starting with a more limited universal program would allow for later expansion (Forest 2004), a position that is confirmed by a policy expert involved in researching the proposal. The switch to catastrophic drug coverage as a policy goal also had the potential to make the proposal more attractive to both the pharmaceutical

\footnotetext{
${ }^{246}$ For more details on recommendations for a national catastrophic PD plan in Canada by non-corporate (i.e. non-insurance and non-pharmaceutical industries) stakeholders, see Phillips (2016: 3-6).
} 
and private insurance industries, since it would mainly target patients who might have previously had to forgo drug treatment for financial reasons and would act as a complement rather than a substitute for private insurance.

Starting in 2009, the Canadian L\&H insurance industry trade association expressed its pressing demand to the Canadian government for the implementation of universal catastrophic drug coverage. ${ }^{247}$ Furthermore, in 2013, the CLHIA called for greater collaboration between insurers and governments in facing the financial impact of high cost drugs: "The CLHIA recommends that: From a social policy perspective that it would be in the interest of governments and private insurers to enter into a dialogue to develop a national, comprehensive, high cost drug strategy in order to ensure the sustainability of drug coverage going forward.” (CLHIA, 2013a: 29).

In addition to the $\mathrm{L} \& \mathrm{H}$ insurance industry, the Canadian research-based pharmaceutical manufacturers trade association also called for universal catastrophic drug coverage. In 2010, a public position in favour of such a public program was published on the organization's website (Boothe, 2015: 105; Daw and Morgan, 2012: 24). ${ }^{248}$ Moreover, the Canadian Pharmacists Association (CPhA) also expressed its demand for the creation of universal catastrophic coverage in Canada. Such a public statement was available on the organization's website as of 2008 (Daw and Morgan, 2012: 24). Even more recently, the CPhA commissioned a report from PDCI Market Access Inc. on the costs of universal pharmacare in Canada (PDCI Market Access Inc., 2016). Without explicitly calling for universal catastrophic drug coverage, this

\footnotetext{
247 "On the topic of prescription drugs, we are urging the federal government, the provinces and the territories to work with the insurance companies to ensure that no Canadians need take on undue financial hardship as a result of prescription drug costs. [...]. That means the establishment of catastrophic drug coverage for all Canadians [...]." (Swedlove, 2009: 5-6).

${ }^{248}$ As of August 22 2016, the 2010 public statement from Rx\&D (now "Innovative Medicines Canada") in favor of universal catastrophic drug coverage, as referenced by Daw and Morgan (2012: 24), was not available online.
} 
preliminary report indicates

[i]t is believed that if the federal government invested in a nationwide "geared to income" catastrophic plan resembling those of the provinces, not only would access to prescription drugs be improved (especially for low income families) but issues that are associated with a single payer government monopoly, such as reduced incentives for cost effective prescribing quality, could be avoided. (ibid.: 24)

In 2010, a publication from the Cancer Advocacy Coalition of Canada - a pharmaceutical industry-funded cancer patients and survivors group - presented universal catastrophic coverage as an "obvious solution" (Emerson, 2010). Finally, according to the 2015 "Face to Face in Drug Plan Management" survey, 87\% of surveyed senior benefits decision makers agree (47\% "strongly agree" and 40\% "somewhat agree") that "Canada needs a publicly funded national catastrophic drug program to take some of the costs pressures off plan sponsors" (Benefits Canada, 2015: 33).

\subsubsection{Public catastrophic coverage in Canada: an overview}

As Phillips (2016: 7) explains, "[a]lthough no national catastrophic drug coverage program exists, most Canadians have some protection against high out-of-pocket drug costs through a variety of private, provincial/territorial and federal drug plans."

On the one side, the non-competitive institutional arrangements established by the Canadian L\&H industry trade association through the CDIPC responded to the inability of individual insurers and group benefits plans to control both non-recurring and recurring catastrophic PD claims. Section 5.2.2 indeed showed that L\&H insurers and group plans' sponsors are still reluctant to implement cost-control mechanisms such as (annual and lifetime) maximums and formulary management mechanisms. However, in provinces where private PD coverage is mandatory, the picture of catastrophic coverage is different. For instance, in Quebec, with the support of the legally-required industry-run 
catastrophic drug pooling system (QDIPC) created at the same time as the general public PD plan (see 5.2.2.C), "private plans are required to provide minimum coverage standards equivalent to those offered by the provincial public plan. This regulation enables the province to ensure that $100 \%$ of its residents have protection against catastrophic drug costs through both public and private programs." (Phillips, 2016: 7). On the other side, the beneficiaries of the public federal PD plans and of the Public Service Health Care Plan (managed by the Treasury Board and administered by the top Canadian L\&H insurer, Sun Life) "are relatively well protected from catastrophic drug costs through the provision either of $100 \%$ coverage or of partial coverage with out-of-pocket expenses capped at $\$ 3,000$ per year." (ibid.: 8 ). ${ }^{249}$

In terms of public catastrophic coverage: (i) seven provinces offer plans including catastrophic coverage "for individuals in the general population who have no other form of coverage and are experiencing high drug costs relative to income" (ibid.); (ii) public catastrophic PD coverage is also offered through general public PD plans by two provinces (Quebec and Alberta); and (iii) a third category of programs - targeted drug coverage programs - is offered by provinces and territories as a form of supplemental or additional catastrophic PD coverage to targeted populations (ibid.: 10). Furthermore, the New Brunswick Drug Plan rather covers uninsured individuals or individuals underinsured by employment PD plans. "Under the program, individuals pay a premium, which is based upon their income level, as well as a co-payment on each prescription with a maximum cap - also income-based - for each prescription.” (ibid.: 9). However, New Brunswick is the only province without "an overall limit on out-of-pocket costs."

\footnotetext{
${ }^{249}$ For further details, see Table 5.2.
} 
(ibid.).

The programs offered by most provinces and territories ${ }^{250}$ to targeted population usually offer coverage as follow:

People with specific illnesses that require high-cost prescription drugs (the lionesses coverage vary by province and territory) receive $100 \%$ of drug costs[;] People on social assistance and seniors with low incomes receive full drug costs, less minimal co-payments in some programs[;] Seniors with high incomes tend to face premiums, deductibles and higher co-payments, although these amounts are usually capped. (ibid.)

The provinces of Quebec (RGAM), Alberta (Non-Group Coverage Benefit) and New Brunswick (New Brunswick Drug Plan) offer general public PD coverage to populations not covered by other type of coverage. In addition to charging an incomebased premium to individuals and households, Quebec's RGAM provides catastrophic drug coverage through an upper payment limit (at \$1,029 as of 2016), and out-of-pocket expenses are capped at $\$ 25$ per prescription by Alberta’s program (ibid.: 9).

According to a study over the 2000-2010 period by Daw and Morgan (2012: 23), "income-based catastrophic coverage - with high deductibles based on household income - has emerged as the national standard for public drug benefits for the non-senior population (and in some cases also for seniors)." As of 2016, seven provinces - British Columbia, Manitoba, Newfoundland and Labrador, Nova Scotia, Ontario, Prince Edward Island and Saskatchewan - offer income-based catastrophic coverage to the general working population (i.e. non-senior and non-social assistance population) through "programs with varying benefit payment structures (premiums, deductibles and co-

\footnotetext{
${ }^{250}$ As Phillips (2016: 10) notes, "many residents in the territories are recognized Inuit and therefore have access to Health Canada's Non-Insured Health Benefits Program, which provides full drug coverage for recognized Inuit, in addition to programs offered by the territorial governments. Therefore, many of the programs offered by the territories are intended for residents who do not have coverage through this program, such as Métis and non-Aboriginal Canadians who are either seniors or have specific illnesses or low incomes."
} 
payments) as well as caps on payments.” (Phillips, 2016: 8). Table 5.5 presents Phillips'

(ibid.: 9) latest update concerning maximum out-of-pocket costs in the seven provinces with income-based public catastrophic drug coverage.

\section{Table 5.5. Maximum out-of-pocket expenditures in provincial catastrophic programs $^{251}$}

\begin{tabular}{||l|l||}
\hline \multicolumn{1}{|c||}{ Province } & \multicolumn{1}{c|}{ Cap } \\
\hline British Columbia & $1.3 \%-3.2 \%$ of net family income \\
\hline Saskatchewan & $3.4 \%$ of total adjusted family income ${ }^{\mathrm{b}}$ \\
\hline Manitoba & $2.97 \%-6.73 \%$ of total adjusted family income ${ }^{c}$ \\
\hline Ontario & $4 \%$ of net family income, plus a fee of $\$ 2$ per prescription ${ }^{d}$ \\
\hline Nova Scotia & Varying percentage of total adjusted family income \\
\hline Newfoundland and Labrador & $5 \%, 7.5 \%$ or $10 \%$ of net family income \\
\hline Prince Edward Island & $3 \%, 5 \%, 8 \%$ or $12 \%$ of net family income \\
\hline \hline
\end{tabular}

Notes: a. Government of British Columbia, Ministry of Health Services, Fair PharmaCare Assistance Levels - Regular, August 2009.

b. Patented Medicine Prices Review Board, Appendix A: "Public Drug Plan Design" - Saskatchewan, in NPDUIS Compass Rx: Annual Public Drug Plan Expenditure Report 2012/13, $1^{\text {st }}$ ed., 1 September 2015; and Government of Saskatchewan, "Special Support Program."

c. Manitoba Health, Healthy Living and Seniors, Pharmacare Deductible Estimator for the 2015/2016 benefit year, Manitoba Pharmacare Program.

d. Government of Ontario, A Guide to Understanding the Trillium Drug Program, 2013.

e. Government of Nova Scotia, Nova Scotia Pharmacare Programs - The Nova Scotia Family Pharmacare Program, December 2012.

f. Newfoundland Labrador Department of Health and Community Services, "Plan Overview," Prescription Drug Program.

g. Government of Prince Edward Island, "Catastrophic drug coverage for all Islanders," News release, 10 May 2013.

\subsubsection{Partial conclusions: the expansion of provincial catastrophic coverage}

In 2013, the CLHIA published a report on PD policy titled Ensuring the accessibility, affordability and sustainability of prescription drugs in Canada. In this report, the CLHIA (2013a: 35-9) concluded with 23 recommendations; by seeking to better control

\footnotetext{
${ }^{251}$ From Phillips (2016: 9).
} 
drug prices, all of these recommendations directly or indirectly involved the state in the efforts to ensure the sustainably of private PD benefits plans. While its calls for the establishment of a Canada-wide universal catastrophic PD coverage have so far failed to translate into new federal policies, the Canadian L\&H insurance industry's will to promote the integration of private PD benefits with public coverage might have produced concrete results on the level of provincial governments. Following Phillips (2016), it must concluded that the trend observed by Daw and Morgan (2012: 23) according to which "[a]11 changes to general non-senior pharmacare plans that occurred from 2000 to 2010 represented moves towards the income-based catastrophic model" has continued in the past few years. In fact, from six provinces with public catastrophic PD coverage in 2012, seven provinces now have implemented such coverage, since the government of Prince Edward Island has established its own catastrophic PD coverage in 2013 (Phillips, 2016: 9). In part as a result from being the only provinces without maximums on out-ofpocket PD expenditures, New Brunswick had the highest rate of cost-related nonadherence to prescriptions made as of 2014 (see Busby and Pedde, 2015: 7). ${ }^{252}$

As for now, it is impossible to empirically assess the extent and success or failure of the integration of private PD coverage with public plans due to the novelty of such initiatives and strategies from the Canadian L\&H insurance industry and the ensuing lack of information and data. Nevertheless, from the perspective of the institutional constitution of insurance markets, public catastrophic PD coverage must be understood as a function of "the state as the ultimate risk manager" (see Moss, 2002) or - in insurance terms - of "the state as the insurer of last resort" (see Ericson et al., 2003; Ericson and

${ }^{252}$ On cost-related non-adherence to prescribed medicines in Canada, see Law (2012). 
Doyle, 2004c). Indeed, governmental insurance programs, public catastrophic coverage, state guarantee funds and other governmental backstops are constitutive institutional arrangements for private insurance markets. This is even more the case in times of instability and crisis such as in the context of the emergence of the nichebuster pharmaceutical business model featuring the arrival of high price specialty medicines.

\subsection{Conclusions}

\subsubsection{Summary}

Part 5.1 described the historical evolution of the institutional decisions and arrangements underlying the current Canadian PD insurance market. It first presented a brief history of healthcare in Canada in order to better understand how the institutional constitution (IC) of the Canadian PD insurance market first and foremost rests on the historical exclusion of PD coverage from the federally created and provincially controlled public universal healthcare systems. Second, the resulting hybrid patchwork system of public/private PD plans was displayed and discussed as the source of the fragmented Canadian PD coverage and drug purchasing power, both contributing to high and rising PD expenditures in Canada. Finally, Part 5.1 concluded with a quick overview of the Canadian pharmaceutical system, repeatedly characterized as having complex drug regulations, pro-pharmaceutical industry official pricing, inefficient innovation policies and fragmented drug purchasing power (Gagnon, 2015; Lexchin, 2015; Morgan et al., 2015), and leading to the high costs of PDs in Canada. In this context, the recent shift from the former "blockbuster" pharmaceutical business model to the new "nichebuster" model featuring the rise of high cost specialty drugs was presented as a major challenge to the 
Canadian patchwork PD coverage system as a whole and to the private PD insurance market in particular.

Then, Part 5.2 aimed at assessing both the ability of the Canadian PD insurance market - through the employment benefits group plans - at facing the rise of high price specialty drugs and the responses from the Canadian L\&H insurance industry to the new nichebuster pharmaceutical business model. From the perspective of the IC of insurance markets framework, Part 5.2 sought to provide answers to one of the two components of Chapter 5's central question: which non-competitive institutional arrangements contribute at ensuring the constitution of the Canadian PD insurance market in the context of the rise of high price specialty drugs?

Apart from the historical exclusion of PD coverage from the provincially administered public universal healthcare systems, the tax-subsidies to employersponsored private health benefits at the federal level ${ }^{253}$ and the late 1990s federal demutualization policies represent key elements of the IC of the current Canadian PD insurance market. After having described the concentrated structure of the Canadian L\&H insurance industry - the top three Canadian L\&H insurers having capture $65.3 \%$ of market share by total revenue from employment benefits L\&H insurance group plans as of 2015 - and the non-standardized organization and design of employment health and PD benefits group plans, Part 5.2 assessed the ability of the design of drug benefits group plans at facing the rise of high price specialty medicines. Despite being fragmentary in terms of both years of reference and sources of datasets, the information and data

\footnotetext{
${ }^{253}$ Except in the province of Quebec where employer health benefits group plans are mandatory, the federal government promotes private health insurance and the private provision of health services benefits by considering health and dental benefits offered by employers as non-taxable income for employees (M-A Gagnon, 2012).
} 
collected corroborate Kratzer et al.'s (2013) study of the evolution of plans' design between 1998 and 2010. While the use of deductibles seems to be diminishing, two main trends can be observed. First, the transfer of costs to patients through the use of costsharing mechanisms (co-insurance and copayment) appears to be on the rise. Second, the use and evolution of cost-control mechanisms remain limited. ${ }^{254}$ Simply put, the Canadian L\&H insurers are either unable or unwilling to comprehensively control costs, and tend to shift costs towards plan sponsors and members through private PD drug plans. According to a qualitative study of large unionized workplaces with ASO plan, a consensus actually exists between private employers, unions, benefits consultancies and insurance companies over the need for the "external intervention from government to help transform established norms in terms of private drug plan design." (O'Brady et al., 2015: 230).

Part 5.2 then shed light on the responses from the individual Canadian $\mathrm{L} \& \mathrm{H}$ insurers and the Canadian L\&H insurance industry as a whole to the arrival of high cost specialty medicines. In the context of the limited evolution of plans' design, the L\&H insurance industry is responding to the rise of high cost specialty drugs through a series of isolated corporate initiatives and, most importantly, through structural, industry-wide non-competitive institutional arrangements. Seeking to better control costs, the Canadian L\&H insurers are creating isolated corporate communication efforts - for instance through newsletters - aiming at informing plan sponsors and members about the initiatives developed by the insurers in response to the rise of specialty drugs. Two

\footnotetext{
${ }^{254}$ In fact, while maximums are increasingly implemented, their usage is still relatively low at around a quarter of plans. The vast majority of plans still do not use formulary management measures. While the use of generic substitution measures is slowly increasing, the use of prior authorization is also still limited.
} 
programs established in isolation by the Canadian L\&H insurers exemplify these initiatives claiming to be aiming at better controlling costs: case management and assessment programs. As for now, the outcomes of these isolated initiatives cannot be empirically assessed due to the novelty of such efforts and the lack of publicly available data concerning them.

On the structural level, the Canadian L\&H insurance industry is responding to the rise of specialty drugs with two collaborative industry-wide measures implemented through its trade association, the CLHIA: the formulation of standardized guidelines for the coordination of benefits between private plans and the integration of private benefits to public PD coverage, and the establishment of an industry-wide catastrophic drug pooling agreement through the establishment of the Canadian Drug Insurance Pooling Corporation (CDIPC). The CLHIA's coordination and integration standardized guidelines presumably seek to promote, on the one side, greater distribution of the costs between the different private benefits group plans available to employees and their dependents and, on the other, the partial shifting of the costs of private PD benefits towards public plans. ${ }^{255}$ Perhaps most importantly, since 2013, the CLHIA implemented an industry-wide two-level integrated pooling system of catastrophic drug claims from fully insured plans by creating the CDIPC. Through this industry-run not-for-profit corporation, the CLHIA formulated the standard rules for the EP3 arrangement pooling of non-recurring high cost drug claims from a single employer/plan sponsor at the level of a single insurer. The CDIPC also provides an industry pooling arrangement of

\footnotetext{
${ }^{255}$ While, the effectiveness of the CLHIA's coordination and integration of benefits' guidelines is hard to assess since no data concerning their usage and outcomes is available as of now, two examples from top 10 Canadian group L\&H insurers illustrate this tendency for private insurers to seek the integration of the private PD coverage they offer with public plans and programs.
} 
recurring catastrophic drug claims from members of fully insured plans, itself integrating the individual insurer-level EP3 pooling.

The standardized insurer-level EP3 pooling arrangements and their integration into the CDIPC's industry-wide pooling represent non-competitive institutional arrangements developed by the Canadian L\&H insurance industry in response to drug inflation in general and to the rising high cost specialty drugs in particular. Nonetheless, the most structural responses from the L\&H insurers to the arrival of high cost specialty medicines mainly aim at protecting the financial interests of the insurers since the CDIPC is not a "means to neutralize drug cost growth," not an "instrument for insurers to reduce high cost drug prices through purchasing power," and not a "means to control or neutralize inflationary growth, utilization, and costs of expensive new drugs" (Berty, 2016: 15-6). Moreover, the CDIPC does not include self-insured group plans - such as ASO plans - in which plan-sponsors, members and dependents are most vulnerable to cost fluctuations.

Considering the will from private insurers and the L\&H insurance industry as a whole to increasingly integrate private PD coverage with public plans, Part 5.3 attempted to provide answers to the second component of this chapter's main question: which political-legal interventions contribute at ensuring the constitution of the Canadian PD insurance market in the context of the rise of high price specialty drugs? After having presented the recent calls in favor of the creation of a national and universal public catastrophic drug coverage program from the major Canadian PD insurance market stakeholders - the CLHIA, the Canadian association of research-based pharmaceutical manufacturers and the Canadian Pharmacists Association -, an overview of public 
catastrophic PD coverage in Canada was presented. While these calls have so far failed to translate into new federal policies, the Canadian L\&H insurance industry's strategy to promote the integration of private PD benefits with public coverage appears to have produced concrete results on the level of provincial governments. Following Phillips (2016), the trend observed by Daw and Morgan (2012) between from 2000 to 2010 has continued its evolution in the past few years. From six provinces with public catastrophic PD coverage in 2012, seven provinces now have implemented such coverage since the government of Prince Edward Island has established its own public catastrophic PD coverage in 2013 (Phillips, 2016). ${ }^{256}$

In conclusion, the current lack of data prevents the empirical assessment of the extent and outcomes of the integration of private PD benefits with public coverage. Despite the slowly increasing use of annual maximums by group plans, the calls by the main PD insurance market stakeholders for the establishment of a national and universal public catastrophic program and the move by the provinces towards public catastrophic programs signal an emerging trend towards the unloading of the "bad" PD insurance risks on standard and catastrophic public programs.

\subsubsection{Results}

Both private insurance and out-of-pocket funding are considered to be 'private' financing models, but it must be remembered that both of these entail government involvement in the form of regulation. A health care system based on private insurance must be heavily regulated in order to provide effective coverage, as the demand for profits will lead to the attempt to limit coverage to healthier individuals (at the expense of the sick) and constrain payment for treatment as often as possible. (Fierlbeck, 2011: 12)

\footnotetext{
${ }^{256}$ Under the current circumstances, it is impossible to empirically assess the extent and success or failure of the integration of private PD coverage with public plans due to the novelty of such initiatives and strategies from the Canadian L\&H insurance industry and the ensuing lack of information and data.
} 
The analyses presented above led to the formulation of answers to the specific question raised by this dissertation: which political-legal interventions and non-competitive institutional arrangements contribute at ensuring the constitution of the Canadian prescription drug insurance market in the context of the rise of high price specialty drugs?

While the historical exclusion of PD coverage from the federally-regulated and provincially administered public universal healthcare systems, the tax-subsidies to employer-sponsored private health benefits at the federal level (except in Quebec) and the late 1990s federal demutualization policies account for the deep IC of the Canadian PD insurance market, the Canadian L\&H insurance industry is responding to the rise of high costs specialty drugs with the industry-wide two-level integrated pooling system of catastrophic drug claims from fully insured plans through the CDIPC and the formulation, by the CLHIA, of the standardized guidelines for the coordination of PD benefits between private plans and the integration of private benefits with public coverage. Moreover, despite the failure - up until now - of the Canadian L\&H insurance industry's calls for the creation of national and universal public catastrophic PD coverage, public catastrophic coverage is being increasingly implemented at the provincial level. Finally, the lack of data prevents the empirical assessment of the extent and outcomes of the integration of private PD benefits with public coverage as mentioned in CLHIA's Guideline G4. While the slowly increasing use of maximums by the group plans might suggest otherwise, the CLHIA's 2013 report, the calls for the establishment of a national and universal public catastrophic program and the move by the provinces towards public catastrophic programs all signal the emergence of a tendency to unload 
the "bad" insurance risks on standard and catastrophic public PD programs. The theory of the IC of insurance markets and the concept of insurance risks as fictitious commodities account for these institutional interventions and strategies.

Through the interplay with the pharmaceutical industry as a third-party market innovating with the rise of high cost specialty medicines, the L\&H insurance industry is in a position to capitalize an empirical form of uncertainty related to health - as a component of both the human livelihood and social provisioning - but also the high cost of specialty drugs as an empirical form of uncertainty generated by the productive and business organization of the pharmaceutical industry itself. Under these circumstances, the firm-level private insurance governance itself faces instability and fails at organizing and commoditizing these empirical forms of uncertainties into privately managed and profitable insurance risks by virtue of the incentive-based controls of the insured (i.e. group plans' sponsors and members) and other corporate strategies. The private insurance governance proves unable to manage the instability and cost inflation generated by the emergence of "bad" risks constituted by the recurring and non-recurring catastrophic claims of high price specialty drugs.

Facing the arrival of high cost specialty medicines, the Canadian L\&H insurers as well as the employers sponsoring PD benefits plans tend to transfer costs to patients through the use of cost-sharing mechanisms (co-insurance and copayment) and make limited use of cost-control mechanisms such as formulary management despite recent isolated initiatives from individual insurers (such as Manulife's DrugWatch assessment program) aiming at importing public-style drug listing and HTAs. In the case of private PD insurance, the function of incentive-based and cost controls appears paradoxical since 
insurers have historically operated as third party payers. As previously mentioned, since private insurers are paid a percentage of the costs of PD plans' total claims, Canadian private PD insurance usually amount to being a quasi "open bar" with no incentives to control neither drug prices nor coverage expenditures (Lexchin, 2015; Silversides, 2009). This is the reason why physicians ask "Do you have a drug plan [i.e. private]?" as they write prescriptions; what they are actually meaning is "Do you care how much this costs?" (see Martinez, 2012: 10). Simply put, the Canadian L\&H insurance industry has no financial interests and faces no financial incentives in comprehensively controlling, reducing or eliminating the empirical uncertainties - generated by high drug prices and high costs specialty medicines - it capitalizes as fictitiously commoditized insurance risks. As a matter of fact, a qualitative study of large unionized workplaces with ASO plan based on interviews of 18 experts from private employers, unions, benefits consultancies and insurance companies found a consensus over the need for the "external intervention from government to help transform established norms in terms of private drug plan design.” (O’Brady et al., 2015: 230).

Since the firm-level private insurance governance fails at organizing and commoditizing the uncertainties generated by catastrophic high costs specialty drugs claims as "good" insurance risks, and since it has no financial incentives for significantly controlling, reducing or eliminating the empirical uncertainties it capitalizes, these new bad catastrophic insurance risks must be controlled and reduced through non-competitive institutional arrangements and insurers tend to shift costs directly towards insuredpatients. Both the individual insurers and the L\&H insurance industry as a whole must seek to decommoditize those bad risks by unloading them onto reciprocal and 
redistributive institutional arrangements, and also by individualizing these bad risks towards relatively autarchic arrangements.

First, due to the slowly increasing level of cost controls in the design of private PD benefits group plans, the Canadian L\&H insurance industry developed reciprocal non-competitive institutional arrangements through the CDIPC's industry-wide two-level integrated pooling system of catastrophic drug claims from fully insured plans. This means the risks to the self-insured plans in which plan sponsors, members and ultimately dependents bear more risk - such as ASO plans - are not mutualized by this industrywide arrangements. Moreover, the CLHIA formulated standardized guidelines for the coordination of PD benefits between the individual private plans.

Second, and as a consequence, the bad insurance risks of catastrophic high cost specialty drug claims are also decommoditized by being unloaded on provincial catastrophic PD programs organized on redistributive bases. The CLHIA also promotes the integration of private PD benefits with public PD coverage in its standardized industry guidelines. As for now, it is impossible to empirically assess the extent and success or failure of the integration of private PD coverage with public plans due to the novelty of such initiatives and strategies from the Canadian L\&H insurance industry and the ensuing lack of information and data. Nonetheless, the fragmented data collected from the currently available grey literature (see Section 5.2.2) tentatively points to a growth in the use of annual and lifetime maximums in private PD benefits plans. While such an evolution in plan design would potentially signal the unloading of the "bad" private insurance risks on the public programs, additional data and further research are required. From the perspective of the IC of insurance markets, however, public 
catastrophic PD coverage must be understood as a function of "the state as the ultimate risk manager" (see Moss, 2002), or in insurance-terms of "the state as the insurer of last resort." Especially in times of instability and uncertainty such as in the context of the rise of high cost specialty drugs, governmental insurance programs, public catastrophic coverage, state guarantee funds and various other governmental backstops are constitutive institutional arrangements for private insurance markets.

Finally, through rising co-insurance and co-payments and slowly increasing maximums, costs are being transferred towards plans' sponsors and members. From the perspective of the theory of the IC of insurance markets, this cost-shifting results in the individualization of a portion of the costs of the bad insurance risks of catastrophic specialty drug claims towards individuals and households, but also towards plans' sponsors. As a matter of fact, in 2014 , it is estimated that $22.2 \%$ ( $\$ 6.4$ billion) of the total PD expenditures was financed out-of-pocket in Canada (CIHI, 2015: 8). This number can be expected to increase in the near future if the status quo is maintained. Figure 5.7 presents a summarization of the previous analysis - through the lens of the theory of the IC of insurance markets - of how the Canadian PD insurance market faces the arrival of high cost specialty drugs. 


\section{Figure 5.8. The Canadian PD insurance market facing the rise of specialty drugs}

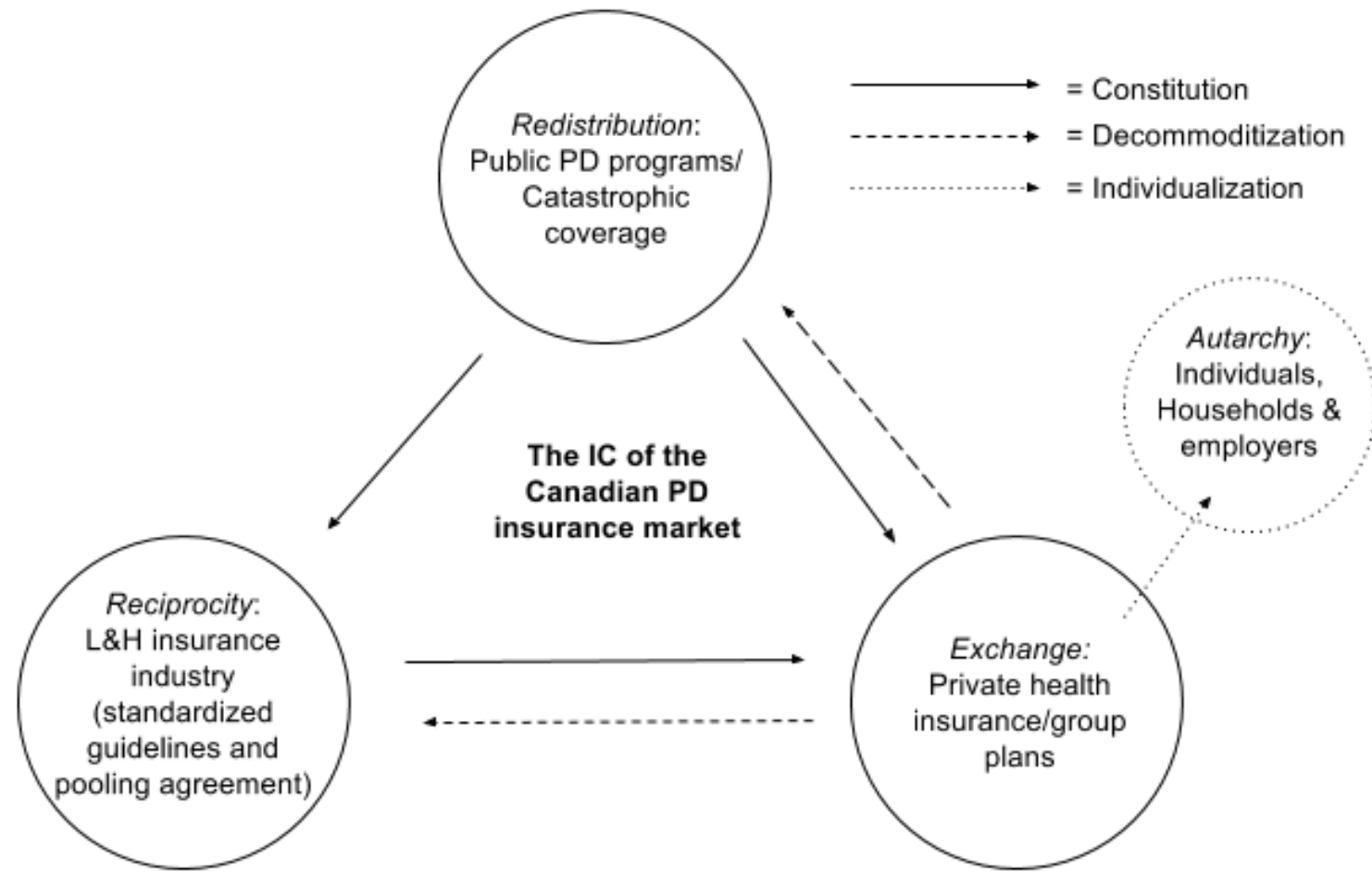

It appears that this specific configuration of the institutional modes of economic integration ensuring a relative integrity to the Canadian PD insurance market in the context of rising high cost specialty drugs reinforces the private exchange of PD insurance, at least for the time being. By shifting costs on redistributive, reciprocal and relatively autarchic arrangements, the Canadian L\&H insurers would seek to unload the bad private risks - through the decommoditization of the catastrophic high costs specialty drug claims - outside of their balance sheets. While such a conclusion must be carefully made until further analyses are conducted later in time and with expanded access to data, it is not unsupported in literature. As Gagnon (2014: 13) warns, "in a fragmented health care system (public/private) cost savings at one point in the system can often translate 
into cost increases elsewhere in the same system. In fact, in such a context, savings for some simply means transferring costs to others."

Moreover, the four Polanyian institutional forms of the market economy sheds light on what can be expected in terms of the future evolution of this institutional configuration. First and foremost, the fragmented public/private PD coverage in Canada, the will to further integrated private coverage with public plans and the calls for universal public catastrophic coverage from the Canadian L\&H insurance industry contradict the myths of the "neo-liberal deregulation" 257 and the diagnosis of the "retreat of the state" (see Strange, 1996) in the globalized economy. All around the world, the distribution of prescribed pharmaceutical products on markets - despite the globalized pharmaceutical production chain - is still organized nationally and regionally by public programs and/or private insurers. Even in countries in which private insurers play a large role in PD coverage such as Canada and the US, governments are central stakeholders in PD insurance markets.

Second, in this context, the Canadian L\&H insurers offering PD coverage have limited exposure to international pressures due to foreign ownership restrictions included in the Insurance Companies Act (S.C. 1991, c. 47). ${ }^{258}$ However, the impacts of trade agreements such as the recent Trans Pacific Partnership (TPP) and the potential Transatlantic Trade and Investment Partnership (TTIP) both on financial sector regulations and drugs and pharmaceutical policies are yet to be seen. Third, in the near

\footnotetext{
257 On the myth of the neoliberal deregulation, see for instance Panitch and Konings (2009).

258 According to the CLHIA (2015b: 30), “[d]uring the past decade, the market share of total industry premiums (and premium equivalents) held by Canadian-incorporated firms has fallen slightly to 89 per cent of the current market, down from a 91 per cent share. Over the same period, the market share of total premiums for Canadian-owned firms has followed a similar pattern, slipping from 84 per cent in 2004 to 81 per cent in 2014."
} 
future, the current expansionary monetary regime and credit-driven growth might provide favourable conditions for the Canadian L\&H insurers' support of the status quo. On the one hand, despite the fact that federal, provincial and municipal bonds represented only $20.76 \%$ of total Canadian L\&H insurance industry investments in 2014 - as compared with $34.63 \%$ in corporate securities and $25.41 \%$ in mutual funds ${ }^{259}$-, the current lowinterest rates might not offer the best financial conditions to Canadian L\&H insurers. On the other, not only do Canadian L\&H insurers have access to cheap money, but plans sponsors and members also do. ${ }^{260}$

From the Polanyian perspective, however, one must move beyond any forms of economic determinism by rather locating the concrete form of the double-movement at play. As mentioned above, the Canadian L\&H insurance industry acknowledged the issues of accessibility, affordability and sustainability in the current PD coverage system in Canada. In its 2013 report, the CLHIA (2013a: 35-9) concluded with 23 recommendations for reforms, most of which seek to better control drug prices. Most importantly, all of these recommendations directly or indirectly involve the state in the efforts to ensure the sustainably of private PD benefits group plans. When, in the context of the arrival of a new pharmaceutical business model, the Canadian L\&H insurance industry as a whole promotes the integration of the coverage it offers with public plans and the establishment of public universal catastrophic coverage, it is as if private insurers stopped believing in private insurance governance as being efficient and self-sustainable. While the "physicians-insurers-pharmaceuticals" triad is the main proponent of a "reform

\footnotetext{
${ }^{259}$ According to the CLHIA's (ibid.: 27) numbers for 2014, out of total investments of $\$ 642.509$ billion, the Canadian L\&H insurers own \$133.394 billion in federal, provincial and municipal bonds, \$222.444 billion in corporate securities and $\$ 163.277$ billion in mutual funds.

${ }^{260}$ No study of PD-related indebtedness in Canada is currently available in literature.
} 
of the status quo" - that is to say a reform of the current Canadian hybrid PD insurance system - other stakeholders offer counter-reactions to the outcomes of the fragmented PD coverage in Canada and to the impact of high cost drugs on the Canadian PD insurance market.

On the one side, the political-legal aspect of the double-movement is clearly noticeable, as explained above, in the interventions from legislators, policy-makers and the state as the insurer of last resort. On the other side, a rather divided social movement has taken form around the discussions over PD coverage in Canada. Some of the most organized and vocal movements are patient groups. Some of these patient groups - such as the Cancer Advocacy Coalition of Canada (CACC) - are actually funded by pharmaceutical producers and the pharmaceutical industry trade association (see Section 5.2.2). This type of patient groups tend to defend the status quo, to consider that private plans provide better access to medications - for instance in oncology -, to advocate for public catastrophic coverage, and to suggest that cost control measures concerning formulary listing, public plans and universal coverage can lead to reduced access (see Bonnett, 2010: 16; Emerson, 2010). Accordingly, and while further research is needed, this suggests that astroturfing - defined as a corporate public relations strategy aiming to appear as the result of grassroots movements (see Greenberg et al., 2011; Gustein, 2009) - might partially explain the configuration of the double-movement in the case of the institutional constitution of the Canadian PD insurance market.

The other constituent of the social movement involved in the institutional constitution of the Canadian PD insurance market can be described as the pro-public healthcare movement, including some healthcare professionals, unions, academic and 
research communities, consumer advocacy groups, as well as some policy-makers and legislators. For example, the Canadian Federation of Nurses Unions publicly called for the establishment of public, universal, and single-payer pharmacare coverage in Canada by publishing a report defending such a program (see Gagnon, 2014). ${ }^{261}$ Even more recently, a group of academics and researchers published a report titled Pharmacare 2020. The Future of Drug Coverage in Canada, also calling for and defending the creation of universal pharmacare in Canada. This report presented recommendations "reviewed and endorsed by over 100 university-affiliated professors and clinical experts in pharmaceutical policy, health policy, health economics, health services research, medicine, pharmacy, nursing, and psychology." (Morgan, Martin, et al., 2015: 3). It is estimated that a Canada-wide "[u]niversal public drug coverage would reduce total spending on prescription drugs in Canada by $\$ 7.3$ billion (worst-case scenario $\$ 4.2$ billion, best-case scenario $\$ 9.4$ billion)." (Morgan et al., 2015: 1).

\footnotetext{
261 According to this report (Gagnon, 2014: 24-9), the private health insurance governance generates collective costs in four ways. Private health insurance risk pooling first results into skimming strategies, meaning that as the private insurers tend to accept covering the "good risks" of healthy individuals and richer workers, public plans are left with the less healthy and wealthy "bad risks." In fact, in addition to the regional iniquities in PD coverage in Canada (see Demers et al., 2008), the Canadians from 18 to 34 years old as well as low to middle income and part-time workers are the most at risk of being either underinsured or uninsured for PD coverage in Canada (see Kapur and Basu, 2005). Second, more than half of the money spent on PD by the Canadian L\&H insurers in 2012 can be considered as waste "because they either reimbursed medicines that were more expensive without providing additional therapeutic value, or because they paid unnecessary dispensing fees." (Gagnon, 2014: 27). Third, in addition to being costly for the federal government (see M-A Gagnon, 2012), the tax-subsidies to private PD benefits group plans - except in Quebec - constitute a regressive fiscal policy: "the employer's contribution to the drug plan (corresponding to a part of the salary) is tax free. Therefore, there is no income tax on that portion of the salary. Consequently, the more you earn, and the higher your marginal tax rate is, the more you benefit from this tax subsidy. The final result is $[\ldots]$ the richer you are, the more you benefit from tax subsidies." (Gagnon, 2014: 29). Finally, while the administrative costs in the public sector were estimated at $1.8 \%$ in 2012 (CIHI, 2014: 61), the administrative costs - including profits - charged by the Canadian for-profit health benefits plan insurers were estimated at $18 \%$ in 2012 (Frank, 2014). In the US, the private health insurers are legally prohibited to charge more than $20 \%$ in administrative costs to health benefits group plans (Law et al., 2014).
} 
According to a qualitative study of large unionized workplaces with ASO plan, a consensus actually exists between private employers, unions, benefits consultancies and insurance companies over the need for the "external intervention from government to help transform established norms in terms of private drug plan design." (O’Brady et al., 2015: 230). But the case study of the impact of the nichebuster pharmaceutical business model on the Canadian PD insurance market leads one to think that the fundamental organizing principle of the insurance industry - that is the moral hazard paradigm as the epistemic form of the utopia of the self-regulating private insurance governance (see Part 3.1.) - ultimately risks being increasingly put into question per se.

\subsubsection{Policy recommendations}

As explained in Section 5.2.2, the study of the insurance industry at large and especially of private benefits group plans is made difficult due to the restricted access to insurance sector data. For instance, neither the major official database such as Statistics Canada and Institut de la statistique du Québec, nor the Canadian life and health (L\&H) insurance industry trade association (i.e. the CLHIA) offer disaggregated data on health and PD benefits and private PD premiums spent in Canada. Access to L\&H insurance industry and employment benefits group plans database (Telus Health, Applied Management Consultants and Mercer) is especially restricted by virtue of being proprietary in nature and hence prohibitively priced for researchers without adequate research funding. Access to comprehensive employment benefits group plans data should be of major concerns to both researchers and policymakers. In order to support research, the establishment of a 
centralized, transparent, accessible and publicly managed and funded private $\mathrm{L} \& \mathrm{H}$ benefits database - for instance at Statistics Canada - is recommended. 


\section{Chapter 6. Conclusion}

\subsection{Summary and secondary conclusions}

Businesses often define as regulation only those government rules that they feel unfairly limit their ability to shift costs onto others. (Block and Somers, 2014: 40)

Through a review of the heterodox private insurance studies literature, Chapter 2 first concluded that the emerging sociology of insurance has mainly focused on the epistemic and cultural components of the construction of private insurability. In order to shift the analytical focus to the institutional construction and maintenance of private insurability, Chapter 2 then discussed the shortcomings of the dominant frameworks in contemporary economic sociology, pointed to the limits of both Marx and Weber in the study of institutions, and briefly presented Durkheim's and Veblen's foundational contributions to economic sociology and the institutionalist tradition. This chapter concluded by discussing the recent reinterpretations of Polanyi's institutional analysis, focusing on the political and legal constitution of the economy and of markets as the theoretical bases for the institutional economic sociology of private insurance.

In order to overcome the neglect of the institutional constitution of the insurance industry in the emerging sociology of insurance literature, Chapter 3 started by formulating a critique of the orthodox moral hazard paradigm based on evidence from socio-legal studies of private insurance. As the insurance sector version of the selfregulating market utopia, the moral hazard paradigm constitutes the insurance industry's own self-representation portraying the instability inherent to the insurance contract as being primarily generated by the behavior of the insured, pictured as highly aware, knowledgeable, calculative, and self-interested. By alleviating most, if not all responsibility for the destabilization of private insurance from the insurer's back, the 
moral hazard paradigm enables insurers to epistemologically legitimize private risk classication and contractual incentive-based controls of the insured. In doing so, it claims that private insurance governance is able to autonomously ensure its own stability and profitability.

Chapter 3 then turned to the moral risks paradigm, elaborated by the ethnographic sociology of the insurance industry, as a more adequate representation of private insurance as a social relationship. Against the insurer-biased moral hazard paradigm, the ethnographic sociology of private insurance suggests that the moral risk paradigm better represents the nature of private insurance as a social relationship, that is "the paradoxical tendency of the structure and culture of the insurance institution to facilitate and encourage risky behavior on behalf of the various players in the insurance relationship." (Ericson and Doyle, 2006: 993). By pointing to the instabilities and uncertainties intrinsically generated by the insurantial relationship, the ethnographic sociology of private insurance's moral risks paradigm thus broadens the analysis of private insurance governance beyond risk classification and incentive-based controls of the insured and reveals that the functioning of the insurance industry requires non-actuarial types of knowledge and non-competitive institutional arrangements.

From the perspective of economic sociology, the moral risks paradigm raises the theoretical issue of the capacity of institutions to mediate and organize various uncertainties as profitably covered, commodified and transferrable risks. Chapter 3 hence developed a Polanyian theory of the institutional constitution of markets as a framework for the sectoral analysis of capitalism in general and insurance markets in particular. Following the recent wave of post-embeddedness Polanyian literature, the conceptual 
apparatus of The Great Transformation (Polanyi, 1944) was reconstructed through the core concept of insurance risks as fictitious commodities pointing to the political-legal interventions and the non-competitive institutional arrangements the insurance industry depends on in order to profitably cover empirical uncertainties as insurance risks within markets as institutions. The three central concepts of Polanyian institutional economic sociology shed light on the three central processes of the institutional constitution of insurance markets: (1) the necessarily incomplete and destabilizing institutionalization of the self-regulating market utopia allows us to examine the institutional production of uncertainty; (2) the concept of insurance risks as fictitious commodities illuminates the institutional mediation of empirical uncertainties into fictitiously commoditized insurance risks; and (3) the diversity of the modes of institutional integration (redistributionintervention, reciprocity-mutuality, and relative autarchy) enables the analysis of the decommoditization and individualization of insurance risks.

Accordingly, the theory of the institutional constitution of markets raises the following general question: which political-legal interventions and other non-competitive institutional arrangements contribute to ensuring the constitution of insurance markets? Chapter 3 concluded with a presentation of research hypotheses and secondary research questions, the method and methodologies employed, and a brief discussion of the nature of the data analysed in the two case studies presented in Chapters 4 and 5.

By bringing into focus the legal aspect of the institutional constitution of private insurance, Chapter 4 offered a historical primer for the theory of the institutional constitution of insurance markets. Building on the social and economic history of insurance literature, it presented a Polanyian analysis of the case study of the historical 
construction of insurance law in England from 1664 to 1774 through the institutionalization of the insurable interest principle, which reveals the modern origins of the insurance industry. As a concrete illustration of the Polanyian critique of the economistic fallacy, the ancient origins of insurance thesis - that is the assumption that private insurance originated as marine insurance in ancient history - was first debunked. In ancient commercial empires and late medieval mercantilism insurance as such never emerged as a relatively autonomous profit-making activity as it could not be distinguished from credit nor currency exchange. ${ }^{262}$ While previously conflated, insurance, credit and currency exchange slowly became relatively autonomous financial operations following the Agrarian revolution in $16^{\text {th }}$ century England and especially with the rise of English financial capitalism at the turn of the $18^{\text {th }}$ century.

Chapter 4 then suggested that the Polanyian concept of the diversity of the institutional modes of economic integration allows us to make sense of the modern origins of private insurance. Through reciprocal institutional arrangements, the insurance industry initially emerged as life and fire insurance mutual societies at the end of the $17^{\text {th }}$ century. These mutual societies permitted the institutionalization of class and patriarchal solidarity by providing banking facilities to their members, and employing pre-actuarial risk management based on mutuality and observational knowledge as core organizational principles. Through redistributive institutional arrangements and state interventions, these first insurers moreover emerged as central institutional investors in the context of the political-legal institutionalization of the primacy of private property, the first nationally

\footnotetext{
${ }^{262}$ In the late Middle Ages, the first instances of third-party marine risks hedging and of insurance on the lives of other persons represented prototypical forms of insurance since these financial operations were still structured under a trade-centered credit system characterized by long-distance sea trade and emerging modern colonialism.
} 
collateralized debt and the first modern central bank. The insurance industry also greatly contributed to the rise of Great Britain's imperial power on the international scene. As a core institution in the constitution of the early institutional arrangements of English capitalism, the insurance industry was an active component in the attempted institutionalization of the first society of the self-regulating market utopia since it contributed to the extension of the opportunities for private capitalization by facilitating the preservation of inheritance and access to liquidity.

The initial institutional constitution of private insurance both generated and made possible the capitalization of specific uncertainties. On the one hand, from the creation of the first insurance mutual societies from the 1690s until the 1720s, the British insurance industry experienced an intense boom in the context of a monetary regime characterized by rapid credit growth, as it got involved in the speculative euphoria leading to the South Sea Bubble. The enactment of the Bubble Act in 1720 reveals that both the British government and the South Sea Company were highly concerned by the explosive growth of the insurance industry as a whole and the financial uncertainty it contributed to generating. Following its takeoff in the first half of the $18^{\text {th }}$ century, the insurance industry then generated increasing moral and legal uncertainties. While the early $18^{\text {th }}$ century criticisms over insurantial speculation and gambling were not purely moralistic and instead concentrated on the fraudulent and criminal intents and ramifications of some widespread insurance industry practices, a series of cases increasingly sparkled public debates and led to court battles over the way in which law had to deal with human life as capital. Facing these uncertainties, the initial institutional constitution of private 
insurance required the enactment of four pieces of legislation $(1664,1720,1746$ and 1774) culminating with the institutionalization of the insurable interest principle.

By requiring that the beneficiary of insurance coverage can demonstrate an objective financial or emotional interest in the insured property or life, this principle allowed for the political-legal recognition of insurance against widespread insurantial speculation and especially against gambling over lives. The integration of the insurable interest principle into common law through the 1746 Marine Insurance Act and the 1774 Gambling Act was based on a materialist theory of value according to which the distinction between insurance and gambling was to be made on the bases of commercial value and economic productivity (O'Malley, 2003). As one of the basic principles of insurance law, the insurable interest principle was actually aiming at the insurance industry as a whole by seeking to remove incentives for underwriting highly risky and highly profitable gambling-like and speculative policies often involving fraudulent schemes and potential criminal actions.

From around 1664 to 1774 , legislators, judges and courts seem to have become aware that the organizational structure of private insurance and the financial incentives ingrained in the insurance industry - not the irresponsible insured - were the sources of the deep moral, legal and material conflicts generated by the insurantial relationship. Against the orthodox moral hazard paradigm, the early history of the insurance industry and the enactment of the Gambling Act provide historical evidence that the moral risk paradigm model better describes the nature of the private insurance relationship. From the Polanyian perspective, this is especially significant: more than three quarters of a century before the first explicit formulation of the moral hazard paradigm as the 
insurance version of the self-regulating market utopia, private insurance governance already proved unstable and uncertainty generating. Hence, it can be concluded from Chapter 4 that the epistemic constitution of the insurance industry long lagged behind its political-legal constitution.

By bringing into focus the political aspect of the institutional constitution of private insurance and the analysis of insurance markets as politically and legally constituted institutions, Chapter 5 then presented the central case study of this dissertation: the institutional constitution of the Canadian prescription drug insurance market in the context of the rise of high cost specialty drugs. Following the theory of the institutional constitution of markets, this central chapter aimed at providing answers to this dissertation's specific research question: which political-legal interventions and noncompetitive institutional arrangements contribute to ensuring the constitution of the Canadian PD insurance market in the context of the rise of high price specialty drugs?

On the one hand, the deep institutional constitution of the Canadian prescription drug insurance market can be first explained by the historical exclusion of prescription drug coverage from federally legislated and provincially administered public universal healthcare systems, by the tax subsidies for private employer-sponsored drug plans at the federal level (except in Quebec) and by the late 1990s federal demutualization legislation. On the other hand, in the context of the rise of the high costs specialty medicines, the institutional constitution of the Canadian prescription drug insurance market is first ensured through two non-competitive institutional arrangements: the life and health $(\mathrm{L} \& \mathrm{H})$ insurance industry-wide two-level integrated pooling system of catastrophic drug claims from fully insured plans through the Canadian Drug Insurance Pooling 
Corporation (CDIPC) and the formulation, by the Canadian Life and Health Insurance Association (CLHIA), of standardized guidelines for the coordination of prescription drug benefits between private plans and for the integration of private prescription drug coverage with public plans. The institutional constitution of the Canadian prescription drug insurance market is also facing the rise of specialty drugs by indirectly relying on the implementation of provincial public catastrophic coverage. While the calls from the Canadian L\&H insurance industry for the creation of a national and universal public catastrophic coverage program have so far failed to translate into federal policies, the provinces are increasingly implementing their own public catastrophic prescription drug coverage in order to solve access issues.

Through the interplay with the pharmaceutical industry as a third-party market innovating with the rise of the high cost specialty drugs, the L\&H insurance industry is in a position to capitalize both on an empirical form of uncertainty related to health - as a component of the human livelihood and social provisioning - and on the high cost of specialty drugs as an empirical form of uncertainty generated by the productive and business organizations of the pharmaceutical industry. Despite being concerned by the sustainability of employer-sponsored private plans, the Canadian L\&H insurance industry has no financial interests and faces no financial incentives in comprehensively controlling, reducing or eliminating the empirical uncertainties generated by high drug prices and high cost specialty drug claims it capitalizes as fictitiously commoditized insurance risks. Under these circumstances, the firm-level private insurance governance based on the moral hazard paradigm - itself faces instability and uncertainty and fails at organizing and commoditizing these empirical forms of uncertainties into privately 
managed and profitable insurance risks by virtue of incentive-based controls of the insured (i.e. group plans' sponsors and members) and other isolated corporate strategies. Facing the rise of high cost specialty drugs, the Canadian L\&H insurers tend to transfer costs to patients through the use of cost-sharing mechanisms (co-insurance and copayment) and make limited use of cost-control mechanisms (e.g. mandatory generic substitution and other formulary management measures) despite some recent isolated initiatives from individual insurers aiming at importing public-style drug listing and health technology assessments.

In the case of private prescription drug insurance, the function of the incentivebased controls and the use of cost-control mechanisms appear paradoxical since insurers have historically operated as third-party payers with no incentives to comprehensively control costs. The catastrophic claims generated by the rise of specialty medicines represent "bad risks" in the insurers' risk pools and must hence be unloaded on other institutional modes of economic integration through decommoditization and individualization processes. Since the firm-level private insurance governance fails at organizing and commoditizing the uncertainties generated by the catastrophic high costs specialty drug claims into "good" insurance risks, and since it has no financial incentives for comprehensively controlling, reducing or eliminating the empirical uncertainties it capitalizes, both the individual insurers and the L\&H insurance industry as a whole must seek to decommoditize those bad risks by unloading them onto reciprocal-mutual and redistributive institutional arrangements, and also by individualizing these bad risks towards relatively autarchic arrangements. 
First, because of the lack of comprehensive cost-controlling in the design of private prescription drug benefits group plans, the Canadian L\&H insurance industry developed reciprocal non-competitive institutional arrangements through the CDIPC's industry-wide two-level integrated pooling system of catastrophic drug claims from fully insured plans only. Moreover, the CLHIA formulated standardized guidelines for the coordination of prescription drug benefits between private plans. Second, the CLHIA's guidelines also promote the integration of private prescription drug benefits with public coverage in its standardized industry guidelines. As a consequence, the bad insurance risks of catastrophic high cost specialty drug claims can also be decommoditized by being unloaded on provincial catastrophic prescription drug coverage organized on redistributive bases. From the perspective of the institutional constitution of insurance markets, public catastrophic prescription drug coverage must be understood as a function of "the state as the ultimate risk manager" (see Moss, 2002) or, in insurance terms, of "the state as the insurer of last resort" (Ericson et al., 2003; Ericson and Doyle, 2004c). As insurers of last resort, the provincial catastrophic coverage programs represent market makers for the Canadian prescription drug insurance market. Finally, through the slowly growing use of maximums, costs are being transferred to plan sponsors and members. This cost-shifting results in the individualization of a portion of the costs related to the bad insurance risks of catastrophic specialty drug claims towards plan sponsors, insured employees and their dependents.

In the last analysis, it appears that this specific configuration of the institutional modes of economic integration ensuring a relative integrity to the Canadian prescription drug insurance market in the context of the arrival high cost specialty medicines 
reinforces the private exchange of PD insurance, at least for the moment. By shifting costs into redistributive, reciprocal and relatively autarchic institutional arrangements, the Canadian L\&H insurers are seeking to unload the bad risks - through the decommoditization and individualization of catastrophic high costs specialty drug claims - onto other institutions and directly onto the individuals. Such a conclusion, however, must be carefully made until further analyses are conducted later in time and with expanded access to data. Still, the fundamental organizing principle of the insurance industry - that is the moral hazard paradigm as the epistemic form of the utopia of selfregulating private insurance governance - ultimately risks being increasingly put into question per se. When, in the context of the emergence of the new nichebuster pharmaceutical business model, the Canadian L\&H insurance industry as a whole establishes non-competitive risk pooling arrangements and requests both the integration of the coverage it offers with public coverage and the establishment of public universal catastrophic coverage, it is as if private insurers stopped believing in private insurance governance as being efficient and self-sustainable. Chapter 5 concluded with a discussion of the concrete form of the double-movement in the institutional constitution of the Canadian PD insurance market as well as with a policy recommendation, the establishment of a centralized, transparent, accessible and publicly managed and funded private $\mathrm{L} \& \mathrm{H}$ benefits database.

\subsection{General conclusions}

Building on previous chapters, some general conclusions can be made concerning Polanyian institutional economic sociology. Through its core concept of insurance risks as fictitious commodities, the theory of the institutional constitution of markets 
contributes to socio-economic discussions of the concepts of uncertainty and risk. Under its canonical Knightian version, the neoclassical theory defines risk as an actuarially quantifiable occurrence as opposed to uncertainty understood as a condition under which decisions are made without available historical statistics. This approach allows for the defense of the self-regulating market utopia by picturing the entrepreneur as a planner in risk-taking and the firm as the space for the efficient mitigation and organization of uncertainty (see Knight, 1921). In contrast to the neoclassical theory, the ethnographic sociology of private insurance (Ericson et al., 2003; Ericson and Doyle, 2004c) rather suggests that the boundaries between uncertainty and risk are not as clear as what orthodox approaches claim. Ericson and his collaborators revealed that private insurers cover a wide range of uncertainties as insurance risks, despite a lack of both archivalhistorical and probabilistic data. This finding that private insurability can be constructed by the institutional production of the various forms of knowledge private insurers seek in constructing the insurability of unquantifiable uncertainties and turning them into knowable, and thus insurable risks, means that even highly "uncertain risks" are privately capitalized by the insurance industry. In contrast to what the neoclassical theory of uncertainty claims, the ethnographic sociology of private insurance rejects both the radical dichotomy between uncertainty and risk and the actuarial concept of risk.

The ethnographic sociology of private insurance has also found that, despite claiming to rely on actuarial underwriting and risk mutualization as its core organizational principles, private insurance governance ironically leads - in addition to the coverage of uncertain risks - to the un-pooling of risks (i.e. deselection), risks and fraud creation, and financial risk-taking (Doyle and Ericson, 2010). Through the moral 
risks paradigm, these authors hence show that private insurance governance cannot selfsufficiently stabilize the insurantial relationship and autonomously ensure the profitably of the private insurance business. ${ }^{263}$ Instead of focusing on knowledge in the study of the construction of private insurability, the Polanyian institutional analysis rather brings the institutional interventions and arrangements into the analytical foreground.

The theory of the institutional constitution of markets sheds light on the construction of private insurability, notwithstanding the availability of archival-historical and probabilistic data allowing for the actuarial calculus of risk or the catastrophic scale of the empirical uncertainty covered as insurance risk. Insurance markets concerning which archival-historical data is both available and highly predictive - such as in L\&H insurance - can be destabilized by the rise of uncertainty - for example due to a new pharmaceutical business model - while maintaining relative integrity and profitability. This can be explained by the institutional mediation of the underlying empirical uncertainties covered by the insurance industry through their fictitious commoditization as insurance risks.

The empirical uncertainties underlying insurance risks are initially generated and mediated in wider institutional and societal settings, out of the scope of private insurance governance. From the perspective of the Polanyian institutional analysis, the uncertainties experienced by individuals and threatening the modes of social provisioning, nature, the political institutionalization of society, and the market economy itself represent the raw materials which insurers capitalize. Before being institutionally mediated and organized

\footnotetext{
${ }^{263}$ For instance, in addition to the production of non-actuarial knowledge, the most catastrophic risks such as terrorism-related events are made privately insurable thanks to surveillance technologies, private security, financial securitization and public-private collaborations (Ericson and Doyle, 2004c).
} 
as insurance risks, these underlying uncertainties are substantive in that they are initially empirically experienced in the "non-insurance" world through various "extra-insurantial" modes of perception, organization and provisioning. While different non-private insurance institutions and arrangements can perform the removal, reduction and control of empirical uncertainties, the financial and organizational incentives the insurance industry deals with prevent insurers from seeking the complete removal of uncertainties it capitalizes as insurance risks. Moreover, the private insurance governance cannot autonomously ensure the specific levels of uncertainty reduction and control it requires in order to profitably cover substantive uncertainties as insurance risks. Hence, while the empirically experienced uncertainties represent the insurers' "raw material," the private insurance governance requires political-legal interventions and other non-competitive institutional arrangements in order to ensure the relatively stable and profitable capitalization of these empirical uncertainties. As a result, this dissertation developed the following general definition of insurance markets: insurance markets are politically and legally constituted institutions designed for the private capitalization of the uncertainties of the market economy, of the modes of social provisioning and, potentially, of the various aspects of human livelihood.

The Polanyian framework thus considers "insurance risk" as the organizing principle of the private capitalization of the underlying empirical uncertainty. The concept of insurance risks as fictitious commodities highlights the gap between this organizing principle of the private insurance governance and its destabilizing and uncertainty generating attempt at autonomously covering and commoditizing empirical uncertainties, on the one side, and the necessary political and legal constitution of 
insurance markets as institutions, on the other. In other words, the private capitalization of empirical uncertainties depends on the fictitious commoditization of these uncertainties as insurance risks by virtue of (i) the political-legal and non-competitive reduction and control of the underlying uncertainties covered as capital by the insurers and (ii) the decommoditization and individualization of insurance risks through their unloading as empirical uncertainties towards redistributive, reciprocal and autarchic institutional modes of economic integration. In this context, answers to the general research question can be formulated: which political-legal interventions and other noncompetitive institutional arrangements contribute to ensuring the constitution of insurance markets?

First, the interventions of the legislator appear as a major component of the institutional constitution of insurance markets. Corroborating Baker's (2010) insight according to which insurance is law-intensive business, the two case studies presented in this dissertation have found that law-making is essential for the construction maintenance of insurance markets. While the legal institutionalization of the insurable interest principle contributed to the historical emergence of private insurance as a relatively autonomous business, the exclusion of prescription drug coverage from the Canadian federal health law, the federal tax-subsidies for private prescription drug benefits and the late 1990s federal demutualization laws all contributed to the current constitution of the Canadian prescription drug insurance market. Second, policy-making also proved crucial for the constitution of the studied insurance markets. While the availability of public insurance facilitates private insurance skimming by covering the most vulnerable insured individuals considered to be "bad risks" by private insurers (e.g. social assistant 
recipients and low-income seniors in the case of prescription drug insurance), governments provide public catastrophic coverage working as backstops on which these bad private insurance risks can be decommoditized. Public insurance programs can also support the risks that private insurers individualize by virtue of various underwriting and contractual means, again through a process of decommoditization of private insurance risks as fictitious commodities. Third, the state as the insurer of last resort is hence a central stakeholder in insurance markets and intervenes as an insurance market maker, for instance through the establishment of provincial catastrophic prescription drug programs in Canada in the context of the destabilizing emergence of the nichebuster pharmaceutical business model.

Finally, Chapter 5 has also shed light on specific non-competitive institutional interventions and arrangements that the Canadian prescription drug insurance market developed in order to face the rise of the high cost specialty medicines. These included calls from the Canadian L\&H insurance industry for the establishment of a national and universal catastrophic drug coverage program, the formulation by the CLHIA of industry standardized guidelines for the coordination of prescription drug benefits between the different private plans and for the integration of private coverage with public prescription drug programs. Moreover, through its industry trade association, the Canadian L\&H insurance insurers also established an industry-wide two-level pooling system of catastrophic prescription drug claims from fully insured group plans. To sum up, the existence of the L\&H insurance industry trade association, its calls for specific politicallegal interventions, the formulation of insurance industry standardized guidelines and the establishment of an industry-wide agreement all represent non-competitive institutional 
interventions and arrangements contributing to the institutional constitution of the Canadian PD insurance markets.

In stark contrast with the neoclassical theory, the theory of the institutional constitution of markets concludes that empirical uncertainties, not actuarial risks, are the conditions of possibility for the operation of private insurance. Moreover, both the actuarial computation of risks and the extra-actuarial knowledge of uncertainty are insufficient conditions for the construction of private insurability and the constitution of insurance markets. The institutional mediation and organization of empirical uncertainties as fictitiously commoditized insurance risks account for the basic determinant of private insurability. Insurance risks, as fictitious commodities, cannot be disconnected from empirically experienced uncertainties; private insurance capitalization requires the fictitious commoditization of empirical uncertainties into insurance risks through political-legal interventions and non-competitive institutional arrangements.

\subsection{Limitation and future research areas}

As explained in Chapter 5, the main limitation of this dissertation stems from the fact that the study of the insurance industry is made difficult due to restricted access to insurance sector data. This is one of the reasons why the ethnographic sociology of the insurance industry (Ericson et al., 2003; Ericson and Doyle, 2004c) provided such innovative and important findings for the emerging field of the sociology of insurance. For example, neither the major official database, such as Statistics Canada and the Institut de la statistique du Québec, nor the Canadian L\&H insurance industry trade association - the CLHIA - offer disaggregated data on group health and prescription drug benefits and 
private prescription drug premiums spent in Canada. Access to life and health insurance industry and employment benefits group plans database - the main ones being corporately managed by Telus Health, Applied Management Consultants and Mercer - is restricted by virtue of being proprietary in nature and hence prohibitively priced for researchers without significant research funding. This is why Chapter 5 recommended the establishment of a centralized, transparent, accessible and publicly managed and funded private $\mathrm{L} \& \mathrm{H}$ benefits database - for instance at Statistics Canada - in order to support research.

While the theory of the institutional constitution of markets could well be analytically useful for the study of non-insurance markets, the concept of insurance risks as fictitious commodities opens the way to the analysis of other insurance branches and markets. Two cases would be of special research interest from the perspective of Polanyian institutional economic sociology: the construction of the cyber-insurance market and the impact of climate change on the insurance industry. Cyber-risks and risks related to climate change such as flood, drought and fire, represent two instances in which private insurers must turn to the political-legal and non-competitive reduction and control of the underlying uncertainties constituted by data breaches and cyber-attacks or by the potential destruction of cars, houses, buildings and infrastructure. These represent only two cases among many others in which the Polanyian theory of the institutional constitution of markets and the concept of insurance risks as fictitious could investigate the political-legal interventions and non-competitive institutional arrangements necessary for private insurance capitalization of substantive uncertainties. 
The study of the institutional constitution of insurance markets raises crucial political and normative implications related to the analysis of the degrees of reduction and control of the empirical uncertainties fictitiously covered as insurance risks. Following this dissertation, the "biggest risk" of private insurance governance might well be the unwillingness of the insurance industry to contribute to the removal of some empirical uncertainties underlying insurance risks. Moreover, the possibility for the insurance industry to privately capitalize the coverage of empirical uncertainties as fictitiously commoditized insurance risks - through political-legal interventions and noncompetitive institutional arrangements - while at the same time transferring the costs stemming from the control and reduction of these empirical uncertainties on the citizenry and on society as a whole should lead to important sociological investigations and political discussions. 


\section{References}

Abraham, J. (2002). The pharmaceutical industry as a political player. The Lancet, 360(9344), 1498-1502.

Abraham, K. S. (1986). Distributing Risk. Insurance, Legal Theory, and Public Policy. New Haven/London: Yale University Press.

Abraham, K. S. (2008). The Liability Century. Insurance and Tort Law from the Progressive Era to 9/11. Cambridge (MA): Harvard University Press.

Abraham, K. S., \& Liebman, L. (1993). Private insurance, social insurance, and tort reform: toward a new vision of compensation for illness and injury. Columbia Law Review, 93(1), 75-118.

Abraham, K. S., \& Schwarcz, D. (2015). Insurance Law and Regulation. Cases and Materials (Sixth edition). St. Paul (MN): Foundation Press.

ADB\&IA Inc. (unknown). Benefit Plan Definitions. Accurate Design Benefits \& Insurance Agencies Inc., Mississauga. Retrieved August 18, 2016, from http://www.accdesign.com/usercontent/documents/Understanding_Benefits.doc

Aglietta, M. (1976). A Theory of Capitalist Regulation. The US Experience. London: Verso.

Aglietta, M., \& Orléan, A. (Eds.). (1998). La monnaie souveraine. Paris: Odile Jacob.

Aglietta, M., \& Orléan, A. (2002). La monnaie entre violence et confiance. Paris: Odile Jacob.

Alborn, T. (1994). A calculating profession: Victorian actuaries among the statisticians. In Accounting and Science. Natural Inquiry and Commercial Reason. Cambridge (MA): Cambridge University Press, pp. 81-119.

Alborn, T. (2002). The first fund managers: life insurance bonuses in Victorian Britain. Victorian Studies, 45(1), 65-92.

Alborn, T. (2009). Regulated Lives: Life Insurance and British Society, 1800-1914. Toronto: Toronto University Press.

Alborn, T. (2010). A licence to bet: life insurance and the Gambling Act in the British Courts. In G. Clark, G. Anderson, C. Thomann, \& J. M. Graft Von Der Schulenburg (Eds.), The Appeal of Insurance. Toronto: University of Toronto Press, pp. 107-126.

Alborn, T., \& Murphy, S. A. (Eds.). (2013a). Anglo-American Life Insurance, 1800-1914. Volume 1: What is Life Insurance? Why Should you Insure? Selling Life Insurance to the Public. London: Pickering \& Chatto.

Alborn, T., \& Murphy, S. A. (Eds.). (2013b). Anglo-American Life Insurance, 18001914. Volume 2: Running a Life Insurance Company. London: Pickering \& Chatto.

Alborn, T., \& Murphy, S. A. (Eds.). (2013c). Anglo-American Life Insurance, 1800-1914. Volume 3: Mortality and Risk. London: Pickering \& Chatto.

Anacleto, J. (2015). Data Trends and National Benchmarks; Perspective Overview. TELUS Health Drug Conference, Toronto, March 25 (available on demand).

Anacleto, J. (2016). Data Trends and High Cost Specialty Drugs. Presented at the Society of Actuaries 2016 Canadian Health Seminar - Session 5: High Cost Drug Boot Camp: Everything You Need to Know, Toronto, May. Retrieved August 18, 
2016, from https://www.soa.org/Files/Pd/2016/canadian-health-seminar/pd-201605-canadian-health-session-5.pdf

AODP. (2016). Global Climate 500 Index 2016. Insurance Sector Analysis (p. 34). London: Asset Owners Disclosure Project. Retrieved October 15, 2016, from http://aodproject.net

Ardent, G. (1976). Histoire financière de l'Antiquité à nos jours. Paris: Gallimard.

Arrow, K. J. (1963). Uncertainty and the welfare economics of medical care. The American Economic Review, 53(5), 941-973.

Arrow, K. J. (1968). The economics of moral hazard: further comment. The American Economic Review, 58(3), 537-539.

Artous, A. (2000). Marx, l'État moderne et la sociologie de l'État. L'Homme et La Société, (136-137), 111-126.

Ashiagbor, D., Kotiswaran, P., \& Perry-Kessaris, A. (Eds.). (2013). Towards and Economic Sociology of Law. Malden/Oxford: Wiley-Blackwell.

Atmeh, S. M. (2011). Regulation not prohibition: the comparative case against the insurable interest doctrine. Northwestern Journal of International Law \& Business, 32(1), 93-140.

Badgley, R. F., \& Wolfe, S. (1967). Doctor's Strike. Medical Care and Conflict in Saskatchewan. Toronto: Macmillan of Canada.

Baird, D. G., Epstein, R. A., \& Sunstein, C. R. (2006). Symposium of the Law and Economics of Consumer Choice. The University of Chicago Law Review, 73(1), $1-2$.

Baker, T. (1996). On the genealogy of moral hazard. Texas Law Review, 75(2), 237-292.

Baker, T. (2002). Risk, insurance, and the social construction of responsibility. In T. Baker \& J. Simon (Eds.), Embracing Risk. Chicago: The University of Chicago Press, pp. 33-51.

Baker, T. (2003). Containing the promise of insurance: adverse selection and risk classification. In R. V. Ericson \& A. Doyle (Eds.), Risk and Morality. Toronto: University of Toronto Press, pp. 258-282.

Baker, T. (2010). Insurance in sociolegal research. Annual Review of Law and Social Science, 6, 433-447.

Baker, T., \& Griffith, S. J. (2007). The missing control in corporate governance: the directors' \& officers' liability insurer. The Georgetown Law Journal, 95, 17951842 .

Baker, T., \& Griffith, S. J. (2011). Ensuring Corporate Misconduct. How Liability Insurance Undermines Shareholder Litigation. Chicago/London: The University of Chicago Press.

Baker, T., \& McElrath, K. (1996). Whose safety net? Home insurance and inequality. Law \& Social Inquiry, 21(2), 229-264.

Baker, T., \& McElrath, K. (1997). Insurance claims discrimination. In G. D. Squires (Ed.), Insurance Redlining. Disinvestment, Reinvestment, and the Evolving Role of Financial Institutions. Washington (DC): The Urban Institute Press, pp. 141156.

Barrow, C. W. (1993). Critical Theories of the State. Marxist, Neo-Marxist, PostMarxist. Madison: The University of Wisconsin Press. 
Barrow, C. W. (2002). The Miliband-Poulantzas Debate: an Intellectual History. In S. Aronowitz \& P. Bratsis (Eds.), Paradigm Lost: State Theory Reconsidered. Minneapolis: University of Minnesota Press, pp. 17-52.

Beck, U. (1992a). From industrial society to the risk society: questions of survival, social structure and ecological Enlightenment. Theory, Culture \& Society, 97(9), 97123.

Beck, U. (1992b). Risk Society. Towards a New Modernity. London/Thousand Oaks/New Delhi/Singapore: Sage Publications.

Beck, U. (2002). The terrorist threat: world risk society revisited. Theory, Culture \& Society, 19(4), 39-55.

Beck, U. (2006). Power in the Global Age. A New Global Political Economy. Cambridge: Polity Press.

Beck, U. (2009). World at Risk. Cambridge: Polity Press.

Benefits Canada. (2015). Face to Face in Drug Plan Management - Research results. Survey results presented at the Face to Face Drug Plan Management Conference, Toronto. Retrieved August 18, 2016, from http://www.benefitscanada.com/benefits/other/2015-face-to-face-drug-planmanagement-conference-coverage-75502

Bensa, E. (1897). Histoire du contrat d'assurance au Moyen Âge. Paris: Albert Fontemoing.

Bernstein, P. L. (1996). Against the Gods. The Remarkable Story of Risk. New York: John Wiley \& Sons, Inc.

Berty, D. (2015). Session 3: Canadian Drug Insurance Pooling Corporation (CDIPC). Presented at the The Society of Actuaries: 2015 Canadian Health Seminar, St. Andrew's Club \& Conference Center, Toronto, April. Retrieved August 18, 2016, from https://www.soa.org/Files/Pd/2015/canadian-health-seminar/2015-canadianhealth-session-3.pdf

Berty, D. (2016). CDIPC Overview For Benefits 3 Conference. Presented at the Benefits3 Medavie Blue Cross Conference, Moncton, April. Retrieved August 18, 2016, from http://046vip.net/session-7-9yHhw

Black, F., \& Scholes, M. (1973). The pricing of options and corporate liabilities. Journal of Political Economy, 81(3), 637-654.

Blanchard, O. (2008). Neoclassical synthesis. In S. N. Durlauf \& L. E. Blume (Eds.), The New Palgrave Dictionary of Economics (Second), pp. 896-899.

Block, F. L. (2001). Introduction. In K. Polanyi, The Great Transformation. The Political and Economic Origins of Our Time. Boston: Beacon Press, pp. xviii-xxxviii.

Block, F. L., \& Keller, M. R. (2011). State of Innovation. The U.S. Government's Role in Technology Development. Boulder, CO: Paradigm Publishers.

Block, F. L., \& Somers, M. R. (2014). The Power of Market Fundamentalism. Karl Polanyi's critique. Cambridge, Massachusetts: Harvard University Press.

Boiteux, L.-A. (1968). La fortune de mer. Le besoin de sécurité et les débuts de l'assurance maritime. Paris: SEVPEN.

Bonnett, C. (2010). Does Private Insurance Protect Canadians From The Cost of Cancer Drugs? (Report Card on Cancer in Canada: Insurance) (pp. 14-18). Toronto: Cancer Advocacy Coalition of Canada. Retrieved August 18, 2016, from http://www.canceradvocacy.ca/reportcard/2009/pdf/Does\%20Private\%20Insuranc 
e\%20Protect $\% 20$ Canadians $\% 20$ from $\% 20$ the $\% 20$ Cost $\% 20$ of $\% 20$ Cancer $\% 20$ Drug s\%20-\%20Chris\%20Bonnett.pdf

Boothe, K. (2015). Ideas and the Pace of Change. National Pharmaceutical Insurance in Canada, Australia, and the United Kingdom. Toronto: University of Toronto Press.

Borscheid, P. (2012). Introduction. In P. Borscheid \& N. V. Haueter (Eds.), World Insurance: The Evolution of a Global Risk Network. Oxford: Oxford University Press, pp. 1-34.

Borscheid, P., \& Haueter, N. V. (2012). World Insurance: The Evolution of a Global Risk Network. Oxford: Oxford University Press.

Bougen, P. D. (2003). Catastrophic risk. Economy and Society, 32(2), 253-274.

Bougen, P. D. (2009). Governing alongside the specter of risk society: legislating US terrorism risk insurance, 2001-2007. The Open Law Journal, (2), 33-41.

Bourdieu, P. (2000). Les structures sociales de l'économie. Paris: Éditions du Seuil.

Boyer, R. (2003). Les institutions dans la théorie de la régulation. Cahiers D'économie Politique, (44), 79-101.

Boyer, R. (2004). Théorie de la régulation: 1. Les fondamentaux. Paris: La Découverte.

Brewer, E. I., Mondschean, T. S., \& Strahan, P. E. (1997). The role of monitoring in reducing the moral hazard problem associated with government guarantees: evidence from the life insurance industry. The Journal of Risk and Insurance, 64(2), 301-322.

Brisset, N. (2012). Deux approaches de l'influence du discours économique sur les phénomènes sociaux. Revue de Philosophie Économique, 13(2), 25-62.

Brisset, N. (2014). Performer par le dispositif? Un retour critique sur la théorie de la performativité. L'Année Sociologique, 64(1), 217-246.

Burawoy, M. (2003). For a sociological Marxism: the complementary convergence of Antonio Gramsci and Karl Polanyi. Politics and Society, 31(2), 193-261.

Burchell, G., Gordon, C., \& Miller, P. (1991). The Foucault Effect. Studies in Governmentality. Chicago: University of Chicago Press.

Busby, C., \& Pedde, J. (2015). Should public drug plans be based on age or income? (No. 417). C.D. How Institute. Retrieved from http://site.ebrary.com/id/11009493

Butler, M., \& Tiedemann, M. (2011). The Federal Role in Health and Health Care (In Brief No. 2011-91-E), Ottawa: Library of Parliament (Legal and Social Affairs Division/Parliamentary Information and Research Service), $5 \mathrm{p}$.

CACC. (2013, 2014). Sponsors/Partners. Retrieved July 11, 2016, from http://www.canceradvocacy.ca/partners.html

Caillé, A. (2009). Anti-utilitarisme et sociologie économique. In P. Steiner \& F. Vatin (Eds.), Traité de sociologie économique. Paris: Presses Universitaires de France, pp. 89-130.

Callon, M. (1998a). Introduction: the embeddedness of economic markets in economics. In The Laws of the Market. Oxford/Malden, MA: Blackwell Publishers/Sociological Review, pp. 1-57.

Callon, M. (Ed.). (1998b). The Laws of the Markets. Oxford/Malden, MA: Blackwell Publishers/Sociological Review.

Callon, M., \& Latour, B. (1991). La science telle qu'elle se fait. Anthologie de la sociologie des sciences de langue anglaise. Paris: La Découverte. 
Callon, M., Millo, Y., \& Muniesa, F. (Eds.). (2007). Market Devices. Malden, MA: Wiley-Blackwell.

Canadian Museum of History. (unknown). Canadian Life Insurance Officers Association. Retrieved July 5, 2016, from http://www.historymuseum.ca/cmc/exhibitions/hist/medicare/medic-3k03e.shtml

Cangiani, M., \& Maucourant, J. (2008). Introduction. In K. Poalnyi, M. Cangiani \& J. Maucourant (Eds.), Essais de Karl Polanyi, Paris: Éditions du Seuil, pp. 9-46.

Carpenter, D. P., \& Moss, D. A. (Eds.). (2014). Preventing Regulatory Capture: Special Interest Influence and How to Limit It. New York: Cambridge University Press.

Carruthers, B. G. (1996). City of Capital: Politics and Markets in the English Financial Revolution. Princeton: Princeton University Press.

Carter, B. (2014, February 10). Head to head: comparing ASO to fully insured plans. Retrieved July 20, 2016, from http://www.benefitscanada.com/benefits/healthbenefits/head-to-head-comparing-aso-to-fully-insured-plans-49318

Ceccarelli, G. (2001). Risky business: theological and canonical thought on insurance from the thirteenth to the seventeenth century. Journal of Medieval and Early Modern Studies, 31(2), 607-658.

Chan, C. S. (2012a). Culture, state, and varieties of capitalism: a comparative study of life insurance markets in Hong Kong and Taiwan. British Journal of Sociology, 63(1), 97-122.

Chan, C. S. (2012b). Marketing Death. Culture and the Making of a Life Insurance Market in China. New York: Oxford University Press.

Charbonneau, M. (2009). Le Methodenstreit: plus qu'un "conflit de méthodes." Centre D'études Sur L'intégration et La Mondialisation (CEIM), 1(4). Retrieved November 4, 2013, from http://www.ieim.uqam.ca/IMG/pdf/MethodenstreitCEIM-revision1-MCharbonneau.pdf

Charbonneau, M. (2011). La théorie de la société du risque à l'épreuve de l'économie politique de l'assurance: état des lieux du débat sociologique autour du principe d'inassurabilité privée chez Ulrich Beck (Master's Thesis). Université du Québec à Montréal, Montréal.

Chavance, B. (2009). Institutional Economics. London/New York: Routledge.

CIA. (2010). Educational Note: Valuation of Group Life and Health Policy Liabilities. Canadian Institute of Actuaries, (ommittee on Life Insurance Financial Reporting No. 210034, 56 p., Retrieved August 18, 2016, from http://www.actuaries.ca/members/publications/2010/210034e.pdf

CIHI. (2012). Drivers of Prescription Drug Spending in Canada (Spending and Health Workforce) (p. 40). Ottawa: Canadian Institute for Health Information.

CIHI. (2014). National Health Expenditure Trends, 1975 to 2014. Canadian Institute for Health Information.

CIHI. (2015). Prescribed Drug Spending in Canada, 2013: A Focus on Public Drug Programs. Ottawa: Canadian Institute for Health Information. Retrieved August 18, 2016, from http://www.deslibris.ca/ID/247858

Cioffi, J. W. (2010). Public Law and Private Power. Corporate Governance Reform in the Age of Finance Capitalism. Ithaca/London: Cornell University Press.

Clark, G. (1999). Betting on Lives. The Culture of Life Insurance in England, 1695-1775. Manchester: Manchester University Press. 
Clark, G. (2002). Embracing fatality through life insurance in eighteenth-century England. In T. Baker \& J. Simon (Eds.), Embracing Risk. Chicago: The University of Chicago Press, pp. 80-96.

Clark, G. (2010). The slave's appeal: insurance and the rise of commercial property. In G. Clark, G. Anderson, C. Thomann, \& J. M. Graft Von Der Schulenburg (Eds.), The Appeal of Insurance. Toronto: The University of Toronto Press, pp. 52-74.

Clark, J. B. (1892). Insurance and business profit. The Quarterly Journal of Economics, $7(1), 40-54$.

CLHIA. (unknown). About CLHIA - Mission and Objectives. Retrieved July 5, 2016, from

https://www.clhia.ca/domino/html/clhia/CLHIA_LP4W_LND_Webstation.nsf/pa ge/6EBFE54D9D076C568525780E0056B1BE?OpenDocument

CLHIA. (2012, April 3). News release: Canadian Life and health insurance industry launches industry initiative to protect Canadians' drug coverage. The Canadian Life and Health Insurance Association. Retrieved April 8, 2016, from https://www.clhia.ca/domino/html/clhia/CLHIA_LP4W_LND_Webstation.nsf/pa ge/B573ED1EB3CE940685257EAC0065911C/\$file/News_Release_drug_covera ge.pdf

CLHIA. (2013a). CLHIA report on prescription drug policy. Ensuring the accessibility, affordability and sustainability of prescription drugs in Canada. Toronto/Montreal/Ottawa: The Canadian Life and Health Insurance Association, 39 p. Retrieved April 8, 2016, from http://clhia.uberflip.com/i/406567-clhiareport-on-prescription-drug-policy

CLHIA. (2013b). Guideline G4 - Coordination of benefits: group health and dental. The Canadian Life and Health Insurance Association. Retrieved April 8, 2016, from https://www.clhia.ca/domino/html/clhia/CLHIA_LP4W_LND_Webstation.nsf/res ources/Guidelines/\$file/Guideline_G4.pdf

CLHIA. (2013c). Guideline G17 - Coordination of benefits for out-of-country/out-ofprovince/territory medical expenses. The Canadian Life and Health Insurance Association. Retrieved April 8, 2016, from https://www.clhia.ca/domino/html/clhia/CLHIA_LP4W_LND_Webstation.nsf/res ources/Guidelines/\$file/Guideline_G17.pdf

CLHIA. (2015a). A guide to the coordination of benefits. The Canadian Life and Health Insurance Association. Retrieved April 8, 2016, from http://clhia.uberflip.com/i/199338-a-guide-to-the-coordination-of-benefits

CLHIA. (2015b). Canadian Life and Health Insurance Facts, 2015 Edition. Toronto: The Canadian Life and Health Insurance Association.

Coase, R. H. (1937). The nature of the firm. Economica, 4(16), 386-405.

Cockerell, H. (1984). Lloyd's of London. A Portrait. Cambridge (UK): WoodheadFaulkner.

Cohen, A., \& Siegelman, P. (2010). Testing for adverse selection in insurance markets. Journal of Risk and Insurance, 77(1), 39-84.

Collier, R. (2011). Bye, bye blockbusters, hello niche busters. Canadian Medical Association Journal, 183(11), E697-E698.

Commons, J. R. (1921). VI. Health program. In J. R. Commons (Ed.), Trade Unionism and Labor Problems. Boston: Ginn and Company, pp. 81-93. 
Cotterrell, R. (2013). Rethinking "embeddedness": law, economy, community. In D. Ashiagbor, P. Kotiswaran, \& A. Perry-Kessaris, Towards an Economic Sociology of Law. Malden/Oxford: Wiley-Blackwell, pp. 49-67.

Coughlin \& Associates Ltd. (2013). Private drug plans "not sustainable," Great-West Life executive says. Retrieved August 13, 2016, from http://www.coughlin.ca/en/news.aspx?id=101

Courbage, C., \& Liedtke, P. M. (2003). On insurability, its limits and extensions. Insurance Research and Practice, 18(2). Retrieved November 7, 2011, from http://www.nottingham.ac.uk/business/cris/ukec/2002paper7.pdf

Crompton, R. (1979). Trade unionism and the insurance clerk. Sociology, 13, 403-426.

Cummins, J. D., \& Venard, B. (Eds.). (2007). Handbook of International Insurance. Between Global Dynamics and Local Contingencies. New York: Springer.

Daston, L. J. (1987). The domestication of risk: mathematical probability and insurance, 1650-1830. In L. Kruger, L. J. Daston, \& M. Heidelberger (Eds.), The Probabilistic Revolution. Cambridge (MA.): The MIT Press, pp. 237-260.

Daston, L. J. (1988). Classical Probability in the Enlightenment. Princeton: Princeton University Press.

Daw, J. R., \& Morgan, S. G. (2012). Stitching the gaps in the Canadian public drug coverage patchwork? A review of provincial pharmacare policy changes from 2000 to 2010. Health Policy, 104(1), 19-26.

De Donder, P., \& Hindriks, J. (2009). Adverse selection, moral hazard and propitious selection. Journal of Risk and Uncertainty, 38(1), 73-86.

De Goede, M. (2005). Virtue, Fortune, and Faith. A Genealogy of Finance. Minneapolis: University of Minnesota Press.

De Roover, F. E. (1945). Early examples of marine insurance. The Journal of Economic History, 5(3), 172-200.

Dean, M. (1999). Governmentality. Power and Rule in Modern Society. London: Sage Publications.

Demers, V., Melo, M., Jackevicius, C., Cox, J., Kalavrouziotis, D., Rinfret, S., ... Pilote, L. (2008). Comparison of provincial prescription drug plans and the impact on patients' annual drug expenditures. Canadian Medical Association Journal, $178(4), 405-409$.

Desrosières, A. (1993). La politique des grands nombres. Histoire de la raison statistique. Paris: La Découverte.

Dews, P. (2007). Logics of Disintegration: Poststructuralist Thought and the Claims of Critical Theory. London/New York: Verso.

Didry, C. (1990). De l'État aux groupes professionnels: les itinéraires croisés de L. Duguit et É. Durkheim au tournant du siècle (1880-1900). Genèses, 2, 5-27.

Dockès, P. (2007). Les deux faces de l'esprit du capitalisme et leur crise. Le Cercle des économistes, pp. 241-253. Retrieved April 3, 2015, from http://www.lecercledeseconomistes.asso.fr/IMG/pdf/Actes2007.pdf

Dolgin, E. (2010). Big pharma moves from "blockbusters" to "niche busters." Nature Medicine, 16, 837.

Dostaler, G. (2005). Keynes et ses combats. Paris: Albin Michel. 
Doyle, A., \& Ericson, R. V. (2010). Five ironies of insurance. In G. Clark, G. Anderson, C. Thomann, \& J. M. Graft Von Der Schulenburg (Eds.), The Appeal of Insurance. Toronto: University of Toronto Press, pp. 226-247.

Dupuy, J.-P. (2002). Pour un catastrophisme éclairé. Quand l'impossible est certain. Paris: Éditions du Seuil.

Durkheim, É. (1893). De la division du travail social. Paris: Presses Universitaires de France.

Durkheim, É. (1894). Les règles de la méthode sociologique. Paris: Presses Universitaires de France.

Durkheim, É. (1911). Jugements de valeur et jugement de réalité. Revue de Métaphysique et de Morale, XIX, 437-453.

Ehrlich, I., \& Becker, G. S. (1972). Market insurance, self-insurance and self-protection. Journal of Political Economy, 80(4), 623-648.

EKOS. (2013, May 22). Canadian view on prescription drug coverage. Retrieved July 9, 2016, from http://www.ekospolitics.com/index.php/2013/05/canadian-views-onprescription-drug-coverage/

Emerson, D. (2010). No Hope for a Universal Catastrophic Drug Plan? (Report Card on Cancer in Canada: Catastrophic Drug Coverage). Toronto: Cancer Advocacy Coalition of Canada, p. 20.

Empire Life. (2014). Healthcare pooling. Product guide for fully insured and ASO extended healthcare benefit policies. The Empire Life Insurance Company. Retrieved August 18, 2016, from http://www.empire.ca/docs/pdf/G-0080HealthcarePoolingProductGuide-EN-web.pdf

Empire Life. (2015). Prior authorization drug program: protecting employees' health and the health of your drug plan - A guide for benefit plan administrators. The Empire Life Insurance Company. Retrieved August 18, 2016, from http://www.empire.ca/docs/pdf/GRP-1027-PBM-PriorAuthorization-BRO-webEN.pdf

Epstein, R. A. (1985). Products liability as an insurance market. The Journal of Legal Studies, 14(3), 645-669.

Ericson, R. V., Barry, D., \& Doyle, A. (2000). The moral hazards of neo-liberalism: lessons from the private insurance industry. Economy and Society, 29(4), 532-58.

Ericson, R. V., \& Doyle, A. (2003). Risk and Morality. Toronto: University of Toronto Press.

Ericson, R. V., \& Doyle, A. (2004a). Catastrophe risk, insurance and terrorism. Economy and Society, 33(3), 135-173.

Ericson, R. V., \& Doyle, A. (2004b). Criminalization in private: the case of insurance fraud. In Law Commission of Canada (Ed.), What is a Crime? Defining Criminal Conduct in Contemporary Society. Vancouver: UBC Press, pp. 99-124.

Ericson, R. V., \& Doyle, A. (2004c). Risk, Insurance, and the Limits of Knowledge. Toronto: University of Toronto Press.

Ericson, R. V., \& Doyle, A. (2006). The institutionalization of deceptive sales in life insurance: five sources of moral risk. British Journal of Criminology, 46, 9931010.

Ericson, R. V., Doyle, A., \& Barry, D. (2003). Insurance as Governance. Toronto: Toronto University Press. 
Ewald, F. (1986). L'État providence. Paris: Grasset.

Ewald, F. (1991). Insurance and risk. In G. Burchell, C. Gordon, \& P. Miller (Eds.), The Foucault effect. Studies in governmentality. Chicago: The University of Chicago Press, pp. 197-211.

Express Scripts Canada. (2016). 2015 Drug Trend Report (Drug Trend) (p. 72). Express Scripts Canada. Retrieved October 18, 2016, from http://www.expressscripts.ca/knowledge-centre/drug-trend-reports

Farace, D. J., \& Schöpfel, J. (Eds.). (2010). Grey Literature in Library and Information Studies. Berlin; New York: De Gruyter Saur.

Federici, S. (2004). Caliban and the Witch: Women, The Body And Primitive Accumulation. New York: Autonomedia.

Fierlbeck, K. (2011). Health Care in Canada. A Citizen's Guide to Policy and Politics. Toronto: University of Toronto Press.

Finkelstein, A. (2014a). Moral Hazard in Health Insurance. New York: Columbia University Press.

Finkelstein, A. (2014b). Moral hazard in health insurance: developments since Arrow (1963). In A. Finkelstein, Moral Hazard in Health Insurance. New York: Columbia University Press.

Fligstein, N. (1990). The Transformation of Corporate Control. Cambridge: Harvard University Press.

Fligstein, N. (2001). The Architecture of Markets. An Economic Sociology of TwentyFirst-Century Capitalist Societies. Princeton and Oxford: Princeton University Press.

Fligstein, N., \& Dauter, L. (2007). The Sociology of Markets. Annual Review of Sociology, 33(1), 105-128.

Foucault, M. (1966). Les mots et les choses. Paris: Gallimard.

Foucault, M. (1969). L'archéologie du savoir. Paris: Gallimard.

Foucault, M. (1991). Governmentality. In G. Burchell, C. Gordon, \& P. Miller (Eds.), The Foucault Effect. Studies in Governmentality. Chicago: The University of Chicago Press, pp. 87-104.

Foucault, M. (1997). Il faut défendre la société. Cours au Collège de France, 1975-1976. Paris: Gallimard/Seuil.

Foucault, M. (2004a). Naissance de la biopolitique. Cours au Collège de France (19781979). Paris: Gallimard.

Foucault, M. (2004b). Sécurité, territoire, population. Cours au Collège de France (1977-1978). Paris: Gallimard.

Frank, S. (2012). Session/Séance: 10 - Large amount drug pooling mechanism and cost drivers. Annual meeting, Canadian Institute of Actuaries, June. Retrieved August 18, 2016, from http://www.actuaries.ca/meetings/annual/2012/presentations/Session_10_Frank.p df

Frank, S. (2014). Published letters - Correcting the record, April 16. Retrieved September 29, 2016, from http:/www.cmaj.ca/content/186/12/E470/reply

Fraser Group. (2013). Welcome to Fraser Group. Retrieved July 18, 2016, from http://frasergroup.com 
Fraser Group. (2016a). Group Universe Report: 2015 Data Year, Canada (p. 3). Fraser Group. Retrieved July 18, 2016, from http://www.frasergroup.com/assets/files/GUR-Public-Release-Canada.pdf

Fraser Group. (2016b). Group Universe Report: 2015 Data Year, Quebec (p. 3). Fraser Group. Retrieved July 18, 2016, from http://www.frasergroup.com/assets/files/GUR-Public-Release-Quebec.pdf

Frerichs, S. (2009). The legal constitution of market society: probing the economic sociology of law. Economic Sociology: The European Electronic Newsletter, $10(3), 20-25$.

Friedman, D. D. (1987). Law and economics. In The New Palgrave: A Dictionary of Economic Theory and Doctrine. New York: Macmillan.

Friedman, M. (1962). Capitalism and Freedom. Chicago: The University of Chicago Press.

Fulbrook, M. (1978). Max Weber's "interpretative sociology": a comparison of conception and practice. The British Journal of Sociology, 29(1), 71-82.

Gagnon, B. (2012). Health Benefits in Canada. In W. F. Bluhm (Ed.), Group Insurance. Sixth Edition. Winsted (CT): Actex Publications, Inc., pp. 91-109.

Gagnon, M.-A. (2007). Penser le capitalisme cognitif selon Thorstein Veblen: connaissance, pouvoir et capital. Interventions Économiques, (36).

Gagnon, M.-A. (2009). The Nature of Capital in the Knowledge-based Economy: The Case of the Global Pharmacentical Industry (PhD dissertation). York University, Toronto.

Gagnon, M.-A. (2012). Pharmacare and Federal Drug Expenditures: A Prescription for Change. In G. B. Doern \& Stoney (Eds.), How Ottawa Spends, 2012-2013. The Harper Majority, Budget Cuts and The New Opposition. Montréal/Kingston: McGill-Queen's University Press, pp. 161-172.

Gagnon, M.-A. (2014). A Roadmap to a Rational Pharmacare Policy in Canada. Ottawa: The Canadian Federation of Nurses Union.

Gagnon, M.-A. (2015). New drug pricing: does it make any sense? Prescrire International, 24(162), 192-195.

Gagnon, M.-A., \& Gold, R. E. (2011). Public Financial Support to the Canadian Brandname Pharmaceutical Sector: A Cost-Benefit Analysis (A Report for Health Canada). Ottawa: Health Canada.

Gagnon, M.-A., \& Hébert, G. (2010). The economic case for universal pharmacare. Costs and benefits of publicly funded drug coverage for all Canadians. Ottawa: Canadian Centre for Policy Alternatives/Institut de recherche et d'informations socio-économiques, 84 p. Retrieved July 18, 2016, from http://public.eblib.com/choice/publicfullrecord.aspx?p=3270885

Gallant, J. (2014). Toronto woman with rare disease fights province for life-saving but costly drug. Toronto Star. Toronto. Retrieved July 18, 2016, from https://www.thestar.com/news/gta/2014/12/04/toronto_woman_with_rare_disease fights_province_for_lifesaving_but_costly_drug.html

Gerst, E. D. (2008). Vulture Culture. Dirty Deals, Unpaid Claims and the Coming Collapse of the Insurance Industry. New York: American Management Association. 
Gibson, S. G., \& Lemmens, T. (2014). Niche markets and evidence assessment in transition: a critical review of proposed drug reforms. Medical Law Review, 22(2), 200-220.

Gislain, J.-J., \& Steiner, P. (1995). La sociologie économique, 1890-1920: Émile Durkheim, Vilfredo Pareto, Joseph Schumpeter, François Simiand, Thorstein Veblen et Max Weber. Paris: Presses Universitaires de France.

Glenn, B. J. (2000). The shifting rhetoric of insurance denial. Law and Society Review, 34(4), 779-808.

Goldman, D. P., Joyce, G. F., Lawless, G., Crown, W. H., \& Willey, V. (2006). Benefit design and specialty drug use. Health Affairs, 25(5), 1319-1331.

Government of Canada. (1964). Royal Commission on Health Services. Volume 1 (No. Z1-1961-1). Ottawa: Queen's Printer/Canadian Government.

Gowri, A. (1977). The Irony of Insurance: Community and Commodity (PhD dissertation). University of Southern California, Los Angeles.

Graeber, D. (2011). Debt: the first 5,000 years. New York: Melville House.

Grande, D. (2012). The cost of drug coupons. The Journal of the American Medical Association, 307(22).

Granovetter, M. (1973). The strength of weak ties. American Journal of Sociology, 78(6), 1360-1380.

Granovetter, M. (1985). Economic action and social structure: the problem of embeddedness. American Journal of Sociology, 91(3), 481-510.

Great-West Life. (unknowna). DrugSolutions. Retrieved August 18, 2016, from http://www.greatwestlife.com/001/Home/Group_Products/Group_Benefits/Health

Dental_Benefits/Health_Benefits/Prescription_Drug_Benefits/s7_029157

Great-West Life. (unknownb). Group Benefits. The Great-West Life Assurance Company (*corporate brochure available on demand). Retrieved August 18, 2016, from http://www.greatwestlife.com/001/Contact_Us/index.htm

Great-West Life. (unknownc). Prior authorization, pharmacy and health case management information (corporate form). The Great-West Life Assurance Company. Retrieved August 18, 2016, from https://www.lagreatwest.com/web5/groups/group/@public/documents/web_conte nt/s7_012165.pdf

Greenberg, J., Knight, G., \& Westersund, E. (2011). Spinning climate change: corporate and NGO public relations strategies in Canada and the United States. International Communication Gazette, 73(1), 65-82.

Greenberg, M. R., \& Cunningham, L. A. (2013). The AIG Story. Hoboken (NJ): John Wiley \& Sons, Inc.

Grenier, J.-Y., \& Orléan, A. (2007). Michel Foucault, l'économie politique et le libéralisme. Annales. Histoire, Sciences Sociales, 62nd year(5), 1155-1182.

Grootendorst, P. (2002). Beneficiary cost sharing under Canadian provincial prescription drug benefit programs: history and assessment. The Canadian Journal of Clinical Pharmacology, 9(2), 79-99.

Gustein, D. (2009). Not a Conspiracy. How Business Propaganda Hijacks Democracy. Key Porter Books. 
Hacker, J. S. (1998). The historical logic of national health insurance: structure and sequence in the development of British, Canadian and U.S. medical policy. Studies in American Political Development, 12(Spring 1998), 57-130.

Hacker, J. S. (2006). The Great Risk Shift. The Assault on American Jobs, Families, Health Care, and Retirement and How You Can Fight Back. Oxford: Oxford University Press.

Hacking, I. (1975). The Emergence of Probability. Cambridge: Cambridge University Press.

Hacking, I. (1990). The Taming of Chance. Cambridge: Cambridge University Press.

Haggerty, K., Doyle, A., \& Chan, J. (Eds.). (2011). Crime, Institutional Knowledge and Power: The Rich Criminological Legacy of Richard Ericson. Farnham (UK): Ashgate.

Hall, P. A., \& Soskice, D. (2001). Varieties of Capitalism. The Institutional Foundations of Comparative Advantage. Oxford: Oxford University Press.

Harris, R. (1994). The Bubble Act: its passage and its effects on business organization. The Journal of Economic History, 54(3), 610-627.

Hatchuel, A., Pezet, É., Starrkey, K., \& Lenay, O. (Eds.). (2005). Gouvernement, organisation et gestion. L'héritage de Michel Foucault. Sainte-Foy: Presses de l'Université Laval.

Hayek, F. A. (1944). The Road to Serfdom. Chicago: The University of Chicago Press.

Hayek, F. A. (1960). The Constitution of Liberty. Chicago: The University of Chicago Press.

Hayek, F. A. (1988). The Fatal Conceit. The Errors of Socialism. (W. W. Bartley III, Ed.) (Vol. 1). Chicago: University of Chicago Press.

Haynes, J. (1895). Risk as an economic factor. Quarterly Journal of Economics, 9(4), 409-449.

Health Canada. (2011). Canada's Health Care System (Reports and Publications). Ottawa: Health Canada. Retrieved August 18, 2016, from http://www.hcsc.gc.ca/hcs-sss/pubs/system-regime/2011-hcs-sss/index-eng.php

Heimer, C. A. (1982). The racial and organizational origins of insurance redlining. Journal of Intergroup Relations, 10, 42-60.

Heimer, C. A. (1985). Reactive Risk and Rational Action. Managing Moral Hazard in Insurance Contracts. Berkeley: University of California Press.

Hoffman, F. L. (1896). Race Traits and Tendencies of The American Negro. New York: American Economic Association/Macmillan.

Holdsworth, W. S. (1917). The early history of the contract of insurance. Columbia Law Review, 17(2), 85-113.

Holmstrom, B. (1979). Moral hazard and observability. The Bell Journal of Economics (The RAND Corporation), 10(1), 74-91.

Hoover, C. B. (1926). The sea loan in Genoa in the twelfth century. The Quarterly Journal of Economics, 40(3), 495-529.

Horan, C. D. (2011). Actuarial Age: Insurance and the Emergence of Neoliberalism in the Postwar United States (PhD dissertation). University of Minnesota.

Hughes, E. C. (1930). Book review: Capital and Finance in the Age of the Renaissance, a Study of the Fuggers and Their Connections. Richard Ehrenberg, H. M. Lucas; A History of Lloyd's, From the Founding of Lloyd's Coffee House to the Present 
Day Charles Wright, C. Ernest Fayle; The Sociology of Life Insurance. Edward A. Woods. American Journal of Sociology, 35(4), 655.

Hunt, A. (1993). Explorations in Law and Society. Towards a Constitutive Theory of Law. New York: Routledge.

Hurley, J., \& Guindon, G. E. (2008). Private health insurance in Canada. CHEPA Working Paper Series (McMaster University), (8-4), 38.

Immergut, E. M. (1992). The rules of the game: The logic of health policy-making in France, Switzerland, and Sweden. In S. Steinmo, K. Thelen, \& F. Longstreth (Eds.), Structuring politics (pp. 57-89). Cambridge: Cambridge University Press.

Investment Guild. (2013). Be aware of drug co-pay cards/coupons. Investment Guild (Toronto, Ontario), March 18. Retrieved August 18, 2016, from http://www.canadanursery.com/Storage/52/6266_Drug_Co-Pay_Cards_Coupons_(March_2013)-1.pdf

Jackman, M. (1995). The regulation of private health care under the Canada Health Act and the Canadian charter. Constitutional Forum, 6(2), 54-60.

Jessop, B. (2007a). Dialogue of the deaf: reflections on the Poulantzas-Miliband debate. In P. Wetherly, C. W. Barrow, \& P. Burnham (Eds.), Class, Power and the State in Capitalist Society: Essays on Ralph Miliband. Basingstoke: Palgrave, pp. 132157.

Jessop, B. (2007b). Knowledge as a fictitious commodity: insights and limits of a Polanyian perspective. In A. Buğra \& K. Ağartan (Eds.), Reading Karl Polanyi for The Twenty-First Century. Market Economy as a Political Project (pp. 115134). New York: Palgrave Macmillan.

Joly, Y., Braker, M., \& Le Huynh, M. (2010). Genetic discrimination in private insurance: global perspectives. New Genetics and Society, 29(4), 351-368.

Kaplan, M., \& Kaplan, E. (2006). Chances Are... Adventures in Probability. New York: Viking Books.

Kapur, V., \& Basu, K. (2005). Drug coverage in Canada: who is at risk? Health Policy, 71(2), 181-193.

Karagyozova, T., \& Siegelman, P. (2012). Can propitious selection stabilize insurance markets? Journal of Insurance Issues, 35(2), 121-158.

Keucheyan, R. (2007). Le constructivisme. Des origines à nos jours. Paris: Hermann.

Keynes, J. M. (1921). A Treatise on Probability. London: Macmillan.

Keynes, J. M. (1936). The General Theory of Employment, Interest and Money. London: Macmillan.

Keynes, J. M. (1937). The general theory of employment. The Quarterly Journal of Economics, 51(2), 209-223.

Kim, J. (2013). Modern politics as a trust scheme and its relevance to modern banking. Journal of Economic Issues, 47(4), 807-826.

Kim, Y. A., Rascati, K. L., Prasla, K., Godley, P., Goel, N., \& Dunlop, D. (2011). Retrospective Evaluation of the Impact of Copayment Increases for Specialty Medications on Adherence and Persistence in an Integrated Health Maintenance Organization System. Clinical Therapeutics, 33(5), 598-607.

Kindleberger, C. P., \& Aliber, R. Z. (2011). Manias, Panics, and Crashes. A History of Financial Crises. Hampshire/New York: Palgrave Macmillan. 
Kingston, C. (2007). Marine insurance in Britain and America, 1720-1844. Journal of Economic History, 67(2), 379-409.

Knafo, S. (2008). The state and the rise of speculative finance in England. Economy and Society, 37(2), 172-192.

Knight, F. H. (1921). Risk, Uncertainty and Profit. Boston/New York: A.M. Kelley.

Kopf, E. W. (1929). Notes on the origin and development of reinsurance. Proceedings of the Casualty Actuarial Society, 16(33-34), 22-92.

Kratzer, J., McGrail, K., Strumpf, E., \& Law, M. R. (2013). Cost-control mechanisms in Canadian private drug plans. Healthcare Policy, 9(1), 35-43.

Kreitner, R. (2000). Speculations of contract, or how contract law stopped worrying and learned to love risk. Columbia Law Review, 100(4), 1096-1138.

Krikler, J. (2007). The Zong and the Lord Chief Justice. History Workshop Journal, 64(1), 29-47.

Krippner, G., Granovetter, M., Block, F., Biggart, N., Beamish, T., Hsing, Y., ... O'Riain, S. (2004). Polanyi Symposium: a conversation on embeddedness. SocioEconomic Review, 2(1), 109-135.

Krippner, G. R. (2001). The elusive market: embeddedness and the paradigm of economic sociology. Theory and Society, 30, 775-810.

Krugman, P. (2009). The Return of Depression Economics and the Crisis of 2008. New York/London: W. W. Norton \& Company.

Lacher, H. (1999a). Embedded liberalism, disembedded markets: reconceptualizing the Pax Americana. New Political Economy, 4(3), 343-360.

Lacher, H. (1999b). The politics of the market: re-reading Karl Polanyi. Global Society, 13(3), 313-326.

Lacher, H. (2007). The slight transformation: contesting the legacy of Karl Polanyi. In A. Buğra \& K. Ağartan (Eds.), Reading Karl Polanyi for the Twenty-First Century. Market Economy as a Political Project. Palgrave MacMillan: New York, pp. 4964.

Lafontaine, C. (2004). L'empire cybernétique. Des machines à penser à la pensée machine. Paris: Éditions du Seuil.

Lander, J., \& Van Hoyweghen, I. (2014). Streitkultur and the governance of genetic testing and insurance in Germany. New Genetics and Society, 33(1), 42-59.

Latour, B. (1991). Nous n'avons jamais été modernes. Essai d'anthropologie symétrique. Paris: La Découverte.

Laville, J.-L. (2009). Services aux personnes: le rôle des associations. In P. Steiner \& F. Vatin (Eds.), Traité de sociologie économique. Paris: Presses Universitaires de France, pp. 411-449.

Lavoie, M. (1985). La distinction entre l'incertitude keynésienne et le risque néoclassique. Économie Appliquée, 37(2), 493-518.

Law, M. R., Cheng, L., Dhalla, I. A., Heard, D., \& Morgan, S. G. (2012). The effect of cost on adherence to prescription medications in Canada. Canadian Medical Association Journal, 184(3), 297-302.

Law, M. R., Daw, J. R., Cheng, L., \& Morgan, S. G. (2013). Growth in private payments for health care by Canadian households. Health Policy, 110(2-3), 141-146. 
Law, M. R., Kratzer, J., \& Dhalla, I. A. (2014). The increasing inefficiency of private health insurance in Canada. Canadian Medical Association Journal, (Early release), 1-5.

Lawrence, A., Houghton, J., \& Thomas, J. (2014). Where is the evidence: realising the value of grey literature for public policy and practice. Swinburn Institute for Social Research.

Le Goff, J. (1982). Time, Work, and Culture in the Middle Ages. London: University of Chicago Press.

Leaver, A. (2015). Fuzzy knowledge: an historical exploration of moral hazard and its variability. Economy and Society, 44(1), 91-109.

Lee, F. S. (2009). A History of Heterodox Economics: Challenging the Mainstream in the Twentieth Century. London; New York: Routledge.

Lehtonen, T.-K. (2014). Picturing how life insurance matters. Journal of Cultural Economy, 7(3), 308-333.

Lehtonen, T.-K., \& Liukko, J. (2011). The forms and limits of Insurance solidarity. Journal of Business Ethics, 103, 33-44.

Lepage, S. (2016, May). High Cost Drug Bootcamp: Everything You Need to Know. Presented at the Society of Actuaries 2016 Canadian Health Seminar - Session 5: High Cost Drug Boot Camp: Everything You Need to Know, St. Andrew's Club \& Conference Center, Toronto. Retrieved August 18, 2016, from https://www.telushealth.co/page/wpcontent/uploads/2015/03/telushealth_conference2015_01-john-anacleto.pdf.

Lévesque, B., Mendell, M., \& Rouzier, R. (2003). New forms of financing social economy entreprises and organizations in Québec. In The Non-Profit Sector in the 21st Century. A Stakeholder for Economy and Society. Paris: OECD, pp. 106130.

Lexchin, J. (2015). Drug pricing in Canada. In Z.-U.-D. Babar (Ed.), Pharmaceutical Prices in the 21st Century. Cham: Springer International Publishing, pp. 25-41.

Light, D. W., \& Lexchin, J. R. (2012). Pharmaceutical research and development: what do we get for all that money? BMJ, 345, e4348-e4348.

Lloyd's of London. (unknown). Corporate history. Retrieved January 24, 2014, from http://www.lloyds.com/lloyds/about-us/history/corporate-history

Lobo-Guerrero, L. (2011). Insuring Security. Biopolitics, Security and Risk. London/New York: Routledge.

Lobo-Guerrero, L. (2012). Insuring War. Sovereignty, Security and Risk. London/New York: Routledge.

Lombardi, M. (2000). Demutualization in Canada: toward growth and international competitiveness. The Actuary, 34(1), 3-4.

Loshin, J. (2007). Insurance law's hapless busybody: a case against the insurable interest requirement. Yale Law Journal, 117(3), 474-486.

Luessenhop, E., \& Mayer, M. (1995). Risky Business. An Insider's Account of the Disaster at Lloyd's of London. New York.

Luhmann, N. (1991). Risk. A Sociological Theory. New Brunswick: Aldine Transaction.

Mabbett, D. (2015). Polanyi in the European single market: the re-regulation of insurance. Economic Sociology: The European Electronic Newsletter, 17(1), 2531 . 
MacKenzie, D. A., Muniesa, F., \& Siu, L. (2007). Do Economists Make Markets? On the Performativity of Economics. Princeton: Princeton University Press.

Maioni, A. (1998). Parting at the Crossroads: the Emergence of Health Insurance in the United States and Canada. Princeton (NJ): Princeton University Press.

Manulife. (unknown). Specialty Drug Care - case management services are coming to Quebec. Retrieved August 18, 2016, from http://tinyurl.com/hdmx7hf

Manulife. (2015a). Introducing Manulife DrugWatch. Applying rigorous oversight to help ensure value for money in a dramatically changing drug market. The Manufacturers Life Insurance Company. Retrieved August 18, 2016, from http://pointbreakcg.com/wp-content/uploads/2015/09/DrugWatchBrochure_GC2690-E.pdf

Manulife. (2015b). Specialty drug care. Delivering savings and supporting healthier outcomes. The Manufacturers Life Insurance Company. Retrieved August 18, 2016, from https://www.manulife.ca/wps/wcm/connect/236c888a-57d1-4577a67b-

81bd692a3029/Specialty+Drug+Care+Plan+Sponsor+Brochure+GB3843E.pdf?M $\mathrm{OD}=\mathrm{AJPERES} \& C A C H E I D=236 \mathrm{c} 888 \mathrm{a}-57 \mathrm{~d} 1-4577-\mathrm{a} 67 \mathrm{~b}-81 \mathrm{bd692a3029}$

Marshall, A. (1920). Principles of Economics. London: Macmillan.

Marshall, J. M. (1976). Moral hazard. The American Economic Review, 66(5), 880-890.

Martin, F. (1876). The History of Lloyd's and of Marine Insurance in Great Britain with an Appendix Containing Statistics Relating to Marine Insurance. London: Macmillan and Co.

Martinez, B. (2012). Pharmaceutical Policy Research Collaboration, May 302012. Presented at the Canadian Association for Health Services and Policy Research Conference, Montréal, May. Retrieved August 18, 2016, from https://www.cahspr.ca/fr/presentation/52442cc337dee8ff49eea024

Marx, K. (1859). A Contribution to the Critique of Political Economy. Translated from the Second German Edition (1904). (N. I. Stone, Trans.). Chicago: Charles H. Kerr \& Company.

Marx, K. (1867). Capital. A Critique of Political Economy. (Vol. 1). Moscow: Progress Publishers.

Marx, K., \& Engels, F. (1848). Manifesto of the Communist Party. Moscow: Progress Publishers.

Maucourant, J. (1995). The substantive economy of money: Karl Polanyi in the tradition of the "old institutionalism." Working Paper Du Centre Walras, (177), 20 p.

Maucourant, J. (2005). Avez-vous lu Polanyi? Paris: La Dispute.

Maucourant, J., \& Plociniczak, S. (2013). The institution, the economy and the market: Karl Polanyi's institutional thought for economists. Review of Political Economy, 25(3), 512-531.

Mauss, M., \& Fauconnet, P. (1901). Sociologie. In M. Mauss, Oeuvres (Vol. 3). Paris: Presses Universitaires de France.

Maximum Benefits. (unknown). Administrative Services Only (ASO). Maximum Benefits (Winnipeg). Retrieved August 18, 2016, from http://www.maximumbenefit.ca/forms-categories/solutions/resources-1/216aso/file 
Mazzucato, M. (2013). The Entrepreneurial State. Debunking Public vs. Private Sector Myths. London/New York: Anthem Press.

McFall, L. (2009). The agencement of industrial branch life assurance. Journal of Cultural Economy, 2(1-2), 49-65.

McFall, L. (2015a). Devising Consumption. Cultural Economies of Insurance, Credit and Spending (First Edition). New York; London: Routledge, Taylor \& Francis Group.

McFall, L. (2015b). Is digital disruption the end of health insurance? Some thoughts on the devising of risk. Economic Sociology: The European Electronic Newsletter, $17(1), 32-44$.

Meiksins Wood, E. (1991). The Pristine Culture of Capitalism. An Essay on Old Regimes and Modern States. London: Verso.

Meiksins Wood, E. (2002). The Origins of Capitalism. A Longer View. London/New York: Verso.

Mendell, M., \& Neamtan, N. (2010). The social economy in Quebec: towards a new political economy. In Why the Social Economy Matters. Toronto: University of Toronto Press, pp. 32-58.

Menger, C. (1883). Investigations into the Method of the Social Sciences with Special Reference to Economics. (F. J. Nock, Trans.). New York/London: New York University Press.

Mercer. (unknown). Health and benefits - Employee benefits, consulting and brokerage. Retrieved August 16, 2016, from http://www.mercer.ca/en/what-we-do/healthand-benefits/employee-benefits.html

Merton, R. C. (1977). Analytical derivation of the cost of deposite insurance and loan guarantees: an application of modern option pricing theory. Journal of Banking and Finance, 1, 3-11.

Miliband, R. (1969). The State in Capitalist Society. London: Weidenfeld \& Nicolson.

Miller, P. (1986). Accounting for progress: national planning and budgeting in France. Accounting, Organizations and Society, 12(3), 235-265.

Miller, P. (1990). On the interrelations between accounting and the state. Accounting, Organizations and Society, 15(4), 315-338.

Miller, P. (1991). Accounting innovation beyond the enterprise: problematizing investment decisions and programming economic growth in the U.K. in the 1960s. Accounting, Organizations and Society, 16(8), 733-762.

Miller, P., Hopper, T., \& Laughlin, R. (1991). The new accounting history: an introduction. Accounting, Organizations and Society, 16(5-6), 395-403. https://doi.org/10.1016/0361-3682(91)90036-E

Miller, P., \& O'Leary, T. (1987). Accounting and the construction of the governable person. Accounting, Organizations and Society, 12(3), 235-265.

Miller, P., \& O'Leary, T. (1993). Accounting expertise and the politics of the product: economic citizenship and modes of corporate governance. Accounting, Organizations and Society, 18(2-3), 187-206.

Miller, P., \& Power, M. (1992). Accounting, law and economic calculation. In M. Bromwich \& A. G. Hopwood (Eds.), Accounting and the Law. New Jersey: Prentice Hall. 
Miller, P., \& Rose, N. (1990). Governing economic life. Economy and Society, 19(1), 131.

Miller, P., \& Rose, N. (2008). Governing The Present. Administering Economic, Social and Personal life. Cambridge: Polity Press.

Montalban, M., \& Sakinç, M. E. (2013). Financialization and productive models in the pharmaceutical industry. Industrial and Corporate Change, 22(4), 981-1030.

Morgan, S. G., Daw, J., Law, M., Abraham, L., \& Martin, D. (2015). Estimated cost of universal public coverage of prescription drugs in Canada. Canadian Medical Association Journal, (March 16 2015). Retrieved August 16, 2016, from http://www.cmaj.ca/site/press/cmaj.141564.pdf

Morgan, S. G., Martin, D., Gagnon, M.-A., Mintzes, B., Daw, J. R., \& Lexchin, J. (2015). Pharmacare 2020. The Future of Drug Coverage in Canada. Vancouver: The Pharmaceutical Policy Research Collaboration, University of British Columbia, $20 \mathrm{p}$.

Morgan, S., Grootendorst, P., Lexchin, J., Cunningham, C., \& Greyson, D. (2011). The cost of drug development: a systematic review. Health Policy, 100(1), 4-17.

Moss, D. A. (2002). When All Else Fails. Government as the Ultimate Risk Manager. Cambridge: Harvard University Press.

Moureau, N., \& Rivaud-Danset, D. (2004). L'incertitude dans les théories économiques. Paris: La Découverte.

Muniesa, F., \& Callon, M. (2009). La performativité des sciences économiques. In P. Steiner \& F. Vatin (Eds.), Traité de sociologie économique. Paris: Presses Universitaires de France, pp. 289-324.

Nau, H. H., \& Steiner, P. (2002). Schmoller, Durkheim, and old European institutionalist economics. Journal of Economic Issues, 36(4), 1005-1024.

Nitzan, J., \& Bichler, S. (2009). Capital as Power. A study in Order and Creorder. New York: Routledge.

Norel, P. (2004). L'invention du marché. Une histoire économique de la mondialisation. Paris: Éditions du Seuil.

North, D. C. (1990). Institutions, Institutional Change and Economic Performance. Cambridge: Cambridge University Press.

NPDUIS. (2016). Private drug plans in Canada: high-cost drugs and beneficiaries, 2005 to 2015. Ottawa: PMPRB/CIHI. Retrieved October 30, 2016, from http://www.pmprbcepmb.gc.ca/CMFiles/NPDUIS/2016_Conference_Posters/post_6_privhi.pdf

O’Brady, S., Gagnon, M.-A., \& Cassels, A. (2015). Reforming private drug coverage in Canada: inefficent drug benefit design and the barriers to change in unionized settings. Health Policy, 119(2), 224-31.

O'Hara, P. A. (2002). The contemporary relevance of Thorstein Veblen's institutionalevolutionary political economy. History of Economics Review, Winter 2002(35), 78-103.

O’Malley, P. (1991). Legal networks and domestic security. Studies in Law, Politics and Society, 171(11), 165-184.

O'Malley, P. (2003). Moral uncertainties: contract law and distinctions between speculation, gambling and insurance. In R. V. Ericson \& A. Doyle (Eds.), Risk and Morality. Toronto: University of Toronto Press, pp. 231-257. 
Orléan, A. (1999). Le pouvoir de la finance. Paris: Odile Jacob.

Orléan, A. (2004). L'économie des conventions: définitions et résultats. In A. Orléan (Ed.), Analyse économique des conventions (Second). Paris: PUF, pp. 9-48.

Orléan, A. (2005). La sociologie économique et la question de l'unité des sciences sociales. L'Année Sociologique, 55(2), 279-306.

Orléan, A. (2009). La sociologie économique de la monnaie. In P. Steiner \& F. Vatin (Eds.), Traité de sociologie économique. Paris: Presses Universitaires de France, pp. 209-246.

Ossandon, J. (2015). Insurance and the sociologies of markets. Economic Sociology: The European Electronic Newsletter, 17(1), 6-15.

Palmer, B. B. (1990). The eclipse of materialism: marxism and the writings of social history in the 1980's. The Socialist Register, 26, 111-146.

Panitch, L., \& Konings, M. (2009). Myths of neoliberal deregulation. New Left Review, 57(May-June), 69-83.

Parsons, T. (1937). The Structure of Social Action. New York: Macmillan.

Paton, J. (2010). Labour as a (fictitious) commodity: Polanyi and the capitalist "market economy." Economic and Labour Relations Review, 21(1), 77-87.

Patriarche, D. (2016, May). What's going on in small and mid-sized drug plans: a broker/client perspective. Presented at the Canadian Pension \& Benefits Institute, Canadian Pension \& Benefits Institute Conference, The Westin Ottawa Hotel, Ottawa, Canada. Retrieved from PDF file provided by the speaker.

Pauly, M. V. (1968). The economics of moral hazard: comment. The American Economic Review, 58(3), 531-537.

Pauly, M. V. (1974). Overinsurance and public provision of insurance: the roles of moral hazard and adverse selection. Quarterly Journal of Economics, 88(1), 44-62.

PCPA. (2016). Pan-Canadian Pharmaceutical Alliance: Completed Negotiations. As of August 31, 2016. Ottawa: The pan-Canadian Pharmaceutical Alliance/Council of the Federation Secretariat, 4 p. Retrieved October 15, 2016, from http://www.canadaspremiers.ca/phocadownload/pcpa/2016/pcpa_completed_nego tiations_august31_2016.pdf

PDCI Market Access Inc. (2016). Pharmacare Costing in Canada. Preliminary Report: Assessment of a National Pharmacare Model Cost Estimate Study. Commissioned by the Canadian Pharmacists Association (p. 33). Retrieved October 15, 2016, from http://www.pdci.ca/wp-content/uploads/2016/01/Pharmacare-PreliminaryReport-PDCI-January-2016.pdf

Pearson, R. (1990). Thrift or dissipation: the business of life insurance in the early nineteenth century. Economic History, 43(Journal Article), 236-254.

Pearson, R. (1993). Taking risks and containing competition: diversification and oligopoly in the fire insurance markets of the north of England in the early nineteenth century. Economic History Review, 46, 39-64.

Pearson, R. (1995). The development of reinsurance markets in Europe during the nineteenth century. Journal of European Economic History, 24(3), 557-572.

Pearson, R. (1997). Towards an historical model of services innovation: the case of the insurance industry, 1700-1914. Economic History Review, 2, 235-256.

Pearson, R. (2001). The birth of a global reinsurer: Swiss Re of Zurich, 1864-79. Financial History Review, 8(1), 27-47. 
Pearson, R. (2002a). Growth, crisis and change in the insurance industry: a retrospect. Accounting, Business and Financial History, 12(3), 1-18.

Pearson, R. (2002b). Moral hazard and the assessment of insurance in eighteenth- and early-nineteenth century Britain. Business History Review, 76(1), 1-35.

Pearson, R. (2002c). Shareholder democracies? English joint-stock companies and the politics of corporate governance during the Industrial Revolution. English Historical Review, (117), 840-866.

Pearson, R. (2004). Insuring the Industrial Revolution. Fire Insurance in Great Britain, 1700-1850. Aldershot (UK): Ashgate.

Pearson, R. (2010a). Fire, property insurance and perceptions of risk in eighteenthcentury Britain. In G. Clark, G. Anderson, C. Thomann, \& J. M. Graft Von Der Schulenburg (Eds.), The Appeal of Insurance. Toronto: University of Toronto Press, pp. 75-106.

Pearson, R. (Ed.). (2010b). The Development of International Insurance. London: Pickering \& Chatto Publishers.

Pearson, R. (2010c). The growth, organization, and diffusion of the British insurance industry. In Instituto de Ciencias del Seguro (Ed.), Encuentro International sobre la Historia del Seguro. Madrid: Fundacion Mapfre, pp. 13-42.

Pearson, R. (2010d). Working on the frontiers of risk: the insurance industry in NorthWest England since 1700. Manchester Region History Review, (21), 104-127.

Pearson, R. (2012). United Kingdom: pioneering insurance internationally. In P. Borscheid \& N. V. Haueter (Eds.), World Insurance: The Evolution of a Global Risk Network. Oxford: Oxford University Press, pp. 67-97.

Pearson, R., \& Lonnborg, M. (2008). Regulatory regimes and multinational insurers before 1914. Business History Review, 82(1), 59-86.

Pearson, R., \& Richardson, D. (2001). Business networking in the Industrial Revolution. Economic History Review, 54(4), 657-679.

Phelps, E. (2007). Uncertainty bedevils the best system. Financial Times. Retrieved January 20, 2011, from http://us.ft.com/ftgateway/superpage.ft?news_id=fto041420091505108798

Phillips, K. (2016). Catastrophic drug coverage in Canada (Background Paper No. 2016-10-E) (p. 19). Ottawa: Library of Parliament (Legal and Social Affairs Division/Parliamentary Information and Research Service). Retrieved October 15, 2016, from http://www.lop.parl.gc.ca/Content/LOP/ResearchPublications/201610-e.html?cat=health

Pignarre, P. (2003). Le grand secret de l'industrie pharmaceutique. Paris: La Découverte.

Plociniczak, S. (2007). Au-delà d'une certaine lecture standard de la Grande Transformation. Revue Du MAUSS, 29(1), 207-224.

PMPRB. (2013). The Drivers of Prescription Drug Expenditures: A Methodological Report. (No. H82-15/2013E-PDF). Ottawa: Patented Medicine Prices Review Board. Retrieved August 18, 2016, from http://epe.lacbac.gc.ca/100/201/301/weekly_checklist/2014/internet/w14-01-UE.html/collections/collection_2013/cepmb-pmprb/H82-15-2013-eng.pdf

Polanyi, K. (1944). The Great Transformation. The Political and Economic Origins of Our Time. Boston: Beacon Press. 
Polanyi, K. (1957). XIII. The economy as instituted process. In K. Polanyi, C. M. Arensberg, \& H. W. Pearson (Eds.), Trade and Market in the Early Empires. Economies in History and Theory. Chicago: Gateway, pp. 243-270.

Polanyi, K. (1977). The Livelihood of Man. (H. W. Pearson, Ed.). New York: Academic Press.

Polanyi, K., Arensberg, C. M., \& Pearson, H. W. (Eds.). (1957a). Trade and Market in the Early Empires. New York: Free Press.

Polanyi, K., Arensberg, C. M., \& Pearson, H. W. (1957b). XII. The place of economies in societies. In K. Polanyi, C. M. Arensberg, \& H. W. Pearson (Eds.), Trade and Market in the Early Empires. New York: Free Press, pp. 239-242.

Portelance, E. (2014). Le régime général d'assurance médicaments: constats et enjeux. École d'actuariat, Université Laval (Québec), April. Retrieved from https://www.act.ulaval.ca/fileadmin/act/documents/PDF/Workshop/Assurance_m edicaments/Power_point_Estelle_Portelance.pdf

Poulantzas, N., \& Miliband, R. (1972). The problem of the capitalist state. In R. Blackburn (Ed.), Ideology in Social Science: Readings in Critical Social Theory. New York: Pantheon Books, pp. 238-262.

Power, M. (1999). The Audit Society: Rituals of Verification. Oxford: Oxford University Press.

Power, M. (2007). Organized Uncertainty. Designing a world of risk management. Oxford: Oxford University Press.

Pradier, P.-C. (2003). L'actuariat au siècle des Lumières: risque et décision économiques et statistiques. Revue Économique, 54(1), 139-156.

Pradier, P.-C. (2006). La notion de risque en économie. Paris: La Découverte.

Prudential. (1915). The Documentary History of Insurance, 1000 B.C. - 1875 A.D. Prudential Insurance Company of America.

Quinn, S. (2007). Securitization of sovereign debt: corporations as a sovereign debt restructuring mechanism in Britain, 1694 to 1750. Texas Christian University Department of Economics Working Paper Series, (Working Paper Nr. 07-01).

Quinn, S. (2008). The transformation of morals in markets: death, benefits, and the exchange of life insurance policies. American Journal of Sociology, 114(3), 738780.

Quirke, V. (2005). From Alkaloids to Gene Therapy: A Brief History of Drug Discovery in the 20th Century. In S. Anderson (Ed.), Making Medicines: A Brief History of Pharmacy and Pharmaceuticals. London: Pharmaceutical Press, pp. 177-202.

Redwood, H. (1987). The Pharmaceutical Industry. Trends, Problems, Achievements. Felixstowe: Oldwicks Press.

Rose, N., \& Miller, P. (1992). Political power beyond the state: problematics of government. The British Journal of Sociology, 43(2), 173-205.

Ross, H. L. (1970). Settled Out of Court. The Social Process of Insurance Claims Adjustment. New York: Aldine Publishing.

Rousseau, J.-J. (1764). Lettres écrites de la montagne. Paris: Armand-Aubrée.

Roy, W. R. (1997). Socializing Capital. The Rise of the Large Industrial Corporation in America. Princeton: Princeton University Press.

Samuelson, P. A., \& Nordhaus, W. D. (2010). Economics (19th ed). Boston: McGrawHill Irwin. 
Schumpeter, J. (1908). Das wesen und der hauptinhalt der theoretischen Nationalokonomie. Leipzig: Duncker \& Humbolt.

Schumpeter, J. (1909). On the concept of social value. The Quarterly Journal of Economics, 28, 213-232.

Schumpeter, J. (1942). Capitalism, Socialism and Democracy. London/New York: Harper \& Row.

Servet, J.-M. (1993). L'institution monétaire de la société selon Karl Polanyi. Revue Économique, 44(6), 1127-1150.

Shavell, S. (1979). On moral hazard and insurance. Quarterly Journal of Economics, 93(4), 541-562.

Shiller, R. J. (1993). Macro Markets. Creating Institutions for Managing Society's Largest Economic Risks. Oxford: Clarendon Press.

Shillington, C. H. (1972). The Road to Medicare in Canada. Toronto: DEL Graphics.

Shyllon, F. O. (1974). Black Slaves in Britain. London: Oxford University Press.

Siegelman, P. (2004). Adverse selection in insurance markets: an exaggerated threat. Yale Law Journal, 113(5), 1223-1281.

Silversides, A. (2009). Ontario's law curbing the cost of generic drugs sparks changes for pharmacies and other Canadian buyers. Canadian Medical Association Journal, 181(3-4), E43-E45.

Simmel, G. (1900). Philosophie des Geldes. Leipzig: Duncker \& Humbolt.

Simon, J. (1987). The emergence of risk society: insurance, law and the state. Socialist Review, 95, 61-89.

Simon, J. (1988). The ideological effects of actuarial practices. Law and Society Review, $22,772-800$.

Smith, K. T. (2012). The basics of ASO, December 11. Retrieved July 20, 2016, from http://www.benefitscanada.com/benefits/health-benefits/the-basics-of-aso-34925

Smith, K. T. (2013). A guide to ASO plans, May 30. Retrieved July 25, 2016, from http://www.benefitscanada.com/benefits/health-benefits/primed-for-aso-39251

Sombart, W. (1913). Krieg und Kapitalismus. München: Duncker \& Humbolt.

Squires, G. D. (Ed.). (1997a). Insurance Redlining. Disinvestment, Reinvestment, and the Evolving Role of Financial Institutions. Washington (DC): The Urban Institute Press.

Squires, G. D. (1997b). Race, politics and the law: recurring themes in insurance redlining debates. In G. D. Squires (Ed.), Insurance Redlining. Disinvestment, Reinvestment, and the Evolving Role of Financial Institutions. Washington (DC): The Urban Institute Press, pp. 1-26.

SSQ Groupe Financier. (2016). Structure de propriété, 1er janvier 2016. Retrieved July 18, 2016, from https://ssq.ca/documents/10674/0/Structure+de+propriété_français_2016_01_01.p df/f5261de8-a719-45ad-bc6f-e30314706bcd

Statistics Canada. (2014). Annual Demographic Estimates: Canada, Provinces and Territories, 2014 (No. 91-215-X). Ottawa: Minister of Industry, 188 p. Retrieved from http://www.statcan.gc.ca/pub/91-215-x/91-215-x2014000-eng.pdf

Steiner, P. (2005a). La sociologie économique. Paris: La Découverte.

Steiner, P. (2005b). Le marché selon la sociologie économique. Revue Européenne de Sciences Sociales, (132), 31-64. 
Steiner, P. (2008a). Foucault, Weber and the history of the economic subject. The European Journal of the History of Economic Thought, 15(3), 503-527.

Steiner, P. (2008b). Who is right about the modern economy: Polanyi, Zelizer, or both? Theory and Society, 38(1), 97-110.

Steiner, P. (2013). Mauss, les groupements professionnels et l'atmosphère du don. Les Études Sociales, 156-157(1), 105-122.

Steiner, P., \& Vatin, F. (2009). Introduction. Le fait économique comme fait social. In P. Steiner \& F. Vatin (Eds.), Traité de sociologie économique. Paris: Presses Universitaires de France, pp. 1-12.

Sterling, J. S., \& Moore, W. E. (1987). Weber's analysis of legal rationalization: A critique and constructive modification. Sociological Forum, 2(1), 67-89.

Stern, D., \& Reissman, D. (2006). Specialty Pharmacy Cost Management Strategies of Private Health Care Payers. Journal of Managed Care Pharmacy, 12(9), 736-744.

Stiglitz, J. E. (1983). Risk, incentive and insurance: the pure theory of moral hazard. Geneva Papers on Risk and Insurance, 8(26), 4-33.

Stone, D. (2002). Beyond moral hazard: insurance as moral opportunity. In T. Baker \& J. Simon (Eds.), Embracing Risk. Chicago: The University of Chicago Press, pp. $52-79$.

Strange, S. (1996). The Retreat of the State. The Diffusion of Power in the World Economy. Cambridge: Cambridge University Press.

Streeck, W., \& Thelen, K. (Eds.). (2005). Beyond Continuity. Institutional Change in Advanced Political Economies. Oxford: Oxford University Press.

Summers, L. (2007, September 23). Beware of moral hazard fundamentalists. Financial Times. $\quad$ Retrieved July 18, 2016, from http://didattica.unibocconi.it/mypage/upload/48805_20081002_034354_8077SUMMERS 1.20071002.094803.PDF

Sun Life. (unknown). Pharma 101. Retrieved August 23, 2016, from https://www.sunlife.ca/Canada/sponsor/Group+benefits/Group+benefits+products $+\&+$ services/Pharmaceutical+benefits/Pharma +101 ? vgnLocale=en_CA

Sun Life Financial. (unknown). My drug plan. The Sun Life Assurance Company of Canada. Retrieved August 23, 2016, from http://www.sunlife.ca/static/canada/Planadvisor/About\%20Group\%20Benefits/G B\%20News\%20archive/Episode\%2014/My\%20Drug\%20Plan\%20Member\%20br ochure\%20GB10089-E-11-12.pdf

Supiot, A. (2007). Homo Juridicus. On the Anthropological Function of the Law. (S. Brown, Trans.). London/New York: Verso.

Swedberg, R. (2003). The case for an economic sociology of law. Theory and Society, $32(1), 1-37$.

Swedlove, F. (2009). CLHIA report on health care policy: towards a sustainable, accessible, quality public health care system. Keynote address presented at the Canadian Life and Health Insurance Association, National Press Club, June. Retrieved August 23, 2016, from https://clhia.ca/domino/html/clhia/clhia_lp4w_lnd_webstation.nsf/resources/Healt $\mathrm{h}+\mathrm{Care} / \$$ file/Health_Care_Policy_Launch_speech_030609.pdf

Swisher, P. N. (2005). The insurable interest requirement for life insurance: a critical reassessment. Drake Law Review, 53, 477-543. 
Taylor, M. G. (1978). Health Insurance and Canadian Public Policy. The Seven Decisions that Created the Canadian Health Insurance System and their Outcomes. Montréal/Kingston: McGill-Queen's University Press.

The Benefits Consultant. (unknowna). Group health insurance - deductibles, cosinsurance and out-of-pocket maximums. Retrieved July 25, 2016, from http://www.benefitsconsultant.ca/group-benefits/group-health-insurancedeductibles-coinsurance-and-out-of-pocket-maximums.html

The Benefits Consultant. (unknownb). Group health insurance - prescription drugs. Retrieved July 25, 2016, from http://www.benefitsconsultant.ca/groupbenefits/group-health-insurance-prescription-drugs.html

The Benefits Consultant. (unknownc). Underwriting: fully pooled. Retrieved July 20, 2016, from http://www.benefitsconsultant.ca/underwriting_administration/underwriting-fullypooled.html

The Benefits Consultant. (unknownd). Underwriting: Refund-Accounting. Retrieved August 9, 2016, from http://www.benefitsconsultant.ca/underwriting_administration/underwritingrefund-accounting.html

The Insurance \& Investment Journal. (2014). Life and Health Insurance: Premiums and market share of the largest life insurers in Canada, 2013. Retrieved July 16, 2016, from http://insurance-journal.ca/article/premiums-and-market-share-of-thelargest-life-insurers-in-canada-2013/

The Monetary Times. (1902). The Canadian Life Insurance Officers' Association. The Monetary Times. Trade Review and Insurance Chronicle, Toronto, November 28, pp. 674-708.

Thelen, K. (2004). How Institutions Evolve. The Political Economy of Skills in Germany, Britain, the United States, and Japan. Cambridge: Cambridge University Press.

Treiber, H. (2011). Insights into Weber's sociology of law. In K. Papendorf, S. Machura, \& K. Andenæs (Eds.), Understanding Law in Society: Developments in SocioLegal Studies. Zürich ; London: Lit Verlag, (pp. 21-79).

Trenerry, C. F. (1926). The Origin and Early History of Insurance. Including the Contract of Bottomry. Westminster: P.S. King \& Son.

Van Hoyweghen, I. (2007). Risks in the Making. Travels in Life Insurance and Genetics. Amsterdam: Amsterdam University Press.

Van Hoyweghen, I. (2014). On the politics of calculative devices: performing life insurance markets. Journal of Cultural Economy, 7(3), 334-352.

Van Hoyweghen, I., \& Horstman, K. (2010). Solidarity matters: embedding genetic technologies in private and social insurance arrangements. New Genetics \& Society, 29(4).

Van Nierkerk, J. P. (1998). The Development of the Principles of Insurance Law in the Netherland from 1500 to 1800 (Vol. 1). Claremont: Juta \& Co. LTD.

Vance, W. R. (1908). The early history of insurance law. Columbia Law Review, 8(1), 117.

Veblen, T. (1899). The Theory of the Leisure Class. An Economic Study of Institution. Mineola (NY): Dover Publications. 
Veblen, T. (1904). The Theory of Business Enterprise. New Brunswick/London: Transaction Books.

Veitch, K. (2013). Law, social policy, and the constitution of markets and profit making. In Towards an Economic Sociology of Law. Malden/Oxford: Wiley-Blackwell, (pp. 137-154).

Vogel, S. K. (1996). Freer Markets, More Rules. Regulatory Reform in Advanced Industrial Countries. Ithaca/London: Cornell University Press.

Voltaire, M. D. (1753). Le siècle de Louis XIV (Vol. 2). Francfort: Veuve Knoch \& J. G. Eslinger.

Webb, V. E. (2011). Edward Woods. Wealth Channel Magazine, (Fall), 113.

Weber, M. (1905). The Protestant Ethic and the Spirit of Capitalism. London: Routledge.

Weber, M. (1978). Economy and Society. An Outline of Interpretative Sociology. (G. Roth \& C. Wittich, Eds.) (Vol. 1 \& 2). Berkeley and Los Angeles: University of California Press.

Wennerlind, C. (2011). Casualties of Credit. The English Financial Revolution, 16201720. Cambridge/London: Harvard University Press.

White, H. C. (1981). Where do markets come from? American Journal of Sociology, $87(3), 517-547$.

WHO. (unknown). Medical devices: health technology assessment. Retrieved July 12, 2016, from http://www.who.int/medical_devices/assessment/en/

Williamson, O. E. (1975). Markets and Hierarchies, Analysis and Antitrust Implications. A Study in the Economics of Internal Organization. New York/London: The Free Press.

Wolfenden, H. H. (1932). The Real Meaning of Social Insurance. Its Present Status and Tendencies. Toronto: Macmillan.

Wood, D. (2002). Medieval Economic Thought. Cambridge (UK): Cambridge University Press.

Woods, E. A. (1928). The Sociology of Life Insurance. Life Insurance: its Economics and Social Relations. New York: Appleton.

Zelizer, V. (1979). Morals and Markets. The Development of Life Insurance in the United States. New Brunswick: Transaction Books. 